NIST NCSTAR 1-5E

Federal Building and Fire Safety Investigation of the World Trade Center Disaster

\title{
Experiments and Modeling of Multiple Workstations Burning in a Compartment
}

Anthony Hamins

Alexander Maranghides

Kevin B. McGrattan

Thomas J. Ohlemiller

Robert L. Anleitner 


\section{Federal Building and Fire Safety Investigation of the World Trade Center Disaster}

\section{Experiments and Modeling of Multiple Workstations Burning in a Compartment}

Anthony Hamins

Alexander Maranghides

Kevin B. McGrattan

Thomas J. Ohlemiller

Robert L. Anleitner

Building and Fire Research Laboratory

National Institute of Standards and Technology

September 2005

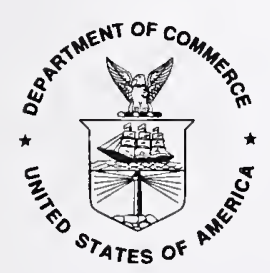

U.S. Department of Commerce

Carlos M. Gutierrez, Secretary

Technology Administration

Michelle O'Neill, Acting Under Secretary for Technology

National Institute of Standards and Technology

William Jeffrey, Director 


\section{Disclaimer No. 1}

Certain commercial entities, equipment, products, or materials are identified in this document in order to describe a procedure or concept adequately or to trace the history of the procedures and practices used. Such identification is not intended to imply recommendation, endorsement, or implication that the entities, products, materials, or equipment are necessarily the best available for the purpose. Nor does such identification imply a finding of fault or negligence by the National Institute of Standards and Technology.

\section{Disclaimer No. 2}

The policy of NIST is to use the International System of Units (metric units) in all publications. In this document, however, units are presented in metric units or the inch-pound system, whichever is prevalent in the discipline.

\section{Disclaimer No. 3}

Pursuant to section 7 of the National Construction Safety Team Act, the NIST Director has determined that certain evidence received by NIST in the course of this Investigation is "voluntarily provided safety-related information" that is "not directly related to the building failure being investigated" and that "disclosure of that information would inhibit the voluntary provision of that type of information" (15 USC 7306c).

In addition, a substantial portion of the evidence collected by NIST in the course of the Investigation has been provided to NIST under nondisclosure agreements.

\section{Disclaimer No. 4}

NIST takes no position as to whether the design or construction of a WTC building was compliant with any code since, due to the destruction of the WTC buildings, NIST could not verify the actual (or as-built) construction, the properties and condition of the materials used, or changes to the original construction made over the life of the buildings. In addition, NIST could not verify the interpretations of codes used by applicable authorities in determining compliance when implementing building codes. Where an Investigation report states whether a system was designed or installed as required by a code provision, NIST has documentary or anecdotal evidence indicating whether the requirement was met, or NIST has independently conducted tests or analyses indicating whether the requirement was met.

\section{Use in Legal Proceedings}

No part of any report resulting from a NIST investigation into a structural failure or from an investigation under the National Construction Safety Team Act may be used in any suit or action for damages arising out of any matter mentioned in such report (15 USC 281a; as amended by P.L. 107-231).

National Institute of Standards and Technology National Construction Safety Team Act Report 1-5E Natl. Inst. Stand. Technol. Natl. Constr. Sfty. Tm. Act Rpt. 1-5E, 158 pages (September 2005) CODEN: NSPUE2

\section{U.S. GOVERNMENT PRINTING OFFICE WASHINGTON: 2005}

For sale by the Superintendent of Documents, U.S. Government Printing Office Internet: bookstore.gpo.gov — Phone: (202) 512-1800 - Fax: (202) 512-2250 Mail: Stop SSOP, Washington, DC 20402-0001 


\section{ABSTRACT}

A series of large-scale experiments were conducted in the National Institute of Standards and Technology (NIST) Large Fire Laboratory from November 4 to December 10, 2003, to assess the accuracy with which the NIST Fire Dynamics Simulator (FDS) predicts the thermal environment in a burning compartment. In addition, the experiments established a data set to validate prediction of the heat release rate associated with the burning of office furnishings similar in type to those found in the World Trade Center (WTC) towers. The experiments were designed to recreate aspects of the WTC fires including issues associated with limited ventilation, fire spread and growth on real furnishings, and the effects of debris and jet fuel on the heat release rate of fires burning under conditions believed to be similar to those occurring on September 11, 2001.

Within a steel-frame compartment (nominally $3 \mathrm{~m}$ by $7 \mathrm{~m}$ by $4 \mathrm{~m}$ high) lined with calcium silicate boards were placed three computer workstations (office modules or workstations) composed of tables, desks, fabric-lined partitions, carpeting, a task chair, paper-filled filing cabinets and bookshelves, as well as a personal computer, keyboard, and monitor. The same configuration of furnishings was used in all experiments except one in which the workstation components were rearranged into component pieces to represent a disrupted non-standard configuration, which may have occurred as aircraft entered the WTC structure. In some of the experiments, several liters of jet fuel were distributed about the workstation components or ceiling tiles within the compartment until a large percentage of the horizontal surfaces of the furnishings were covered. A $2 \mathrm{MW}$ hydrocarbon fire generated by nozzles spraying onto a $1 \mathrm{~m}$ by $2 \mathrm{~m}$ pan was used to ignite the compartment furnishings. The fuel was a commercial blend of heptane isomers.

Six fire experiments were conducted and nearly 70 instruments were used to measure a number of important variables including the heat release rate of the fire and the vertical profiles of gas phase temperatures. A $2 \mathrm{MW}$ hydrocarbon spray fire burning for $10 \mathrm{~min}$ (or $2 \mathrm{~min}$ if jet fuel was present) was used to ignite the furniture. A fire spread through the workstations and was allowed to burn until the compartment contents became a charred jumble and the heat release rate was small, which was typically one hour after fire initiation. The measurements led to findings regarding the thermal behavior of the compartment and the importance of the jet fuel and the presence of dislodged ceiling tiles.

The FDS software was used to simulate the heat release rate and thermal environment in the compartment prior to the experiments. FDS predicted the peak upper layer gas temperature to within approximately 10 percent of the measurements on average, which was good agreement considering model sensitivity to input parameters such as the heat release rate and experimental uncertainties associated with the measurement. A comparison of the predictions with other measurements was also good. The results of the comparison of the FDS calculations with measurements provided confidence in the application of FDS to the analysis of the thermal environment in compartments with multiple office workstations burning, which is a key part of the WTC Investigation.

Keywords: fire model, heat release rate, World Trade Center. 
This page intentionally left blank. 


\section{TABLE OF CONTENTS}

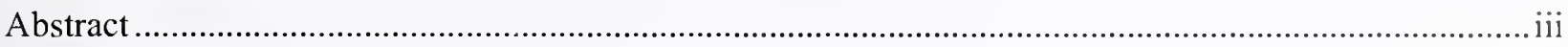

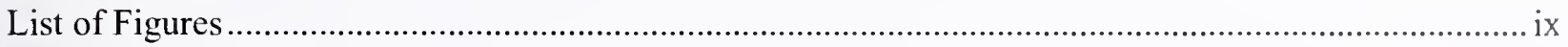

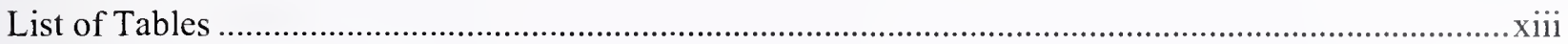

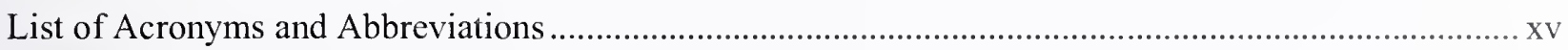

Preface

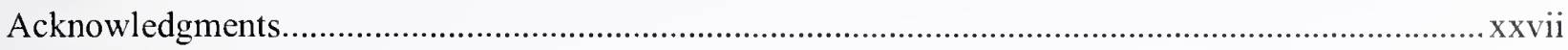

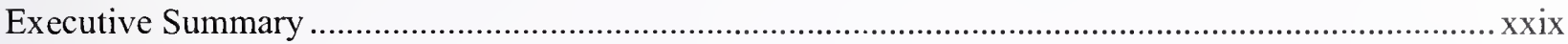

\section{Chapter 1}

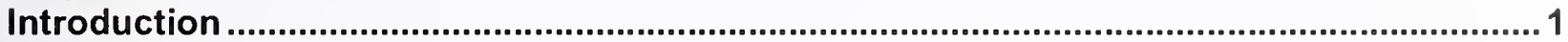

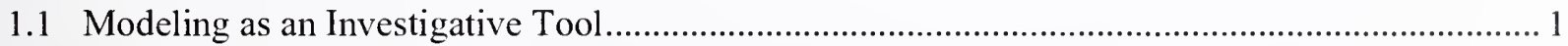

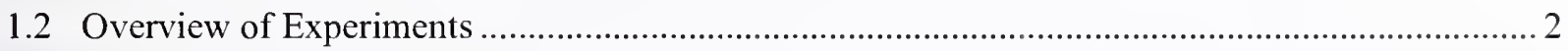

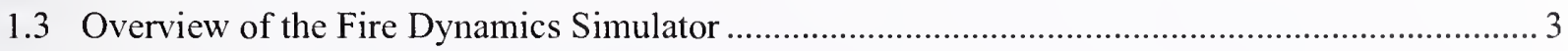

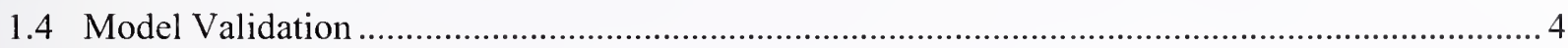

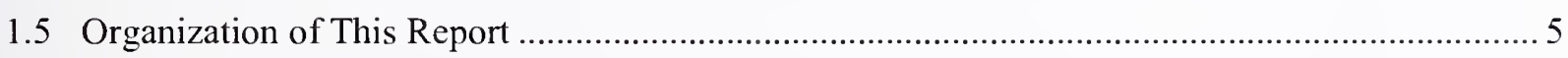

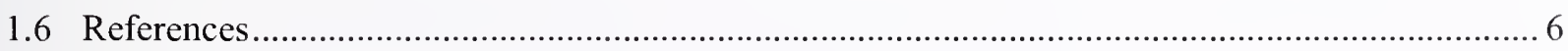

\section{Chapter 2}

Experimental Configuration, Apparatus, and Procedures ....................................................

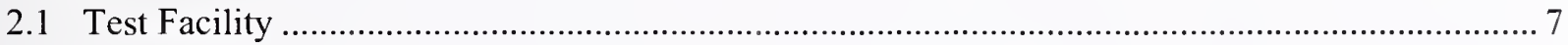

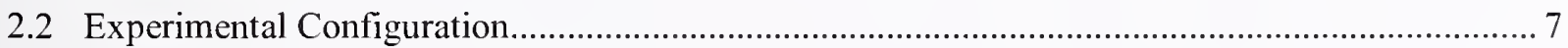

2.3 Test Variables and Test Matrix .......................................................................................... 10

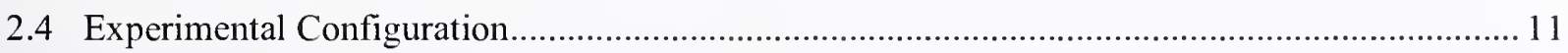

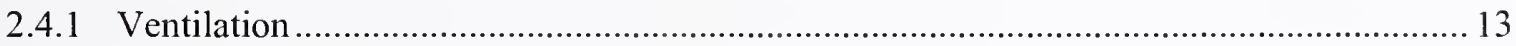

2.4.2 Description of the Multi-Workstation Configuration ........................................................ 14

2.5 Fuel Flow, Burner, and Delivery System.............................................................................. 20

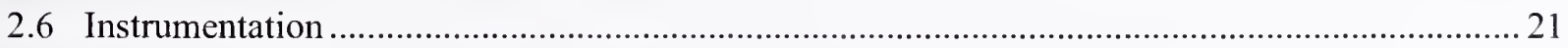

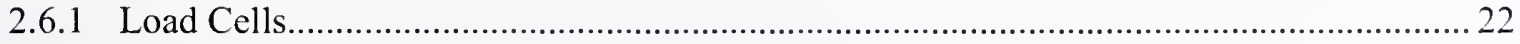

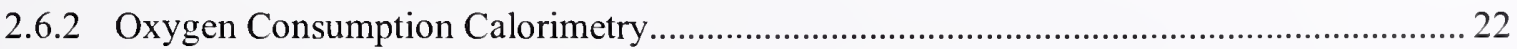

2.6.3 Thermocouple Trees - Compartment Temperatures .......................................................... 23

2.6.4 Thermocouples - Desk Surface Temperatures............................................................... 23

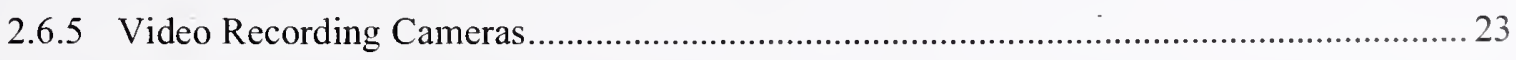

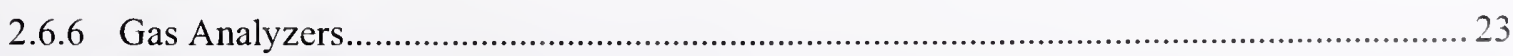




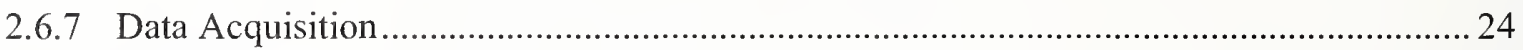

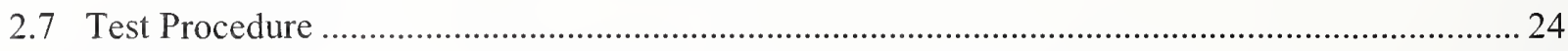

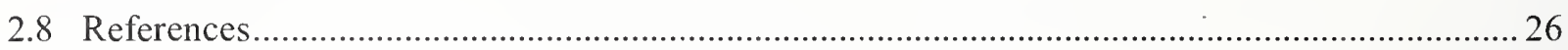

\section{Chapter 3}

Fire Behavior and Flame Spread .................................................................... 27

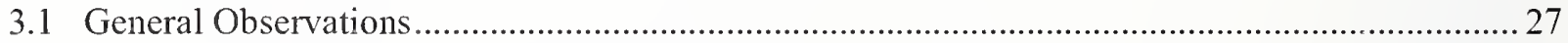

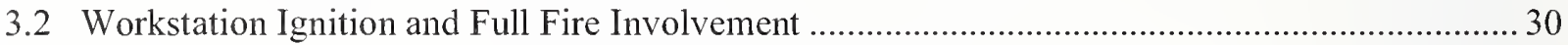

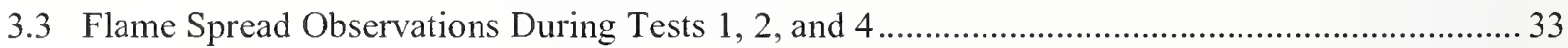

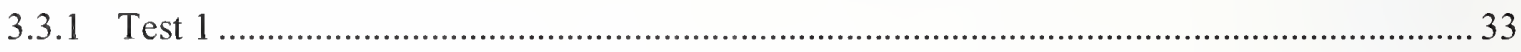

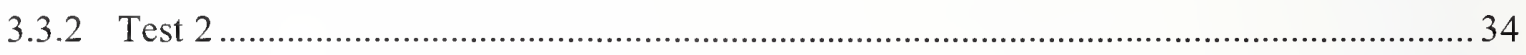

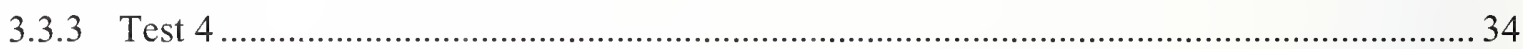

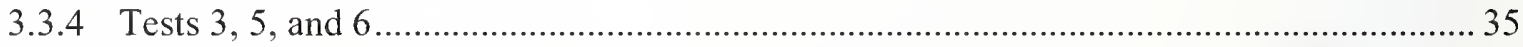

3.3.5 Burner Location Effect on Ignition and Flame Spread............................................... 35

3.4 Flame Spread Video and Thermometry Comparison ....................................................... 36

3.5 Key Events in the Evolution of the Compartment Fires ........................................................ 36

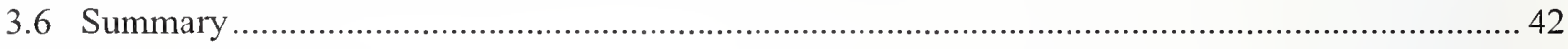

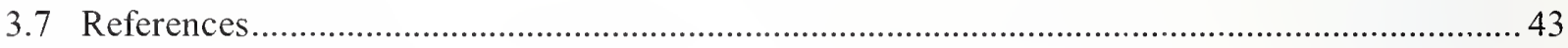

\section{Chapter 4}

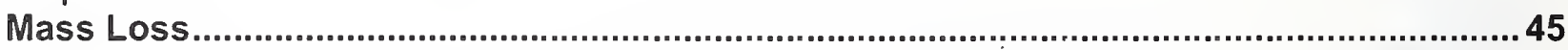

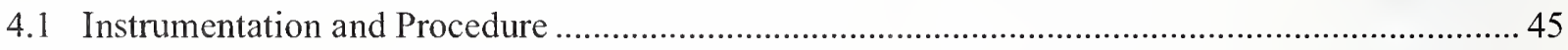

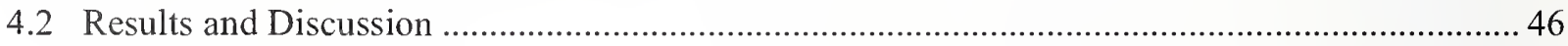

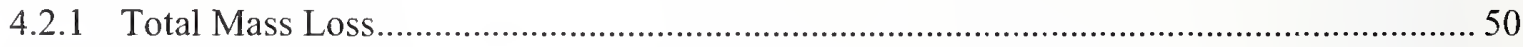

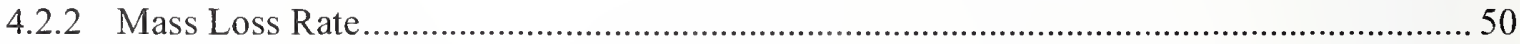

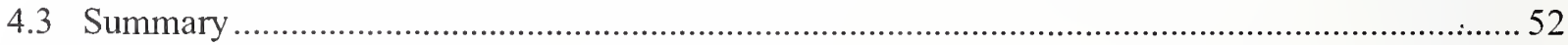

\section{Chapter 5}

Heat Release Rate ............................................................................................ 53

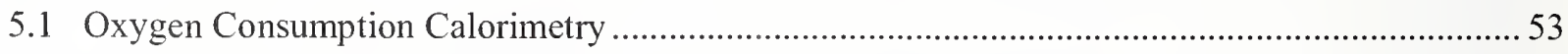

5.1.1 Description of the Heat Release Rate Measurement Facility ....................................... 53

5.1.2 Calibration and Measurement Uncertainty.......................................................... 54

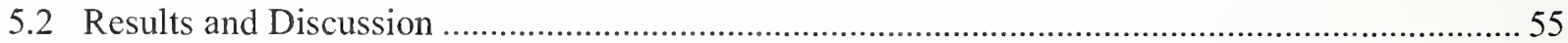

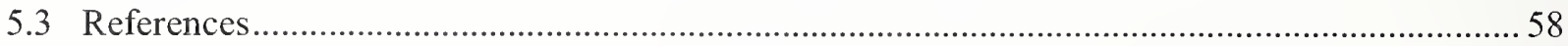




\section{Chapter 6}

Gas Temperature

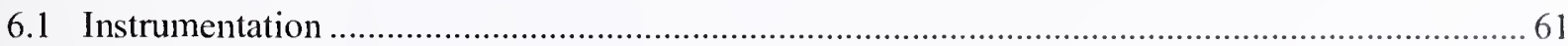

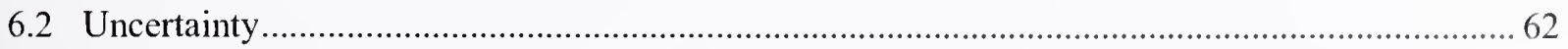

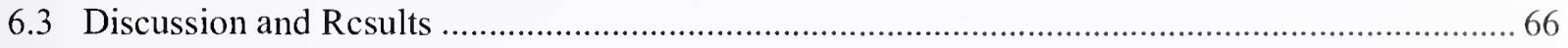

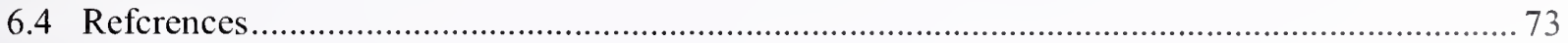

\section{Chapter 7}

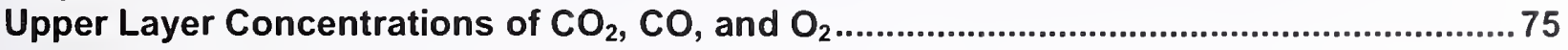

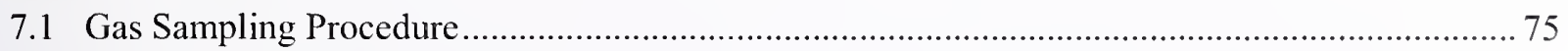

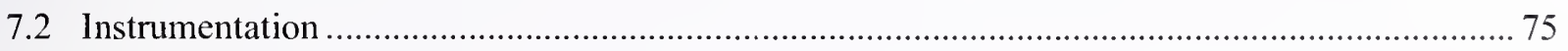

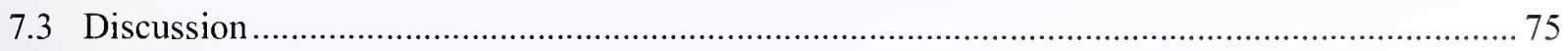

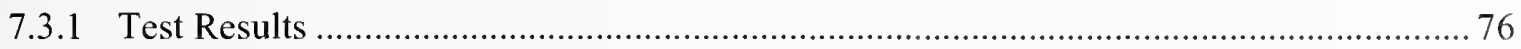

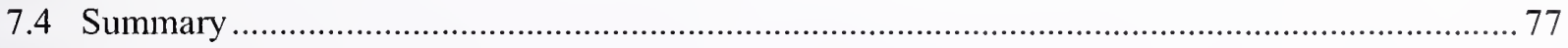

\section{Chapter 8}

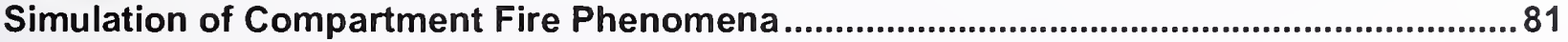

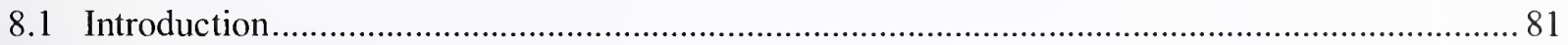

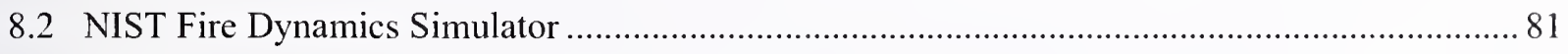

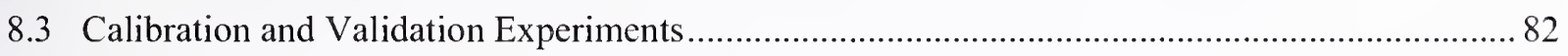

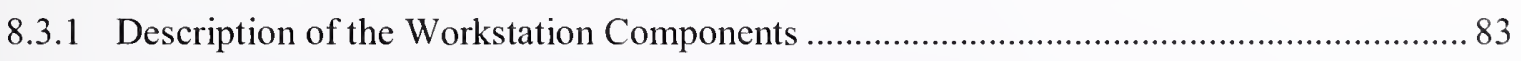

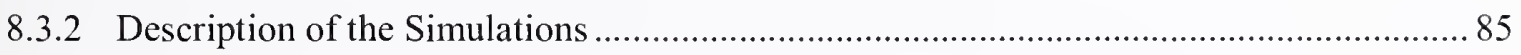

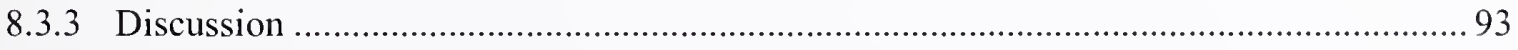

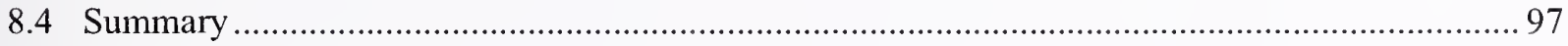

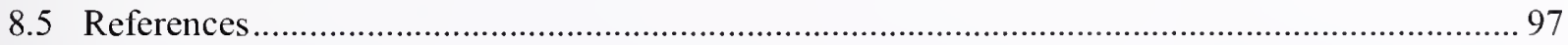

Chapter 9

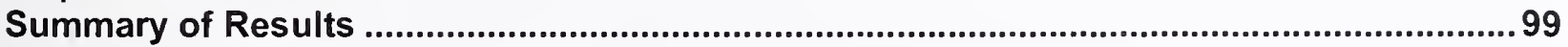

Appendix A

Location of Compartment Contents and Instrumentation ............................................. 101

Appendix B

Gas Analyzer Data

Appendix C

Gas Phase Temperatures

Appendix D

Comparison of Simulations and Measurements. 
This page intentionally left blank. 


\section{LIST OF FIGURES}

Figure $\mathrm{P}-1$. The eight projects in the fcderal building and firc safcty investigation of the WTC disaster. xix

Figure 2-1. The workstation layout on the 91st floor of WTC 1. Locations with hand-drawn lines represent location where aircraft impact may have disrupted the original layout................. 7

Figure 2-2. Plan view of the experimental configuration.

Figure 2-3. West side of experimental enclosure. Five ventilation openings are present. The knee wall was removed for access to instrumentation.

Figure 2-4. Elevation view of experimental configuration........................................................... 14

Figure 2-5. Views of interior of test compartment. ............................................................ 18

Figure 2-6. Image highlighting the arrangement of ceiling tiles used in Tests 3 and 4 . The spray burner and compartment openings are visible towards the rear.

Figure 2-7. The arrangement of "rubblized" Workstations 1 (left) and 2 (right) with ceiling tiles before Test 5 . Part of the spray burner is visible on the left.

Figure 2-8. The arrangement of Workstation 3 before Test 5.

Figure 2-9. Spray burner and fire pan abutting Workstation 1 before Test 2 (location B1).

Figure 3-1. View of the fire compartment $1 / 2 \mathrm{~min}$ after the start of Test 5.................................. 28

Figure 3-2. View of the fire compartment several minutes after the start of Test 5 .........................28

Figure 3-3. View of the fire compartment with test windows before the start of Test $6 \ldots \ldots \ldots \ldots \ldots \ldots \ldots . . . . . . . .29$

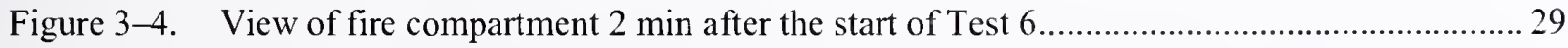

Figure 3-5. Determining ignition and full-involvement times from thermocouple data. .................... 32

Figure 3-6. Temperature measurements as a function of time for thermocouples on the desks of

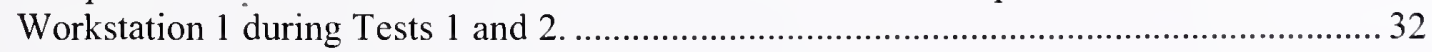

Figure 3-7. View external to the compartment $30 \mathrm{~s}$ before ignition of the spray burner in Test $6 \ldots \ldots . . . .37$

Figure 3-8. View external to the compartment $5 \mathrm{~s}$ before ignition of the spray burner in Test $6 \ldots \ldots \ldots . . .38$

Figure 3-9. View external to the compartment $5 \mathrm{~s}$ after ignition of the spray burner in Test $6 \ldots \ldots \ldots \ldots . . . . .38$

Figure 3-10. View external to the compartment $30 \mathrm{~s}$ after ignition of the spray burner in Test $6 \ldots \ldots \ldots . . . .39$

Figure 3-11. View external to the compartment $4 \mathrm{~min} 30 \mathrm{~s}$ after ignition of the spray burner in Test 6 .

Figure 3-12. View external to the compartment $9 \mathrm{~min} 30 \mathrm{~s}$ after ignition of the spray burner in Test 6 .

Figure 3-13. View external to the compartment $17 \mathrm{~min}$ after ignition of the spray burner in Test $6 \ldots . . .40$ 
Figure 3-14. Photograph of the north face of WTC 1 recorded at 8:53:15 a.m. on September 11, 2001. Labels showing floor and column numbers were added to the original photograph.

Figure 3-15. Photograph of the south face of WTC 1 taken at approximately 9:41:30 a.m. on

September 11,2001. Column and floor numbers were added to the original

photograph.

Figure 4-1. The mass of Workstations 1, 2, and 3 as a function of time during Test 1.....................46

Figure 4-2. The mass of Workstations 1, 2, and 3 as a function of time during Test 2...................... 47

Figure 4-3. The mass of Workstations 1, 2, and 3 as a function of time during Test 3.....................47

Figure 4-4. The mass of Workstations 1, 2, and 3 as a function of time during Test 4..................... 48

Figure 4-5. The mass of Workstations 1, 2, and 3 as a function of time during Test 5 . The power to the load cells under Workstations 1 and 2 failed for $2.5 \mathrm{~min}$ at $180 \mathrm{~s} \ldots \ldots \ldots \ldots \ldots \ldots \ldots \ldots . . . . . . . . . . . .48$

Figure 4-6. The mass of Workstations 1,2, and 3 as a function of time during Test 6.

Figure 4-7. The sum of the mass of Workstations 1, 2, and 3 for Tests 1 through 6 . The power to the load cells under Workstations 1 and 2 failed for $2 \mathrm{~min}$ at $180 \mathrm{~s}$ in Test 5 . ....

Figure 4-8. The mass of Workstations 1, 2, and 3 as a function of time during Test 1, showing straight line fits to each of the three burning periods for Workstation 1. The data is taken from Fig. 4-1.

Figure 5-1. The heat release rate as a function of time for Tests 1 through 6.

Figure 5-2. The load cell mass loss and the heat release rate $(\dot{Q})$ as a function of time during Test 1. The rapid burning $\left(\Delta \mathrm{t}_{\mathrm{rb}}\right)$ and slow burning $\left(\Delta \mathrm{t}_{\mathrm{s}}\right)$ periods are indicated.

Figure 6-1. Comparison of bare bead and aspirated thermocouple measurements as a function of time at a location $213 \mathrm{~cm}$ below the ceiling on Tree 4 during Test 1.

Figure 6-2. Comparison of bare bead and aspirated thermocouple measurements as a function of time at a location $305 \mathrm{~cm}$ below the ceiling on Tree 4 during Test 1.

Figure 6-3. Comparison of bare bead and aspirated thermocouple measurements as a function of time at a location $213 \mathrm{~cm}$ below the ceiling on Tree 4 during Test 2.

Figure 6-4. Comparison of bare bead and aspirated thermocouple measurements as a function of time at a location $305 \mathrm{~cm}$ below the ceiling on Tree 4 during Test 1.

Figure 6-5. The difference between the bare bead and the aspirated thermocouple measurements as a function of the bare bead temperature for the data presented in Figs. 6-1 through $6-4$.

Figure 6-6. Bare bead thermocouple measurements as a function of time at four locations (below the ceiling) on Tree 1 during Test 1 .

Figure 6-7. Bare bead thermocouple measurements as a function of time at four locations (below the ceiling) on Tree 1 during Test 2. 
Figure 6-8. Barc bead thermocouple measurements as a function of time at four locations (below the ceiling) on Trec 1 during Test 3.

Figure 6-9. Bare bead thermocouple mcasurements as a function of time at four locations (below the ceiling) on Tree 1 during Test 4.

Figure 6-10. Bare bead thermocouple measurements as a function of time at four locations (below the ceiling) on Trce 1 during Test 5 .

Figure 6-11. Bare bead thermocouple measurements as a function of time at four locations (below the ceiling) on Tree 1 during Tcst 6.

Figure 6-12. Bare bead thermocouple mcasurements as a function of time at four locations (below the ceiling) on Tree 4 during Test 1.

Figure 6-13. Bare bead thermocouple measurements as a function of time at four locations (below the ceiling) on Tree 4 during Test 1 .

Figure 6-14. Bare bead thermocouple measurements as a function of time at four locations (bclow the ceiling) on Tree 4 during Test 3.

Figure 6-15. Bare bead thermocouple measurements as a function of timc at four locations (below the ceiling) on Tree 4 during Test 4.

Figure 6-16. Bare bead thermocouple measurements as a function of time at four locations (below the ceiling) on Tree 4 during Test 5 .

Figure 6-17. Bare bead thermocouple measurements as a function of time at four locations (below the ceiling) on Tree 4 during Test 6 .

Figure 7-1. The volume fractions of $\mathrm{O}_{2}, \mathrm{CO}$, and $\mathrm{CO}_{2}$ on a dry basis as a function of time during Test 1

Figure 7-2. The volume fractions of $\mathrm{O}_{2}, \mathrm{CO}$, and $\mathrm{CO}_{2}$ on a dry basis as a function of time during Test 2 ...

Figure 7-3. The volume fractions of $\mathrm{O}_{2}, \mathrm{CO}$, and $\mathrm{CO}_{2}$ on a dry basis as a function of time during Test 3

Figure 7-4. The volume fractions of $\mathrm{O}_{2}, \mathrm{CO}$, and $\mathrm{CO}_{2}$ on a dry basis as a function of time during Test 4

Figure 7-5. The volume fractions of $\mathrm{O}_{2}, \mathrm{CO}$, and $\mathrm{CO}_{2}$ on a dry basis as a function of time during Test 5

Figure 7-6. The volume fractions of $\mathrm{O}_{2}, \mathrm{CO}$, and $\mathrm{CO}_{2}$ on a dry basis as a function of time during Test 6 .

Figure 8-1. Comparison of the measured and simulated $\dot{Q}$ for a single workstation......................... 85

Figure 8-2. Geometry of the simulations.

Figure 8-3. Comparison of the measured $\dot{Q}$ with the simulated $\dot{Q}$ using two grids sizes for Test 1 .

Figure 8-4. Comparison of the measured and simulated temperatures at $2.5 \mathrm{~cm}$ and $274 \mathrm{~cm}$ below the ceiling on Tree 4 (rear of the compartment) during Test 1 . 
Figure 8-5. Comparison of the measured and simulated temperatures at $2.5 \mathrm{~cm}$ and $274 \mathrm{~cm}$ below the ceiling on Tree 3 (middle of the compartment) during Test 1

Figure 8-6. Comparison of the measured and simulated temperatures at $2.5 \mathrm{~cm}$ and $274 \mathrm{~cm}$ below the ceiling on Tree 2 (middle of the compartment) during Test 1

Figure 8-7. Comparison of the measured and simulated temperatures at $2.5 \mathrm{~cm}$ and $274 \mathrm{~cm}$ below the ceiling on Tree 1 (front of the compartment) during Test 1 .

Figure 8-8. Comparison of the measured and simulated $\dot{Q}$ for Test 1 .

Figure 8-9. Comparison of the measured and simulated $\dot{Q}$ for Test 2. 90

Figure 8-10. Comparison of the measured and simulated $\dot{Q}$ for Test 3 . 90

Figure 8-11. Comparison of the measured and simulated $\dot{Q}$ for Test 4 . 91

Figure 8-12. Comparison of the measured and simulated $\dot{Q}$ for Test 5 . 91

Figure 8-13. Comparison of the measured and simulated $\dot{Q}$ for Test 6 . 92

Figure 8-14. Comparison of the measured and simulated $\mathrm{O}_{2}$ and $\mathrm{CO}_{2}$ volume fractions on a dry basis for Test 1 . 


\section{LIST OF TABLES}

Table P-1. Federal building and fire safety investigation of the WTC disaster.............................. Xviii

Table P-2. Public meetings and briefings of the WTC Investigation.......................................... xxi

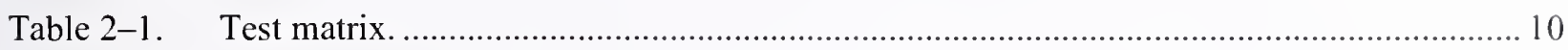

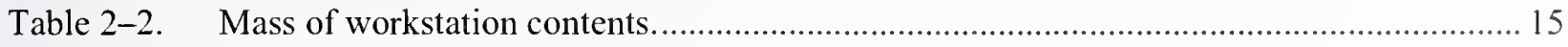

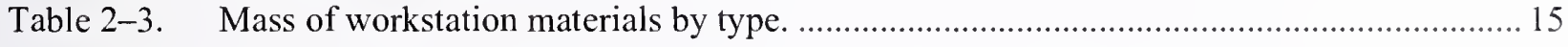

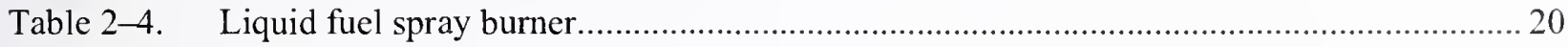

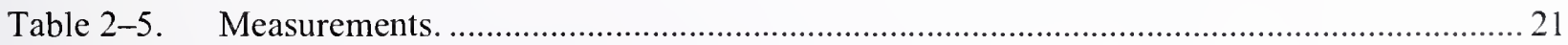

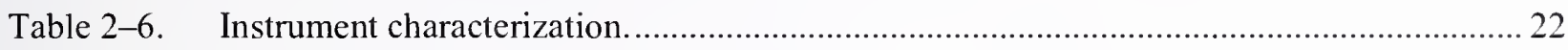

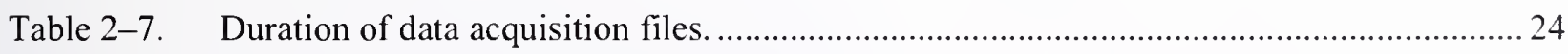

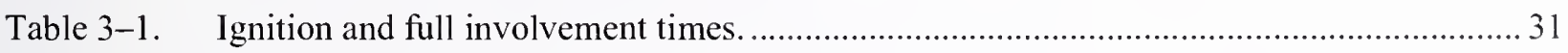

Table 3-2. Description of key events in evolution of the compartment fires.................................. 36

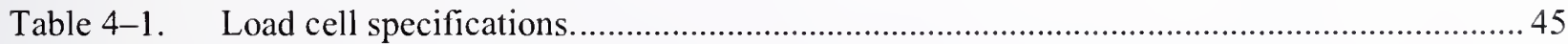

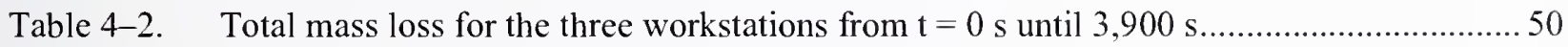

Table 4-3. The mass loss rate for each of the workstations during the rapid and slow burning periods for Tests 1 through 6 .

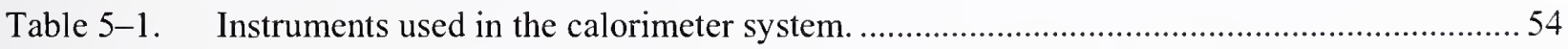

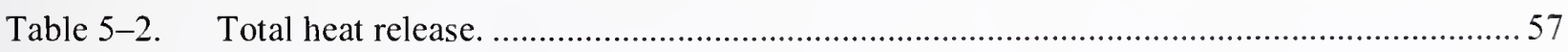

Table 6-1. Component and expanded temperature measurement uncertainty ................................. 62

Table 8-1. Heat release rate, $\dot{Q}$, when one-half of the energy was released. ................................ 95

Table 8-2. Time when one-half of the energy was released. ${ }^{\mathrm{a}}$........................................................ 95

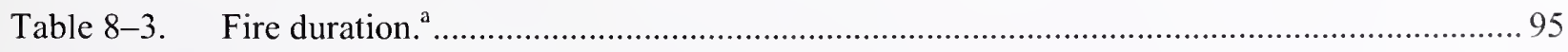


This page intentionally left blank. 


\section{LIST OF ACRONYMS AND ABBREVIATIONS}

\section{Acronyms}
ASTM
ASTM International
BFRL Building and Fire Research Laboratory
BPS Building Performance Study
CFD computational fluid dynamics
DAQ data acquisition
DTAP dissemination and technical assistance program
FDS Fire Dynamics Simulator
FEMA Federal Emergency Management Agency
FMRC Factory Mutual Research Corporation
FSI Fire-Structure Interface
FVM Finite Volume Method
LES Large Eddy Simulation
NIST National Institute of Standards and Technology
PANYNJ Port Authority of New York and New Jersey
P.L. Public Law
R\&D research and development
SEAoNY Structural Engineers Association of New York
SLE "special limits of error"
USC United States Code
WTC World Trade Center
WTC 1 World Trade Center 1 (North Tower)
WTC 2 World Trade Center 2 (South Tower)
WTC 7 World Trade Center 7

\section{Abbreviations}

$\begin{array}{cl}{ }^{\circ} \mathrm{C} & \text { degrees Celsius } \\ { }^{\circ} \mathrm{F} & \text { degrees Fahrenheit } \\ \mu \mathrm{m} & \text { micrometer }\end{array}$




$\begin{array}{ll}\mathrm{cm} & \text { centimeter } \\ \mathrm{g} & \text { gram } \\ \mathrm{in.} & \text { inch } \\ \mathrm{ft} & \text { feet } \\ \mathrm{GJ} & \text { gigajoule } \\ \mathrm{GW} & \text { gigawatt } \\ \mathrm{K} & \text { Kelvin } \\ \mathrm{Kg} & \text { kilogram } \\ \mathrm{kJ} & \text { kilojoule } \\ \mathrm{kW} & \text { kilowatt } \\ \mathrm{L} & \text { liter } \\ \mathrm{m} & \text { meter } \\ \mathrm{m}^{2} & \text { square meter } \\ \mathrm{m}^{3} & \text { cubic meter } \\ \mathrm{mA} & \text { milliamperes } \\ \mathrm{MJ} & \text { megaJoule } \\ \mathrm{mm} & \text { millimeter } \\ \mathrm{MW} & \text { megawatt } \\ \mathrm{min} & \text { minute } \\ \mathrm{S} & \text { second } \\ & \text { watt } \\ \mathrm{M} & \end{array}$




\section{PREFACE}

\section{Genesis of This Investigation}

Immediately following the terrorist attack on the World Trade Centcr (WTC) on September 11, 2001, the Federal Emergency Management Agency (FEMA) and the American Society of Civil Engineers began planning a building performance study of the disaster. The week of October 7, as soon as the rescue and search efforts ceased, the Building Performance Study Team went to the site and began its asscssment. This was to be a brief effort, as the study team consisted of experts who largcly volunteered their time away from their other professional commitments. The Building Performance Study Tcam issued its report in May 2002, fulfilling its goal "to determine probable failure mechanisms and to identify areas of future investigation that could lead to practical measures for improving the damage resistance of buildings against such unforeseen events."

On August 21, 2002, with funding from the U.S. Congress through FEMA, the National Institute of Standards and Technology (NIST) announced its building and fire safety investigation of the WTC disaster. On October 1, 2002, the National Construction Safety Team Act (Public Law 107-231), was signed into law. The NIST WTC Investigation was conducted under the authority of the National Construction Safety Team Act.

The goals of the investigation of the WTC disaster were:

- To investigate the building construction, the materials used, and the technical conditions that contributed to the outcome of the WTC disaster.

- To serve as the basis for:

- Improvements in the way buildings are designed, constructed, maintained, and used;

- Improved tools and guidance for industry and safety officials;

- Recommended revisions to current codes, standards, and practices; and

- Improved public safety.

The specific objectives were:

1. Determine why and how WTC 1 and WTC 2 collapsed following the initial impacts of the aircraft and why and how WTC 7 collapsed;

2. Determine why the injuries and fatalities were so high or low depending on location, including all technical aspects of fire protection, occupant behavior, evacuation, and emergency response;

3. Determine what procedures and practices were used in the design, construction, operation, and maintenance of WTC 1,2, and 7; and

4. Identify, as specifically as possible, areas in current building and fire codes, standards, and practices that warrant revision. 
NIST is a nonregulatory agency of the U.S. Department of Commerce's Technology Administration. The purpose of NIST investigations is to improve the safety and structural integrity of buildings in the United States, and the focus is on fact finding. NIST investigative teams are authorized to assess building performance and emergency response and evacuation procedures in the wake of any building failure that has resulted in substantial loss of life or that posed significant potential of substantial loss of life. NIST does not have the statutory authority to make findings of fault nor negligence by individuals or organizations. Further, no part of any report resulting from a NIST investigation into a building failure or from an investigation under the National Construction Safety Team Act may be used in any suit or action for damages arising out of any matter mentioned in such report (15 USC 281a, as amended by Public Law 107-231).

\section{Organization of the Investigation}

The National Construction Safety Team for this Investigation, appointed by the then NIST Director, Dr. Arden L. Bement, Jr., was led by Dr. S. Shyam Sunder. Dr. William L. Grosshandler served as Associate Lead Investigator, Mr. Stephen A. Cauffman served as Program Manager for Administration, and Mr. Harold E. Nelson served on the team as a private sector expert. The Investigation included eight interdependent projects whose leaders comprised the remainder of the team. A detailed description of each of these eight projects is available at http://wtc.nist.gov. The purpose of each project is summarized in Table $\mathrm{P}-1$, and the key interdependencies among the projects are illustrated in Fig. $\mathrm{P}-1$.

\section{Table P-1. Federal building and fire safety investigation of the WTC disaster.}

\section{Technical Area and Project Leader}

Analysis of Building and Fire Codes and Practices; Project Leaders: Dr. H. S. Lew and Mr. Richard W. Bukowski

Baseline Structural Performance and Aircraft Impact Damage Analysis; Project Leader: Dr. Fahim H. Sadek

Mechanical and Metallurgical Analysis of Structural Steel; Project Leader: Dr. Frank W. Gayle

Investigation of Active Fire Protection Systems; Project Leader: Dr. David D. Evans; Dr. William Grosshandler Reconstruction of Thermal and Tenability Environment; Project Leader: Dr. Richard G. Gann

Structural Fire Response and Collapse Analysis; Project Leaders: Dr. John L. Gross and Dr. Therese P. McAllister

Occupant Behavior, Egress, and Emergency Communications; Project Leader: Mr. Jason D. Averill

Emergency Response Technologies and Guidelines; Project Leader: Mr. J. Randall Lawson

\section{Project Purpose}

Document and analyze the code provisions, procedures, and practices used in the design, construction, operation, and maintenance of the structural, passive fire protection, and emergency access and evacuation systems of WTC 1,2, and 7.

Analyze the baseline performance of WTC 1 and WTC 2 under design, service, and abnormal loads, and aircraft impact damage on the structural, fire protection, and egress systems.

Determine and analyze the mechanical and metallurgical properties and quality of steel, weldments, and connections from steel recovered from WTC 1,2 , and 7.

lnvestigate the performance of the active fire protection systems in WTC 1,2 , and 7 and their role in fire control, emergency response, and fate of occupants and responders.

Reconstruct the time-evolving temperature, thermal environment, and smoke movement in WTC 1,2, and 7 for use in evaluating the structural performance of the buildings and behavior and fate of occupants and responders.

Analyze the response of the WTC towers to fires with and without aircraft damage, the response of WTC 7 in fires, the performance of composite steel-trussed floor systems, and determine the most probable structural collapse sequence for WTC 1,2 , and 7 .

Analyze the behavior and fate of occupants and responders, both those who survived and those who did not, and the performance of the evacuation system.

Document the activities of the emergency responders from the time of the terrorist attacks on WTC 1 and WTC 2 until the collapse of WTC 7, including practices followed and technologies used. 


\section{NIST WTC Investigation Projects}

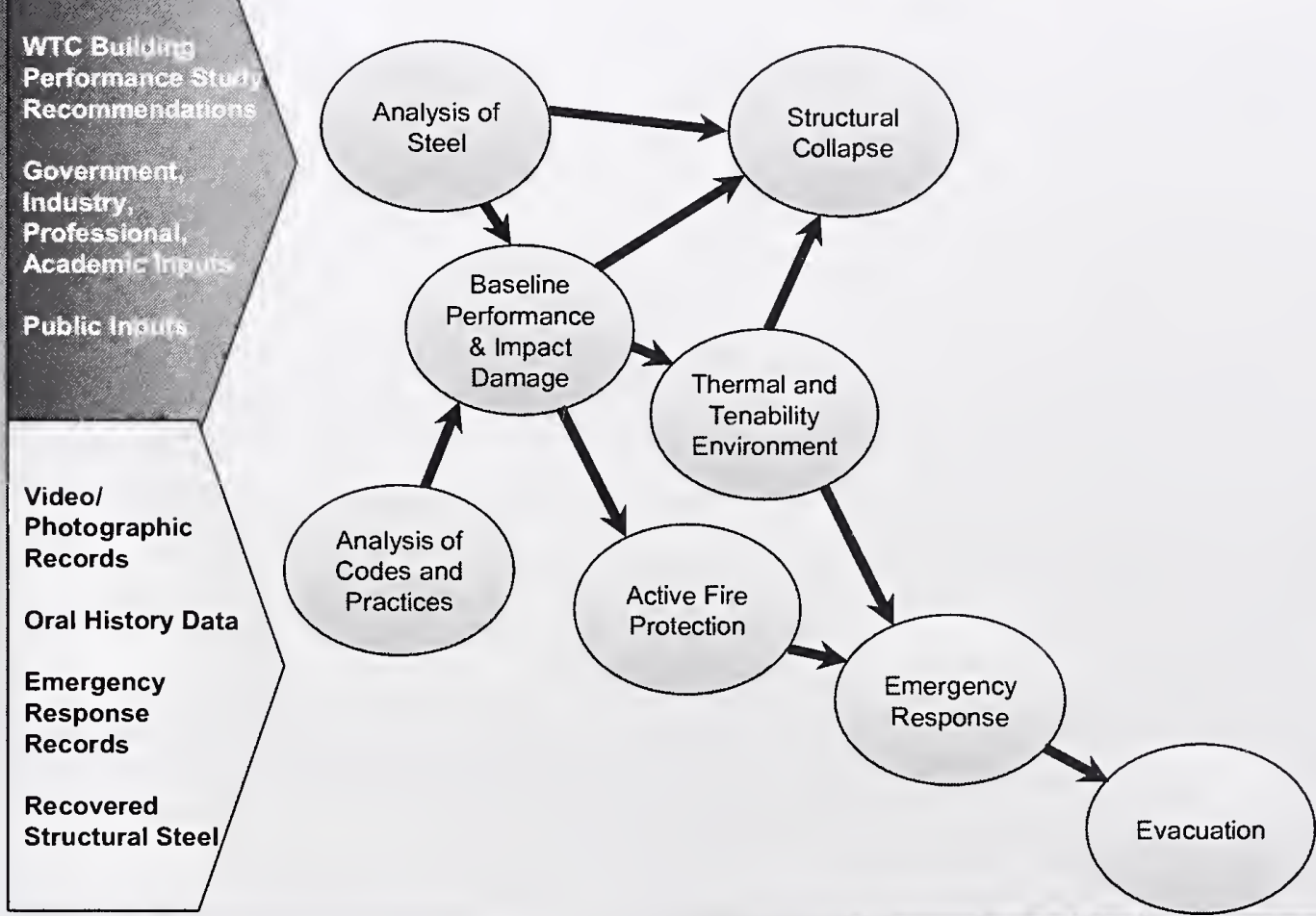

NLT

Figure $\mathrm{P}-1$. The eight projects in the federal building and fire safety investigation of the WTC disaster.

\section{National Construction Safety Team Advisory Committee}

The NIST Director also established an advisory committee as mandated under the National Construction Safety Team Act. The initial members of the committee were appointed following a public solicitation. These were:

- Paul Fitzgerald, Executive Vice President (retired) FM Global, National Construction Safety Team Advisory Committee Chair

- John Barsom, President, Barsom Consulting, Ltd.

- John Bryan, Professor Emeritus, University of Maryland

- David Collins, President, The Preview Group, Inc.

- Glenn Corbett, Professor, John Jay College of Criminal Justice

- Philip DiNenno, President, Hughes Associates, Inc. 
- Robert Hanson, Professor Emeritus, University of Michigan

- Charles Thornton, Co-Chairman and Managing Principal, The Thornton-Tomasetti Group, Inc.

- Kathleen Tierney, Director, Natural Hazards Research and Applications Information Center, University of Colorado at Boulder

- Forman Williams, Director, Center for Energy Research, University of California at San Diego

This National Construction Safety Team Advisory Committee provided technical advice during the Investigation and commentary on drafts of the Investigation reports prior to their public release. NIST has benefited from the work of many people in the preparation of these reports, including the National Construction Safety Team Advisory Committee. The content of the reports and recommendations, however, are solely the responsibility of NIST.

\section{Public Outreach}

During the course of this Investigation, NIST held public briefings and meetings (listed in Table P-2) to solicit input from the public, present preliminary findings, and obtain comments on the direction and progress of the Investigation from the public and the Advisory Committee.

NIST maintained a publicly accessible Web site during this Investigation at http://wtc.nist.gov. The site contained extensive information on the background and progress of the Investigation.

\section{NIST's WTC Public-Private Response Plan}

The collapse of the WTC buildings has led to broad reexamination of how tall buildings are designed, constructed, maintained, and used, especially with regard to major events such as fires, natural disasters, and terrorist attacks. Reflecting the enhanced interest in effecting necessary change, NIST, with support from Congress and the Administration, has put in place a program, the goal of which is to develop and implement the standards, technology, and practices needed for cost-effective improvements to the safety and security of buildings and building occupants, including evacuation, emergency response procedures, and threat mitigation.

The strategy to meet this goal is a three-part NIST-led public-private response program that includes:

- A federal building and fire safety investigation to study the most probable factors that contributed to post-aircraft impact collapse of the WTC towers and the 47-story WTC 7 building, and the associated evacuation and emergency response experience.

- A research and development (R\&D) program to (a) facilitate the implementation of recommendations resulting from the WTC Investigation, and (b) provide the technical basis for cost-effective improvements to national building and fire codcs, standards, and practices that enhance the safety of buildings, their occupants, and emergency responders. 
Table P-2. Public meetings and briefings of the WTC Investigation.

\begin{tabular}{|c|c|c|}
\hline Date & Location & Principal Agenda \\
\hline June 24,2002 & New York City, NY & $\begin{array}{l}\text { Public meeting: Public comments on the Draft Plan for the } \\
\text { pending WTC Investigation. }\end{array}$ \\
\hline August 21, 2002 & Gaithersburg, MD & Media briefing announcing the formal start of the Investigation. \\
\hline December 9, 2002 & Washington, $\mathrm{DC}$ & $\begin{array}{l}\text { Media briefing on release of the Public Update and NIST request } \\
\text { for photographs and videos. }\end{array}$ \\
\hline April 8, 2003 & New York City, NY & $\begin{array}{l}\text { Joint public forum with Columbia University on first-person } \\
\text { interviews. }\end{array}$ \\
\hline April 29-30, 2003 & Gaithersburg, MD & $\begin{array}{l}\text { NCST Advisory Committee meeting on plan for and progress on } \\
\text { WTC Investigation with a public comment session. }\end{array}$ \\
\hline May 7,2003 & New York City, NY & Media briefing on release of May 2003 Progress Report. \\
\hline August 26-27, 2003 & Gaithersburg, MD & $\begin{array}{l}\text { NCST Advisory Committee meeting on status of the WTC } \\
\text { investigation with a public comment session. }\end{array}$ \\
\hline September 17,2003 & New York City, NY & $\begin{array}{l}\text { Media and public briefing on initiation of first-person data } \\
\text { collection projects. }\end{array}$ \\
\hline December 2-3, 2003 & Gaithersburg, MD & $\begin{array}{l}\text { NCST Advisory Committee meeting on status and initial results } \\
\text { and release of the Public Update with a public comment session. }\end{array}$ \\
\hline February 12,2004 & New York City, NY & $\begin{array}{l}\text { Public meeting on progress and preliminary findings with public } \\
\text { comments on issues to be considered in formulating final } \\
\text { recommendations. }\end{array}$ \\
\hline June 18, 2004 & New York City, NY & Media/public briefing on release of June 2004 Progress Report. \\
\hline June $22-23,2004$ & Gaithersburg, MD & $\begin{array}{l}\text { NCST Advisory Committee meeting on the status of and } \\
\text { preliminary findings from the WTC Investigation with a public } \\
\text { comment session. }\end{array}$ \\
\hline August 24, 2004 & Northbrook, IL & $\begin{array}{l}\text { Public viewing of standard fire resistance test of WTC floor } \\
\text { system at Underwriters Laboratories, Inc. }\end{array}$ \\
\hline October $19-20,2004$ & Gaithersburg, MD & $\begin{array}{l}\text { NCST Advisory Committee meeting on status and near complete } \\
\text { set of preliminary findings with a public comment session. }\end{array}$ \\
\hline November 22, 2004 & Gaithersburg, MD & $\begin{array}{l}\text { NCST Advisory Committee discussion on draft annual report to } \\
\text { Congress, a public comment session, and a closed session to } \\
\text { discuss pre-draft recommendations for WTC Investigation. }\end{array}$ \\
\hline April 5, 2005 & New York City, NY & $\begin{array}{l}\text { Media and public briefing on release of the probable collapse } \\
\text { sequence for the WTC towers and draft reports for the projects on } \\
\text { codes and practices, evacuation, and emergency response. }\end{array}$ \\
\hline June 23,2005 & New York City, NY & $\begin{array}{l}\text { Media and public briefing on release of all draft reports for the } \\
\text { WTC towers and draft recommendations for public comment. }\end{array}$ \\
\hline $\begin{array}{l}\text { September 12-13, } \\
2005\end{array}$ & Gaithersburg, MD & $\begin{array}{l}\text { NCST Advisory Committee meeting on disposition of public } \\
\text { comments and update to draft reports for the WTC towers. }\end{array}$ \\
\hline $\begin{array}{l}\text { September 13-15, } \\
2005\end{array}$ & Gaithersburg, MD & $\begin{array}{l}\text { WTC Technical Conference for stakeholders and technical } \\
\text { community for dissemination of findings and recommendations } \\
\text { and opportunity for public to make technical comments. }\end{array}$ \\
\hline
\end{tabular}

- A dissemination and technical assistance program (DTAP) to (a) engage leaders of the construction and building community in ensuring timely adoption and widespread use of proposed changes to practices, standards, and codes resulting from the WTC Investigation and the R\&D program, and (b) provide practical guidance and tools to better prepare facility owners, contractors, architects, engineers, emergency responders, and regulatory authorities to respond to future disasters.

The desired outcomes are to make buildings, occupants, and first responders safer in future disaster events. 


\section{National Construction Safety Team Reports on the WTC Investigation}

A final report on the collapse of the WTC towers is being issued as NIST NCSTAR 1. A companion report on the collapse of WTC 7 is being issued as NIST NCSTAR 1A. The present report is one of a set that provides more detailed documentation of the Investigation findings and the means by which these technical results were achieved. As such, it is part of the archival record of this Investigation. The titles of the full set of Investigation publications are:

NIST (National Institute of Standards and Technology). 2005. Federal Building and Fire Safety Investigation of the World Trade Center Disaster: Final Report on the Collapse of the World Trade Center Towers. NIST NCSTAR 1. Gaithersburg, MD, September.

NIST (National Institute of Standards and Technology). 2006. Federal Building and Fire Safety Investigation of the World Trade Center Disaster: Final Report on the Collapse of World Trade Center 7. NIST NCSTAR 1A. Gaithersburg, MD.

Lew, H. S., R. W. Bukowski, and N. J. Carino. 2005. Federal Building and Fire Safety Investigation of the World Trade Center Disaster: Design, Construction, and Maintenance of Structural and Life Safety Systems. NIST NCSTAR 1-1. National Institute of Standards and Technology. Gaithersburg, MD, September.

Fanella, D. A., A. T. Derecho, and S. K. Ghosh. 2005. Federal Building and Fire Safety

Investigation of the World Trade Center Disaster: Desigu and Construction of Structural Systems.

NIST NCSTAR 1-1A. National Institute of Standards and Technology. Gaithersburg, MD,

September.

Ghosh, S. K., and X. Liang. 2005. Federal Building and Fire Safety Investigation of the World Trade Center Disaster: Comparison of Building Code Structural Requirements. NIST

NCSTAR 1-1B. National Institute of Standards and Technology. Gaithersburg, MD, September.

Fanella, D. A., A. T. Derecho, and S. K. Ghosh. 2005. Federal Building and Fire Safety Investigation of the World Trade Center Disaster: Maintenance and Modifications to Structural Systems. NIST NCSTAR 1-1C. National Institute of Standards and Technology. Gaithersburg, MD, September.

Grill, R. A., and D. A. Johnson. 2005. Federal Building and Fire Safety Investigation of the World Trade Center Disaster: Fire Protection and Life Safety Provisions Applied to the Design and Construction of World Trade Center 1, 2, and 7 and Post-Construction Provisions Applied after Occupancy. NIST NCSTAR 1-1D. National Institute of Standards and Technology. Gaithersburg, $\mathrm{MD}$, September.

Razza, J. C., and R. A. Grill. 2005. Federal Building and Fire Safety Investigation of the World Trade Center Disaster: Comparison of Codes, Standards, and Practices in Use at the Time of the Design and Construction of World Trade Center 1, 2, and 7. NIST NCSTAR 1-1E. National Institute of Standards and Technology. Gaithersburg, MD, September.

Grill, R. A., D. A. Johnson, and D. A. Fanella. 2005. Federal Building and Fire Safety Investigation of the World Trade Center Disaster: Comparison of the 1968 and Current (2003) New 
York City Building Code Provisions. NIST NCSTAR 1-1F. National Institute of Standards and Technology. Gaithersburg, MD, September.

Grill, R. A., and D. A. Johnson. 2005. Federal Building and Fire Safety Investigation of the World Trade Center Disaster: Amendments to the Fire Protection and Life Safety Provisions of the New York City Building Code by Local Laws Adopted While World Trade Center 1, 2, and 7 Were in Use. NIST NCSTAR 1-1G. National Institute of Standards and Technology. Gaithersburg, MD, September.

Grill, R. A., and D. A. Johnson. 2005. Federal Building and Fire Safety Investigation of the World Trade Center Disaster: Post-Construction Modifications to Fire Protection and Life Safety Systems of World Trade Center 1 and 2. NIST NCSTAR 1-1H. National Institute of Standards and Technology. Gaithersburg, MD, September.

Grill, R. A., D. A. Johnson, and D. A. Fanella. 2005. Federal Building and Fire Safety Investigation of the World Trade Center Disaster: Post-Construction Modifications to Fire Protection, Life Safety, and Structural Systems of World Trade Center 7. NIST NCSTAR 1-1I. National Institute of Standards and Technology. Gaithersburg, MD, September.

Grill, R. A., and D. A. Johnson. 2005. Federal Building and Fire Safety Investigation of the World Trade Center Disaster: Design, Installation, and Operation of Fuel System for Emergency Power in World Trade Center 7. NIST NCSTAR 1-1J. National Institute of Standards and Technology. Gaithersburg, MD, September.

Sadek, F. 2005. Federal Building and Fire Safety Investigation of the World Trade Center Disaster: Baseline Structural Performance and Aircraft Impact Damage Analysis of the World Trade Center Towers. NIST NCSTAR 1-2. National Institute of Standards and Technology. Gaithersburg, MD, September.

Faschan, W. J., and R. B. Garlock. 2005. Federal Building and Fire Safety Investigation of the World Trade Center Disaster: Reference Structural Models and Baseline Performance Analysis of the World Trade Center Towers. NIST NCSTAR 1-2A. National Institute of Standards and Technology. Gaithersburg, MD, September.

Kirkpatrick, S. W., R. T. Bocchieri, F. Sadek, R. A. MacNeill, S. Holmes, B. D. Peterson, R. W. Cilke, C. Navarro. 2005. Federal Building and Fire Safety Investigation of the World Trade Center Disaster: Analysis of Aircraft Impacts into the World Trade Center Towers, NIST NCSTAR 1-2B. National Institute of Standards and Technology. Gaithersburg, MD, September.

Gayle, F. W., R. J. Fields, W. E. Luecke, S. W. Banovic, T. Foecke, C. N. McCowan, T. A. Siewert, and J. D. McColskey. 2005. Federal Building and Fire Safety Investigation of the World Trade Center Disaster: Mechanical and Metallurgical Analysis of Structural Steel. NIST NCSTAR 1-3. National Institute of Standards and Technology. Gaithersburg, MD, September.

Luecke, W. E., T. A. Siewert, and F. W. Gayle. 2005. Federal Building and Fire Safety Investigation of the World Trade Center Disaster: Contemporaneous Structural Steel Specifications. NIST Special Publication 1-3A. National Institute of Standards and Technology. Gaithersburg, MD, September. 
Banovic, S. W. 2005. Federal Building and Fire Safety Investigation of the World Trade Center Disaster: Steel Inventory and Identification. NIST NCSTAR 1-3B. National Institute of Standards and Technology. Gaithersburg, MD, September.

Banovic, S. W., and T. Foecke. 2005. Federal Building and Fire Safety Investigation of the World Trade Center Disaster: Damage and Failure Modes of Structural Steel Components. NIST NCSTAR 1-3C. National Institute of Standards and Technology. Gaithersburg, MD, September.

Luecke, W. E., J. D. McColskey, C. N. McCowan, S. W. Banovic, R. J. Fields, T. Foecke, T. A. Siewert, and F. W. Gayle. 2005. Federal Building and Fire Safety Investigation of the World Trade Center Disaster: Mechanical Properties of Structural Steels. NIST NCSTAR 1-3D. National Institute of Standards and Technology. Gaithersburg, MD, September.

Banovic, S. W., C. N. McCowan, and W. E. Luecke. 2005. Federal Building and Fire Safety Investigation of the World Trade Center Disaster: Physical Properties of Structnral Steels. NIST NCSTAR 1-3E. National Institute of Standards and Technology. Gaithersburg, MD, September.

Evans, D. D., R. D. Peacock, E. D. Kuligowski, W. S. Dols, and W. L. Grosshandler. 2005. Federal Building and Fire Safety Investigation of the World Trade Center Disaster: Active Fire Protection Systems. NIST NCSTAR 1-4. National Institute of Standards and Technology. Gaithersburg, MD, September.

Kuligowski, E. D., D. D. Evans, and R. D. Peacock. 2005. Federal Building and Fire Safety Investigation of the World Trade Center Disaster: Post-Constrnction Fires Prior to September 11, 2001. NIST NCSTAR 1-4A. National Institute of Standards and Technology. Gaithersburg, MD, September.

Hopkins, M., J. Schoenrock, and E. Budnick. 2005. Federal Building and Fire Safety Investigation of the World Trade Center Disaster: Fire Sippression Systents. NIST NCSTAR 1-4B. National Institute of Standards and Technology. Gaithersburg, MD, September.

Keough. R. J., and R. A. Grill. 2005. Federal Burilding and Fire Safety Investigation of the World Trade Center Disaster: Fire Alarm Systems. NIST NCSTAR 1-4C. National Institute of Standards and Technology. Gaithersburg, MD, September.

Ferreira, M. J., and S. M. Strege. 2005. Federal Building and Fire Safety Investigation of the World Trade Center Disaster: Smoke Management Systems. NIST NCSTAR 1-4D. National Institute of Standards and Technoiogy. Gaithersburg, MD, September.

Gann, R. G., A. Hamins, K. B. McGrattan, G. W. Mulholland, H. E. Nelson, T. J. Ohlemiller, W. M. Pitts, and K. R. Prasad. 2005. Federal Building and Fire Safety Investigation of the World Trade Center Disaster: Reconstruction of the Fires in the World Trade Center Towers. NIST NCSTAR 1-5. National Institute of Standards and Technology. Gaithersburg, MD, September.

Pitts, W. M., K. M. Butler, and V. Junker. 2005. Federal Building and Fire Safety Investigation of the World Trade Center Disaster: Visual Evidence, Damage Estimates, and Timeline Analysis. NIST NCSTAR 1-5A. National Institute of Standards and Technology. Gaithersburg, MD, September. 
Hamins, A., A. Maranghides, K. B. McGrattan, E. Johnsson, T. J. Ohlemiller, M. Donnelly, J. Yang, G. Mulholland, K. R. Prasad, S. Kukuck, R. Anleitner and T. McAllister. 2005. Federal Building and Fire Safety Investigation of the World Trade Center Disaster: Experiments and Modeling of Structmal Steel Elements Exposed to Fire. NIST NCSTAR 1-5B. National Institute of Standards and Technology. Gaithersburg, MD, September.

Ohlemiller, T. J., G. W. Mulholland, A. Maranghides, J. J. Filliben, and R. G. Gann. 2005. Federal Building and Fire Safety Investigation of the World Trade Center Disaster: Fire Tests of Single Office Workstations. NIST NCSTAR 1-5C. National Institute of Standards and Technology. Gaithersburg, MD, September.

Gann, R. G., M. A. Riley, J. M. Repp, A. S. Whittaker, A. M. Reinhorn, and P. A. Hough. 2005. Federal Building and Fire Safety Investigation of the World Trade Center Disaster: Reaction of Ceiling Tile Systems to Shocks. NIST NCSTAR 1-5D. National Institute of Standards and Technology. Gaithersburg, MD, September.

Hamins, A., A. Maranghides, K. B. McGrattan, T. J. Ohlemiller, and R. Anleitner. 2005. Federal Building and Fire Safety Investigation of the World Trade Center Disaster: Experinemts and Modeling of Multiple Workstations Burning in a Compartment. NIST NCSTAR 1-5E. National Institute of Standards and Technology. Gaithersburg, MD, September.

McGrattan, K. B., C. Bouldin, and G. Forney. 2005. Federal Building and Fire Safety Investigation of the World Trade Center Disaster: Computer Simulation of the Fires in the World Trade Center Towers. NIST NCSTAR 1-5F. National Institute of Standards and Technology. Gaithersburg, MD, September.

Prasad, K. R., and H. R. Baum. 2005. Federal Building and Fire Safety Investigation of the World Trade Center Disaster: Fire Structure Interface and Thermal Response of the World Trade Center Towers. NIST NCSTAR 1-5G. National Institute of Standards and Technology. Gaithersburg, MD, September.

Gross, J. L., and T. McAllister. 2005. Federal Building and Fire Safety Investigation of the World Trade Center Disaster: Structural Fire Response and Probable Collapse Sequence of the World Trade Center Towers. NIST NCSTAR 1-6. National Institute of Standards and Technology. Gaithersburg, MD, September.

Carino, N. J., M. A. Starnes, J. L. Gross, J. C. Yang, S. Kukuck, K. R. Prasad, and R. W. Bukowski. 2005. Federal Building and Fire Safety Investigation of the World Trade Center Disaster: Passive Five Protection. NIST NCSTAR 1-6A. National Institute of Standards and Technology. Gaithersburg, MD, September.

Gross, J., F. Hervey, M. Izydorek, J. Mammoser, and J. Treadway. 2005. Federal Building and Fire Safety Investigation of the World Trade Center Disaster: Fire Resistance Tests of Floor Truss Systems. NIST NCSTAR 1-6B. National Institute of Standards and Technology. Gaithersburg, MD, September.

Zarghamee, M. S., S. Bolourchi, D. W. Eggers, Ö. O. Erbay, F. W. Kan, Y. Kitane, A. A. Liepins, M. Mudlock, W. I. Naguib, R. P. Ojdrovic, A. T. Sarawit, P. R Barrett, J. L. Gross, and 
T. P. McAllister. 2005. Federal Building and Fire Safety Investigation of the World Trade Center Disaster: Component, Connection, and Subsystem Structural Analysis. NIST NCSTAR 1-6C. National Institute of Standards and Technology. Gaithersburg, MD, September.

Zarghamee, M. S., Y. Kitane, Ö. O. Erbay, T. P. McAllister, and J. L. Gross. 2005. Federal Building and Fire Safety Investigation of the World Trade Center Disaster: Global Structural Analysis of the Response of the World Trade Center Towers to Impact Damage and Fire. NIST NCSTAR 1-6D. National Institute of Standards and Technology. Gaithersburg, MD, September.

McAllister, T., R. W. Bukowski, R. G. Gann, J. L. Gross, K. B. McGrattan, H. E. Nelson, L. Phan, W. M. Pitts, K. R. Prasad, F. Sadek. 2006. Federal Building and Fire Safety Investigation of the World Trade Center Disaster: Structural Fire Response and Probable Collapse Sequence of World Trade Center 7. (Provisional). NIST NCSTAR 1-6E. National Institute of Standards and Technology. Gaithersburg, MD.

Gilsanz, R., V. Arbitrio, C. Anders, D. Chlebus, K. Ezzeldin, W. Guo, P. Moloney, A. Montalva, J. Oh, K. Rubenacker. 2006. Federal Building and Fire Safety Investigation of the World Trade Center Disaster: Structural Analysis of the Response of World Trade Center 7 to Debris Damage and Fire. (Provisional). NIST NCSTAR 1-6F. National Institute of Standards and Technology. Gaithersburg, MD.

Kim, W. 2006. Federal Building and Fire Safety Investigation of the World Trade Center Disaster: Analysis of September 11, 2001, Seismogram Data. (Provisional). NIST NCSTAR 1-6G. National Institute of Standards and Technology. Gaithersburg, MD.

Nelson, K. 2006. Federal Building and Fire Safety Investigation of the World Trade Center Disaster: The Con Ed Substation in World Trade Center 7. (Provisional). NIST NCSTAR 1-6H. National Institute of Standards and Technology. Gaithersburg, MD.

Averill, J. D., D. S. Mileti, R. D. Peacock, E. D. Kuligowski, N. Groner, G. Proulx, P. A. Reneke, and H. E. Nelson. 2005. Federal Building and Fire Safety Investigation of the World Trade Center Disaster: Occupant Behavior, Egress, and Emergency Communication. NIST NCSTAR 1-7. National Institute of Standards and Technology. Gaithersburg, MD, September.

Fahy, R., and G. Proulx. 2005. Federal Building and Fire Safety Imvestigation of the World Trade Center Disaster: Analys is of Published Accounts of the World Trade Center Evacuation. NIST NCSTAR 1-7A. National Institute of Standards and Technology. Gaithersburg, MD, September.

Zmud, J. 2005. Federal Building and Fire Safety Investigation of the World Trade Center Disaster: Technical Documentation for Survey Administration. NIST NCSTAR 1-7B. National Institute of Standards and Technology. Gaithersburg, MD, September.

Lawson, J. R., and R. L. Vettori. 2005. Federal Building and Fire Safety Investigation of the World Trade Center Disaster: The Emergency Response Operations. NIST NCSTAR 1-8. National Institute of Standards and Technology. Gaithersburg, MD, September. 


\section{ACKNOWLEDGMENTS}

The authors are grateful to other staff of the National Institute of Standards and Technology: Lauren DeLauter, Edward Hnetkovsky, Jack Lee, Roy McLane, Jay McElroy, and Mike Selepak for their assistance conducting the experiments, to Tyler Smith for assistance with data analysis, to Drs. Richard Gann, George Mulholland, and Rodney Bryant for helpful discussions regarding experimental design and data analysis, and to Dr. Bill Pitts for assistance with selecting World Trade Center photographs for inclusion in this report. 
This page intentionally left blank. 


\section{EXECUTIVE SUMMARY}

This report represents part of the reconstruction of the thermal and tenability environment of the World Trade Center (WTC) Investigation, which was used to evaluate the structural performanec of the buildings. As part of this endeavor, the National Institute of Standards and Technology (NIST) Fire Dynamic Simulator (FDS), a computational model of fire and its effects, was used to reconstruct the timeevolving temperature, thermal environment, and smoke movement in WTC 1, 2, and 7. The FDS is one of the first large-domain computational fluid dynamics (CFD) fire codes that predicts and visualizes the spread, growth and suppression of a fire based on the underlying scientific principles governing fluid motion. The code numerically solves the modeled conservation equations of mass, momentum and energy that govern low-speed, thermally driven flows with an emphasis on smoke and heat transport from fires. The companion software package, called Smokeview, graphically presents the results of the FDS three-dimensional time-dependent simulation. Smokeview animates in three dimensions the smoke particulates, heat fluxes, temperatures and fluid velocities within a building. The FDS/Smokeview software package allows viewing of the simulated results from any angle and from inside or outsidc the computational boundaries.

For application to the WTC Investigation, FDS needed experimental data to guide the adaptation and development of the model for this specific purpose, and to ascertain the accuracy of the model predictions. Ideally, the uncertainty in the agreement with experiments would be much smaller than the effect of varying the unknowns in the actual conditions that occurred on September 11, 2001. As part of the NIST-led Investigation, the results of the FDS calculations were used as input to the NIST FireStructure Interface (FSI) software, which was then used to calculate the heat transfer from the fire to steel members that were part of the WTC buildings. The FSI used the information generated by FDS on the thermal environment and coupled that information to a transient, three-dimensional finite element model with a different grid structure. The coupling was used to help determine the thermal response of simple and complex steel members that were part of the WTC buildings.

To gain confidence in the accuracy of these models as applied to the WTC Investigation, two large-scale test series were conducted to test the numerical computations, plus various small-scale experiments were conducted to provide FDS with input data. The two large-scale test series involved fires in compartments with approximately the same height as a floor in the WTC towers, and both series of experiments were conducted in the NIST Large Fire Laboratory. The results of the first series of tests are described in detail in NIST NCSTAR 1-5B ${ }^{1}$ The objective of the first series of experiments was to assess the accuracy with which the FDS predicted the thermal environment in a burning compartment and to establish a data set to test the prediction of the temperature rise in the structural steel components. A liquid fuel spray burner was used to generate a fixed amount of energy in a compartment that was fitted with various targets and obstructions, including steel structural members such as columns, trusses and rods. The heat release rate drives compartment fire effects, including radiative and convective heat transfer within the compartment and the temperature rise of the gases and the contents of the compartment and its surfaces. The fire sizes tested were between 1.9 MW and 3.4 MW to assure that the structural components were immersed in

1 This reference is to one of the companion documents from this Investigation. A list of these documents appears in the Preface of this report. 
flames and hot gases. The fuels used were well-characterized hydrocarbons or a mixture of hydrocarbons, selected to cover the expected range of soot loading in fires generated by typical office furnishings. The fire conditions were over-ventilated, that is the rate of burning was fuel limited and not limited by the availability of oxygen.

The second series of large-scale experiments described in this report were quite different from the first series of experiments. These experiments were also conducted in the NIST Large Fire Laboratory. The objective of the second study was to assess the accuracy with which the FDS predicted the thermal environment in a burning compartment and to establish a data set to test predictions of the heat release rate associated with the burning of office furnishings similar to those found in the WTC towers. The experiments were designed to recreate aspects of the WTC fires, including issues associated with limited ventilation, fire spread and growth on real furnishings, and the effects of debris and jet fuel on the heat release rate of the fires. A large experimental compartment was fabricated in which office workstations representative of typical office furnishings, not unlike those found in WTC 1, 2, and 7, were burned under conditions believed to be similar to those occurring on September 11, 2001. This series of experiments investigated the accuracy of the fire model for under-ventilated conditions in which burning was limited by the availability of oxygen.

Three computer workstations (office modules or workstations) composed of desks, fabric-lined partitions, carpeting, a task chair, paper-filled filing cabinets and bookshelves, as well as a personal computer, keyboard, and monitor were placed within a steel-frame compartment (nominally $3 \mathrm{~m}$ by $7 \mathrm{~m}$ by $4 \mathrm{~m}$ high) lined with calcium silicate boards. The same configuration of furnishings was used in all experiments except one, in which the workstation components were rearranged or broken into component pieces to represent a disrupted, non-standard configuration, which may have occurred as aircraft entered the WTC structures. In some of the experiments, several liters of jet fuel were poured over the workstation components. In some experiments, ceiling tiles were distributed about the compartment, simulating collapse of the drop ceiling. These tiles covered a large percentage of the horizontal surfaces of the furnishings. A $2 \mathrm{MW}$ hydrocarbon fire generated by four nozzles spraying onto a $1 \mathrm{~m}$ by $2 \mathrm{~m}$ pan was used to ignite the compartment furnishings. A commercial blend of heptane isomers was used as the fuel.

Six fire experiments were conducted, and nearly 70 instruments were used to measure a number of important variables, including the heat release rate of the fire and the vertical profiles of gas phase temperatures. The overall fire behavior was documented using video cameras, viewing the fire from different orientations. Following the establishment of baseline signals from all the measurement devices, the spray burner, and when present, the jet fuel were ignited. The spray fire continued to burn at a steady rate for $10 \mathrm{~min}$ (or $2 \mathrm{~min}$ if jet fuel was present). The fire spread through the workstations and was allowed to burn until the compartment contents had become an unrecognizable charred jumble and the heat release rate was small, which was typically 1 hour after fire initiation. The measurements led to findings regarding the thermal behavior of the compartment and the importance of the jet fuel and the presence of the ceiling tiles.

- In the presence of jet fuel, the fire spread rapidly, and the heat release rate reached a maximum within a few minutes.

- The intact ceiling tiles had little apparent impact on the rate of fire spread or the heat release rate. 
- Upper layer temperatures obtained values as high as $800{ }^{\circ} \mathrm{C}$ to $1,200{ }^{\circ} \mathrm{C}$ after $20 \mathrm{~min}$ to 30 min of exposure, depending on the exact location within the compartment and the test conditions.

- The measured mass loss burning rate of workstations reconfigured into "rubble" to represent what may have occurred when aircraft entered the WTC structure was about 40 percent smaller than that of workstations burning in a standard configuration.

- The value of the measured heat release rate suggests that burning conditions during the second series of experiments were underventilated or oxygen limited.

An independent series of reduced-scale experiments was performed on the burning of a single office workstation in the open, with and without the presence of ceiling tiles and jet fuel (refer to NIST NCSTAR 1-5C), in an effort to calibrate the FDS calculation for the simulations described in this report. The results of the reduced-scale experiments were used as input for FDS, which was then used to simulate the fire spread and growth, heat release rate, and the thermal environment associated with the burning of multiple workstations in a compartment. The numerical accuracy of the FDS predictions was determined through quantitative comparison with the measurements. The comparison of predictions with measurements showed that:

- FDS was able to accurately predict the general shape and magnitude of the time dependent heat release rate.

- FDS predicted the time at which one-half of the energy was released to within approximately 3 min or 22 percent of the measurements.

- FDS predicted the value of the heat release rate when one-half of the energy was released to within $1.1 \mathrm{MW}$ or 9 percent of the measurements on average, which was accurate considering the measurement uncertainty.

- FDS predicted the duration of significant heating of the fires to within approximately 6 min or 15 percent of the measurements on average, although the long tail in the heat release rate curve was under-predicted.

- FDS predicted the peak upper layer gas temperature to within approximately 10 percent of the measurements on average, which was good agreement considering model sensitivity to input parameters such as the heat release rate and uncertainties associated with the measurement.

This study provided a check on the accuracy of the FDS, and the results provided confidence in the application of FDS to the analysis of the thermal environment in compartments with multiple office workstations burning, which is a key part of the investigation of the WTC fires and collapse. 
This page intentionally left blank. 


\section{Chapter 1 \\ INTRODUCTION}

\subsection{MODELING AS AN INVESTIGATIVE TOOL}

Reconstructing the fires and their impact on structural components in the World Trade Center (WTC) buildings on Septembcr 11, 2001, requires extcrisive use of computational models. WTC buildings 1,2, and 7 each survived for a different length of time from the start of the disaster. The duration of their survival resulted from complex interactions among the features of the building construction, the initial damage to the buildings, and the ensuing fires. Accurate computational modeling is critical to the Investigation because of this complexity and because so little direct cvidence is available. While the Investigation Team has compiled and catalogued an extensive array of photographs and video records, these are limited to perspectives external to the building. They cast little light on the physical damagc and the progress of the fires inside the immediate vicinity of the windows and other openings. Analysis of the recovered WTC steel provides limited indication of the maximum temperatures experienced. However, this analysis cannot identify the times at which these peak temperatures were reached and the timevarying history of the thermal environment throughout the buildings. This type of information, combined with characterization of the building damage from the incident aircraft (WTC 1 and WTC 2) or from debris from the collapsing towers (WTC 7), is central to assessing the plausibility of various possible explanations for the collapse of the three buildings. Computer simulation of the fires includes consideration of such factors as:

- The initial building damage (exterior and interior);

- The nature, quantity, and distribution of the combustibles and debris; and

- Changes in the ventilation as the fires progressed.

Additional modeling of the transfer of heat from the fire to the structural components complements these modeling considerations. Combined, the simulations then produce a complete thermal history, filling in the gaps left by the paucity of information. Simulations that capture the esscnce of the photographic evidence and the occupant accounts are then presumed to be the most probable replications of the actual events.

For the use of such models to be a viable investigative tool, it is essential to know the accuracy with which the models capture the physical phenomena of the fires and the concurrent heat transfer to the building structure. Two large-scale test series were conducted to ascertain the accuracy of the numerical model, and various reduced-scale experiments were conductcd to provide the model with input data for different materials. The two large-scale test series involved fires in compartments with approximately the same height as a floor in the WTC towers. Both series of experiments were conducted at the National Institute of Standards and Technology (NIST) Large Fire Laboratory. The results of the first series of 
tests are described in detail in NIST NCSTAR 1-5B. ${ }^{1}$ The objective of that series of experiments was to assess the accuracy with which the NIST Fire Dynamics Simulator (FDS) predicted the thermal environment in a burning compartment and to establish a data set to evaluate the prediction of the temperature rise of structural steel components. In those experiments, a liquid fuel spray burner was used to generate a fixed amount of energy in a compartment that was fitted with various targets and obstructions, including stcel objccts such as columns, trusses, and rods. The fire sizes tested were between 1.9 MW and 3.4 MW to assure that the structural components were immersed in flames and hot gases. The fuels used were well-characterized hydrocarbons or a mixture of hydrocarbons, selected to cover the expected range of soot loading in fires generated by typical office furnishings. The fire conditions were over-ventilated, that is, the rate of burning was fuel limited and not limited by the availability of oxygen.

The second series of experiments described in this report was quite differcnt. The objective of the second study was to assess the accuracy with which the NIST FDS predicted the thermal environment in a burning compartment and to establish a data set to evaluate prediction of the heat release rate associated with the burning of typical office furnishings. The experiments were designed to recreate aspects of the WTC fires including complex phenomena such as limited ventilation, fire spread and growth on real furnishings, and the effects of debris and jet fuel on the heat release rate of the fires. A large compartment was used in which office workstations comparable to those in WTC 1, 2, and 7 were burned under conditions believed to be similar to those that occurred on September 11,2001. This report documents this series of experiments and the comparison of the FDS simulation with the measurements in an effort to determine the accuracy of the model for use in the WTC Investigation.

An independent series of reduced-scale experiments was performed on the burning of a single office workstation in the open, with and without the presence of ceiling tiles and jet fuel (NIST NCSTAR 1-5C) in an effort to calibrate the FDS calculation for the simulations described in this report. The results of the reduced-scale experiments were used as input for FDS, which was then used to simulate the fire spread and growth, heat release rate, and the thermal environment associated with the burning of multiple workstations in a compartment. The numerical accuracy of the FDS predictions was determined through quantitative comparison with the measurements.

\subsection{OVERVIEW OF EXPERIMENTS}

A series of large-scale experiments was conducted in the NIST Large Fire Laboratory from November 4 to December 10, 2003. Workstations, arranged in a manner that is typical of a modern office were placed within a steel-frame compartment $(3 \mathrm{~m}$ by $7 \mathrm{~m}$ by $4 \mathrm{~m}$ ) lined with calcium silicate board (referred to as Marinite). The workstations were composed of several components including desks, a chair, a computer, etc. The fire was initiated by introducing liquid heptane through a four-nozzle spray burner onto a $1 \mathrm{~m}$ by $2 \mathrm{~m}$ pan that was adjacent to one of the workstations and, when present, by igniting jet fuel that had been distributed throughout each of the workstations. The experimental configuration and fire scenarios were selected to examine the effects of (1) the presence of ceiling tiles, (2) the presence of jet fuel, (3) the effect of changing the fuel configuration by breaking the furniture into "piles of rubble."

This reference is to one of the companion documents from this Investigation. A list of these documents appears in the Preface of this report. 
Six experiments were designed to assess the accuracy with which FDS predicts the fire spread, heat release rate, and thermal environment in a compartment burning multiple workstations in a configuration representative of that found in the WTC buildings. In each of these experiments, sets of thrce workstations, identical to the gencric workstations tested previously in the open (NIST NCSTAR 1-5C), were burned in a large compartment with a limited number of openings.

The experimental configuration included natural ventilation flowing through windows along one portion of one wall of the compartment. Fresh air entered and combustion products were exhausted through the openings. Such a configuration may have occurred in the WTC fires as ventilation was restrictcd to flow in and out through open windows. The experimiental configuration and fire scenarios were selected to examine the effects of underventilated burning of realistic furnishings, the presence of jet fuel, and the presence of ceiling tiles. The under-ventilated fire scenario is a challenging test of the fire model. The efficacy of the model has recently been investigated under over-ventilated burning conditions in an independent series of experiments (Hamins et al. 2004).

In summary, the objectives of this study were to assess the accuracy of the FDS predictions of the thermal environment in a burning compartment that recreated salient aspects of the WTC tower fires through comparison with a series of measurements.

\subsection{OVERVIEW OF THE FIRE DYNAMICS SIMULATOR}

The WTC fires were modeled using the NIST Fire Dynamics Simulator/Smokeview (McGrattan 2004) software package. The FDS is one of the first large-domain computational fluid dynamics (CFD) fire models that predicts the spread, growth, and suppression of a fire based on the underlying scientific principles governing fluid motion. Smokeview is an OpenGL graphics based software for visualizing information from large calculations. The purpose of computing is insight, not numbers. Focused on this objective, Smokeview facilitates an understanding of calculation output through visualization of the results. Smokeview animates FDS results in a variety of user selected modes, including the trajectory of smoke, and slices of the temperature and velocity fields within the three-dimensional domain.

The model numerically solves the conservation equations of mass, momentum, and energy that govern low-speed, thermally driven flows with an emphasis on smoke and heat transport from fires. The formulation of the equations and the numerical algorithm are contained in a companion document, called Fire Dynamics Simulator (Version 4) - Technical Reference Guide (McGrattan 2004). The models and their documentation are freely available to the public on the World Wide Web at the NIST site http://www.fire.nist.gov/fds. This site provides links to a setup program for PC installation. It also contains documentation for Smokeview and FDS, sample calculations, software updates, and links for providing feedback about the software.

The core algorithm is an explicit predictor-corrector scheme, second order accurate in space and time. Turbulence is treated by means of the Smagorinsky form of Large Eddy Simulation (LES). For most applications, FDS uses a mixture fraction combustion model. Radiative heat transfer is included in the model via the solution of the radiation transport equation for a non-scattering gray gas, and in some limited cases using a wide-band model. The equation is solved using a technique similar to finite-volume methods for convective transport and uses approximately 100 discrete angles. All solid surfaces are assigned thermal boundary conditions, and information about the burning behavior of the material. More 
detailed information regarding the FDS software is discussed in Chapter 10 of this report and in the technical reference guide (McGrattan 2004) and references therein.

The companion software package, called Smokeview, graphically presents the results of the FDS threedimensional time-dependent simulation. Smokeview is a software tool designed to visualize numerical predictions generated by FDS. FDS and Smokeview are used in concert to respectively model and visualize fire phenomena. Smokeview visualizes both dynamic and static data. Dynamic data is visualized by animating particle flow (showing location and "values" of tracer particles), 2D contour slices (both within the domain and on solid surfaces), and 3D level surfaces. 2D contour slices can also be drawn with colored vectors that use velocity data to show flow direction, speed, and value. Static data are visualized similarly by drawing 2D contours, vector plots, and 3D level surfaces anywhere within a simulation scene at a fixed time.

Normally Smokeview is used in a post-processing step to visualize FDS data after a calculation has been completed. Smokeview may also be used during a calculation to monitor a simulation's progress and before a calculation to visualize the calculation set-up, which may include walls, vents, sprinklers, smoke detectors, etc. In order to set up correct FDS input files more quickly, Smokeview is typically used to edit or create blockages by specifying the size, location, and/or material properties. More detailed information regarding Smokeview can be found in the Smokeview User's Guide (Forney and McGrattan 2004).

The accuracy of the FDS calculation was tested, and the FDS computation was calibrated and modified based on a series of fire experiments reported in NIST NCSTAR 1-5C. Their report describes a series of fire experiments burning individual workstations or workstations. The report also discusses measurement uncertainty, properties of the fires that are most important to the calculation, the initial FDS combustion module, and how the input data for the combustion simulation were obtained. The report concludes with a description of the changes made to the FDS combustion module to better describe the workstation fires. The FDS code, as modified to describe the fuels in the workstation in a simplified manner, was able to provide good estimates of the peak heat release rate (NIST NCSTAR 1-5C). It was not, however, able to accurately predict the time of the peak heat release rate. The present study is different in configuration, objectives, and complexity from the single workstation experiments reported in NIST NCSTAR 1-5C. In this study, the workstations were burned in a compartment rather than in the open (under a ceiling), leading to underventilated or oxygen-limited burning, which undoubtedly affected the rates of fire heat release and flame spread. In this study, the use of multiple workstations arranged about a carpeted passageway led to a variety of possible flame spread time-lines.

\subsection{MODEL VALIDATION}

Sufficient evaluation of fire models is necessary to establish acceptable uses and limitations of models, to ensure the adequacy of their technical basis, appropriateness of their desired use, and confidence level of their predictions. ASTM E 1355 (ASTM International 1997) defines model evaluation as "the process of quantifying the accuracy of chosen results from a model when applied for a specific use." The model evaluation process consists of two main components: verification and validation. Verification is "the process of determining the correctness of the solution of a system of governing equations in a model." Verification does not imply that the governing equations are appropriate; only that the equations are being solved correctly. Validation is defined as "the process of determining the correctness of the assumptions 
and governing equations implemented in a model when applied to the cntire class of problems addresscd by the model." Typically, validation involves comparing model results with experimental mcasurement. Differences that cannot be explained in terms of numerical crror are attributed to the assumptions and simplifications of the physical model.

This part of the NIST Investigation was motivated by the need to validate the models for the WTC application. Throughout its development, FDS has undergone various forms of evaluation, at NIST and elsewhere. McGrattan (2004) provides a summary of the work performed to date to verify and validate FDS for many applications. This document provides the basis for validation of the FDS as applied to investigation of the WTC fires. The intent of these experiments was to test rather than to calibrate the FDS calculations. An FDS simulation of each experiment was carried out before the tests were conducted and model predictions were then compared to the measurements.

The experiments described in this report were designed to provide the data necessary for validation of the fire simulation as applied to modeling the WTC disaster. The primary goal of the experiments was to compare the observed fire progression and heat release rate behavior with that predicted by the FDS software in an effort to obtain an understanding of how the fire might develop and spread from one workstation to another. The experiments allowed comparison of measurements and predictions of a number of critical parameters, which facilitated a check of the accuracy of the predictions and assured that the model was capturing properly the physics of fire dynamics and thermal-structural behavior.

The compartment was instrumented to measure transient fire dynamic effects such as the heat release rate and temperature profiles within the compartment. The instrumentation for the tests measured nearly 150 channels of data, including over 50 thermocouples. Approximately 40 measurements were made to determine the global heat release rate $(\dot{Q})$ of the fire using oxygen consumption calorimetry. The measurements reported here tested the accuracy of the heat release rate and the thermal behavior of the compartment as predicted by FDS. Other important measurements were also made during the experiments. The concentrations of oxygen, carbon monoxide, and carbon dioxide were measured in the upper layer of the compartment. These measurements are an important consistency check on the efficacy of the fire model. Since the calculation of heat release rate is dependent on the burning of oxygen, measurement of the oxygen concentration in the upper layer is an important check on model consistency. The measurement of temperature on the surface of the workstation components allowed tracking of fire spread from one workstation to the next. A video record of the experiments was completed to qualitatively compare model simulations with fire behavior. Tracking the heat release rate of the fire is one of the most important operations of the fire model because it impacts the overall thermal environment of the compartment. It is particularly important in the case of the NIST-led WTC Investigation because the fire model is being applied to simulate the time varying boundary conditions on the structural components in the building. Inaccuracy in the fire model calculations will propagate as inaccuracies in the calculation of thermal load on the building structure. The measurements reported here facilitate a check of the accuracy of the heat release rates predicted by FDS.

\subsection{ORGANIZATION OF THIS REPORT}

A detailed description of the instrumentation, procedure, uncertainties, and results are given in detail below for each of the measurements. Chapter 2 of this report describes the experimental configuration. including the experimental conditions, the fuel flow and details of the test compartment. Chapters 3 
through 7 describe observation and measurements of the fire and flame spread behavior (Chapter 3), the mass loss (Chapter 4), the heat release rate (Chapter 5), the volume fraction of gas species in the upper layer (Chapter 6), and the gas-phase temperature (Chapter 7). Chapter 8 provides a description of the model simulations and a comparison of the measured and simulated thermal environment in the compartment. Chapter 9 summarizes the results of this study. Appendix A contains a detailed list of the location of key compartment contents and instrumentation. Appendix B lists the specific analyzers employed for calorimetry and for measurement of the concentrations of the upper layer gases.

Appendix $C$ presents results not shown in Chapter 6 on the measured gas phase temperatures recorded by the bare bead thermocouples. Appendix D presents results not shown in Chapter 8 that compare the measurements to the simulations.

\subsection{REFERENCES}

ASTM International. 1997. Standard Guide for Evaluating the Predictive Capabilities of Deterministic Fire Models, ASTM E 1355-97, West Conshohocken, PA.

Forney, G. P., and McGrattan, K. 2004 User's Guide for Smokeview Version 4 - A Tool for Visualizing Fire Dynamics Simulation Data. NIST Special Publication 1017, National Institute of Standards and Technology, Gaithersburg, MD, August. ${ }^{2}$

Hamins, A., Maranghides, A., and Mulholland, G. 2003. The Global Combustion Behavior of 1 MW to 3 MW Hydrocarbon Spray Fires Burning in an Open Enviromment, NISTIR 7013, National Institute of Standards and Technology, Gaithersburg, MD, June.

McGrattan, K. B., ed. 2004. Fire Dynamics Simulator (Version 4), Technical Reference Guide. NIST Special Publication 1018. National Institute of Standards and Technology, Gaithersburg, MD, July.

2 All NIST publications cited here and elsewhere in this report are available for download from the World Wide Web: http://fire.nist.gov/bfrlpubs/ 


\section{Chapter 2 \\ Experimental Configuration, ApPaRatus, AND PROCEDURES}

\section{$2.1 \quad$ TEST FACILITY}

Experiments were conducted in the National Institute of Standards and Technology (NIST) Large Fire Laboratory, which is $27 \mathrm{~m}(90 \mathrm{ft})$ by $37 \mathrm{~m}(120 \mathrm{ft})$ in size. Fire products flowed into the largc exhaust hood for measurement of the heat release rate and were then exhausted from the building. The exhaust

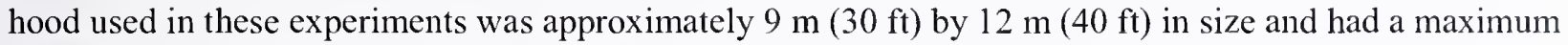
capacity of approximately $15 \mathrm{MW}$. A computerized data acquisition system was used to record the instrumentation signals.

\section{$2.2 \quad$ EXPERIMENTAL CONFIGURATION}

A common furnishing arrangement on several floors of World Trade Center (WTC) 1 was a continuous open space occupied by a large array of workstations (NIST NCSTAR 1-5C). Each office workstation (or workstation or module) was defined by privacy panels on four sides with an opening on one side only. Such an arrangement was used, for example, by the firm that occupied floors 93 to 100 of WTC 1 (NIST NCSTAR 1-5C). More than 950 workstations were used by this firm alone. Figure 2-1 below, which is a reproduction of Fig. 2-17 from the World Trade Center Building Performance Study (McAllister 2002), shows an example of the workstation layout on the 91st floor of WTC 1. The workstations were clustered in sets of six or eight stations sharing at least one common privacy panel with the clusters separated by an aisle. A fire propagating among the stations would have to either pass over (or through) a privacy panel or pass across an aisle. Each station contained an estimated $400 \mathrm{~kg}$ of combustible materials of various types, assuming that all of the file cabinets were full of papers. The hand-drawn lines in Fig. 2-1 represent locations where the aircraft impact may have disrupted the original workstation layout (McAllister 2002).
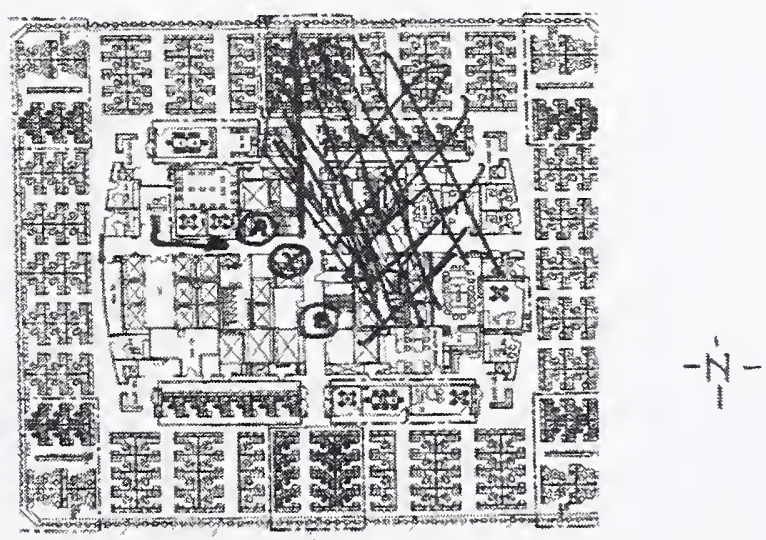

Source: McAllister 2002.

Figure 2-1. The workstation layout on the 91st floor of WTC 1. Locations with hand-drawn lines represent location where aircraft impact may have disrupted the original layout. 
Each experiment described in this report investigated the character of a set of three workstations burning in a compartment. The individual workstations were identical to the generic workstations burned in the open (NIST NCSTAR 1-5C). The workstations were an analog (not a replica) of one type of station used on floors 93 to 100 of WTC 1. There were at least four different workstation layouts used by this firm. From the limited information available, it appears that the fire behavior of the workstation most extensively characterized here would not differ greatly from that of the other layouts. Once validated, it is possible that the fire model could be used to test this assumption. The experiments conducted by NIST (NIST NCSTAR 1-5C) emphasized the global burning behavior of the workstation, as well as details of the fire spread through its various components. The scenario that was emulated in the experiments was fire propagation over and through a privacy panel. The use of a large ignition source was employed to simulate the burning of an adjacent station. There are several relevant categories of parameters pertinent to the unique circumstances of the WTC fires:

- Presence and Quantity of Jet Fuel (Jet A). The impact of the airplanes likely left varying amounts of Jet A distributed throughout the building, including on various surfaces in the workstations. Some areas were probably heavily engulfed with fuel, and others, farther from the impact zone, were probably dry. Those workstations closest to the impact would be expected to be destroyed into rubble, as well as soaked in Jet A. The focus of the NIST experiments was on the propagation and duration of the fire that threatened the steel structure. Because of its high volatility and heat of combustion, even a limited amount of Jet $A$ has the potential to alter the course of a fire. The presence or absence of Jet A was, thus, an important parameter to be examined because propagation away from the impact area could involve both conditions. NIST chose $4 \mathrm{~L}$ of jet fuel per workstation. In these experiments, the same quantities were used for each workstation. In addition, $1 \mathrm{~L}$ was used for the carpeted hall. This was sufficient to lead to simultaneous ignition throughout combustible surfaces in the compartment. ' The quantity chosen, 4 L per workstation, was sufficient to form a continuous layer on the major horizontal surfaces and thus was sufficient to alter the fire growth process substantially. The jet fuel was expected to cause rapid ignition of the combustibles throughout the compartment, but it was not expected to contribute significantly to the measured heat release rate on its own.

- Presence and Quantity of Inert Rubble on Surfaces. The airplanes caused localized destruction of materials in and around the impact zones, and they also caused collapse of the false ceilings on non-impact floors. The ceiling tiles are a nearly inert material (as characterized by measurements in a micro-calorimeter) with a thermal insulating character and are capable of retarding or even preventing the fire involvement of surfaces onto which they fall. This is a difficult effect to predict since it can interact with fire spread on workstation surfaces. The fractional ceiling tile area coverage was 70 percent for the tests that included ceiling tiles. This value was more than twice the value used by NIST (NIST NSTAR 1-5C), which conducted two single workstation burn experiments with the tiles covering about 30 percent of the exposed area. For the single workstations, this resulted in

1 In a designed experiment in which one is examining the potential roles of more than one factor, one attempts to vary each factor by an amount sufficient to be clearly measured but not so much as to cause the factors to interact strongly. A pool of Jet A with an area equal to that of the workstation foot print is itself capable of yielding a fire of greater than $13 \mathrm{MW}$ heat release rate (NIST NCSTAR 1-5C). The combination of jet fuel and other materials would then exceed the capacity of the NIST calorimeter facility. This was an incentive to limit the quantity of jet fuel. 
about a 20 percent reduction in the peak heat release ratc. Increasing the coverage to 70 percent is expected to further reduce the peak heat release ratc since less of the surface area would be accessible for burning.

- Extent of Rubble. The airplane impact zone could be expected to involve extensively fragmented workstation components along with fragmented materials from the airplane itself. This type of fragmentation would likely result in what amounts to "packing" of the various fuel surfaces, leading to decreased ease of air access to those surfaces and, thus, a reduced burning rate. This type of burning is difficult to model, given only the fuel characterizations based on Cone Calorimeter measurements reported in NIST NCSTAR 1-5C. This issue was addressed, in a partial manner, in one of the experiments (Test 5) in which the workstations were configured into a "pile of rubble," or disassembled into a non-standard configuration. In the other five experiments, the workstations were tested in an undisturbed configuration. Results from these five experiments only apply to the extensive areas beyond the immediate impact zones and to WTC 7.

- Fuel Content of File Cabinets. The three file cabinets in the generic workstation were capable of holding a combined load of up to about $150 \mathrm{~kg}$ of paper. Such paper content is normally included in the fire load estimates of office occupancy. When enclosed in steel, however, this effect is partially discounted (NIST NCSTAR 1-5C). It was anticipated that such paper would not contribute appreciably to the fire intensity until the peak heat release rate was past. Small amounts of paper (two reams) were placed in file cabinets on opposite sides of the workstation. The fraction burned was measured in two of the single workstation experiments conducted by NIST (NIST NCSTAR 1-5C). The paper loading elsewhere in the workstations was guided by information about the typical layout of workstations on floors 93 to 100 of WTC 1 , following NIST NCSTAR 1-5C.

- Ignition Scenario. The heat release rate history for a workstation subsequent to ignition, like any complex assemblage of fuels, can be expected to depend significantly on the mode and location of the ignition event. This is particularly true for small, localized ignition versus a large area ignition. In the WTC towers, the airplane impact provided an overwhelming ignition event in the area of impact. This intense fire then spread to other, less disrupted areas, providing a continuing series of large ignition sources. This suggested the scenario used here, which emulates the involvement of multiple workstations in a large-scale spread process. The ignition source chosen was thus quite large, simulating the burning of a workstation adjacent to the workstations of interest.

- Relative location of the fuel and source of ventilation. Fires in the towers were observed to move about the different sides of the building (NIST NCSTAR 1-6A). As the fires spread through the building, it is likely that various ventilation conditions occurred including both underventilated and overventilated burning conditions. Fire Dynamics Simulator (FDS) validation under overventilated conditions was tested previously (Hamins et al. 2003). Among the possible underventilated configurations that occurred, it is likely that fire either propagated through workstations toward open windows or fire propagated through workstations away from open windows. 
From the list of relevant parameters given above, the first three and the last one (the presence of Jet A fuel, ceiling tiles and "rubblized" fuel load, relative location of the fuel and the ventilation source) were selected as being most pertinent for testing the FDS calculation results and were considered part of the experimental design.

There has been some amount of previous work examining the burning behavior of office furnishings. Madrzykowski $(1996,1998)$ measured the heat release rate behavior of workstations representative of those found in some U. S. Government office buildings. The workstations considered here were somewhat larger than those studied by Madrzykowki and they had a smaller paper load ( $50 \mathrm{~kg}$ rather than $98 \mathrm{~kg}$ ). Peak heat release rates $(\dot{Q})$ as high as $7 \mathrm{MW}$ were measured as the number of workstation privacy panels varied from two to four. One of the experiments suggested a potential sensitivity to small details of the events - a thermoplastic shelf support failed early leading to a shelf collapse that spewed loose papers onto the fire, which immediately enhanced it substantially. For the generic workstations tested here, NIST NCSTAR 1-5C reported that shelf collapses did not have a noticeable effect, perhaps because the papers on them were relatively contained.

\subsection{TEST VARIABLES AND TEST MATRIX}

Six experiments were conducted. The test matrix was designed based on appreciation of the plausible WTC fire scenarios and the results of the single workstation experiments (NIST NCSTAR 1-5C). The experiments reported here investigated the impact of several parameters on fire behavior, including the location of the burner, the application of jet fuel distributed about each workstation, and the presence of fallen ceiling tiles with the tile distribution determined from an independent series of reduced scale experiments. A statistical analysis was conducted to determine which combination of experimental parameters should be selected for testing. The resulting test matrix is listed in Table $2-1$. The Table lists the test number, the presence or absence of ceiling tiles and jet fuel, the burner location, the state of the fuel load, and the presence or absence of glass windows ${ }^{2}$.

Table 2-1. Test matrix.

\begin{tabular}{|c|c|c|c|c|c|c|}
\hline Test & Ceiling Tiles & Jet Fuel & Burner Location & Workstations & Windows & Notes \\
\hline 1 & None & None & B1 (Front) & Intact & No & \\
\hline 2 & None & None & B1 (Front) & Intact & No & Test 1 repeat \\
\hline 3 & Present & Present & B1 (Front) & Intact & No & \\
\hline 4 & Present & None & B2 (Rear) & Intact & No & \\
\hline 5 & Present & Present & B2 (Rear) & Organized rubble & No & \\
\hline 6 & None & Present & B2 (Rear) & Intact & Yes & \\
\hline
\end{tabular}

The burner location was selected to challenge the FDS calculation results with different gas flow patterns and to cover the extremes of possible ventilation configurations. The burner was placed either abutting the west end of workstation 1 near the enclosure openings (B1 location) or abutting the east end of workstation 2 close to the east wall of the enclosure (B2 location). Figure 2-1 shows the two locations of the burner relative to the room contents. These two sites resulted in significantly different access to the

2 In Test 6, an assembly containing four glass windows was positioned on the west wall of the enclosure, which was the same wall in which ventilation openings were present. 
air needed for combustion. In the B1 ("front") location, much of the oxygen in the air initially cntering the enclosure was consumed by the burncr and the burning workstation 1, with the result that limited oxygen was available for combustion in the middle and rear of the compartment. With the burner in the B2 ("rear") location, the fresh air passed dircctly to the rear of the compartment.

Four liters of jet fuel were evenly distributed about each workstation, using the samc procedure that was used in the single workstation burn experiments (NIST NCSTAR 1-5C). Onc liter was distributed in the corridor. In the experiments with Jet A prescnt, ignition of the three workstations was designed to occur simultaneously, therefore, challenging the ability of the model to handle rapid flame spread.

The effect of the presence of fallen ceiling tiles was investigated to dctcrmine their effect on flame spread and maximum heat release rate. In three tests, nearly 70 pcrcent of the top surfaces were covered. The effect of lesser coverage (30 percent) was investigated in the previous test series for single workstations (NIST NCSTAR 1-5C). Measurement of the heat release rate of the ceiling tiles showed that they were quasi-inert (Lyon 2004).

One experiment (Test 5) investigated the effect of disassembling each of the workstations into pieces in what is referred to in Table 2-1 as "organized rubble." The pieces werc placcd on top of each other, simulating the effect of an aircraft causing furniture to break-up and collapse into piles. During Test 5, the workstation pieces in workstation 1 were placed unassembled on top of each other, occupying the same footprint as the assembled workstation. The same mass of combustibles was present as in the fully assembled workstation tests. No steel filling cabinets were used in these tests. Ceiling tiles and broken up drywall were intermixed with the rubble in Workstation 1. Workstation 2 was identical to Workstation 1, except without the drywall. Workstation 3 was partially assembled as seen in Fig. 2-8. The same mass of ceiling tile and drywall as in workstation 1 were intermixed with the components in Workstation 3 .

Test 6 had a $2.4 \mathrm{~m}$ by $2.4 \mathrm{~m}$ assembly containing four commercially available glass windows mounted on the north end of the west wall. The assembly was fitted with two different types of glass. Two sections of double-pane tempered glass (with a gel insulation sandwiched between the glass panes) were installed high and low on the right (as seen from outside the compartment) and two sections of single-pane tempered glass were installed high and low on the left. Manzello et al. (2005) describe the glass assembly in detail. No openings or columns were present adjacent to the glass assembly. During the course of the fires, heat broke some of the windows. This resulted in a change in both the degree and pattern of ventilation. The FDS fire model does not predict window breakage. Therefore, for this test, FDS was rerun after experimental determination of the time at which window breakage occurred.

\subsection{EXPERIMENTAL CONFIGURATION}

A schematic of the test configuration is shown in Figs. 2-2 and 2-4. The test series involved fires in compartments with the same height as that in WTC 1 or WTC 2. The steel-frame experimental enclosure was $10.81 \mathrm{~m}$ long by $7.02 \mathrm{~m}$ wide by $3.36 \mathrm{~m}$ tall $(35.5 \mathrm{ft}$ by $23 \mathrm{ft}$ by $11 \mathrm{ft})$. The walls and ceiling were covered with two or three layers of Marinite I (calcium silicate board) each with a thickness of $1.25 \mathrm{~cm}$. A sub-floor $0.48 \mathrm{~m}$ in height was used to house instrumentation and was not included in the above dimensions. The floor was also covered with Marinite I. 


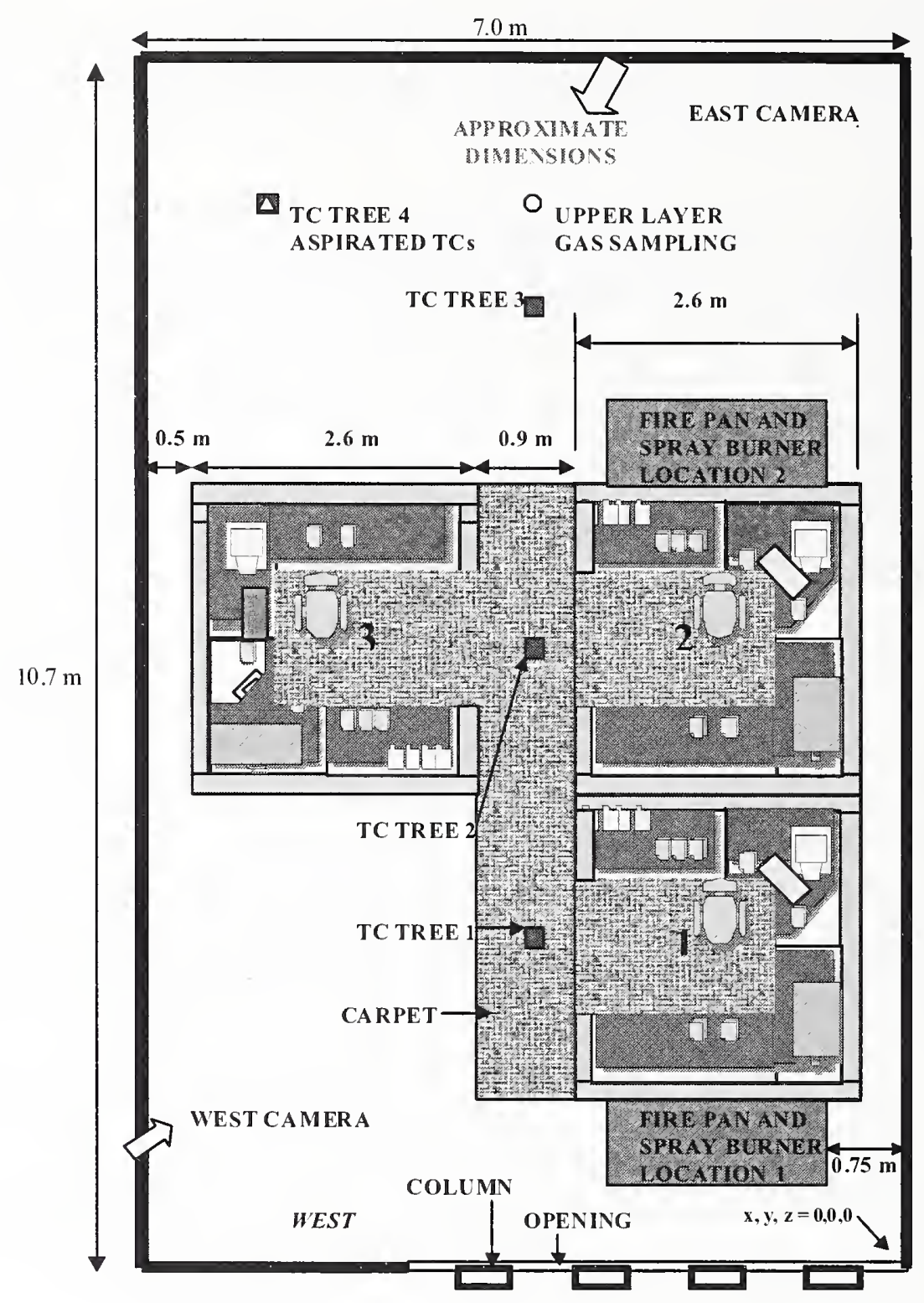

Figure 2-2. Plan view of the experimental configuration.

The compartment dimensions were selected to represent a section of the WTC North tower. The compartment was configured to resemble a section of the Marsh \& McLennan office on the 96th floor where the first plane struck on September 11. The total compartment volume was $255 \mathrm{~m}^{3}$. The compartment was built inside an exoskeleton of steel tubing and beams. The enclosure was equipped with an eave extending down $0.92 \mathrm{~m}$ from the ceiling. The compartment was located so that the exhaust vents were under the NIST $9 \mathrm{~m}$ by $12 \mathrm{~m}$ exhaust hood. Figure 2-3 shows the west side of the experimental enclosure with the knee wall removed for access. The liquid fuel spray burner is evident just behind the ventilation openings between the columns. 


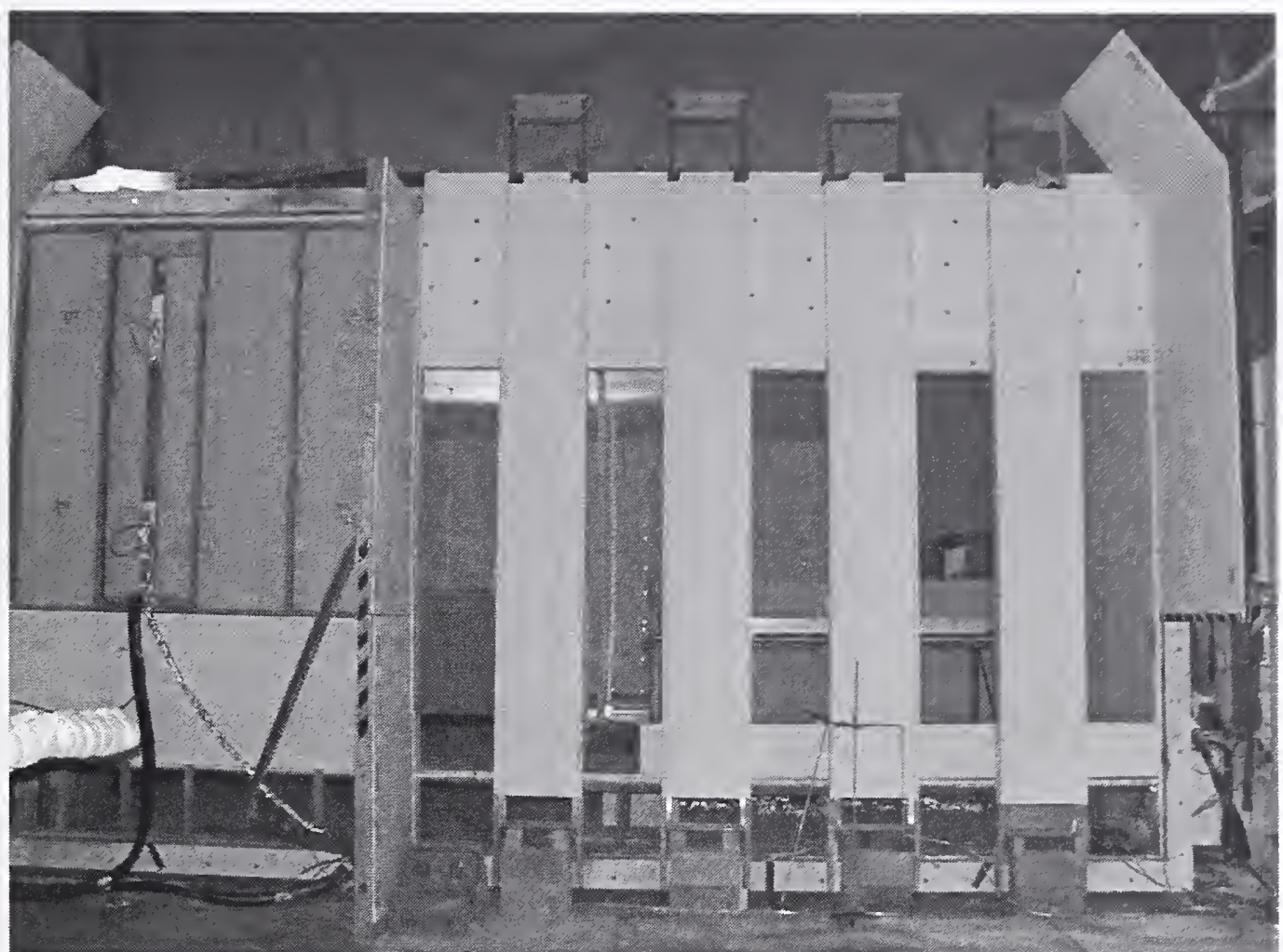

Source: NIST.

Figure 2-3. West side of experimental enclosure. Five ventilation openings are present. The knee wall was removed for access to instrumentation.

Each of three workstations was placed on an isolated platform made of calcium silicate board. The top surface of each platform was flush with the floor of the compartment. Each platform was supported on water-cooled load cells, located in the subfloor, to monitor the mass of the workstation during the test. Two of the workstations were contiguous, exemplifying a part of the type of cluster that existed in many large office spaces. The third workstation was separated from the other two by an aisle, representing a part of a second cluster. This array enabled an assessment of FDS's ability to replicate two different modes of workstation-to-workstation fire spread: direct flame impingement and radiative ignition from the hot ceiling layer. Figure 2-4 shows aspects of the configuration corresponding to Fig. 2-3.

\subsubsection{Ventilation}

The enclosure had five openings and four columns on the front (west wall), mimicking window openings through which fresh air entered, and heat and combustion products were emitted. The openings were $2.12 \mathrm{~m}$ high, started $0.32 \mathrm{~m}$ above the floor, and were each $0.45 \mathrm{~m}$ wide. The narrow openings limited the amount of fresh air that entered the burning enclosure. In one test, (Test 6), the ventilation changed during the experiment as window glass, placed to the left of the ventilation openings, cracked and fell out approximately $3 \mathrm{~min}$ after ignition. 


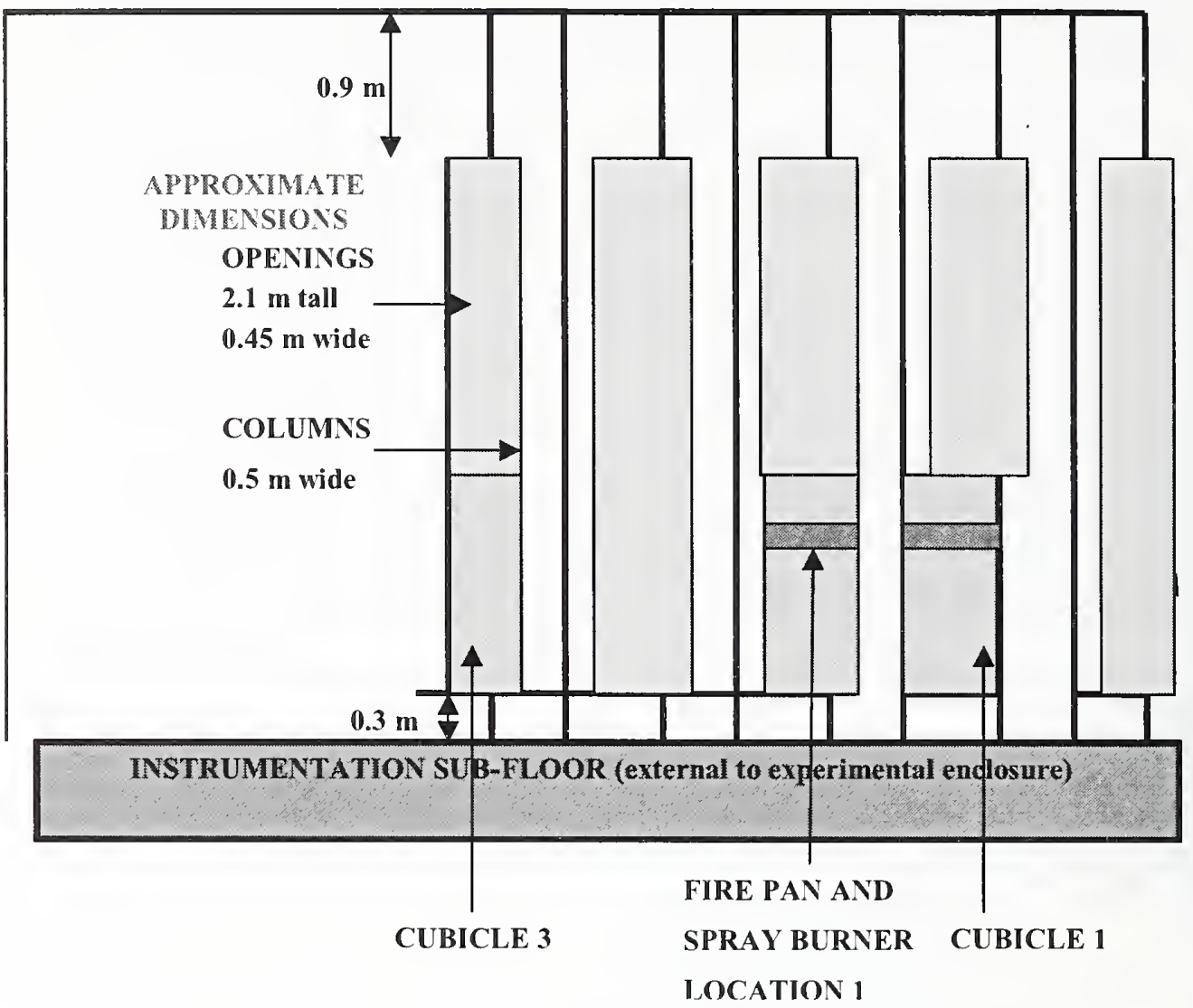

Figure 2-4. Elevation view of experimental configuration.

\subsubsection{Description of the Multi-Workstation Configuration}

Figure 2-2 shows the multi-workstation experimental configuration. The layout was composed of three generic workstations positioned in an "L" shape. Each of the workstation is labeled with a number in Fig. 2-2. The spray burner was located either to the east of Workstation 2 or to the west of Workstation 1. Compartment openings were located on the west side of the compartment. A $0.5 \mathrm{~m}$ wide carpeted passageway separated Workstation 3 from Workstations 1 and 2.

\section{Workstations}

The generic workstation is described in detail in NIST NCSTAR 1-5C. A brief description is given here. The layout, including the placement of the various non-stationary items, was suggested by personnel from the company that supplied office furnishings to the occupants of WTC 1. A frequent visitor to the WTC offices provided observations on the distribution of paper and office clutter (NIST NCSTAR 1-5C).

The generic workstation was a $2.44 \mathrm{~m}$ by $2.44 \mathrm{~m}(8 \mathrm{ft}$ by $8 \mathrm{ft}$ ) workstation. Table $2-2$ lists the contents of the workstation, which included carpeting, privacy wall panels, a chair, bookcases, three filing cabinets, four work surfaces, reams of copier paper, a thermoplastic waste basket, a computer, a monitor, and a keyboard. Table 2-2 also lists the total and the fraction of the mass that was combustible. Each workstation weighed about $557 \mathrm{~kg}$. Approximately 45 percent of the mass of the contents $(249 \mathrm{~kg})$ was combustible. Table 2-3 lumps the workstation contents into four categories. The largest type of material 
was wood/laminate ( 45 percent by mass), followed by paper ( 25 percent), plastics ( 16 percent) and carpct (14 percent). The heats of combustion of these materials, based on the Conc Calorimcter results, varied by nearly a factor of three (NIST NCSTAR 1-5C).

Table 2-2. Mass of workstation contents.

\begin{tabular}{|l|c|c|c|}
\hline \multicolumn{1}{|c|}{ Component } & $\begin{array}{c}\text { Mass } \\
\text { (kg) }\end{array}$ & $\begin{array}{c}\text { Combustible } \\
\text { Fraction }\end{array}$ & $\begin{array}{c}\text { Combustible Mass } \\
\text { (kg) }\end{array}$ \\
\hline $\begin{array}{l}\text { Work surface - melamine laminate over medium } \\
\text { density fiberboard; 4 pieces, 6.1 m total length } \times \\
0.61 \text { m wide } \times 28 \text { mm thick }\end{array}$ & 82.8 & 1.0 & 82.8 \\
\hline 27 reams of paper and 14 document boxes & 63.7 & 1.0 & 63.7 \\
\hline $\begin{array}{l}\text { Plastic kick plates and trim (base of walls, inside } \\
\text { and outside) }\end{array}$ & 7.1 & 1.0 & 7.1 \\
\hline Computer keyboard & 1.2 & 1.0 & 1.2 \\
\hline Plastic waste basket & 0.7 & 1.0 & 0.7 \\
\hline 36 nylon carpet tiles with rubber backing & 38.0 & 0.9 & 34.2 \\
\hline Shelf ends - particle board or dense foam & 3.8 & 0.9 & 3.4 (assumed plastic) \\
\hline $\begin{array}{l}\text { Bulldog chair - fabric, foam, thermoplastic shell } \\
\text { and base }\end{array}$ & 19.4 & 0.8 & 15.5 \\
\hline Computer monitor - ABS & 17.6 & 0.3 & 5.3 \\
\hline Computer processor & 12.3 & 0.3 & 3.7 \\
\hline $\begin{array}{l}\text { 9 wall panels with aluminum angle, wood frames, } \\
\text { fiberglass, and metal mesh, 3 sizes }\end{array}$ & 168.2 & 0.18 & $30.3(25.3 \mathrm{~kg}$ wood, \\
\hline Book shelf & 8.3 & 0.1 & $5.0 \mathrm{~kg}$ fabric) \\
\hline $\begin{array}{l}3 \text { two-drawer steel filing cabinets, 0.91 m long } \times \\
0.51 \text { m deep } \times 0.76 \mathrm{~m} \text { high }\end{array}$ & 142.5 & 0 & 0.8 \\
\hline Total & $\mathbf{5 5 7 . 1}$ & $\mathbf{0 . 4 5}$ & 0.0 \\
\hline
\end{tabular}

Table 2-3. Mass of workstation materials by type.

\begin{tabular}{|c|c|c|c|}
\hline Material & $\begin{array}{c}\text { Mass } \\
(\mathbf{k g})\end{array}$ & Fraction of Total & $\begin{array}{c}\text { Effective Heat of Combustion } \\
(\mathbf{M J} / \mathbf{k g})\end{array}$ \\
\hline Wood/laminate & 111.5 & 0.45 & 14 \\
\hline Paper & 63.7 & 0.25 & 14 \\
\hline Plastics $^{\mathrm{a}}$ & 39.3 & 0.16 & $16-38$ \\
\hline Carpet & 34.2 & 0.14 & 22 \\
\hline
\end{tabular}

a. Includes computer monitor shell (16 MJ/kg), wall fabric $(30 \mathrm{MJ} / \mathrm{kg})$, and chair composite $(38 \mathrm{MJ} / \mathrm{kg})$.

The privacy wall panels were mid-height (1.22 $\mathrm{m}$ high, except for one $1.52 \mathrm{~m}$ high panel section

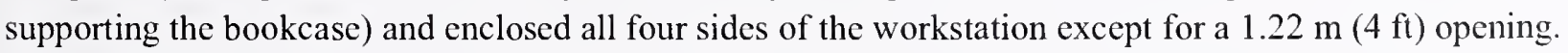
The panels were covcred on both sides with a thermoplastic fabric. The interior structure of the panels was composed of layers of fiberglass and perforated steel. Each panel section had a $38 \mathrm{~mm}$ softwood frame around its periphery, but this was covered in part by fabric and in part by a steel outer frame. The work or desk surfaces (top $0.75 \mathrm{~m}, 29.5 \mathrm{in}$., above the floor) were formed from four unequal sections of laminated, medium density fiberboard, supported by brackets from the wall panels. The office chair was 
upholstered with a non-thermoplastic fabric over polyurethane foam (seat and seat back), supported by a one-piece thermoplastic shell; its five-legged base was also thermoplastic, though there were steel framing and support elements.

The three steel filing cabinets $(0.91 \mathrm{~m}$ wide, $0.51 \mathrm{~m}$ deep, $0.68 \mathrm{~m}$ high, $36 \mathrm{in}$. by $20 \mathrm{in}$. by $27 \mathrm{in}$.) with two horizontal drawers each rested directly on the carpet tiles. The bookcase (1.22 m, $48 \mathrm{in}$. long) had a steel shelf and top, but these were supported only on their ends by combustible end panels; the steel front closure panel was fabric-covered steel, and it was open (on top of the bookcase). The carpet tiles were nylon fiber-faced over a dense foam rubber backing. A square area $2.74 \mathrm{~m}$ by $2.74 \mathrm{~m} \mathrm{(} 9 \mathrm{ft}$ by $9 \mathrm{ft})$ was covered with 36 carpet tiles. The entire assembly rested on top of a double layer of Marinite I ( $13 \mathrm{~mm}$, $1 / 2$ in. thick) sheets. The support structure beneath this was in turn placed atop a set of four weighing cells, one at each corner.

The computer monitor was a nominally a $17 \mathrm{in.} \mathrm{CRT-based} \mathrm{unit.} \mathrm{Its} \mathrm{front} \mathrm{face} \mathrm{was} \mathrm{taped} \mathrm{with} \mathrm{fiberglass}$ tape, and it was pointed toward the wall panel opposite the workstation opening in the event of an implosion. The keyboard was placed in its normal location, parallel to the angled segment of the work surface. The computer processor (tower-type container with plastic only on the front face of the container) was placed on the floor next to a waste paper basket (both on the north side of the workstation, opposite the opening).

The wastebasket was thermoplastic, and it contained one ream of copier paper atop five balled-up paper ream wrappers. Copier paper was chosen to substitute for all types of paper-based products expected in a workstation (loose leaf, catalogs, books, etc.), since it is reproducible and similar in general fire behavior to all such products. It was positioned in both horizontal and vertical arrays, arrangements which potentially may behave quite differently, but this did not appear to be crucial in any of the single workstation experiments (NIST NCSTAR 1-5C).

Copier paper was also distributed along the desks and bookshelves. The paper in the bookcase and the paper in the southwest corner (to the left of the workstation opening) were placed vertically in open, thin cardboard "document boxes", each with an $89 \mathrm{~mm}$ (3.5 in.) wide interior dimension. These boxes had a sloped top edge such that they equaled the long dimension of the paper in the rear but were only $100 \mathrm{~mm}$ (4 in.) tall in front. In the bookcase, each document box contained 1.33 reams of copier paper (a rather loose degree of packing). The ten boxes were grouped in sets of two with equal spacing (approximately $3 \mathrm{~cm}, 1.2 \mathrm{in}$.) between each pair. The four boxes on the desk surface contained one ream each of copier paper (an even looser degree of packing) and were grouped as a set of four units in a line, in contact. Other paper was laid as open horizontal stacks on the desk surface. A few sheets were tacked (as groups of three to five sheets) to the workstation walls on three sides.

Two of the three file cabinets contained a very limited amount of copier paper. Two piles were laid horizontally in two file drawers. Each pile consisted of one ream laid in the drawer corner with the long dimension of the paper aligned with the depth dimension of the drawer topped by a second ream aligned at 90 degrees to the lower ream. Both placements were worst case in terms of heat exposure, i.e., they were against the file cabinets, immediately adjacent to an area subject to intense burning (open area under the desk surface). It was anticipated that the contribution of the copier paper to the heat release rate would be rather small and tend to occur past the peak $\dot{Q}$ for the workstation. 
The chosen ignition sccnario mimicked that used for the single workstation (NIST NCSTAR 1-5C) for the isolated workstations. The concept was to create a scenario in which fire spread was proceeding linearly through a large array of workstations. A large ignition source (a $2 \mathrm{MW}$, four nozzle spray burner over a $2 \mathrm{~m}$ by $1 \mathrm{~m}$ pan) was placed immediately adjacent to the exterior of one wall panel of the test station, simulating the burning of the adjacent workstation. The size and placement (pan bottom $0.81 \mathrm{~m}$ above the floor) of this ignition source were guided by preliminary FDS predictions. Of course, a real workstation would yield a transient heat release rate and, thus, a time-varying heat input to its neighbor. A constant heat release rate for the spray burncr was used for consistency without sacrificing realism.

The entire assembly was placed beneath the NIST $9 \mathrm{~m}$ by $12 \mathrm{~m}$ exhaust hood and calorimeter system to capture the combustion products and measure the total heat release rate during the burning of the workstations. Unlike the experiments on the single workstations (NIST NCSTAR 1-5C), the air supply to the fire was restricted through the compartment openings. The burning behavior was, therefore, ventilation limited during a large portion of the experiments.

\section{Ceiling Tile Distribution in Multi-Workstation Tests}

The distribution of ceiling tiles mimicked that used by for the single workstation (NIST NCSTAR 1-5C), which was based on a series of ambient temperature full-scale and reduced-scale experiments. In the fire tests, the tiles were laid out with their edges parallel to the privacy panels to facilitate reproducible placement in successive tests. Forty-nine tiles were used, and the percentage of the area covered by tiles in the fire experiments was as follows: central floor area, 67 percent; floor area under desk surfaces, 10 percent; desk surface remote from bookcase, 50 percent; two desk surfaces near bookcase, 32 percent; chair seat, 25 percent. All of the tiles were laid flat on horizontal surfaces, and some overlap of tiles was used. Figure 2-5 is a photograph taken before Test 3, which highlights the arrangement of the ceiling tiles used in Tests 3 and 4 for each of the workstations. The spray burner and compartment openings are visible toward the rear of the photograph shown in Fig. 2-6. In Test 5, the ceiling tiles were placed on top and within the "rubblized" workstations as shown in Figs. 2-7 and 2-8.

Analysis using the Federal Aviation Administration micro-calorimeter (Walters and Lyons 2000) showed that under aerobic pyrolysis conditions, the total heat release rate for a virgin ceiling tile sample was $1.9 \mathrm{~kJ} / \mathrm{g} \pm 5$ percent with a char mass fraction of 83 percent remaining after pyrolysis. Each ceiling tile weighed approximately $0.4 \mathrm{~kg}$ so that the total mass of tiles per workstation was approximately $20 \mathrm{~kg}$. This would be expected to yield $40 \mathrm{~kJ}$ of energy. If averaged over a $10 \mathrm{~min}$ period, the heat release rate would be expected to yield approximately $0.07 \mathrm{~kW}$, a negligible contribution to the total heat release rate of the burning workstations, which was on the order of $10 \mathrm{MW}$. 

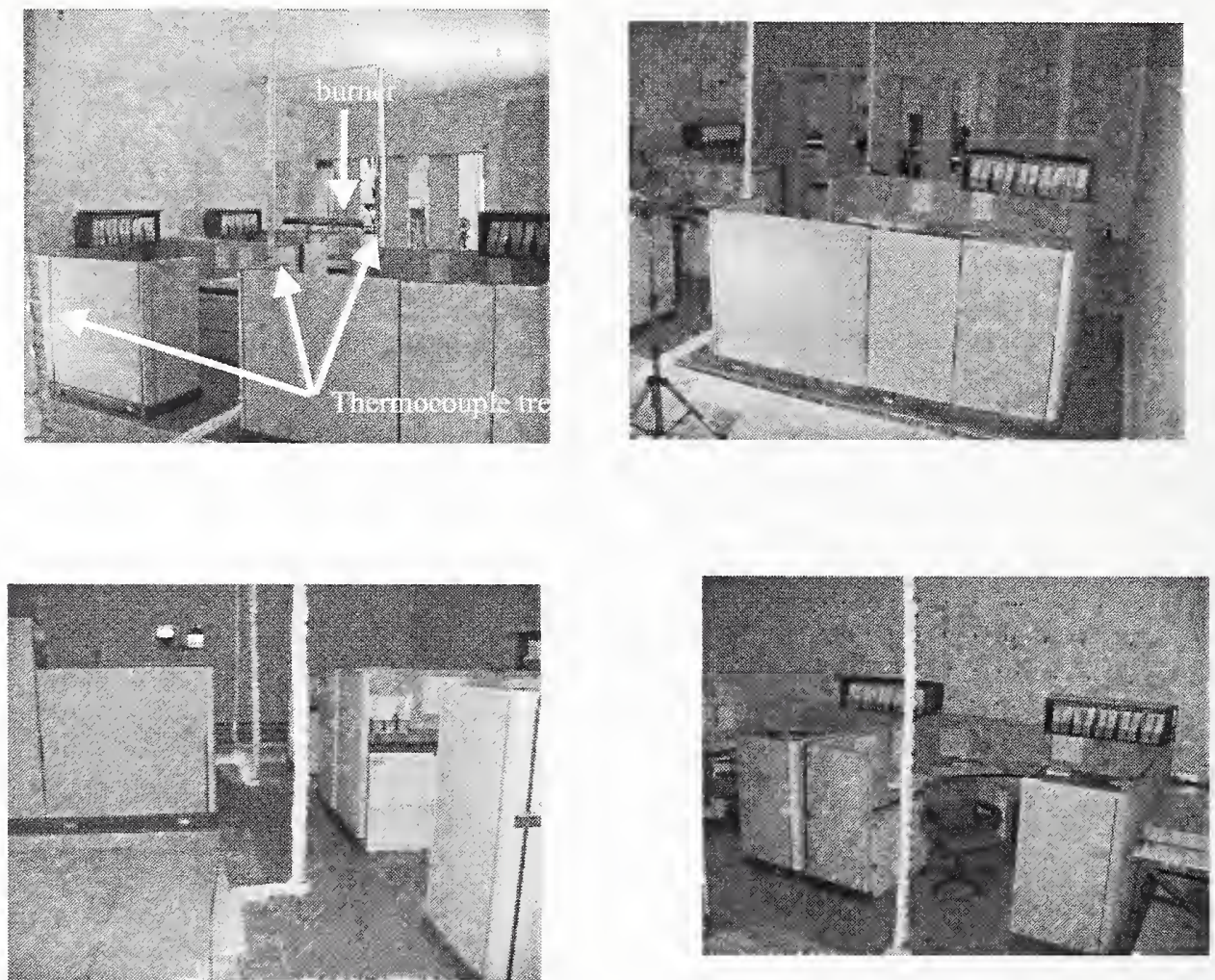

Source: NIST.

Figure 2-5. Views of interior of test compartment.

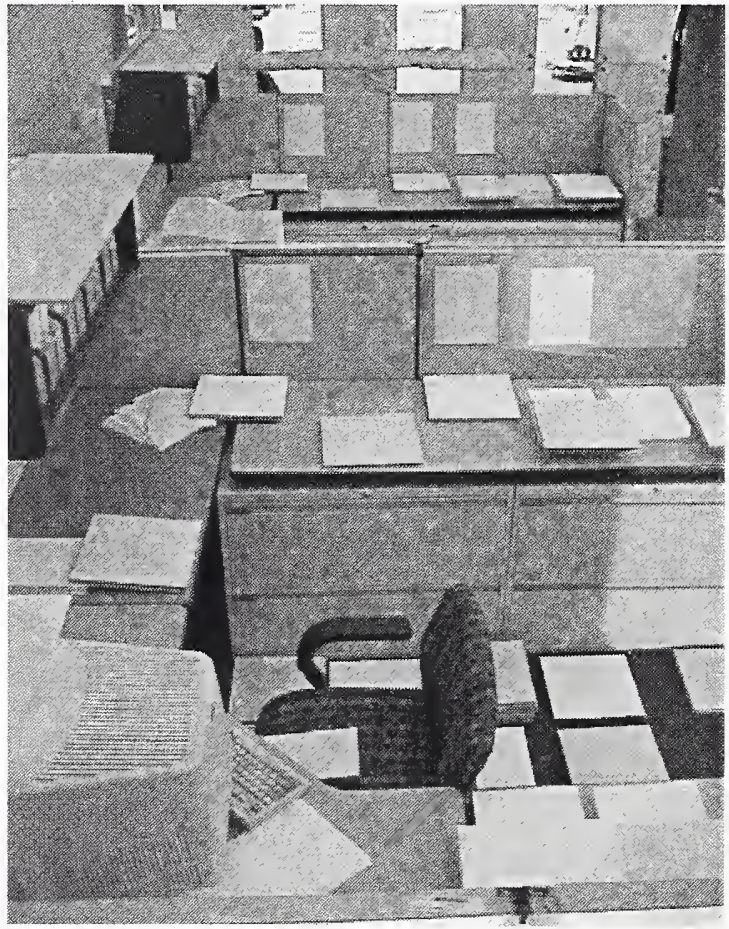

Source: NIST.

Figure 2-6. Image highlighting the arrangement of ceiling tiles used in Tests 3 and 4. The spray burner and compartment openings are visible towards the rear. 


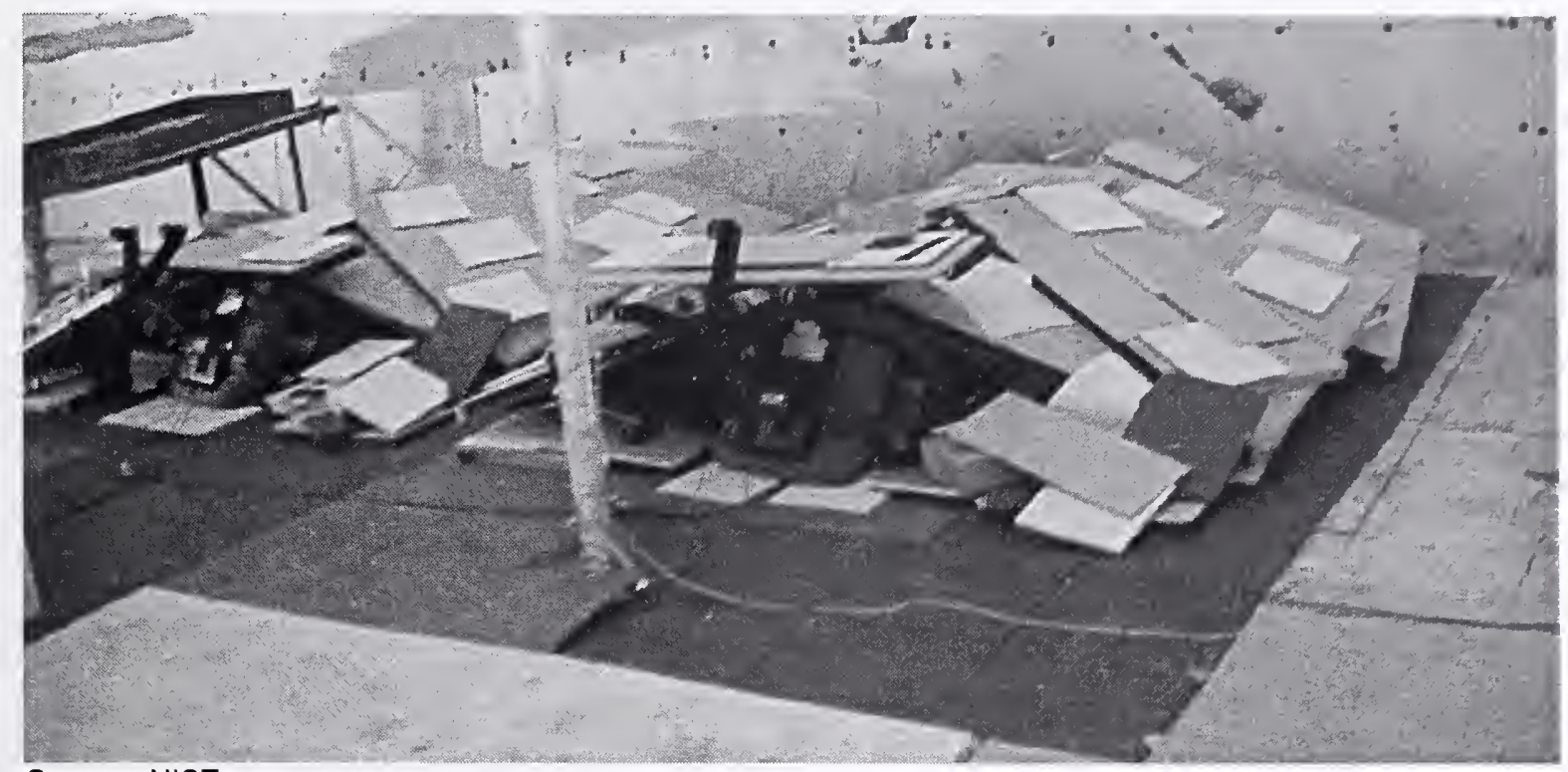

Source: NIST.

Figure 2-7. The arrangement of "rubblized" Workstations 1 (left) and 2 (right) with ceiling tiles before Test 5 . Part of the spray burner is visible on the left.

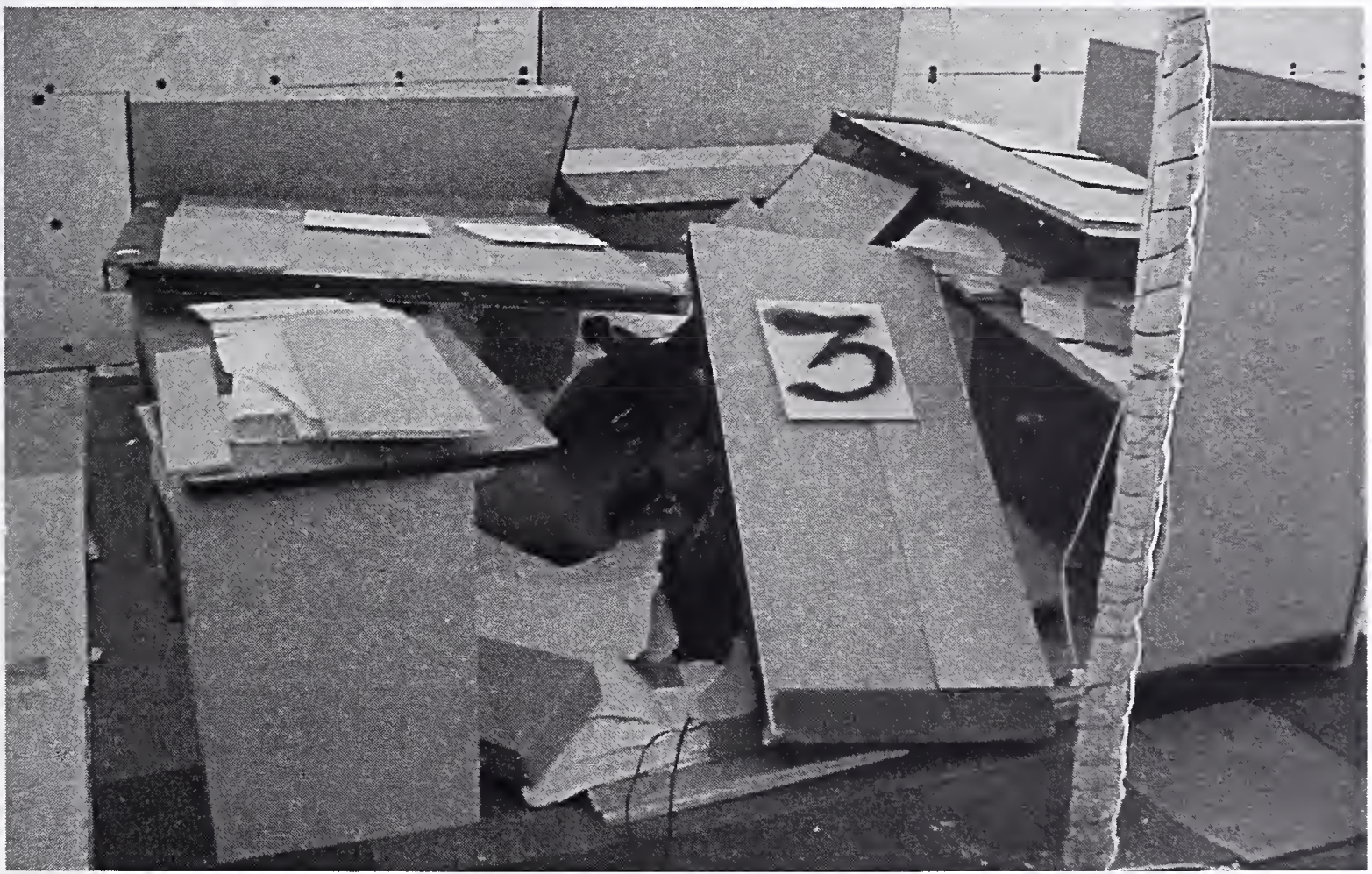

Source: NIST.

Figure 2-8. The arrangement of Workstation 3 before Test 5. 


\subsection{FUEL FLOW, BURNER, AND DELIVERY SYSTEM}

The liquid spray burner, pan, and fuel (mixture of heptanes) were the same as those used for the single workstation (NIST NCSTAR 1-5C). The spray burner was used to cause repeatable rapid ignition on one side of the adjacent workstation. The fuel used was a commercial blend of heptane isomers. Depending on the test, the burner was located abutting the top of a workstation partition at the east end of Workstation 1 or the west end of Workstation 2. The ignition fire intensity was a nominal $2 \mathrm{MW}$ fire. The spray burner was operated for the first few minutes of the tests, for either 2 min or 10 min depending on the test scenario. Table 2-4 lists the burner location, the fuel flow rate, and the duration of the spray.

Table 2-4. Liquid fuel spray burner.

\begin{tabular}{|c|c|c|c|c|}
\hline Test & Location & Initiation & $\begin{array}{c}\text { Flow Rate } \\
(\mathbf{L} / \mathbf{m i n})\end{array}$ & $\begin{array}{c}\text { Duration } \\
\text { (min) }\end{array}$ \\
\hline 1 & B1 & Time $=0 \mathrm{~s}$ & 4.0 & 10 \\
\hline 2 & B1 & Time $=0 \mathrm{~s}$ & 4.0 & 10 \\
\hline 3 & B1 & After Jet A ignition & 4.0 & 2 \\
\hline 4 & B2 & Time $=0 \mathrm{~s}$ & 4.0 & 10 \\
\hline 5 & B2 & After Jet A ignition & 4.0 & 2 \\
\hline 6 & B2 & After Jet A ignition & 4.0 & 2 \\
\hline
\end{tabular}

A blend of heptane isomers (designated here as "heptane") was used as the spray burner fuel. The density, the heat of combustion, and the carbon to hydrogen ratio for the fuels were measured for the commercial heptane and n-heptane. The heat of combustion and the carbon to hydrogen ratio for the commercial heptane was measured to be within 1 percent of the value for $n$-heptane (Galbraith Labs 2003), which was within experimental uncertainty for the measurements. The fuel flow was $4.0 \mathrm{~L} / \mathrm{min}$, which was approximately equivalent to a $2 \mathrm{MW}$ fire. The fuel flow to the hydrocarbon spray burner was calibrated before each of the experiments. The fuel was delivered through four 90 degree spray angle WL $1 / 2$ type stainless steel nozzles spraying downward. The BETE nozzles were spaced $50 \mathrm{~cm}$ apart and located $47 \mathrm{~cm}$ above the fire pan. The $1 \mathrm{~m}$ by $2 \mathrm{~m}$ stainless steel pan was positioned $85 \mathrm{~cm}$ above the floor of the enclosure. Figure 2-9 is a photograph of the spray burner and fire pan abutting workstation 1 before Test 2. In the photograph, the burner is positioned at Location B1, which was near the ventilation openings on the west side of the compartment. The photograph shows that the pan was mounted on a table $80 \mathrm{~cm}$ above the floor.

The ignition of the spray burner initiated the tests, and was defined as the zero reference time for data collection. For the cases when jet fuel was present, the fuel spray was initiated after the jet fuel in the compartment was fully involved. The fuel spray was somewhat coarse and some droplets made it to the pan though there was no significant liquid accumulation there. The duration of the fuel flow was $2 \mathrm{~min}$ for the cases when jet fuel was present and $10 \mathrm{~min}$ in the absence of jet fuel. The fuel flow was monitored using an ExactFlow dual rotor turbine flow meter during the experiments. 


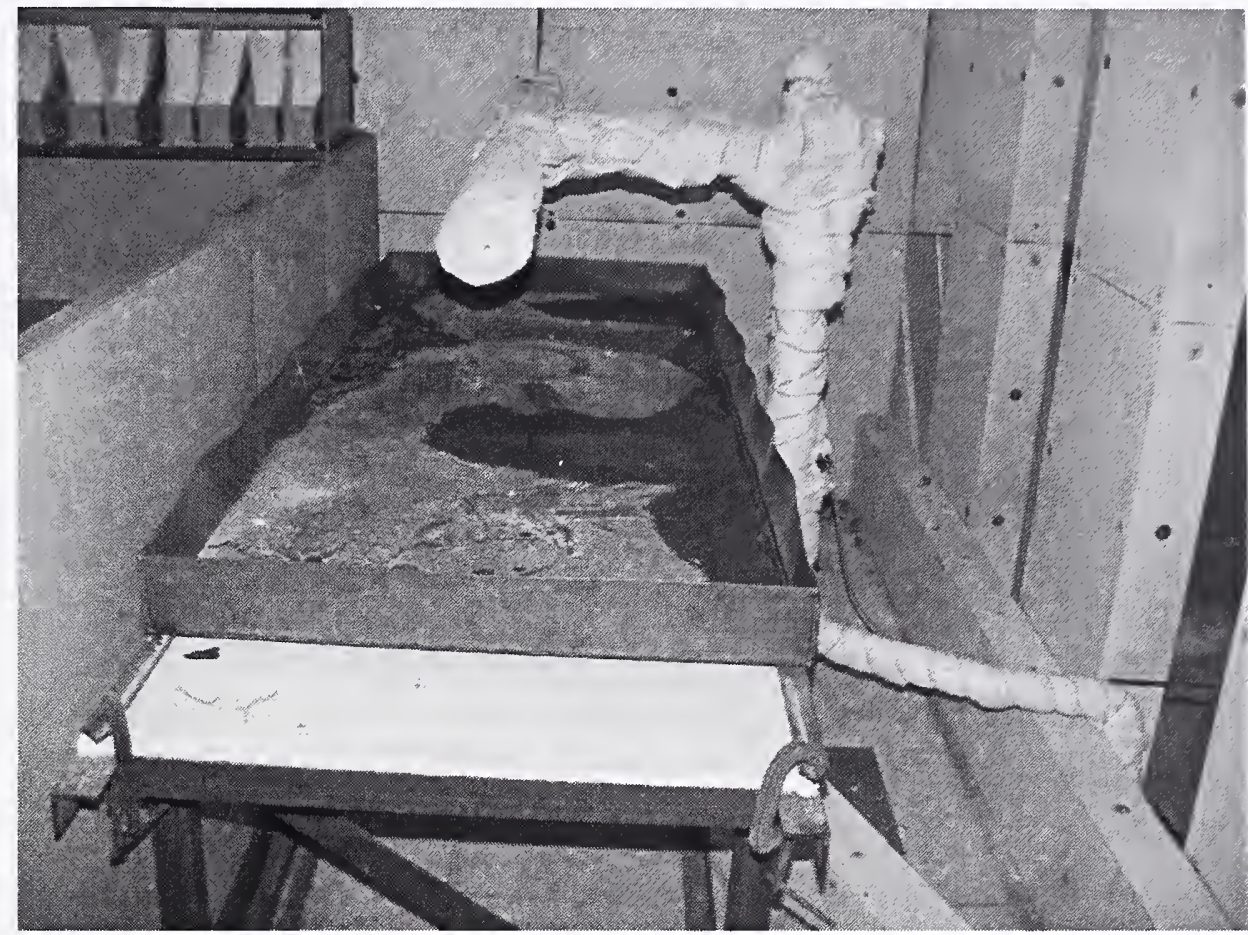

Source: NIST.

Figure 2-9. Spray burner and fire pan abutting Workstation 1 before Test 2 (location B1).

\section{6} INSTRUMENTATION

More than 150 channels of data were acquired for each of the six experiments. Table $2-5$ provides an overview of the instrumentation, measurement technique, and measurement locations used in the experiments. Appendix A lists the location of each instrument.

Table 2-5. Measurements.

\begin{tabular}{|l|c|c|}
\hline \multicolumn{1}{|c|}{ (Chapter) Measurement } & Instrument/Method & Location \\
\hline (3) Spray burner fuel flow & Turbine flow meter & Fuel piping outside enclosure \\
\hline (3) Flame Spread & $\begin{array}{c}\text { Bare-bead thermocouples; digital } \\
\text { video cameras }\end{array}$ & $\begin{array}{c}\text { Thermocouples attached to combustible } \\
\text { surfaces; video cameras with inside \& } \\
\text { outside views. }\end{array}$ \\
\hline (4) Mass loss rate & 3 load cell systems & Sub-floor under each workstation \\
\hline (5) Heat release rate & Oxygen consumption calorimetry & Exhaust duct \\
\hline (6) Gas temperature & $\begin{array}{c}4 \text { trees each with 4 bare-bead } \\
\text { thermocouples }\end{array}$ & Four thermocouple trees \\
\hline $\begin{array}{l}\text { (7) } \mathrm{O}_{2}, \mathrm{CO}_{2} \text { and } \mathrm{CO} \text { volume } \\
\text { fractions (dry basis) }\end{array}$ & $\begin{array}{c}\text { Gas sampling with paramagnetic } \\
\text { and non-dispersive IR }\end{array}$ & Upper layer \\
\hline Video record & Digital video cameras & Inside and outside views \\
\hline
\end{tabular}

Chapters 3 through 7 of this report describe each of the measurements in detail, including the instrumentation that was used, an estimate of uncertainty, and the experimental results. Table 2-6 summarizes some of that information and lists the character of the instrumentation in terms of important 
measurement characteristics, namely, typical values of the expanded measurement uncertainty (with an expansion factor of 2), the measurement time response, and estimates of the spatial resolution of the measurement. These properties characterize and limit the utility of a measurement and are important considerations in terms of comparison of model predictions with measurements. The time response was typically $1 \mathrm{~s}$, varying from $1 \mathrm{~s}$ for the thermocouples to $15 \mathrm{~s}$ for the heat release rate measurement. The spatial resolution of the measurements was typically $1 \mathrm{~cm}$ to $5 \mathrm{~cm}$, varying from sub-centimeter to $1,000 \mathrm{~cm}$ for the mass loss rate measurement of the load cells.

Table 2-6. Instrument characterization.

\begin{tabular}{|l|c|c|c|}
\hline \multicolumn{1}{|c|}{ Instrumentation } & Typical Expanded Uncertainty & $\begin{array}{c}\text { Nominal Time } \\
\text { Response (s) }\end{array}$ & $\begin{array}{c}\text { Spatial Resolution } \\
\text { (cm) }\end{array}$ \\
\hline Load cell & $5 \%$ & 10 & 1,000 \\
\hline $\begin{array}{l}\text { Heat release rate via oxygen } \\
\text { consumption calorimetry }\end{array}$ & $\begin{array}{l}15 \% \\
\text { (for } \dot{Q}>0.8 \mathrm{MW})\end{array}$ & 15 & Global measure \\
\hline $\begin{array}{l}\text { Gas temperature: } \\
\text { Bare bead thermocouple } \\
\text { - Aspirated thermocouple }\end{array}$ & $<120^{\circ} \mathrm{C}($ dependent on temperature) \\
$7{ }^{\circ} \mathrm{C}$ & 1 & 0.5 \\
\hline $\mathrm{CO}^{\text {via non-dispersive } \mathrm{IR}^{\mathrm{a}}}$ & $10 \%$ & 1 & 1 \\
\hline $\mathrm{CO}_{2}$ via non-dispersive $\mathrm{IR}^{\mathrm{a}}$ & $10 \%$ & 10 & 5 \\
\hline $\mathrm{O}_{2}$ via paramagnetic & & 10 & 5 \\
\hline
\end{tabular}

a. Gas volume percentages are reported on a dry basis.

\subsubsection{Load Cells}

The rate of burning of combustible items in the compartment controlled the fire heat release rate and, thereby, the rate of fire spread. Load cells were employed to measure the mass loss of each of the workstations during each of the tests. The mass loss rate determined from the load cell data provided a measure of the fuel gasification rate and computation of the effective heat of combustion of the workstations. A detailed description of the load cells and mass loss rate measurement results is given in Chapter 4.

\subsubsection{Oxygen Consumption Calorimetry}

The west end of the enclosure was located under the NIST $9 \mathrm{~m}$ by $12 \mathrm{~m}$ exhaust hood for collection of the effluent and measurement of the heat release rate using oxygen consumption calorimetry. The plume of gases generated during the tests exited through the west wall of the compartment and were subsequently captured and swept into the exhaust duct. Data collected from an array of differential pressure transducers and thermocouples in the exhaust duct were employed to compute the mass flow rate of the gases in the exhaust duct. A representative gas sample was continuously removed from the exhaust duct by a gas pump. The gaseous sample was pumped to the control room. In the control room, the gas sample was filtered to remove particulate and cooled in a dry ice trap to condense water from the gas. The resulting conditioned dry gas was analyzed using gas analyzers to quantify oxygen $\left(\mathrm{O}_{2}\right)$, carbon monoxide $(\mathrm{CO})$, and carbon dioxide $\left(\mathrm{CO}_{2}\right)$. A detailed description of the heat release rate measurement technique and the measurement results is given in Chapter 5. 


\subsubsection{Thermocouple Trees - Compartment Temperatures}

Thermocouple trees were constructcd by NIST personncl and located at four locations inside the compartment. See Table A-1 in the Appcndix for the exact locations. Thcrmocouples wcre placcd at four positions on the tree, namely, $2.5 \mathrm{~cm}, 91 \mathrm{~cm}, 83 \mathrm{~cm}$, and $274 \mathrm{~cm}$ below the cciling. During Tests 1 and 2, a pair of aspirated thcrmocouplcs were positioncd close to Tree 4 to assess the effect of radiative exchange on the temperature measuremcnts by the nearby bare bead thermocouples.

\subsubsection{Thermocouples - Desk Surface Temperatures}

Thermocouples were employed during the test scries to measurc the surfacc tempcraturcs of the desk surfaces to provide an indication of flame spread from workstation to workstation. During Test 1, each workstation was equipped with three desk surface thermocouples. In Tests 2, 3, 4, and 6, only two thermocouples per desk were used. In Test 5, no thermocouples were located in the workstations. Exact locations are listed in Appendix A. The temperature record was used to assist in the analysis of flame spread from workstation to workstation, which is discussed in Chapter 3.

\subsubsection{Video Recording Cameras}

Two video cameras recorded the events within the compartment during each test. On the east wall, a video camera imaged the eastern walls of Workstations 2 and 3. A portion of the carpet between Workstations 2 and 3 was also visible. A second camera on the western portion of the north wall was aimed to capture events at Workstations 1 and 3. Specifically, the northern partitions of Workstation 1, as well as some of the contents were observed. This camera also recorded the western wall of Workstation 3 and a small section of the northern wall of Workstation 2.

Two video cameras were positioned outside the compartment west wall. One camera recorded the inside of the compartment through the columns. The second camera recorded events at the test wall portion on the western wall. In combination with the thermocouple data, the video record was used to assist in the analysis of flame spread from workstation to workstation, which is discussed in Chapter 3.

\subsubsection{Gas Analyzers}

The $\mathrm{O}_{2}, \mathrm{CO}$, and $\mathrm{CO}_{2}$ were monitored continuously at one location during each test. The compartment hot layer was sampled to provide information on the tenability of the compartment. The sampling location was at $(\mathrm{x}, \mathrm{y}, \mathrm{z})=(970 \mathrm{~cm}, 351 \mathrm{~cm}, 270 \mathrm{~cm})$. The exhaust stack was also sampled to provide data for calorimctry computations. The specific analyzers employed during testing are listed in Appendix B.

In each case, gas was pulled from the sampling location using a pump. Oxygen was quantified using magneto-dynamic, paramagnetic oxygen balances. Carbon monoxide and carbon dioxide were quantified using gas analyzers employing non-dispersive infrared technology. In all cases, gas concentrations were reported on a dry basis. A detailed description of the gas analyzers and the measurement results is given in Chapter 7. 


\subsubsection{Data Acquisition}

The NIST Large Fire Laboratory data acquisition (DAQ) system is a modular system acquired from National Instrumcnts. DAQ boards installed in a standard desktop computer were interfaced with two DAQ chassis. Each chassis, in turn, was connected to multiple modules capable of digitally multiplexing input data signals and supplying the multiplexed signal to the DAQ boards. Terminal blocks capable of up to 32 data channels of input were connected to each module. Each terminal block contained a thermistor used to provide cold junction compensation to each thermocouple measurement.

The DAQ desktop computer runs National Instruments LabView software. The software was customized for calculation of real-time fire behavior parameters, graphical display of real-time data, and data storage. Data from each test was stored in its own data file. The first 2,000 s to 3,000 s contained data recorded during calibration of the calorimeter. Once the calorimeter was "on-line", all test equipment was readied, and test personnel were prepared. Background data was then recorded for use in the calorimetry computations. The background data was typically not recorded until all test preparations were complete. The test director determined termination of data collection. Table 2-7 lists the amount of time background was acquired, the time data acquisition was stopped, which happened when fire suppression occurred or when the calorimeter instrumentation was taken off-line. In some cases, raw data was recorded past the data acquisition stop time listed in the table below. Data was acquired with a sampling rate of $1 \mathrm{~Hz}$. The test duration was approximately 1 hour for each of the Tests, yielding on the order of one million discrete pieces of data.

Table 2-7. Duration of data acquisition files.

\begin{tabular}{|c|c|c|c|c|}
\hline & Background (s) & Test Start (s) & Data Acquisition Stopped (s) & Suppression (s) \\
\hline Test 1 & -150 & 0 & 4,867 & - \\
\hline Test 2 & -328 & 0 & 5,360 & $\sim 5,122$ \\
\hline Test 3 & -522 & 0 & 6,524 & $\sim 9,609$ \\
\hline Test 4 & -327 & 0 & 3,521 & - \\
\hline Test 5 & -686 & 0 & 5,755 & 4,656 \\
\hline Test 6 & -300 & 0 & 5,044 & - \\
\hline
\end{tabular}

\subsection{TEST PROCEDURE}

The procedure was similar to that followed in the experiments reported in NIST NCSTAR 1-5C, except that the ignition burner was turned off after approximately 2 min for Tests 3, 5, and 6 (when jet fuel was present) and after $10 \mathrm{~min}$ for Tests 1,2 , and 4 . The tests continued until the measured heat release rate fell below $0.5 \mathrm{MW}$, which was typically $65 \mathrm{~min}$ after ignition.

The following list describes the sequence of events in preparation for an experiment. The list includes the major steps associated with setup and running of the experiment. A detailed list of test procedures and safety checks was considered before each experiment including the following:

- Checked all connected instrumentation for proper functioning

- Checked load cell platforms for interference 
- Prepared enclosure flooring and installcd carpcting

- Assembled workstations

- Loaded workstations

- Installed thcrmocouples in workstations

- Covered workstations and corridor with drop ceiling tiles when dictated by test matrix

- Photographically documented experimental setup

- Installed column and kneewall

- Checked liquid spray burner fuel flow

- Conducted final check of compartment instrumentation

- Calibrated Heat Release Rate Oxygen Calorimeter and continuous sampling gaseous loop

- Conducted safety brief

- Collected background/baseline data

- Poured Jet A fuel when dictated by test matrix

- Evacuated enclosure

- Ignited spray burner

- Stopped fuel flow to spray burner

- Allowed compartment to cool to ambient

- Tested that compartment was empty of combustion products

- Removed column and kneewall

- Removed burned materials

- Refurbished enclosure as necessary

After each experiment, at least two days were required to remove the debris, inspect the compartment, patch cracks in the marinite, check instrumentation, and install the new workstations. 


\section{$2.8 \quad$ REFERENCES}

Galbraith Labs. 2003. Report of Test Resnlts. Knoxville, TN, March, p. 20.

Hamins, A., Maranghides, A., and Mulholland, G. 2003. The Global Combustion Behavior of 1 MW to 3 MW Hydrocarbon Spray Fires Burning in an Open Environment, NISTIR 7013, National Institute of Standards and Technology, Gaithersburg, MD, June.

Lyon, R. E. 2004. Report of Micro-Calorimeter Tests Resmlts, Federal Aviation Administration, William J. Hughes Technical Center, NJ.

Madryzkowski, D. 1996. "Office Work Station Heat Release Rate Study: Full Scale vs. Bench Scale," Proceedings of Interflam '96, Interscience Communications, Ltd., London, pp. 47-55.

Madryzkowski, D. 1998. "Office Building Fire Research Program: An Engineering Based Approach to Fire Safety Design," Proceedings of the 5th Fire and Materials Conference, San Antonio, Texas, Interscience Communications, Ltd., London, pp. 23-33.

Manzello, S. L., Gann, R. G., Kukuck, S. R., Prasad, K. R., and Jones, W. W., 2005. Fire Performance of a Non-Load Bearing Glass Wall Assembly, to be submitted to Fire and Materials.

McAllister, T., ed. 2002. World Trade Center Building Performance Stndy: Data Collection, Preliminary Observations, and Reconmendations. FEMA 403. Federal Emergency Management Agency. Washington, DC, May.

Walters, R. N., and R. E. Lyon. 1997. Proc. 42 ${ }^{\text {nd }}$ Int. SAMPE Symposimm and Exhibition, 42(2), 1335-1344. 


\section{Chapter 3 \\ FIRE BEHAVIOR AND FLAME SPREAD}

\subsection{GENERAL OBSERVATIONS}

Chapter 2 of this report describes the cxperimental configuration in detail, including the experimental conditions, the fuel flow, ventilation openings, and details of the test compartment. This chapter describes the behavior of the fire, including the flame spread observed during each of the tests. The general appearance of the fires was observed through video recordings from a perspective external to the compartment, as well as from two views within the compartment. Thermocouples were used in conjunction with the video recordings to evaluate the fire behavior, including the mechanisms of fire spread through the workstations and the time of ignition of each workstation.

There were many similarities in the general appearance of the fires as they evolved during the six tests. In the early stages of the fire, an upper layer formed at the ceiling and grcw in size, descending to below the openings. Ignition occurred most quickly in Tests 3, 5, and 6 because Jet A aviation fuel was poured onto the workstation surfaces and other materials, creating a quasi-simultaneous ignition and flaming burning everywhere. In the presence of the jet fuel, a thick black upper layer formed quickly, and copious amounts of smoke were emitted as seen in Fig. 3-1. Figure 3-2 shows the compartment several minutes into Test 5 , when much less black smoke was emitted.

Figures 3-3 and 3-4 show the west view of the compartment before and during Test 6 , respectively. The four windows on the left side of the compartment in Test 6 are seen in Fig. 3-3. During the rapid burning phase of the tests, copious amounts of black smoke were emitted from the compartment. Figure $3-4$ is a view of the fire compartment $2 \mathrm{~min}$ after the start of Test 6 . The windows broke after approximately $3 \mathrm{~min}$ in this test. At the end of the tests, little smoke was emitted from the compartment as the charred remains of the workstation contents continued to slowly burn and release heat.

Examination of the video record of the six experiments demonstrated a number of general noteworthy findings regarding the burning behavior of the fires:

- The burner in the back of the enclosure seemed to accelerate the rate of flame spread (times to ignition and full involvement). It was not clear from the video record that the presence of the ceiling tiles had any significant effect on the burning behavior of the workstations. Any impact by the ceiling tiles may have been overridden by the effects associated with the burner location.

- The presence of Jet A resulted in the enclosure being fully involved in fire in a little over one min. In these tests, rapid full involvement was followed by the formation of a large cloud of black smoke that billowed from the compartment for a few minutes. The smoke layer then dissipated, and the burning continued with less smoke emission. 


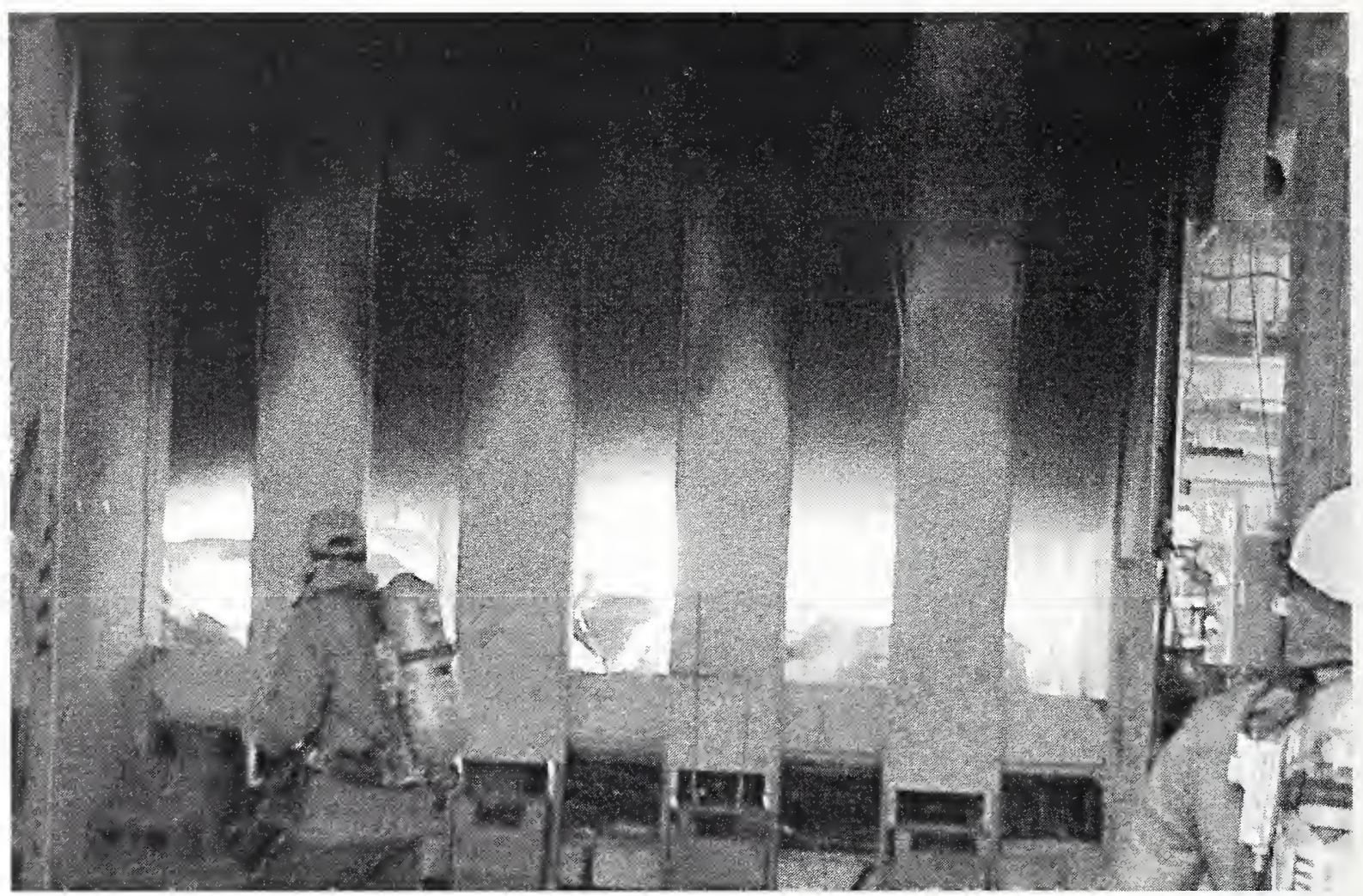

Source: NIST.

Figure 3-1. View of the fire compartment $1 / 2$ min after the start of Test 5.

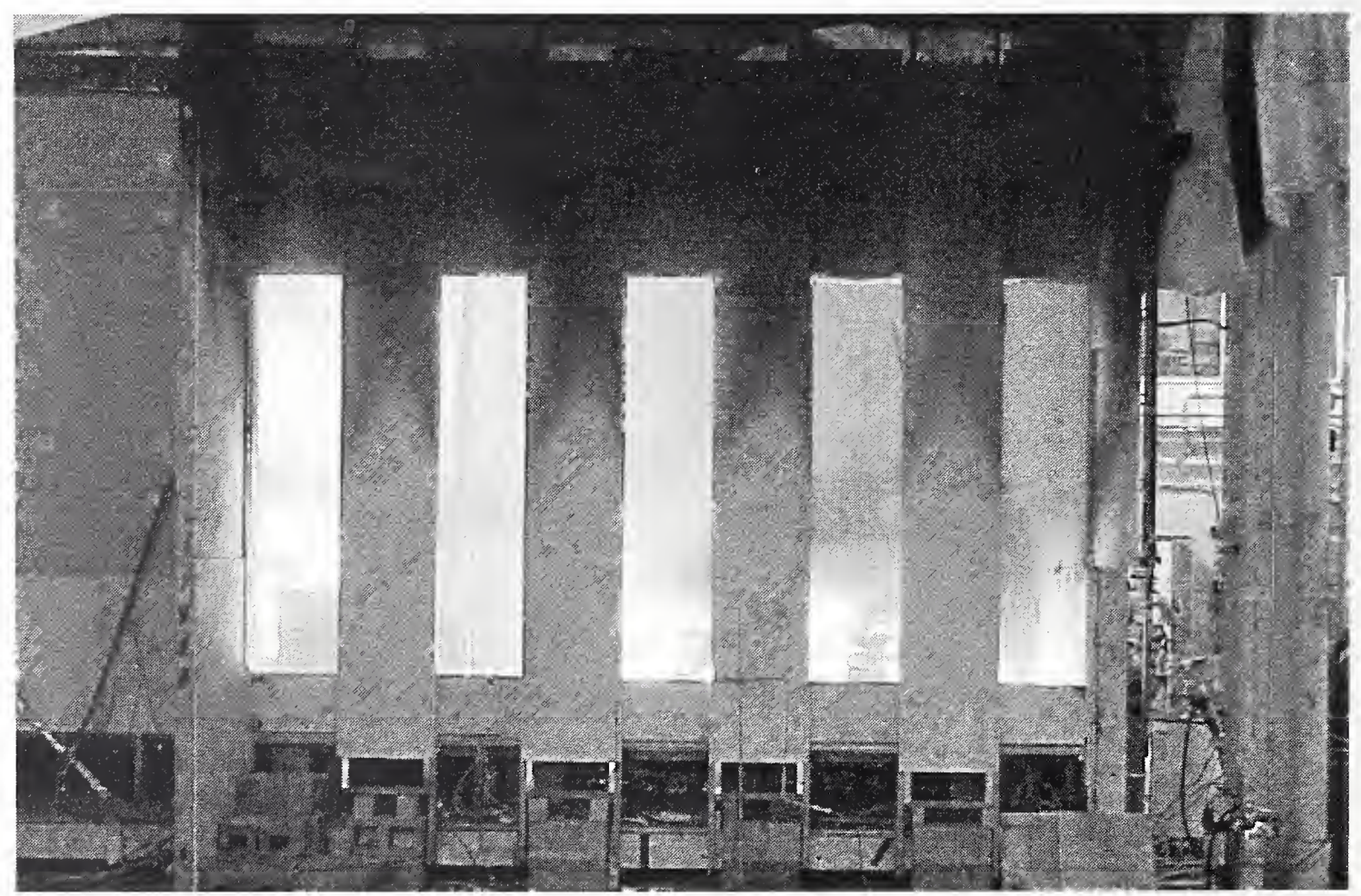

Source: NIST.

Figure 3-2. View of the fire compartment several minutes after the start of Test 5. 


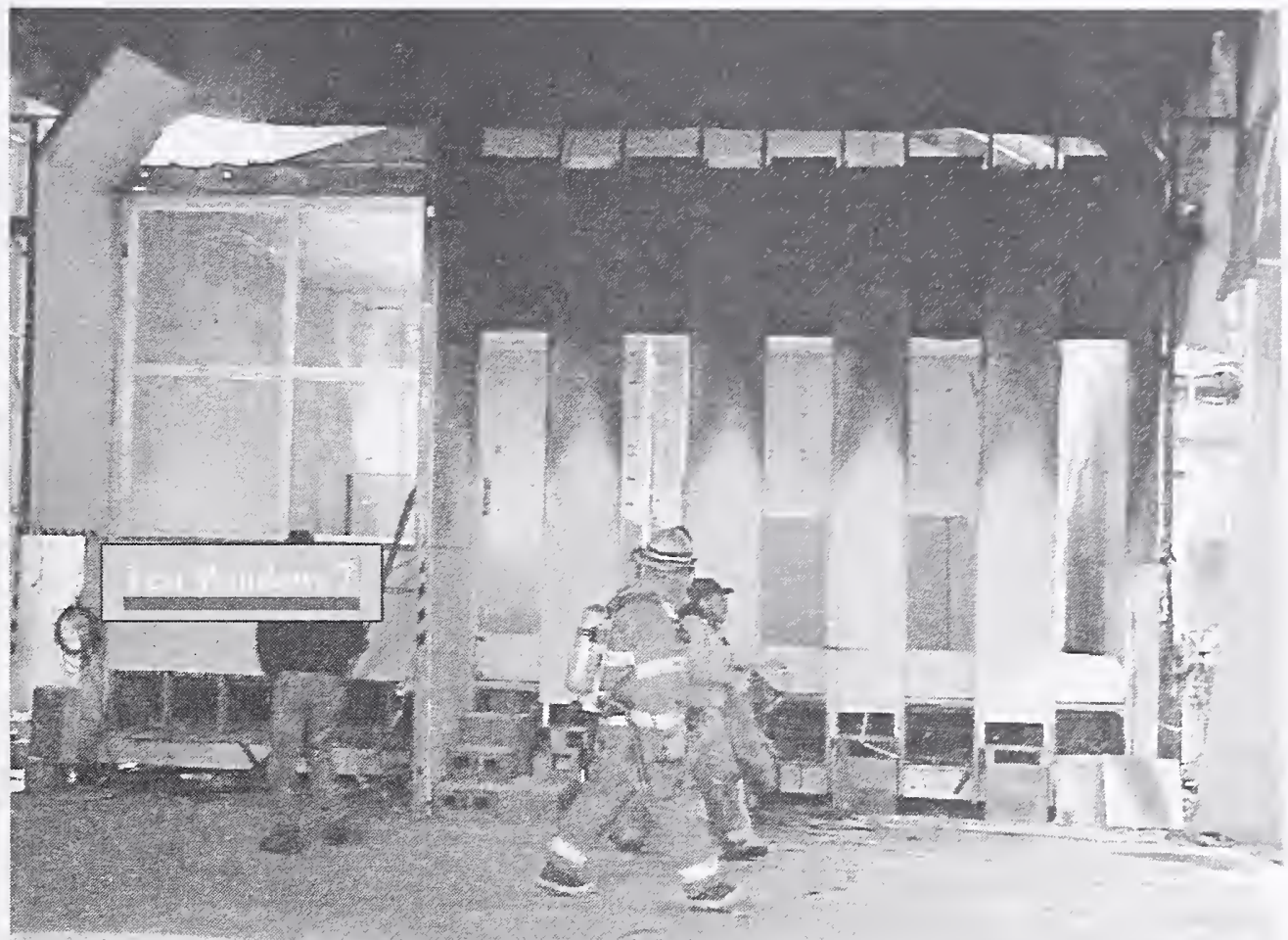

Source: NIST.

Figure 3-3. View of the fire compartment with test windows before the start of Test 6.

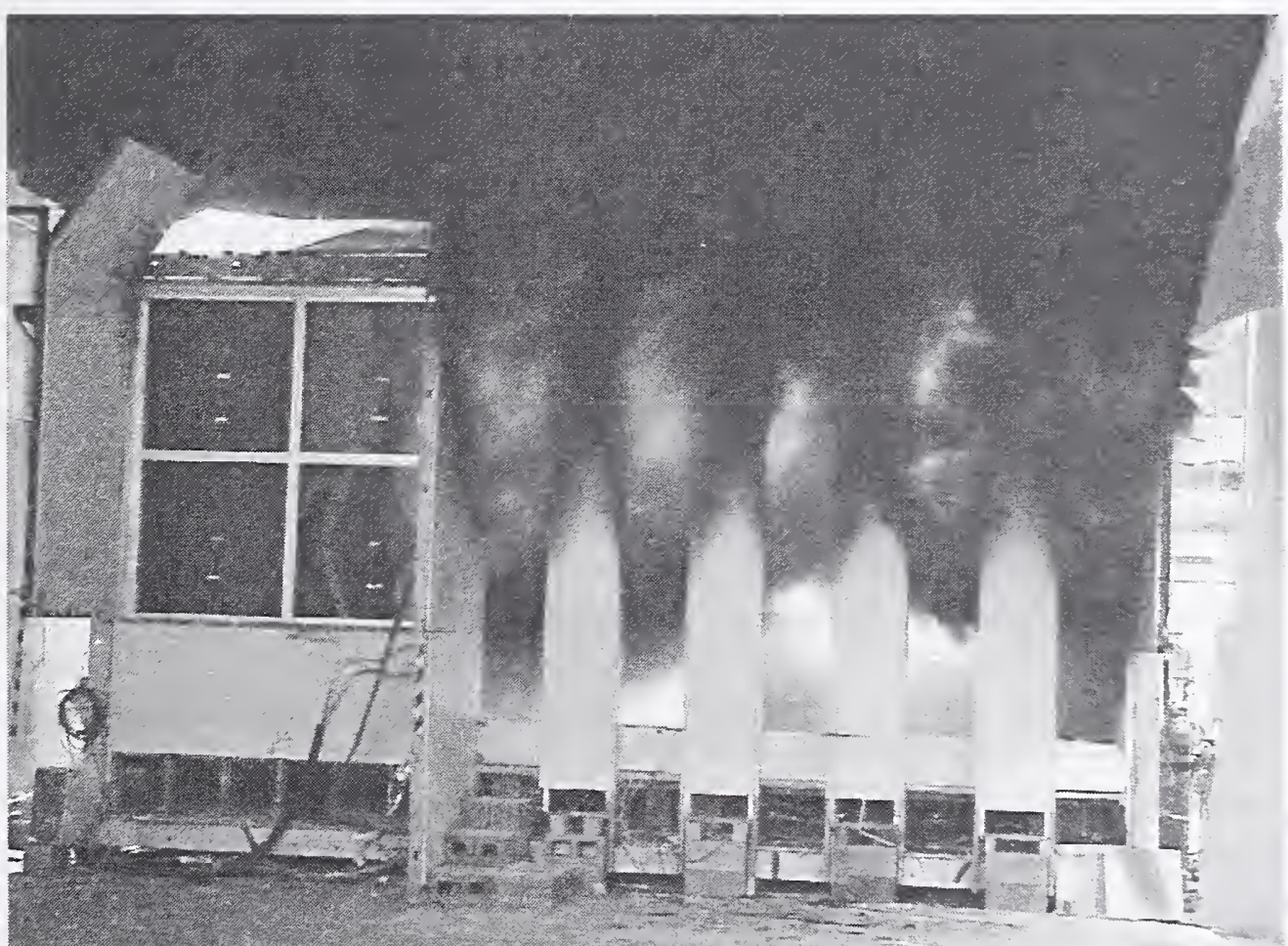

Source: NIST.

Figure 3-4. View of fire compartment 2 min after the start of Test 6. 
- The video record was helpful in documenting the sequence of events that led to flame spread from one workstation to the next and from one side of the compartment to the other.

- The video record suggests that radiation from the hot upper layer of the compartment, rather than flame spread from a contiguous burning item, led to ignition of Workstation 3 in Test 4. This mode of ignition could not be verified for the workstations in the other tests, due to smoke obscuration of the video record, and camera views that limited observation.

- Flame spread can proceed through several means. A common mechanism involves burning brands that are lofted by the convective forces associated with the fire and fall onto combustible materials. Such a mechanism has been observed in warehouse fires and wildland fires, for example, both of which involve cellulosic materials. There is no evidence from the video record that flying brands played a role in flame spread.

- The passageway separating Workstations 1 and 2 from Workstation 3 was carpeted. Burning carpet spread the fire from Workstation 1 to Workstation 3 for both Tests 1 and 2. Of course, the hot upper layer undoubtedly played a role in the rate at which this occurred, as the workstation contents were preheated by radiative heat transfer.

\subsection{WORKSTATION IGNITION AND FULL FIRE INVOLVEMENT}

Thermocouples were used in conjunction with video recordings to evaluate the time of ignition and full fire involvement during Tests 1, 2, and 4. Such data were not reviewed for Tests 3, 5, and 6, because Jet A aviation fuel was poured on the workstation surfaces and other materials prior to ignition, creating a quasi-simultaneous ignition scenario. Table 3-1 lists the estimated times to full involvement for each workstation, determined by desk surface temperature measurements and video review in which time zero was taken as the time the spray burner fire was initiated. Table 3-1 also lists the time to ignition based upon video review. Estimating the ignition time and time to full involvement from the thermocouple and video records is subjective. The values in the table should be thought of as estimates that are intended to provide qualitative information only.

During Tests 1, 2, 3, 4, and 6, two thermocouples were used to measure desk surface temperatures, one thermocouple on the top desk surface and one thermocouple attached to the bottom desk surface. Test 5 did not employ thermocouples mounted to the desk surfaces because the workstations and desks were not assembled in the standard configuration. Examination of the thermocouple temperatures versus time typically shows a period of rapid temperature increase to a value above $400{ }^{\circ} \mathrm{C}$. A tangent line was extrapolated through this temperature ramp and the slope of the temperature-timecurve prior to the ramp. The intersection of the lines was taken as the ignition time. The full involvement time estimate is reported in Table 3-1 for each desk thermocouple. The thermocouple with the later response is indicative of full fire involvement of the workstation. Figure 3-5 shows an example of the estimation approach used to determine ignition and full fire involvement from the desk thermocouple measurements. The uncertainty in the ignition time was estimated as $10 \mathrm{~s}$. 
Table 3-1. Ignition and full involvement times.

\begin{tabular}{|c|c|c|c|c|}
\hline \multirow{7}{*}{ 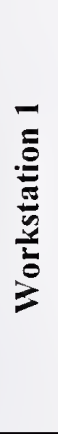 } & Test & $\begin{array}{l}\text { Ignition/Full Involvement } \\
\text { (Thermocouples) (s) }^{\mathrm{a}}\end{array}$ & $\begin{array}{l}\text { Ignition (Camera) } \\
\text { Video (s) }\end{array}$ & $\begin{array}{c}\text { Full Involvement (Camera) } \\
\text { Video }(\mathrm{s})^{\mathrm{a}}\end{array}$ \\
\hline & Test 1 & $405 / 460$ & 18 (north) & 416 (north) \\
\hline & Test 2 & $390 / 420$ & 14 (north) & 434 (north) \\
\hline & Test 3 & $31 / 38$ & (b) & 32 (north) $^{\mathrm{c}}$ \\
\hline & Test 4 & $420 / 470$ & 381 (north) & 420 (north) \\
\hline & Test 5 & (d) & (b) & 73 (north) \\
\hline & Test 6 & $70 / 77$ & (b) & 55 (north) \\
\hline \multirow{6}{*}{ 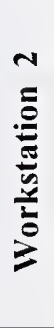 } & Test 1 & $725 / 750$ & 539 (north) & $727(\text { north) })^{\mathrm{e}}$ \\
\hline & Test 2 & $730 / 758$ & 500 (north) & 738 (north) \\
\hline & Test 3 & $24 / 36$ & (b) & 25 (north) \\
\hline & Test 4 & $265 / 370$ & 13 (north) & 270 (north) $^{\mathrm{e}}$ \\
\hline & Test 5 & (d) & (b) & 64 (easi) \\
\hline & Test 6 & $47 / 47$ & (b) & 22 (north) \\
\hline \multirow{6}{*}{ 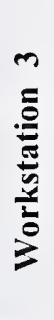 } & Test I & $730 / 802$ & 555 (north) $^{\mathrm{f}}$ & 809 (north) $^{\mathrm{g}}$ \\
\hline & Test 2 & $810 / 810$ & 534 (north) $^{f}$ & 768 (north) $^{\mathrm{g}}$ \\
\hline & Test 3 & $110 / 150$ & (b) & 75 (north) $^{\mathrm{c}}$ \\
\hline & Test 4 & $455 / 465$ & 273 (east) & 410 (east) \\
\hline & Test 5 & (d) & (b) & 57 (east) \\
\hline & Test 6 & $56 / 60$ & (b) & 69 (east) \\
\hline
\end{tabular}

a. $\mathrm{t}=0$ at spray burner ignition.

b. Electric match ignited prior to spray burner ignition.

c. Video image obscured by smoke.

d. Workstations and desks broken up. No thermocouples used.

e. Extensive visible burning inside workstation used as full involvement criteria.

f. Workstation partition ignited from burning carpet.

g. Burning all around west partition was used as full involvement criteria.

During replicate Tests 1 and 2, the full involvement times of Workstations 2 and 3 estimated from the thermocouples were within $10 \mathrm{~s}$ of each other. The largest difference in the time to full involvement for Workstation 1, based upon data from the desk thermocouples, was approximately $40 \mathrm{~s}$. Examination of Workstation 1 thermocouple data from Tests 1 and 2 demonstrates that the response of the desk surface thermocouples during Tests 1 and 2 were very similar. The $40 \mathrm{~s}$ difference is the sole result of the thermocouples attached to the bottom desk surface. Figure 3-6 shows the temperatures of the desk mounted thermocouples on Workstation 1 as a function of time during Tests 1 and 2. Full fire involvement occurred at $460 \mathrm{~s}$ and $420 \mathrm{~s}$ in Tests 1 and 2, respectively.

Ignition of parts of Workstation 1 was rapid in Tests 1 and 2 as seen in the video record and noted in Table 3-1. The rapid ignition of Workstation 1 in these tests was due to the proximity of the spray burner to the workstation. The thermocouple data indicated ignition on the desktops at a later time (see Table 3-1) as the fire spread from the partition. The analogous situation occurred in Test 4 for Workstation 2. 


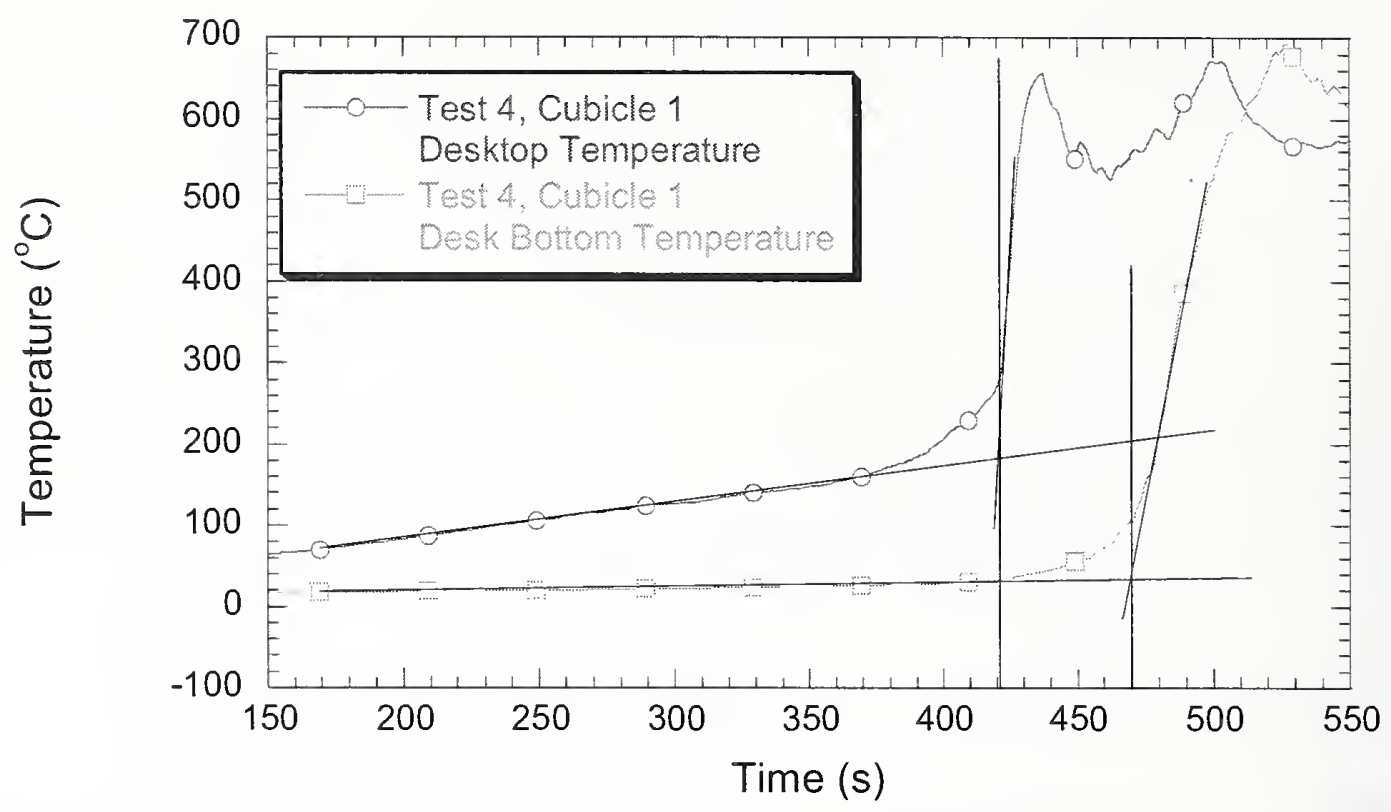

Figure 3-5. Determining ignition and full-involvement times from thermocouple data.

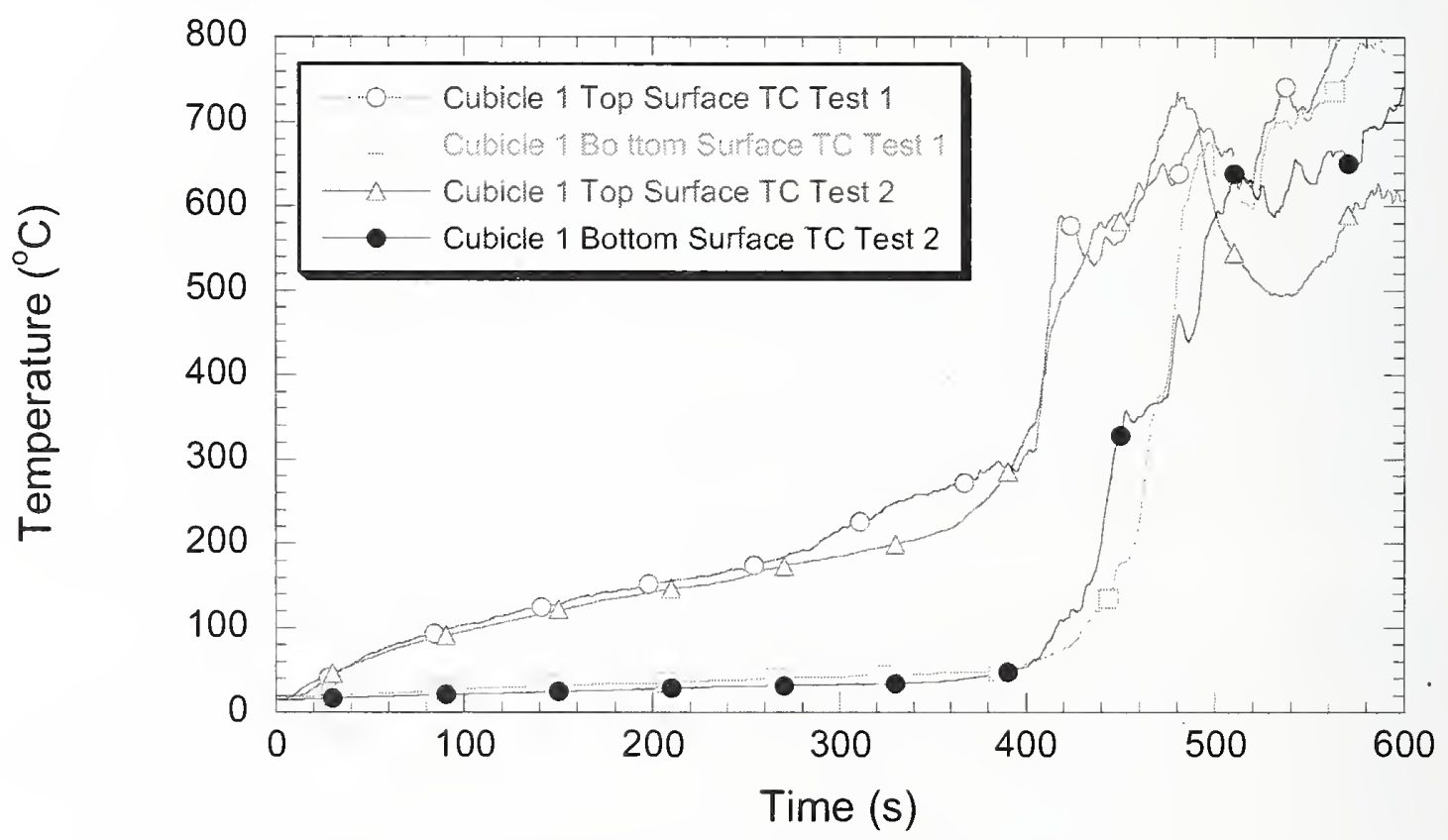

Figure 3-6. Temperature measurements as a function of time for thermocouples on the desks of Workstation 1 during Tests 1 and 2. 


\subsection{FLAME SPREAD OBSERVATIONS DURING TESTS 1, 2, AND 4}

The video record was examined to evaluate the mechanisms of flame spread within the workstations and from workstation to workstation during Tests 1, 2, and 4. During Tests 1 and 2, the heptane spray burner was located adjacent to Workstation 1. During Test 4, the spray burner was located east of Workstation 2 , immediately adjacent to the workstation wall.

\subsubsection{Test 1}

\section{Workstation 1}

The north camera recorded the fabric on the outer portion of the west wall burning and melting in roughly $18 \mathrm{~s}$. Flames were not definitively located within the workstation walls until $120 \mathrm{~s}$ after spray burner ignition. After $259 \mathrm{~s}$, flames began to spread across the desk surface in the southern portion of Workstation 1. From $365 \mathrm{~s}$ to $375 \mathrm{~s}$, the flames spread to the chair arm and quickly involved the entire chair and all visible desk surfaces. Analysis of the north camera video indicate that full involvement occurred at approximately $386 \mathrm{~s}$ following spray burner ignition.

\section{Workstation 2}

The top of Workstation 2 was obscured after approximately $450 \mathrm{~s}$. During Test 1 , the north video camera showed flames beginning to spread along the bottom of the western partition on the north wall of Workstation 2 at $539 \mathrm{~s}$ after ignition. It is uncertain if the burning material was carpet, the melted baseboard from the partition, or both. By $572 \mathrm{~s}$, flames had spread and clearly reached the entrance to Workstation 2. Due to visible obscuration, however, it is not clear if the flame spread to the interior of Workstation 2 was the result of flame spread along the hallway carpet or by another pathway. The video record of the camera in the east wall of the compartment was obscured during the ignition of Workstation 2.

\section{Workstation 3}

The video record of the north camera showed flame spread along the carpet, igniting the southwest corner of Workstation 3 at $555 \mathrm{~s}$. The resulting flames were small. At $599 \mathrm{~s}$, the small flames crept up the southwest corner between the workstation wall and a piece of thermoplastic trim. By $715 \mathrm{~s}$, flames had spread along the bottom of the west wall of Workstation 3, although no determination can be made if the spread came from within the workstation or from along the outer wall. Based upon the north camera video, full involvement of Workstation 3 occurred at $809 \mathrm{~s}$.

During Test 1, the video record of the east camera looking at Workstation 3 became obscured by $544 \mathrm{~s}$. At $717 \mathrm{~s}$, flame activity was seen on the wall segment west of the entrance to Workstation 3 although it is not clear if the fuel was carpeting or a wall segment. By $738 \mathrm{~s}$, the wall segment east of the entrance of Workstation 3 was ignited. Within $15 \mathrm{~s}$, flame activity either ceased or was obscured by compartment smoke. Due to visible obscuration, no further activity was observed by the east camera video until $886 \mathrm{~s}$ at which point a vortex of flames and smoke was observed to occupy the eastern portion of the test compartment. 


\subsubsection{Test 2}

\section{Workstation 1}

The north camera recorded the fabric on the outer portion of west wall burning and melting in roughly $14 \mathrm{~s}$. Flames were not definitively located within the workstation walls until $146 \mathrm{~s}$ after spray burner ignition. After $263 \mathrm{~s}$, flames began to spread across the desk surface in the southern portion of Workstation 1. At $644 \mathrm{~s}$, the chair ignited followed by the remainder of the visible desk surface igniting within $5 \mathrm{~s}$. Analysis of the north camera video indicates that full involvement occurred at approximately $434 \mathrm{~s}$ after spray burner ignition.

\section{Workstation 2}

Video recorded by the north camera shows ignition of the northwest comer of Workstation 2 at $500 \mathrm{~s}$. Flame spread along the bottom of the west partition of Workstation 2 entrance. It is not clear if the burning material is carpet or melted baseboard. Flame spread along this partition reached the workstation entrance within approximately $18 \mathrm{~s}$. However, the top of Workstation 2 became obscured after $420 \mathrm{~s}$. The origin of the flame spread along the partition was not clear. The east camera image was obscured during the Workstation 2 ignition event. Full involvement of Workstation 2 at $738 \mathrm{~s}$ was observed on the north camera video.

\section{Workstation 3}

Video from the north camera clearly shows the ignition of the west wall of Workstation 3 at $534 \mathrm{~s}$. Within $15 \mathrm{~s}$, the melted baseboard of the partitions was burning. The image from the east camera location was obscured.

\subsubsection{Test 4}

\section{Workstation 1}

The desk surface of Workstation 1 ignited at $381 \mathrm{~s}$. By $420 \mathrm{~s}$, the entire desk surface and chair were fully involved, and flaming material dripped to the floor igniting the carpeting.

\section{Workstation 2}

Ignition of Workstation 2 was somewhat obscured by the glare from the spray burner, but appeared to occur at roughly $13 \mathrm{~s}$ on the video from the north camera. Though partially obscured by Workstation 3 and the glare from the spray burner, the north camera video showed complete involvement of Workstation 2 by approximately $270 \mathrm{~s}$.

\section{Workstation 3}

The video recorded by the east camera suggests that Workstation 3 ignited at $273 \mathrm{~s}$ as the result of radiant impingement, not direct flame spread. At 362 and $371 \mathrm{~s}$, flames burst through the partition wall seams, first on the east wall and then the southeast corner. By the time flames began to propagate across the carpet from Workstation 2 to 3 at $386 \mathrm{~s}$, the partition walls of Workstation 3 were fully involved. The 
north camera captured the ignition of the exterior wcst partition from firc activity within the workstation at $418 \mathrm{~s}$.

\subsubsection{Tests 3,5 , and 6}

Jet fuel was distributed about the thrce workstations and the carpctcd passagcway in Tests 3, 5, and 6 . Fire involvement occurred almost simultaneously throughout the furnishings, typically in less than $1 \mathrm{~min}$.

\subsubsection{Burner Location Effect on Ignition and Flame Spread}

The data in Table 3-1 indicate that burner location had little impact on the ignition times of the workstation adjacent to the burner. In Tests 1, 2, and 4, the partition nearest the spray burner ignited within $13 \mathrm{~s}$ to $18 \mathrm{~s}$. The data suggest that the burner location had a significant impact upon the time to full involvement of the adjacent workstation. The discussion below addresses this issue for each workstation.

The data in Table 3-1 demonstrate the significance of burner location with respect to flame spread. During Tests 1 and 2, flames spread from Workstation 1 to Workstation 2 first. Workstation 3 was the last workstation to ignite. Recall that Test 4 differed from Tests 1 and 2 in that the burner was positioned in the east portion of the room, immediately adjacent to Workstation 2. During Test 4, Workstation 2 was the first to ignite with subsequent ignition of Workstation 3 followed by Workstation 1.

\section{Effect of Burner Location on Workstation 1}

The spray burner position had a large effect on the ignition of Workstation 1, but a minor effect only on full involvement. The video record indicates that Workstation 1 required roughly 6 more minutes to ignite during Test 4 than during Tests 1 and 2. Full involvement in all three tests occurred at $7 \mathrm{~min} \pm$ $1 \mathrm{~min}$, according to both thermocouple data and the video record.

\section{Effect of Burner Location on Workstation 2}

The proximity of the spray burner to Workstation 2 in Test 4 resulted in both rapid ignition and rapid full fire involvement. Ignition required only $13 \mathrm{~s}$ as recorded by the north video camera. The data in Table 3-1 indicate that Workstation 2 was fully involved either $6 \mathrm{~min}$ (thermocouple data) or $4.5 \mathrm{~min}$ (video record) after the spray burner was ignited. During Tests 1 and 2, the average value for time to full involvement of Workstation 2 from both the thermocouple data and video record was over $12 \mathrm{~min}$.

\section{Effect of Burner Location on Workstation 3}

The position of the spray burner in Test 4 caused rapid ignition and full involvement of Workstation 3 . Ignition of Workstation 3 during Test 4 occurred after approximately $4.5 \mathrm{~min}$, while the same event took an average of $9 \mathrm{~min}$ during Tests 1 and 2. Averaging data from both the video record and thermocouples, Test 4 full involvement of Workstation 3 occurred at approximately 7.3 min compared to an average of over 13 min during Tests 1 and 2. 


\subsection{FLAME SPREAD VIDEO AND THERMOMETRY COMPARISON}

Table 3-1 lists the estimated workstation ignition and full involvement time based upon thermocouple measurements and the video record. Both desk surface thermocouples and video review were employed to estimate the time to full involvement, except during Test 5 in which thermocouples were not used.

The two techniques were in good agreement. The average difference of the results for the two techniques was less than $30 \mathrm{~s}$. Of the 15 comparable data pairs, 5 of the differences were greater than $30 \mathrm{~s}$, and 3 of these 5 "outliers" were associated with Workstation 3. This is not unexpected given the room setup and difficulty associated with obtaining clear video images during the test series. The north video camera only imaged the outer section of the west wall of Workstation 3. The east camera view of Workstation 3 was obscured by Workstation 2 and also frequently by smoke within the compartment.

In 12 of the 15 data pairs, the estimated time to full involvement from the video was less than that estimated from the thermocouple data. This could again be due to the difficulty associated with trying to image all fire activity occurring within a workstation. For example, review of the Test 1 video record indicates that Workstation 1 becomes fully involved at $416 \mathrm{~s}$, while review of the thermocouple data suggests $460 \mathrm{~s}$ as the appropriate measure. At $416 \mathrm{~s}$, the video clearly shows most of the top desk surface involved with fire activity on both the chair and the carpeting near the workstation entrance. The carpet fire near the entrance does obscure the rest of the workstation floor. At $460 \mathrm{~s}$, the intensity of the fire within Workstation 1 does increase markedly as observed on the video.

\subsection{KEY EVENTS IN THE EVOLUTION OF THE COMPARTMENT FIRES}

The development of the fires in the tests without jet fuel present (Tests 1,2, and 4) was much slower than when jet fuel was present (Tests 3,5, and 6). Key events in the appearance of the fires are summarized in Table 3-2, as observed from a perspective external to the compartment. Table 3-2 compares the timelines in Tests 4 and 6, which highlights the differences in the fire timeline when jet fuel was present as compared to when it was not. The table highlights the ignition, development of a smoke layer and its transport from the compartment, the transition from emission of smoke to the emission of flames through the ventilation openings, and progression to a time when no flames exited the compartment.

Table 3-2. Description of key events in evolution of the compartment fires.

\begin{tabular}{|l|c|c|}
\hline \multicolumn{1}{|c|}{ Event $^{\mathbf{a}}$} & $\begin{array}{c}\text { Test } \mathbf{4} \\
\text { (min:sec) }\end{array}$ & $\begin{array}{c}\text { Test 6 } \\
\text { (min:sec) }\end{array}$ \\
\hline Jet A ignition & NA & $-0: 30^{\text {b }}$ \\
\hline Smoke starts exiting compartment & $0: 10$ & $-0: 05$ \\
\hline Heavy black smoke starts exiting compartment & $3: 30$ & $0: 05$ \\
\hline Start of transition to flaming (very small flames) & $7: 00$ & $0: 30$ \\
\hline Start of flaming only (very little smoke) & $10: 30$ & $4: 30$ \\
\hline Glowing within, but no flames exiting the compartment & $19: 45$ & $9: 30$ \\
\hline Distributed limited burning & $21: 00$ & $17: 00$ \\
\hline
\end{tabular}

a. Time zero (0:00) was defined as the moment when the spray burner was ignited.

b. A negative number implies that the event occurred before ignition of the spray burner.

Key: NA, not applicable, jet fuel was not used in Test 4 . 
The difference in time to particular events betwcen Tcsts 4 and 6 was large. There was a $3 \frac{1}{2} \mathrm{~min}$ difference in Tests 4 and 6 , for example, to the time when heavy black smoke started to exit thc compartment. In the tests with jet fuel present, a smoky upper layer rapidly developed. This is documented in Figs. 3-7 through 3-13 for Test 6, which show the evolution of the fire corresponding to the events listed in Table 3-2 from a camera perspective cxternal to the compartment and facing the compartment openings. A smoke laden upper layer began to fill the compartment within seconds after ignition of the jet fuel (see Fig. 3-7), and smoke began to exit the compartment as seen in Fig. 3-8.

Figure 3-9 shows that the upper layer continued to drop and smoke rapidly flowed through the openings. Figure 3-10 shows that, soon thereafter, flames were observed to exit the compartment. Within a short period of time, flames filled the ventilation openings as shown in Fig. 3-11. The bottom and top single pane windows on the left edge of the window assembly (as seen from outside of the compartment) cracked and fell out approximately $185 \mathrm{~s}$ and $212 \mathrm{~s}$, respectively, after ignition of the spray burner. Figure 3-11 shows flames exiting the area where the top single-pane window had been located. The video record shows that the lower left window was also broken at this time. The double-pane windows on the right in Fig. 3-11 survived over the entire test duration. Manzello et al. (2005) provides a detailed description of the timeline associated with window breakage during this test. As the test proceedcd, the smoke cleared, and only flames could be seen exiting the openings as documented in Fig. 3-12. Finally, limited burning and charring took place at distributed locations about the compartment, and little smoke or flames exited the openings as seen in Fig. 3-13.

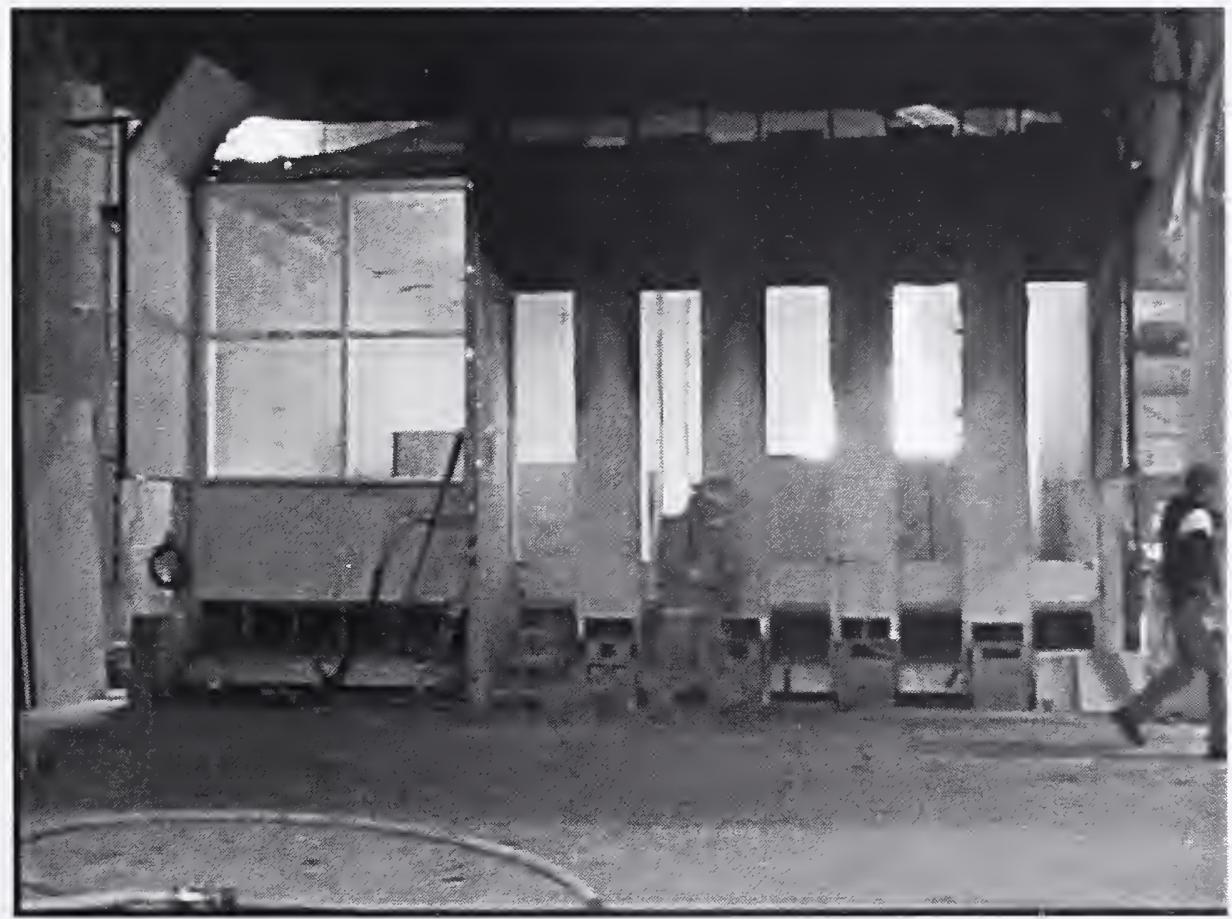

Source: NIST.

Figure 3-7. View external to the compartment $30 \mathrm{~s}$ before ignition of the spray burner in Test 6. 


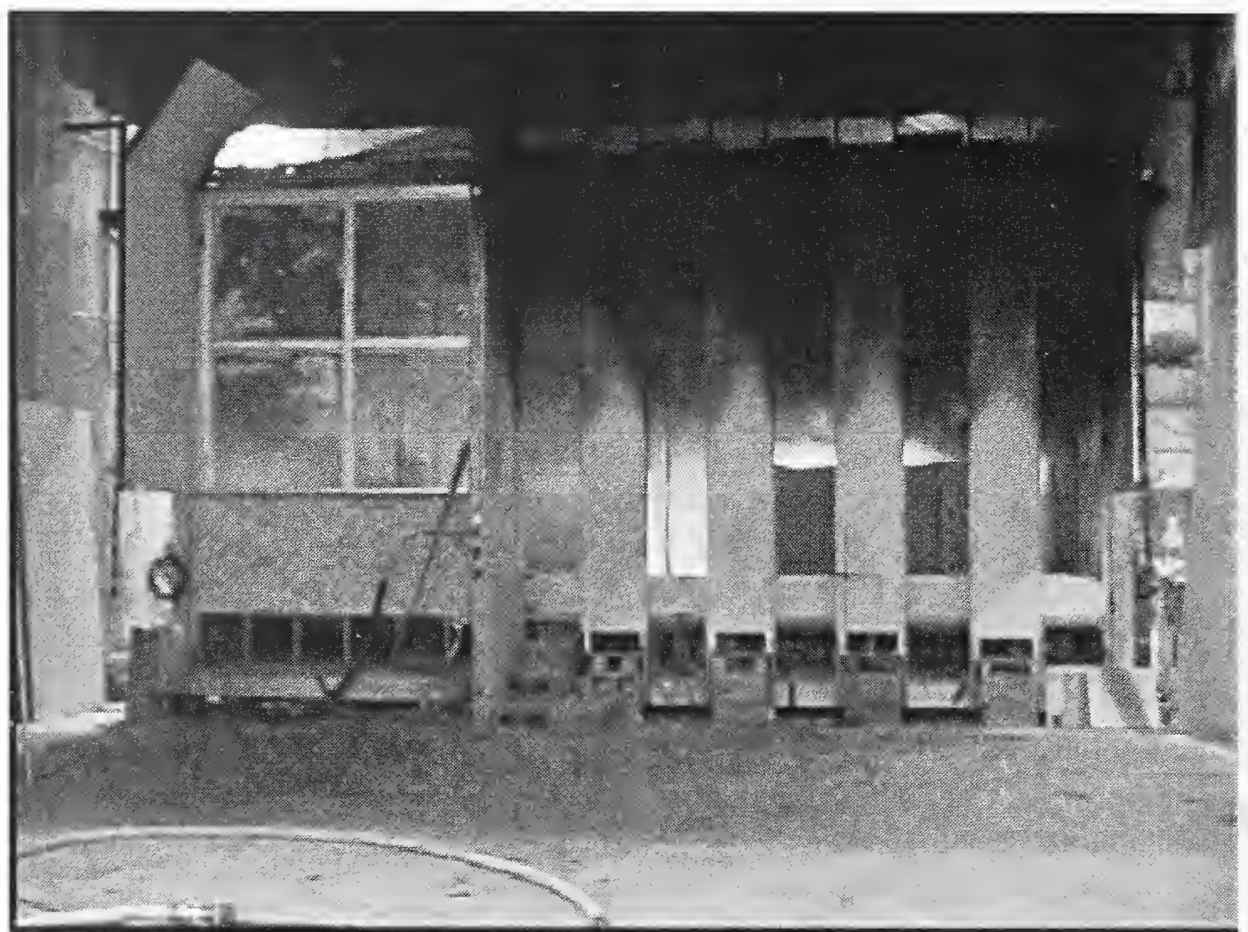

\section{Source: NIST}

Figure 3-8. View external to the compartment $5 \mathrm{~s}$ before ignition of the spray burner in Test 6.

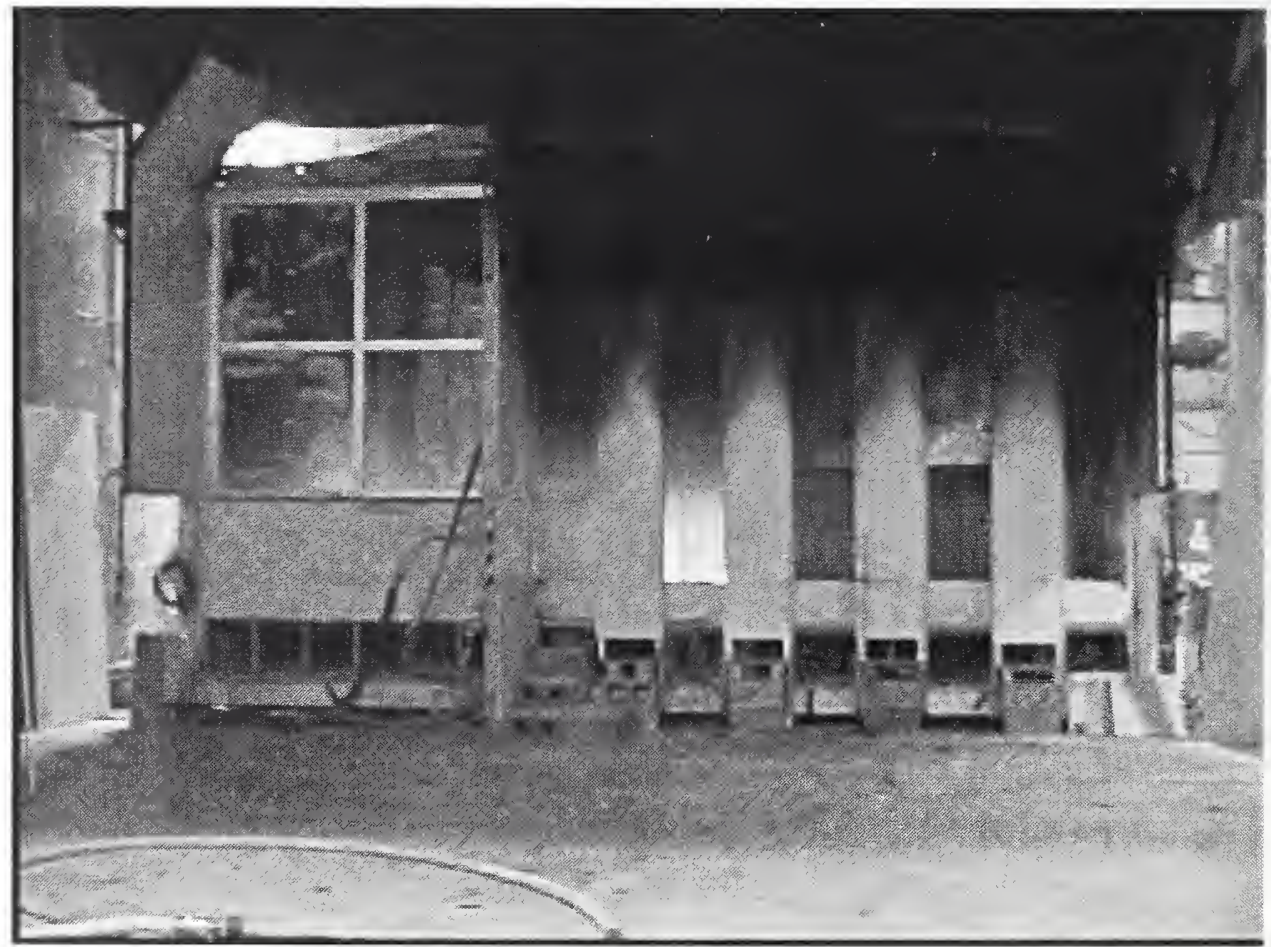

Source: NIST.

Figure 3-9. View external to the compartment $5 \mathrm{~s}$ after ignition of the spray burner in Test 6 . 


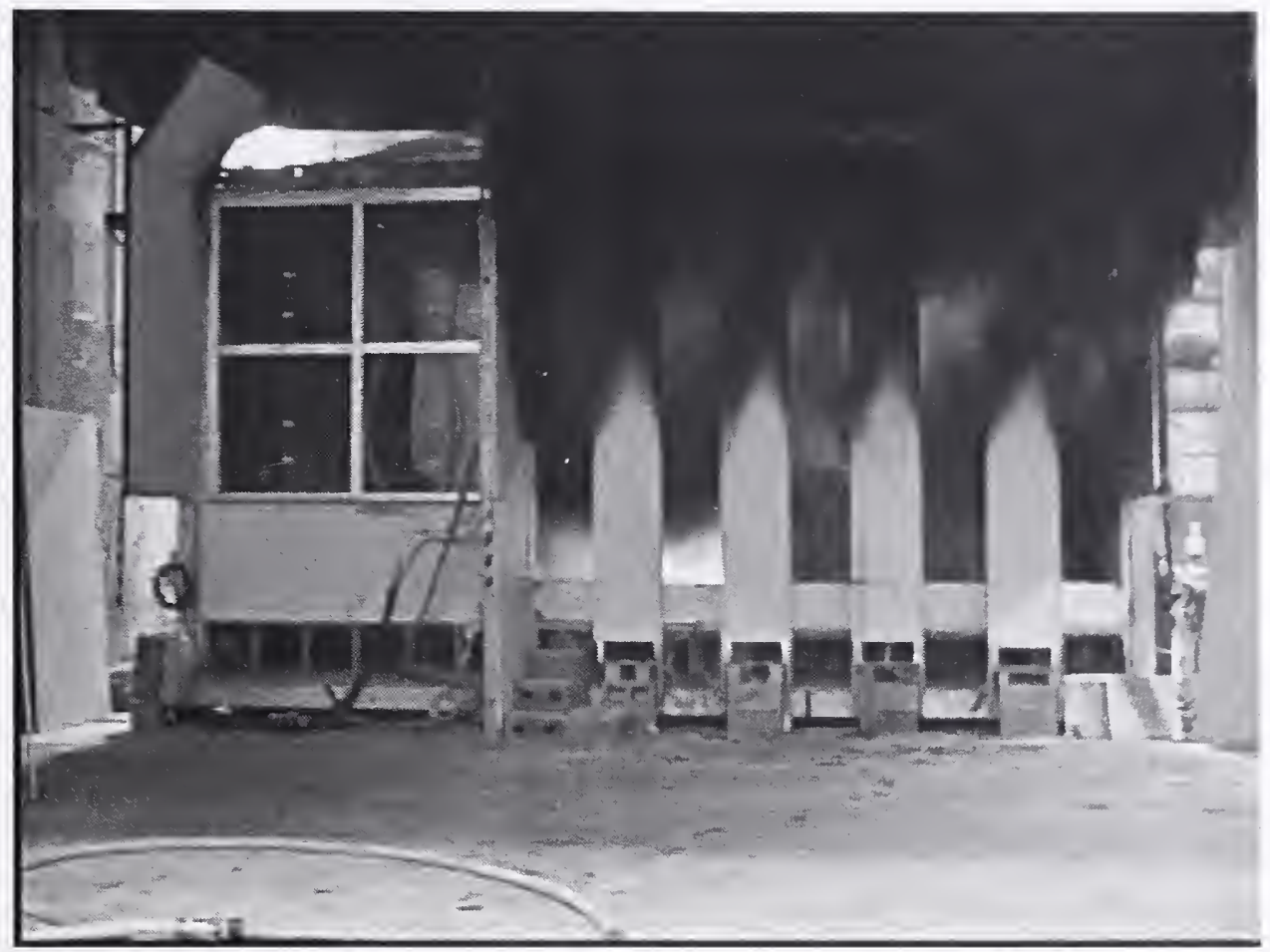

Source: NIST.

Figure 3-10. View external to the compartment $30 \mathrm{~s}$ after ignition of the spray burner in Test 6.

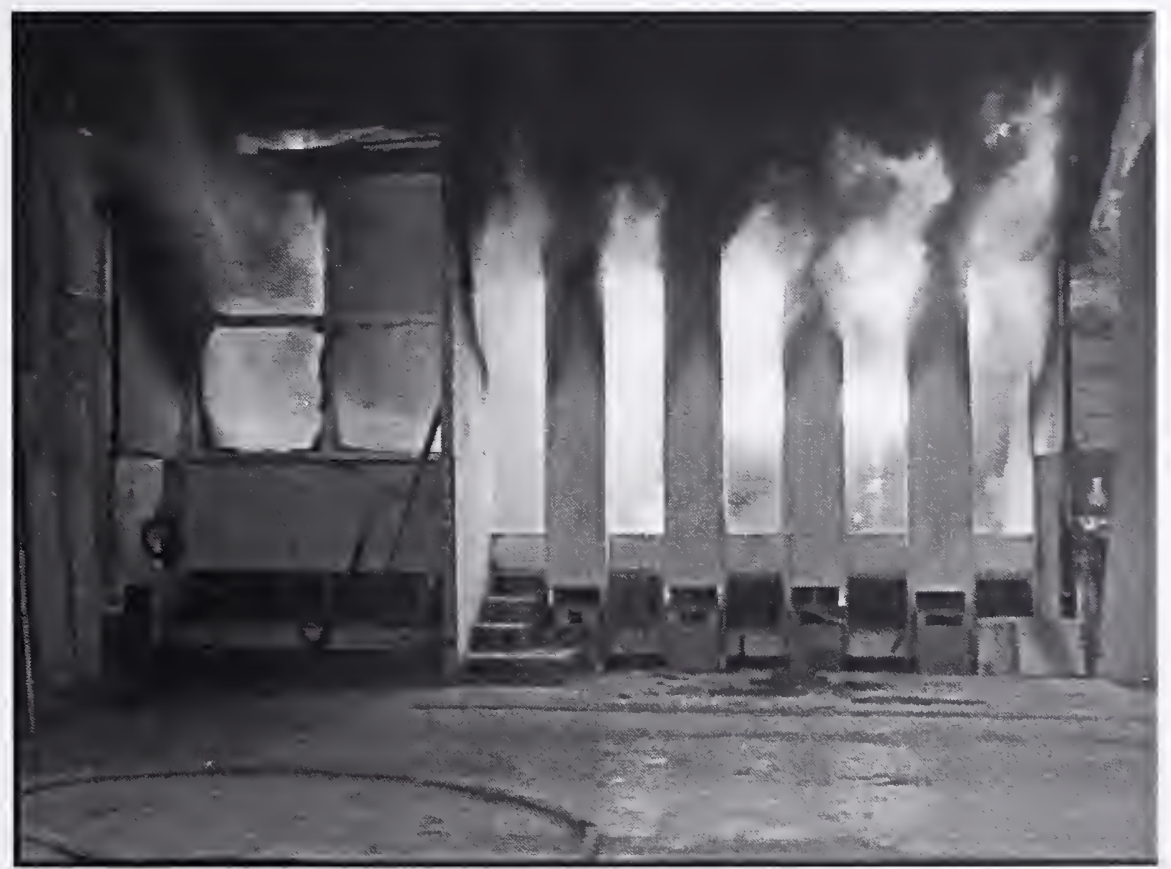

Source: NIST.

Figure 3-11. View external to the compartment $4 \mathrm{~min} 30 \mathrm{~s}$ after ignition of the spray burner in Test 6. 


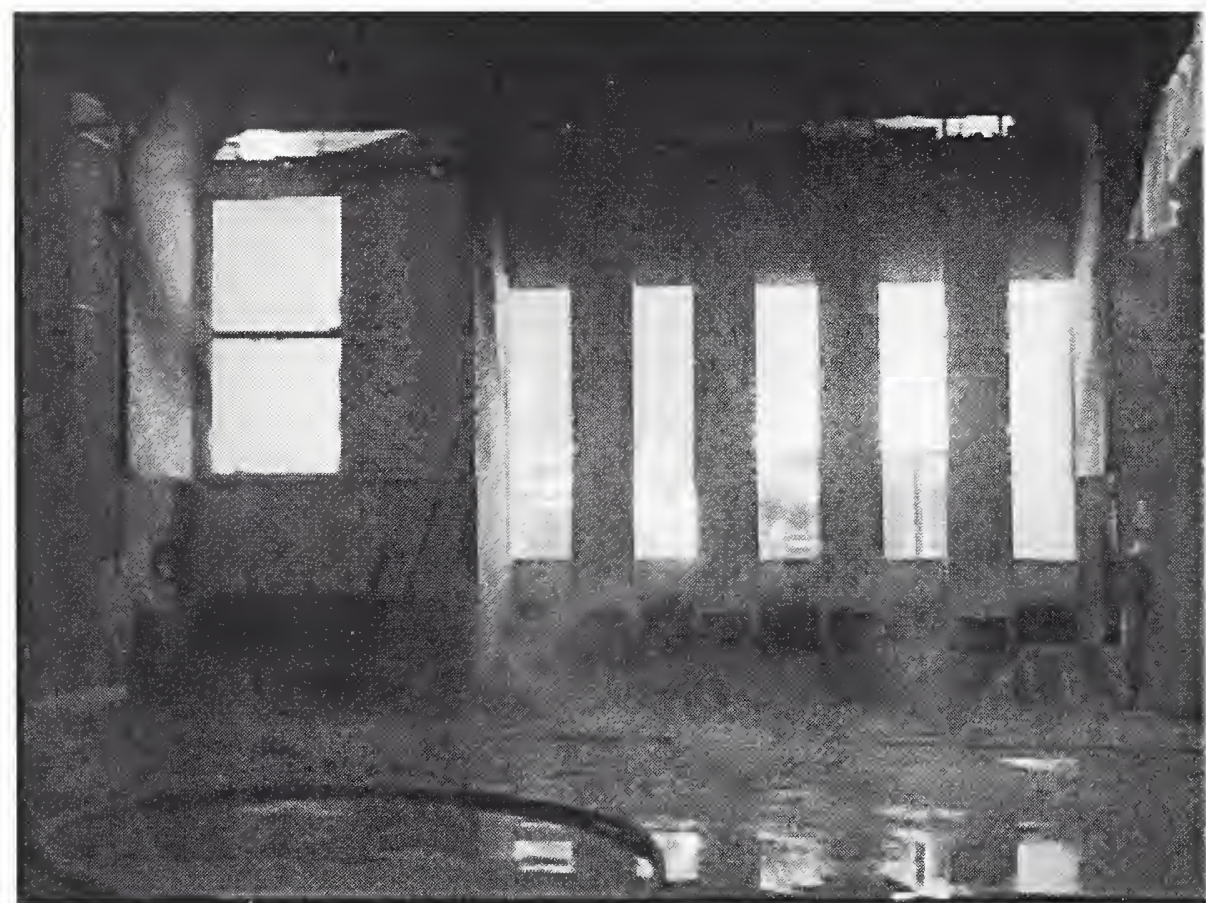

Source: NIST.

Figure 3-12. View external to the compartment 9 min $30 \mathrm{~s}$ after ignition of the spray burner in Test 6.

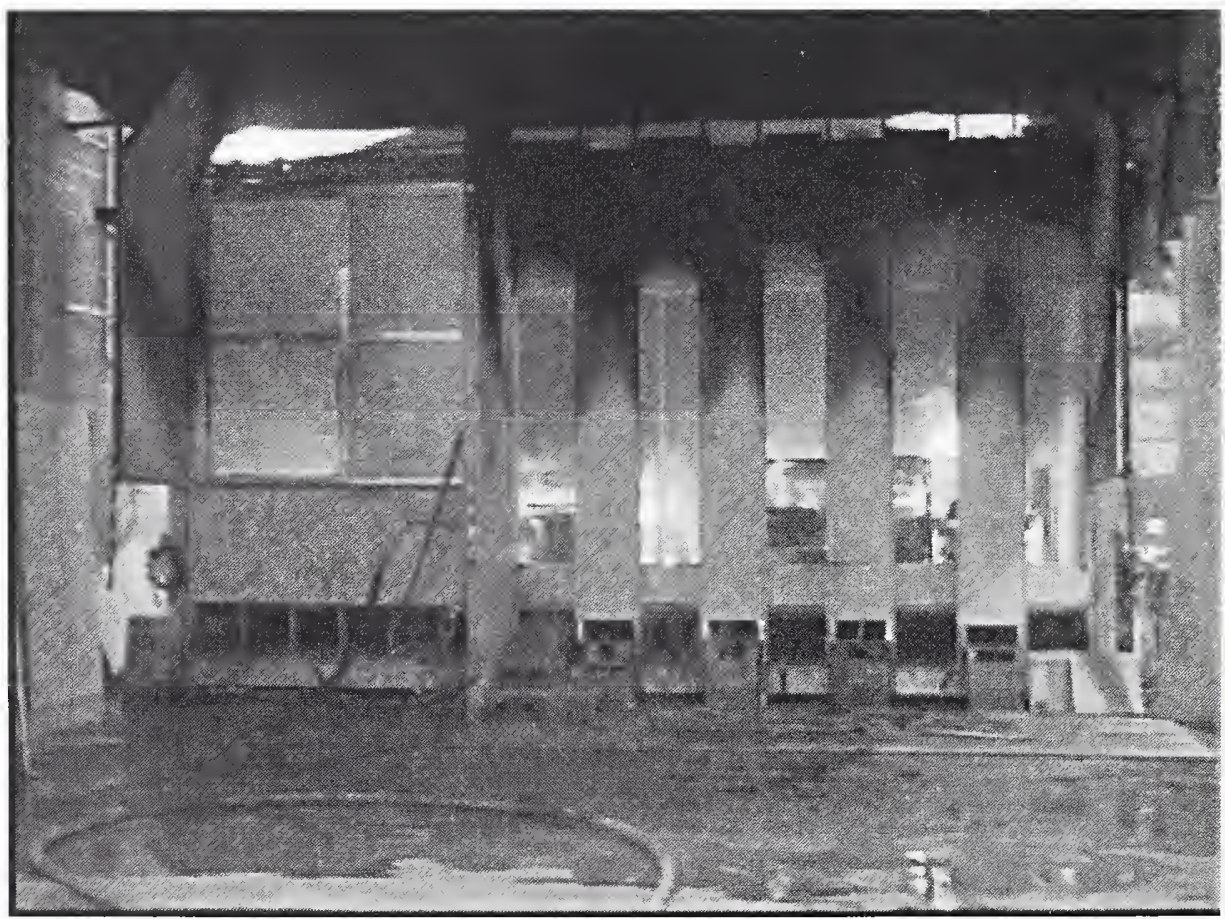

Source: NIST.

Figure 3-13. View external to the compartment 17 min after ignition of the spray burner in Test 6 . 
It is of interest to compare the experimental observations with the extensive photograph record of the World Trade Center (WTC) fires in an attempt to identify common features or differences. NIST compiled, catalogued, and time-stamped an extensive array of photograph and video records of the WTC fires (NIST NCSTAR 1-6A). Naturally, the images are limited to perspectives external to the building. The experiments reported on here appear to recreate aspects of the actual WTC fires. Based on available photographic evidence, NIST reported that the first area in WTC 1 where substantial fire spread and growth was observed was on the north face of the 97th floor; just to the west (to the right in the photograph of the aircraft strike point (NIST NCSTAR 1-6A). Figure 3-14 shows that extensive fire was present at windows 97-1 10 to 97-116 around 8:50 a.m., which was almost 31/2 min after the aircraft impact with the building. NIST found that windows were broken during the aircraft impact and subsequent fireballs. The fire would subsequently spread from this location to the west face.

Figure 3-14 reveals that at any one time, different locations on WTC 1 exhibited different smoke and flame yields as they were at different points in the burning process. Just a few minutes after the aircraft collision, the north face of WTC 1 (see Fig. 3-14) resembles early times during the experiments reported on here, when copious amounts of smoke (see Fig. 3-9) and flames (see Fig. 3-10) were emitted from the compartment. Almost an hour later, Fig. 3-15 shows that similar behavior was displayed on the south face of WTC 1. In this sense, the experiments conducted in this study recreated aspects of the WTC fires that can be thought of as typical of fires burning in compartments.

Figure 3-13 shows smoke markings due to deposits of soot-laden gases flowing from the compartment. The markings take the form of carets (" $\wedge$ " shaped black marks) on the outer columns that define the compartment "windows" or openings. Smoke deposits in the shape of straight lines on the wall adjacent to the glass windows was also observed (see Fig. 3-13). The same type of markings were observed in the WTC fires. Figure 3-15, for example, shows the caret-like markings near windows on the 95th and 96th floors of the south face of WTC 1.

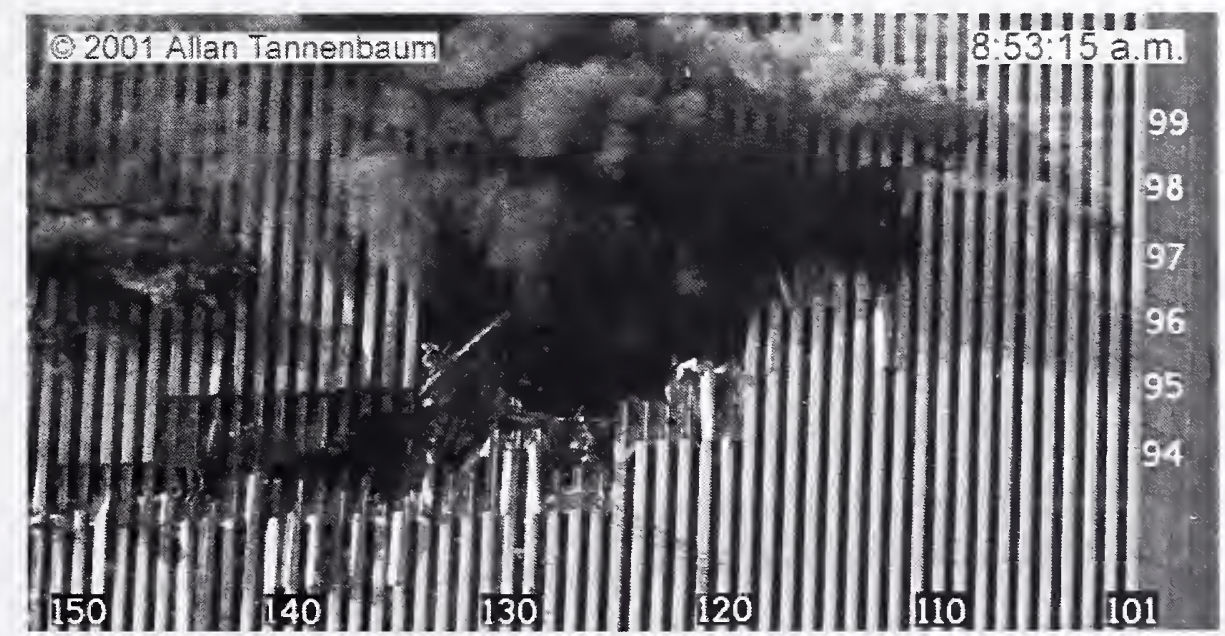

Figure 3-14. Photograph of the north face of WTC 1 recorded at 8:53:15 a.m. on September 11, 2001. Labels showing floor and column numbers were added to the original photograph. 


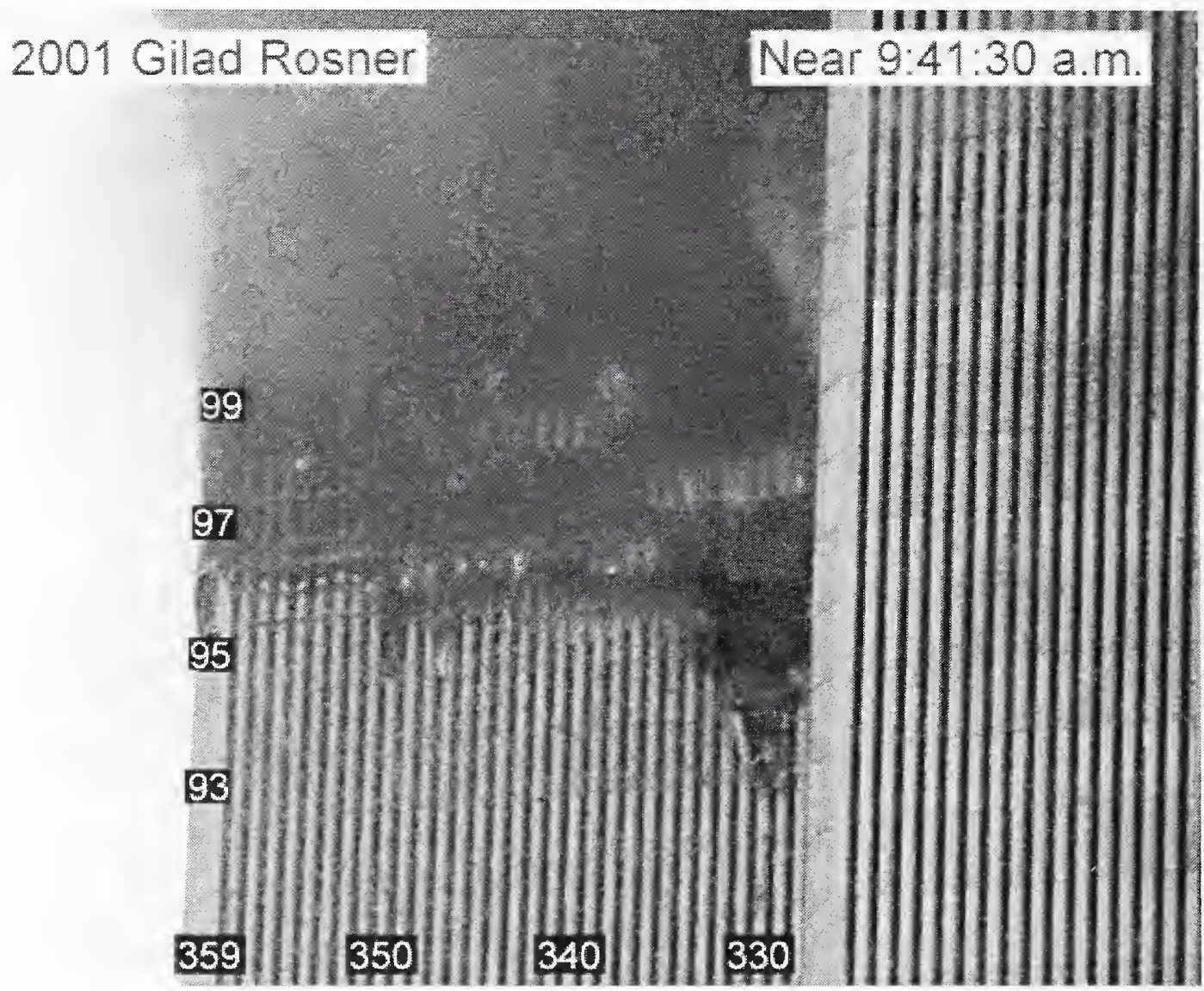

Figure 3-15. Photograph of the south face of WTC 1 taken at approximately 9:41:30 a.m. on September 11, 2001. Column and floor numbers were added to the original photograph.

\subsection{SUMMARY}

During Tests 1 and 2, with the burner next to Workstation 1, all three workstations exhibited reproducible times to full involvement. In both experiments, Workstation 1 reached full involvement in a little over 400 s. Full involvement for Workstation 2 was achieved 300 s later. Workstation 3 reached full involvement less than $100 \mathrm{~s}$ after Workstation 2. In Test 4 , with the burner next to Workstation 2 , Workstation 2 reached full involvement in approximately $300 \mathrm{~s}$. Workstations 1 and 3 were fully involved $150 \mathrm{~s}$ later, with Workstation 3 being ignited from radiation.

The time from ignition to full involvement was also significantly affected by burner placement. For Tests 1 and 2, full involvement occurred $400 \mathrm{~s}$ after ignition of Workstation 1, $200 \mathrm{~s}$ after Workstation 2 ignition and $250 \mathrm{~s}$ after Workstation 3 ignition. In comparison, during Test 4 , despite the presence of ceiling tiles, Workstation 2 was fully involved $250 \mathrm{~s}$ after its ignition; with Workstations 1 and 3 being fully involved 50 and $150 \mathrm{~s}$, respectively, after their ignitions.

The presence of Jet $\mathrm{A}$ in Tests 3, 5, and 6 resulted in all workstations being fully involved in a little over $60 \mathrm{~s}$. 


\section{7}

\section{REFERENCES}

Manzello, S. L., Gann, R. G., Kukuck, S. R., Prasad, K. R., and Jones, W. W. 2005. Fire Performance of a Non-Load Bearing Glass Wall Assembly, to be submitted to Fire and Materials. 
This page intentionally left blank. 


\section{Chapter 4 \\ MASS LosS}

The rate of burning of combustible items in the compartment controlled the fire heat relcasc ratc and, thereby, the rate of fire spread. The combustibles in the compartment consisted of the workstation components, jet fuel added to the workstations, and the hydrocarbon spray burner. The rate of mass loss of each of the workstations was measured during each of the tests using several load cells.

\subsection{INSTRUMENTATION AND PROCEDURE}

Load cells were employed to measure workstation mass loss during cach test. Each workstation, its contents, and flooring rested on a platform mechanically isolated from the adjacent floor. Each platform was supported by a network of four load cells, located in the subfloor. Load cells generate an electrical signal proportional to the load acting upon them. Each load cell network had a total weight capacity of $907 \mathrm{~kg}(2,000 \mathrm{lb})$. The load cells in the subfloor were thermally protccted with both insulation and a single-pass, water cooling system. Temperature inside each enclosure was monitored to insure that the thermal environment did not jeopardize data integrity. Nitrogen was pumped at a low flow into each load cell enclosure to prevent infiltration of corrosive gases. Workstations 1 and 2 employed load cell networks manufactured by Mettler Toledo. Workstation 3 employed a load cell network supplied by The Scale People. Specifics of each system are listed in Table 4-1.

The signals generated by the individual load cells were measured by a load cell terminal for intermediate display and retransmitted to the data acquisition (DAQ) system. The mass loss rate determined from the load cell data provides a measure of the fuel gasification rate and allows for computation of the effective heat of combustion of the workstations and associated materials.

During test preparation, the output from each load cell terminal was monitored to insure that the load cells were not overloaded. The signal outputs from the individual load cells of Workstation 3 were recorded, while the cumulative load cell outputs were recorded for the network of loadcells associated with Workstations 1 and 2. Prior to each test, calibration was accomplished by adding a $25 \mathrm{~kg}$ weight to each load cell, which demonstrated proper output of the load cell electronics.

Table 4-1. Load cell specifications.

\begin{tabular}{|l|c|c|}
\hline \multicolumn{1}{|c|}{ Type } & Mettler & The Scale People \\
\hline Load cell model & $0958-1-4-X 5-2$ & CW-500 \\
\hline Terminal model & JXGA-3080-000 & 665 Digital Indicator (GSE) \\
\hline Capacity & Four $\times 227 \mathrm{~kg}$ load cells & Four $\times 227 \mathrm{~kg}$ load cells \\
\hline Output signal (terminal) & $0-10$ Volt & $0-20 \mathrm{~mA}$ \\
\hline Accuracy & $5 \%$ & $5 \%$ \\
\hline
\end{tabular}


The mass loss rate determined from the load cell data provided a measure of the fuel gasification rate. In concert with the measurement of the heat release rate, the mass loss data provided a global measure of the effective heat of combustion of the workstations, which is discussed in Chapter 5.

\subsection{RESULTS AND DISCUSSION}

Figures 4-1 through 4-6 show the load cell mass measurements for each workstation during each of the six tests. For purpose of comparison, the output of each load cell was normalized such that each load cell reported $900 \mathrm{~kg}$ prior to test initiation. In the following charts, mass data greater than $900 \mathrm{~kg}$ prior to time zero represent artifacts of the experimental procedure, such as personnel moving through the compartment, arming the ignition system, or performing final checks. For all plots, sudden decreases or increases in mass, as evidenced by nearly vertical data, are the result of material falling onto or off of the load cell platform. During Test 5, a circuit breaker tripped three minutes after ignition on the circuit powering load cells under Workstations 1 and 2. It took approximately $2.5 \mathrm{~min}$ for the power to be restored and the load cells to return to service.

For further comparison, Fig. 4-7 shows the sum of all three normalized load cells for Tests 1 through 6. The curves for the various tests were quite similar with the exception of Test 5 , which was unique in terms of the experimental configuration. The mass loss rate or mass burning rate for Test 5 was much slower than for the other tests. Most rapid mass loss occurred earlier during Tests 3, 5, and 6, when jet fuel was present. When jet fuel was not present, the fastest period of mass loss occurred almost $500 \mathrm{~s}$ later. The power to the load cells under Workstations 1 and 2 failed for 2.5 min at $180 \mathrm{~s}$ during Test 5 .

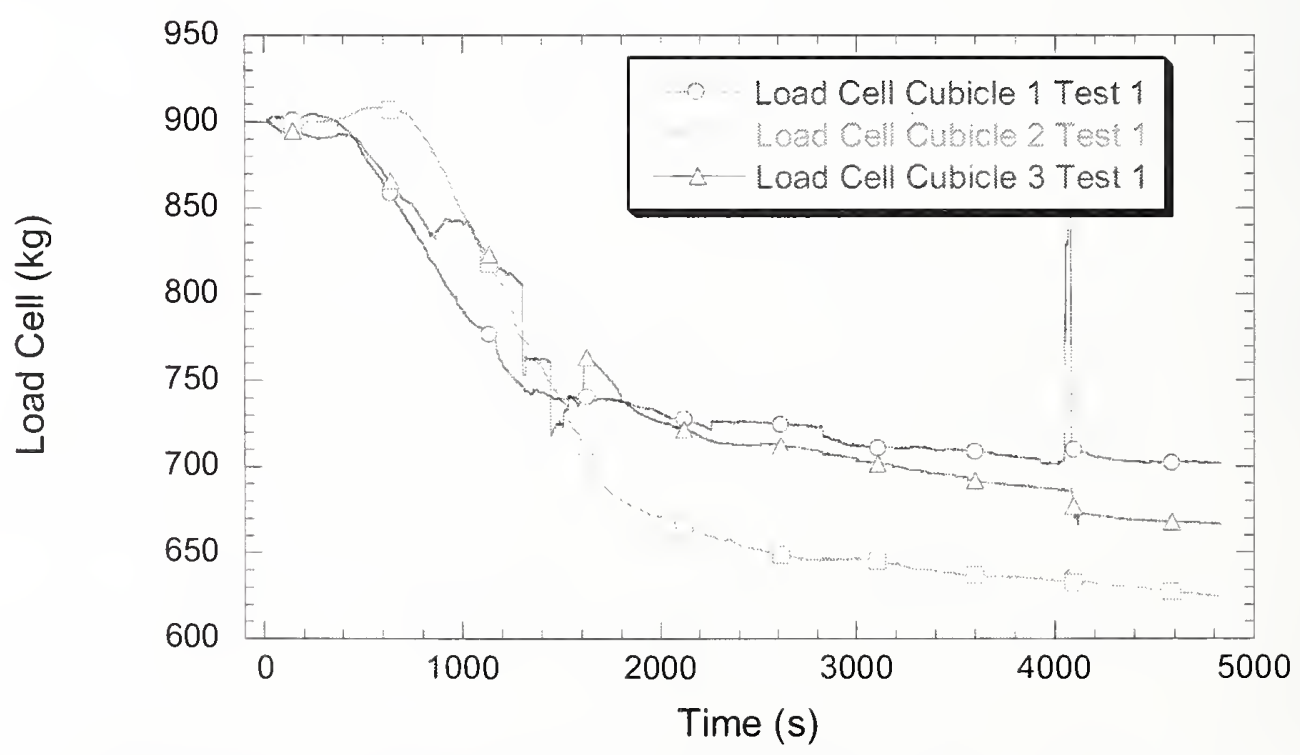

Figure 4-1. The mass of Workstations 1, 2, and 3 as a function of time during Test 1. 


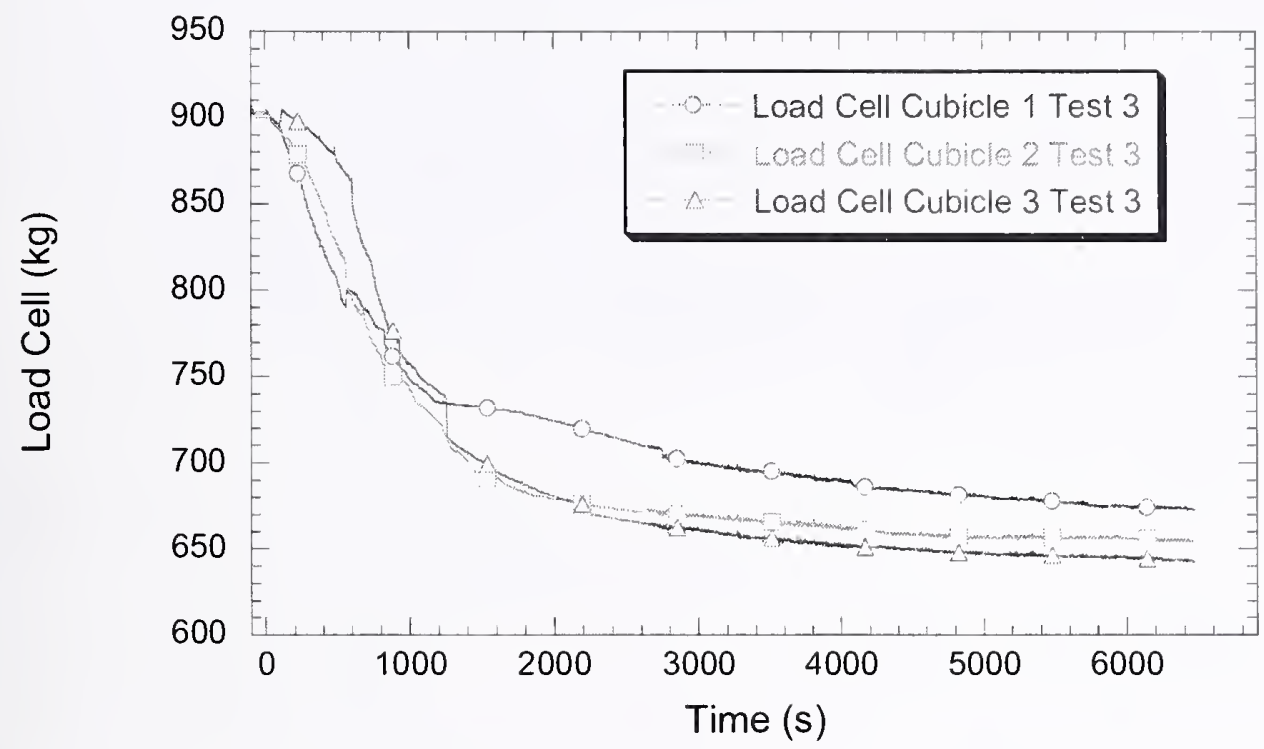

Figure 4-2. The mass of Workstations 1, 2, and 3 as a function of time during Test 2.

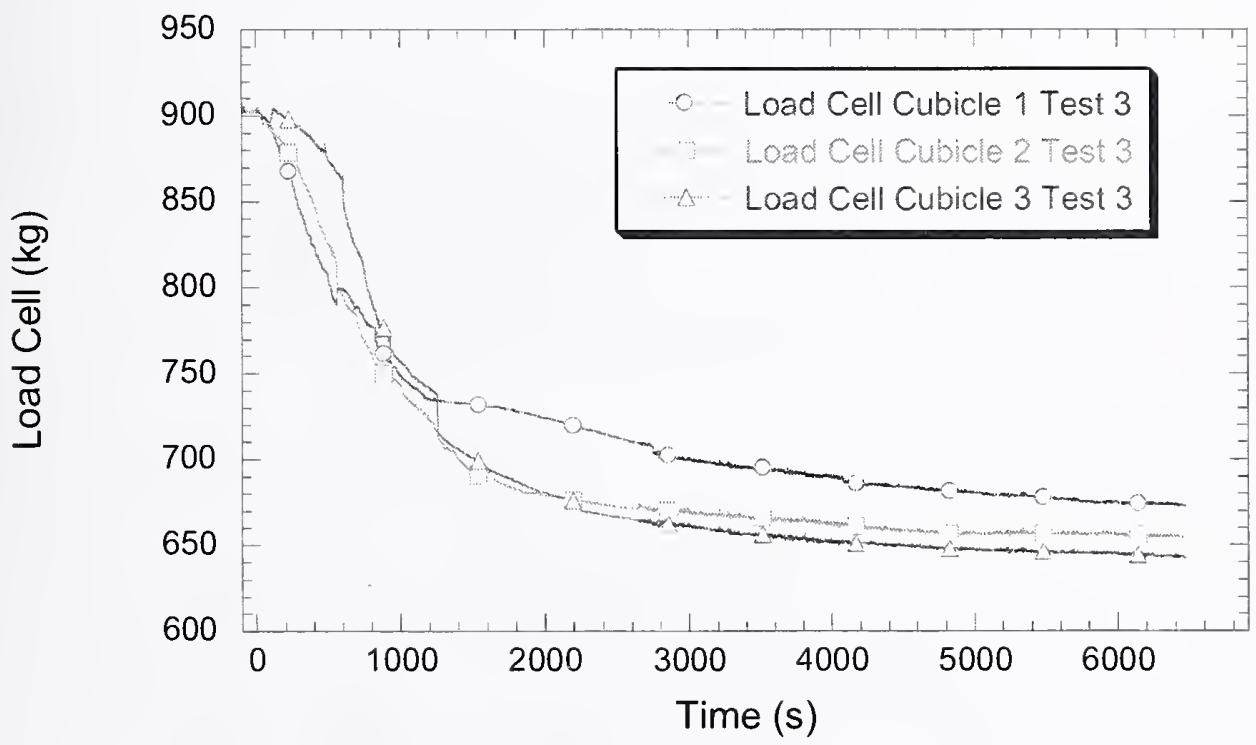

Figure 4-3. The mass of Workstations 1, 2, and 3 as a function of time during Test 3. 


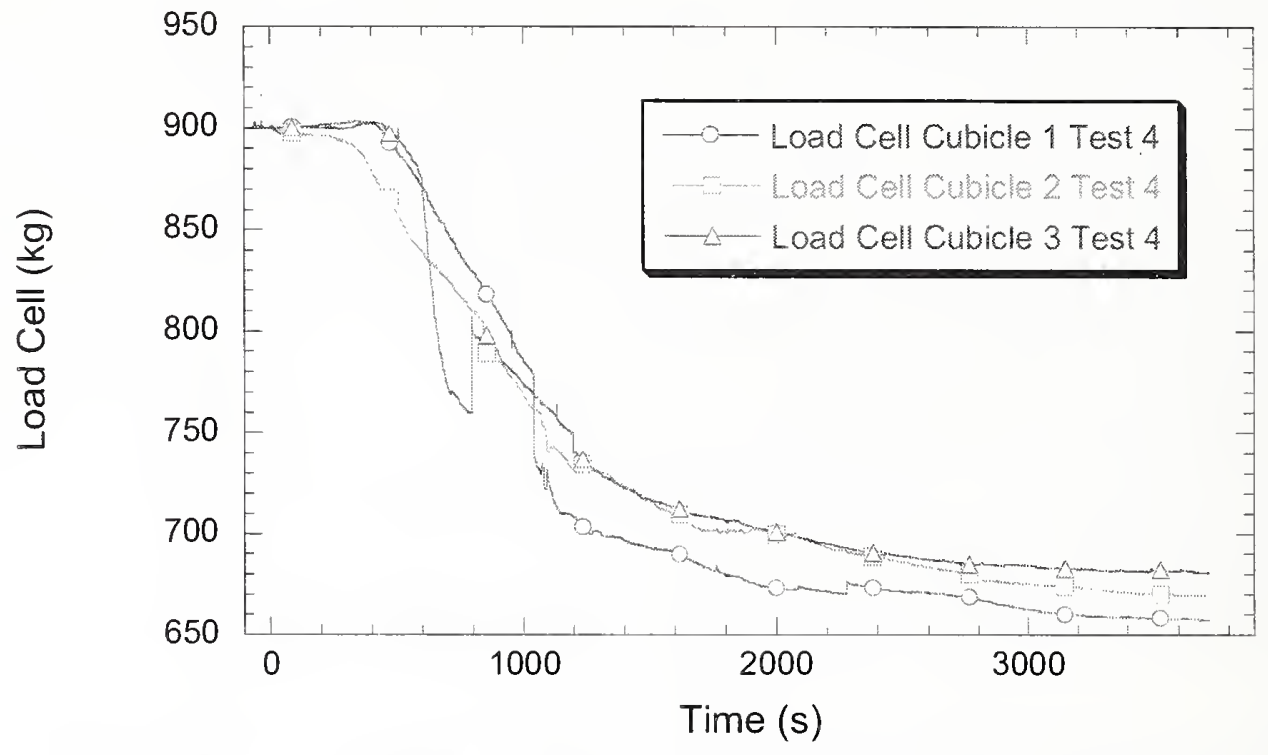

Figure 4-4. The mass of Workstations 1, 2, and 3 as a function of time during Test 4.

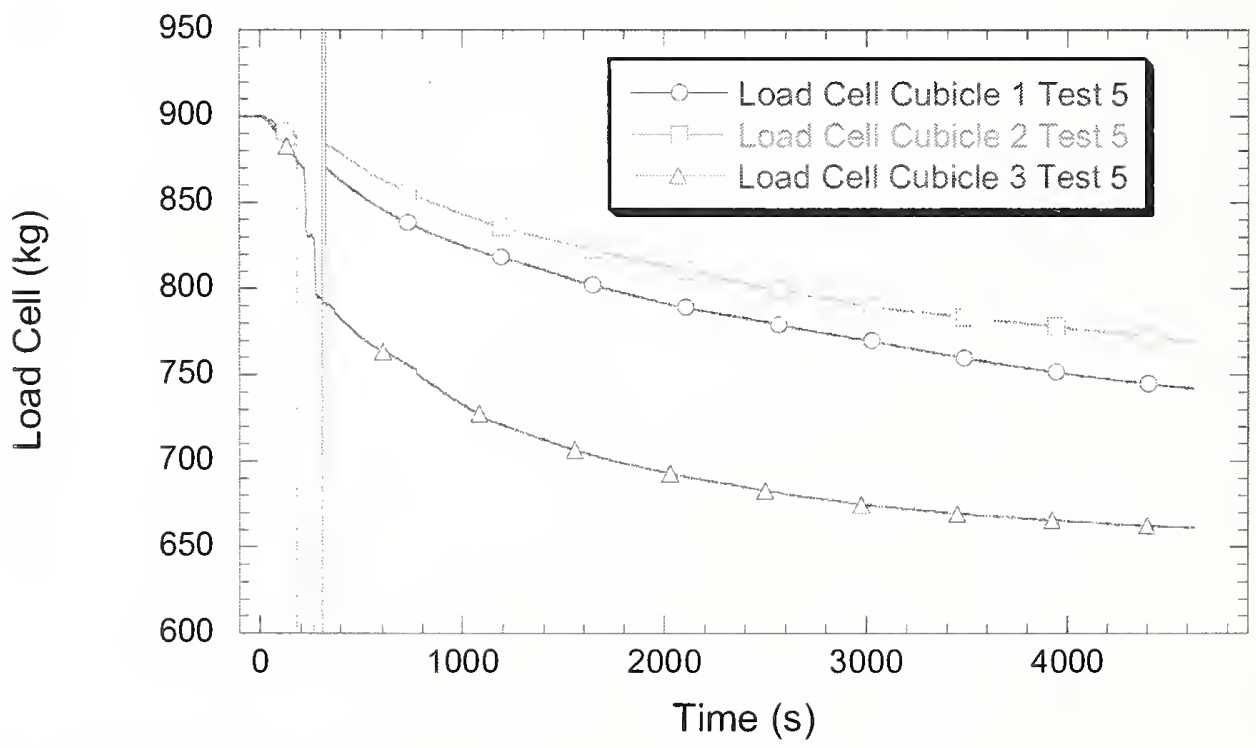

Figure 4-5. The mass of Workstations 1,2 , and 3 as a function of time during Test 5 . The power to the load cells under Workstations 1 and 2 failed for $2.5 \mathrm{~min}$ at $180 \mathrm{~s}$. 


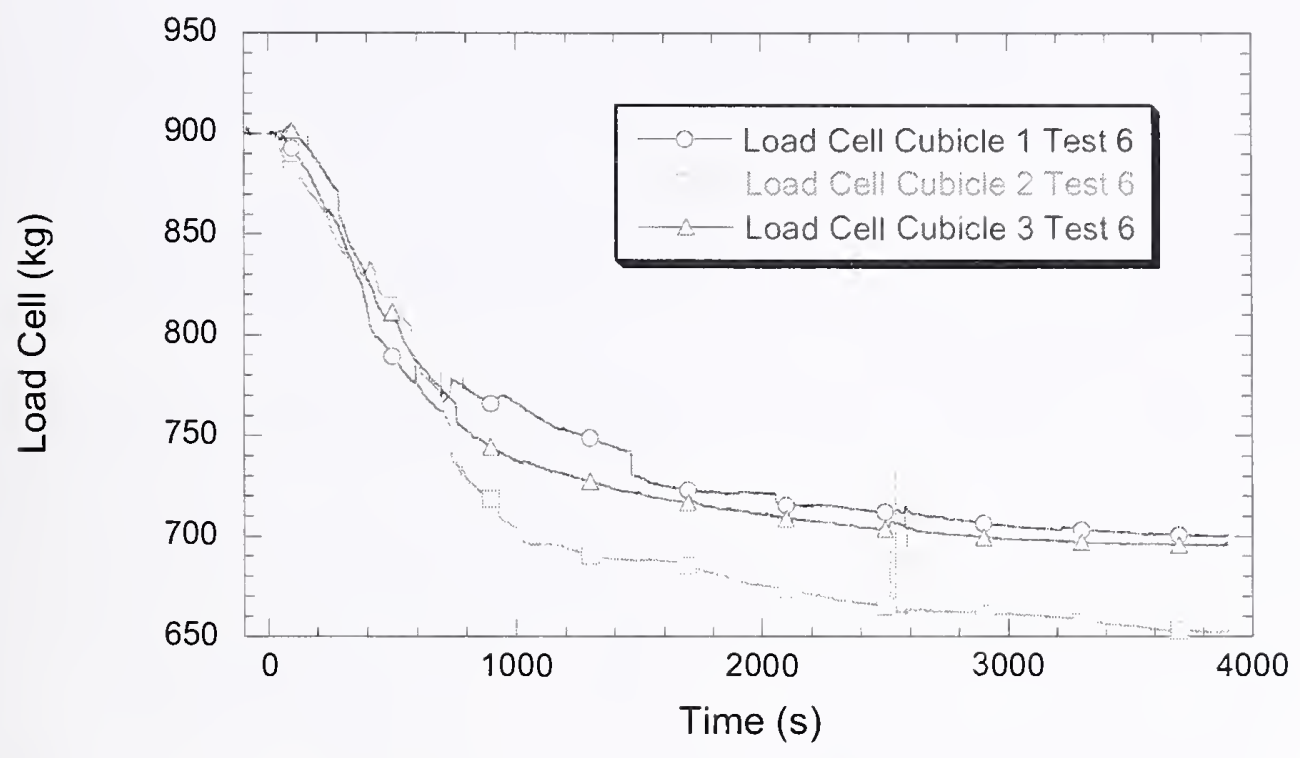

Figure 4-6. The mass of Workstations 1, 2, and 3 as a function of time during Test 6.

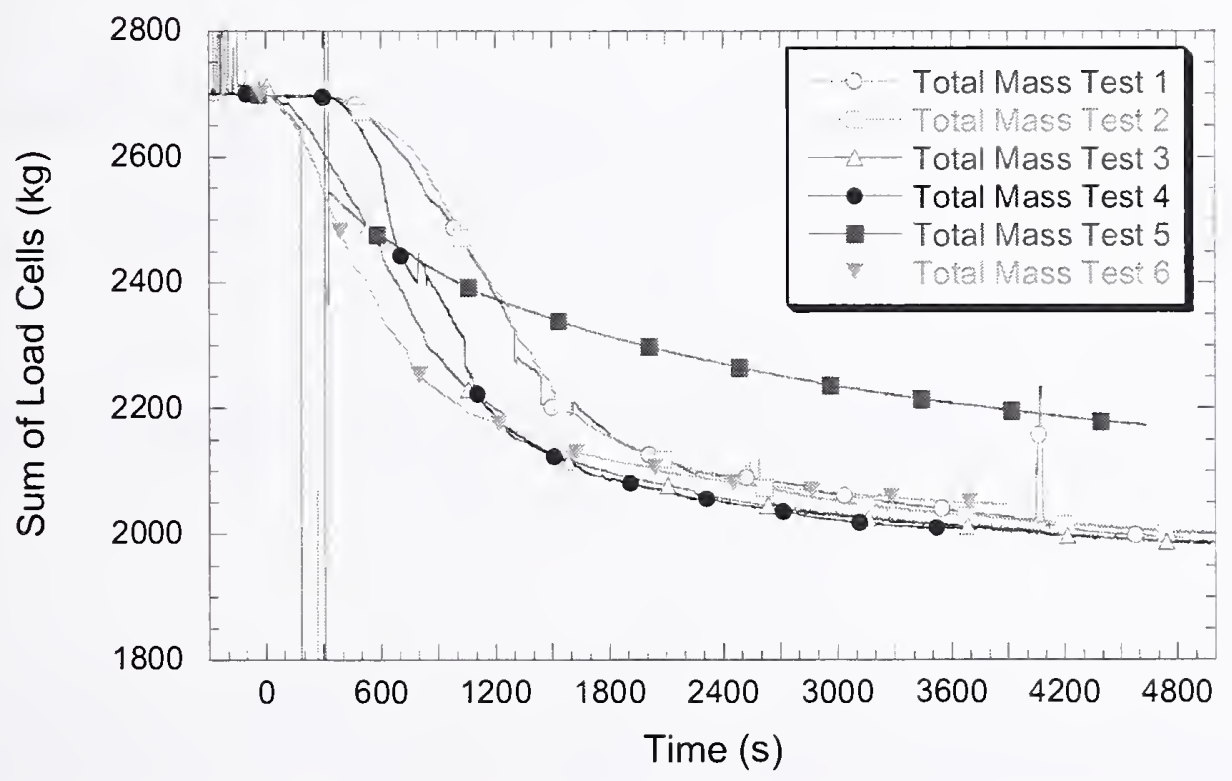

Figure 4-7. The sum of the mass of Workstations 1,2 , and 3 for Tests 1 through 6 . The power to the load cells under Workstations 1 and 2 failed for $2 \mathrm{~min}$ at $180 \mathrm{~s}$ in Test 5. 


\subsubsection{Total Mass Loss}

Table 4-2 shows the total mass loss for each of the load cells from the time of ignition until 3,900 s after ignition during each of the six experiments. The mass loss was small after 3,900 s, and suppression of the fire occurred shortly thereafter in some tests. The mean total mass loss for the tests, excluding Test 5 , was $680 \mathrm{~kg}$ with a standard deviation of 3 percent. The total combustible mass for each workstation was $248.7 \mathrm{~kg}$ (see Table 2-2) or $251.9 \mathrm{~kg}$ in Tests 3, 5, and 6 when jet fuel was present, equivalent to $746.1 \mathrm{~kg}$ for the three workstations or $755.7 \mathrm{~kg}$ when jet fuel was present. The mass loss of Workstation 2 in Tests 1 and 6 was very close or exceeded this value, possibly due to shifting of load onto Load Cell 2 from the adjoining workstation as it burned.

In Test 5, the total mass loss was approximately 25 percent less when compared to the mean mass loss of the other tests. The total mass loss for Load Cell 3 in Test 5 was greater than the total mass loss of Load Cells 1 and 2. This was because the configuration of the workstations in Test 5 was different from the other tests. While Workstation 3 was configured in a non-standard manner, the eombustibles in Workstations 1 and 2 were "shielded" from the fire, as the panels and desk surfaces were laying horizontally on top of each other. The mass loss in Test 5 for Workstations 1 and 2 were about 40 percent less than the workstations burning in the standard configuration.

Table 4-2 suggests that there was no discernable effect of the jet fuel (Tests 3, 5, and 6), the ceiling tiles (Tests 3,4, and 5), or ignition burner location on the total mass loss of the combustible portion of the workstations. From the data in Table 4-2, the mean total mass loss (excluding Test 5) was $681 \mathrm{~kg}$ for the three workstations or $227 \mathrm{~kg}$ per workstation. This was about 14 percent larger than that measured during the single workstation experiments (NIST NCSTAR 1-5C). The mass lost represents about 90 percent of the total combustible mass.

Table 4-2. Total mass loss for the three workstations from $\mathrm{t}=0 \mathrm{~s}$ until $3,900 \mathrm{~s}$.

\begin{tabular}{|c|c|c|c|c|c|c|}
\hline \multicolumn{7}{|c|}{ Mass Loss (kg) } \\
\hline & Test 1 & Test 2 & Test 3 & Test 4 & Test 5 & Test 6 \\
\hline Load 1 & 196 & 226 & 214 & 243 & 147 & 205 \\
\hline Load 2 & 265 & 232 & 241 & 230 & 121 & 248 \\
\hline Load 3 & 212 & 216 & 252 & 220 & 237 & 207 \\
\hline Sum $^{\text {a }}$ & $673 \pm 34$ & $674 \pm 34$ & $707 \pm 35$ & $693 \pm 35$ & $505 \pm 20$ & $660 \pm 33$ \\
\hline
\end{tabular}

a. And calculated standard deviation.

\subsubsection{Mass Loss Rate}

Figure 4-8 shows the time varying mass for each of the three load cells during Test 1 . The mass loss rate is the temporal derivative of the time varying mass taken from the load cell data. The mass loss rate measurements could be naturally partitioned into three distinct time periods: a warm-up period $\left(\Delta \mathrm{t}_{\mathrm{w}}\right)$, a period of rapid burning $\left(\Delta \mathrm{t}_{\mathrm{r}}\right)$, and a longer, slow burning period $\left(\Delta \mathrm{t}_{\mathrm{s}}\right)$. Figure 4-8 shows the three burning periods for the mass loss of Workstation 1 during Test 1 . The transient mass loss rate during each period was approximated as a straight line. This approach minimized noise in the mass loss rate determination, while adequately representing its value. It was possible to apply this method to determine the mass loss rate for each of the load cells for each of the tests except for Workstation 3 in Test 5 in which the mass loss rate behavior during the rapid burning period was atypical and not easily represented by a single 
straight line fit. In that case, the mass loss rate was estimated as the average rate of mass loss over a 1,000 s period. Table $4-3$ presents the mass loss rates during the rapid burning and the slow burning periods for each of the load cells for Tests 1 through 6 . The mean mass loss rates during the rapid burning period for Workstations 1 through 3, excluding Test 5 , was $-0.19 \mathrm{~kg} / \mathrm{s},-0.21 \mathrm{~kg} / \mathrm{s}$, and $-0.19 \mathrm{~kg} / \mathrm{s}$, respectively, yielding a mean value of $-0.20 \mathrm{~kg} / \mathrm{s}$. The mean mass loss rates during the slow burning period for Workstations 1 through 3 , excluding Test 5 , was $-0.009 \mathrm{~kg} / \mathrm{s},-0.010 \mathrm{~kg} / \mathrm{s}$, and $-0.011 \mathrm{~kg} / \mathrm{s}$, respectively, yielding a mean value of $-0.010 \mathrm{~kg} / \mathrm{s}$. Test 5 was excluded from the calculation of the mean value due to the atypical configuration used in that test. The standard relative uncertainty in the mass loss rate was estimated as 15 percent and 30 percent for the rapid and slow burning periods, respectively. The mean mass loss rate during the rapid burning period was nearly 20 times larger than during the slow burning period. The variation in the mass loss rate during the slow burning period was larger than during the rapid burning period. The mass loss rate results are nearly the same for each of the three workstations during both the rapid and the slow burning periods.

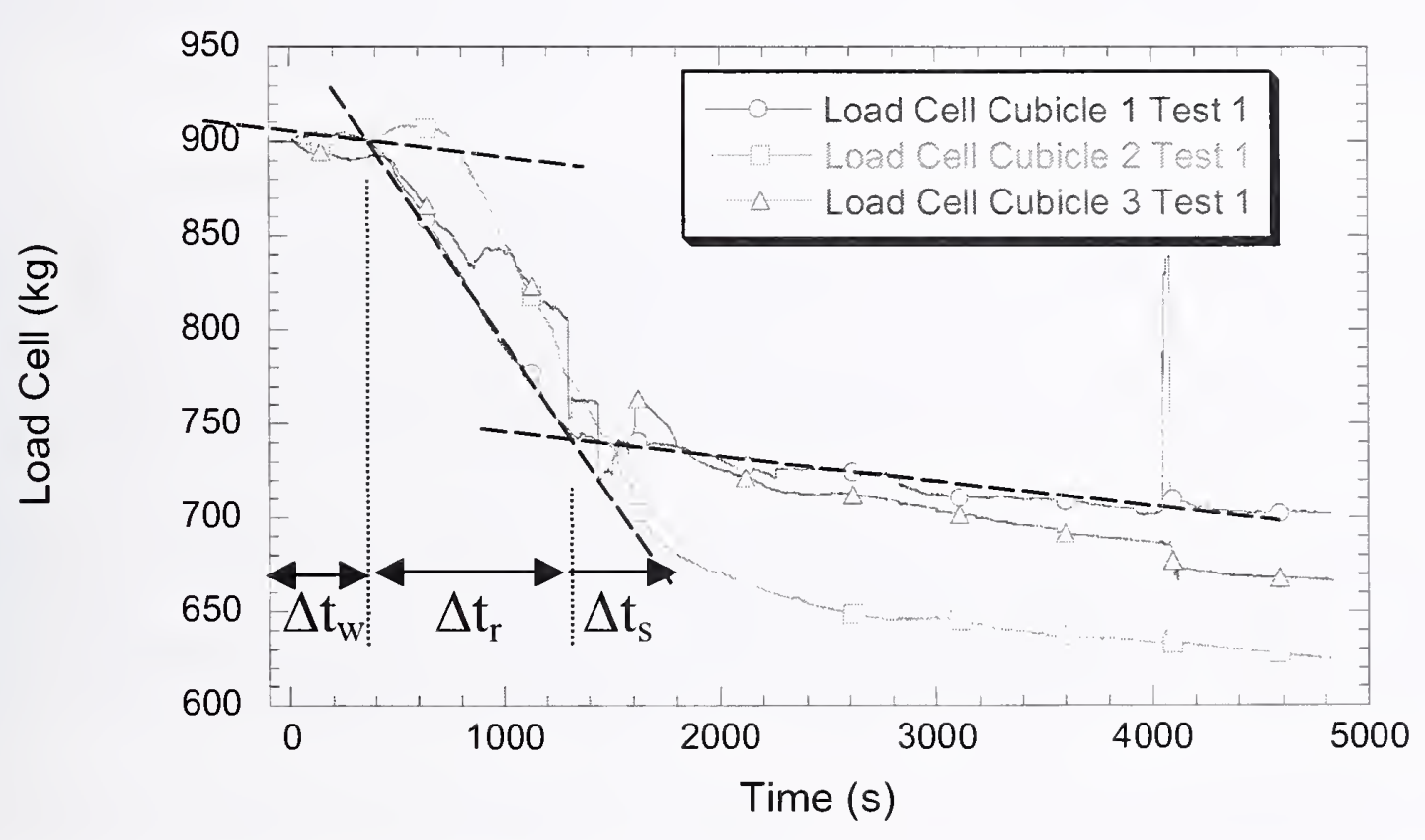

Figure 4-8. The mass of Workstations 1,2 , and 3 as a function of time during Test 1 , showing straight line fits to each of the three burning periods for Workstation 1 . The data is taken from Fig. 4-1. 
Table 4-3. The mass loss rate for each of the workstations during the rapid and slow burning periods for Tests 1 through 6.

\begin{tabular}{|c|c|c|c|c|c|c|}
\hline \multirow[b]{2}{*}{ Test } & \multicolumn{3}{|c|}{$\begin{array}{l}\text { Mass Loss Rate during the rapid burning } \\
\text { period, } \Delta \mathrm{t}_{\mathrm{r}}(\mathrm{kg} / \mathrm{s})^{\mathrm{a}}\end{array}$} & \multicolumn{3}{|c|}{$\begin{array}{l}\text { Mass Loss Rate during the slow burning period, } \\
\qquad \Delta \mathrm{t}_{\mathrm{s}}(\mathrm{kg} / \mathrm{s})^{\mathrm{a}}\end{array}$} \\
\hline & $\begin{array}{c}\text { Workstation } \\
1\end{array}$ & $\begin{array}{l}\text { Workstation } \\
2\end{array}$ & $\begin{array}{c}\text { Workstation } \\
3\end{array}$ & $\begin{array}{c}\text { Workstation } \\
1\end{array}$ & $\begin{array}{c}\text { Workstation } \\
2 \\
\end{array}$ & $\begin{array}{c}\text { Workstation } \\
3 \\
\end{array}$ \\
\hline 1 & -0.17 & -0.24 & -0.11 & -0.0087 & -0.013 & -0.021 \\
\hline 2 & -0.18 & -0.21 & -0.17 & -0.010 & -0.0080 & -0.012 \\
\hline 3 & -0.17 & -0.22 & -0.20 & -0.0054 & -0.0021 & -0.0038 \\
\hline 4 & -0.21 & -0.18 & -0.22 & -0.011 & -0.017 & -0.0098 \\
\hline 5 & -0.085 & -0.055 & -0.17 & -0.022 & -0.019 & -0.012 \\
\hline 6 & -0.21 & -0.22 & -0.23 & -0.010 & -0.011 & -0.0076 \\
\hline Average $^{b}$ & $-0.19 \pm 0.03$ & $-0.21 \pm 0.04$ & $-0.19 \pm 0.06$ & $-0.0090 \pm 0.005$ & $-0.010 \pm 0.007$ & $-0.011 \pm 0.009$ \\
\hline
\end{tabular}

a. The standard relative uncertainty in the mass loss rate was estimated as 15 percent and 50 percent for the rapid and slow burning periods, respectively.

b. Excludes Test 5 .

The mass loss rate results for Test 5 were atypical, particularly for Workstations 1 and 2, which were comprised of unassembled workstations that were configured (in an identical manner except for the addition of drywall to Workstation 1) to simulate piles of rubble (see Figs. 2-6 and 2-7). The mass loss rates for Workstation 3 in Test 5 were similar to the mean values for Workstation 3 in the other tests. This is attributed to the fact that the configuration used for Workstation 3 in Test 5 was much more similar to the configuration used for the workstations in the other tests, except that the furniture was displaced and pushed from its standard configuration as seen in Fig. 2-8. The mass loss rates during the rapid burning period for Workstations 1 and 2 in Test 5 were 26 percent and 45 percent, respectively, of the mean values of the mass loss rates in the other five tests. The mass loss rates during the slow burning period for Workstations 1 and 2 in Test 5 were 240 percent and 190 percent, respectively, of the mean values of the mass loss rates in the other five tests. The rapid burning period, however, dominated the mass loss rate behavior, and the total mass loss in Test 5 was significantly smaller than in the other tests as seen in Table 4-3.

\subsection{SUMMARY}

Measurements of the total mass loss and the mass loss rate are indicators of the fire intensity as materials burn and release heat. The results showed that there was no discernable effect of the jet fuel (Tests 3,5 , and 6), the ceiling tiles (Tests 3,4, and 5), or ignition burner location on the total mass loss of the combustible portion of the workstations. The mass loss burning rate for workstations configured such that the combustibles were "shielded" from the fire was about 40 percent less than the mass loss rate for workstations burning in the standard configuration.

The next section of this report describes the measured heat release rate and its relationship to the mass loss rate data. Whereas the mass loss rate data was independently measured for Workstations 1, 2, and 3, the heat release rate measurement represents the heat generated from all of the combustibles within the compartment and exemplifies the global fire behavior. 


\section{Chapter 5 \\ HeAt Release Rate}

The heat release rate of a fire is a critical cxperimental parameter, as it represents the amount of energy per unit time that is generated by the fire. The value of the heat release rate drives the thcrmal environment, including the radiative and convective heat transfer, the fluid flow, the thermal insult onto secondary items such as structural members, the rate of fire spread and growth, the volume of smoke and toxic products, and ultimately, the hazard associated with a fire. This chapter is divided into two parts. First, the heat release rate determination from oxygen consumption calorimetry is discussed. Then, the mass loss rate information from Chapter 4 is used to detcrmine the effective heat release rate per unit mass of combustibles. Measurement uncertainty is discussed for both measurements.

\subsection{OXYGEN CONSUMPTION CALORIMETRY}

\subsubsection{Description of the Heat Release Rate Measurement Facility}

The fire heat release rate $(\dot{Q})$ was measured using oxygen consumption calorimetry in the standard manner through measurement of exhaust products in the $6 \mathrm{~m}$ by $6 \mathrm{~m}$ hood. This form of fire calorimetry was used by Huggett (1980), who showed that the oxygen deficit in the duct flow (relative to ambient air) is a measure of the heat release rate of a fire. Parker (1982) and Janssens and Parker (1995) discuss the details of the heat release rate calculation.

Bryant et al. (2003) give a comprehensive description of the experimental methodology, hardware, instrumentation, calibration, experimental procedures, and uncertainty. Much of this discussion borrows from that reference. The facility was designed to provide quantitative results with minimum uncertainty. A large number of instruments were employed in the heat release rate measurement (see Table 5-1), including the measurement of temperature and pressure in the exhaust duct.

The combustion products from the compartment flowed into the $9 \mathrm{~m}$ by $12 \mathrm{~m}$ exhaust duct where the gas flow was characterized. The exhaust gas was sampled in the exhaust duct and transported to the instruments in a control room for measurements of the oxygen, carbon dioxide, and carbon monoxide concentrations. The relative humidity was measured in the test bay area, and a correction was made for ambient humidity as an estimate of the water concentration in the duct flow. The computation of heat release rate $(\dot{Q})$ was made following Bryant et al. (2003):

$$
\begin{aligned}
& \dot{Q}=\left[E_{H C} \phi-\left(E_{C O}-E_{H C}\right) \frac{1-\phi}{2} \frac{X_{C O}}{X_{O 2}}\right] \frac{\dot{m}_{e}}{1+\phi(\alpha-1)}\left[\frac{\left(1-X_{H 2 O}^{o}\right) M_{O 2}}{M_{\text {air }}}\right] X_{O 2}^{o} \\
& \text { with } \\
& \phi=\frac{X_{O 2}^{o}\left(1-X_{C O 2}-X_{C O}\right)-X_{O 2}\left(1-X_{C O 2}^{o}\right)}{\left(1-X_{O 2}-X_{C O 2}-X_{C O}\right) X_{O 2}^{o}}
\end{aligned}
$$


$E_{H C}=$ heat of combustion of hydrocarbon fuel

$E_{C O}=$ heat of combustion of carbon monoxide

$\phi \quad=$ oxygen depletion factor

$\dot{m}_{c}=$ mass flow rate in exhaust duct

$\dot{m}_{\text {air }}=$ mass flow rate of air

$\alpha \quad=$ combustion products expansion factor

$M_{i} \quad=$ molecular weight of species $\mathrm{i}$

$X_{i} \quad=$ exhaust-gas concentration measurement of species $\mathrm{i}$

$X_{i}^{o}=$ ambient-gas concentration measurement of species $\mathrm{i}$

Table 5-1. Instruments used in the calorimeter system.

\begin{tabular}{|l|c|c|c|}
\hline \multicolumn{1}{|c|}{$\begin{array}{c}\text { Parameter } \\
\text { Measured }\end{array}$} & Instrument Type & Make and Model & Range \\
\hline Oxygen & Paramagnetic & Servomex 540 & $0 \%-21 \% \mathrm{v} / \mathrm{v}$ \\
\hline Carbon dioxide & Infrared extinction & Siemens Ultramat $5 \mathrm{E}$ & $0 \%-5 \% \mathrm{v} / \mathrm{v}$ \\
\hline Carbon monoxide & Infrared extinction & Siemens Ultramat $5 \mathrm{E}$ & $0 \%-3 \% \mathrm{v} / \mathrm{v}$ \\
\hline Relative humidity & Thin film capacitance & Dickson THDx & $0 \%-95 \%$ \\
\hline Temperature & Thermocouple & Omega K-type & $0{ }^{\circ} \mathrm{C}-1,350{ }^{\circ} \mathrm{C}$ \\
\hline Exhaust velocity & Bi-directional probe & $\begin{array}{c}\text { MKS model } 220 \text { differential } \\
\text { pressure transducer }\end{array}$ & $0 \mathrm{~Pa}-10 \mathrm{~Pa}$ \\
\hline
\end{tabular}

\subsubsection{Calibration and Measurement Uncertainty}

The relative expanded uncertainty of the measured heat release rate in the $9 \mathrm{~m}$ by $12 \mathrm{~m}$ calorimetry system was 0.15 (NIST NCSTAR 1-5C). A propagation of error analysis showed that the dominant source of uncertainty was measurement of the oxygen concentration, the exhaust mass flux, and the assumed value of the heat of combustion of the fuel (Bryant et al. 2003). The expanded uncertainty (with a coverage factor of 2) corresponds to a level of confidence of 94.5 percent. The term "relative" means that the uncertainty is expressed as a ratio of the uncertainty to the measured value, and the term "expanded" means that the uncertainty represents two times the standard deviation of the uncertainty.

Calibration burns using natural gas were conducted several times during the test series to assure accurate measurement of the heat release rate $(\dot{Q})$. The calibration burner used natural gas flowing at a measured and controlled rate. This provided an independent measurement of the heat release rate to compare to the measurement by oxygen consumption calorimetry. The heat output of the burner was held constant for $3 \mathrm{~min}$ to $5 \mathrm{~min}$ at each setting. The measured $\dot{Q}$ was typically within 10 percent of the expected heat release rate based on the natural gas mass flow rate. 
The calorimetry measurement response time was on the order of $15 \mathrm{~s}$ (Bryant et al. 2003). The volume of the test compartment also affected the time response of the measurement, as filling and mixing caused time-averaging and a lag in the calorimetry results relative to the other measurements.

\subsection{RESULTS AND DISCUSSION}

Figure 5-1 shows the heat release rates as a function of time for Tests 1 through 6 . The fuel spray burner was shut after $120 \mathrm{~s}$ when jet fuel was present (Tests 3, 5, and 6); otherwise, it was shut after $600 \mathrm{~s}$. The results show that the heat release rate $(Q)$ obtained peak values that varied from nearly $11 \mathrm{MW}$ to $16 \mathrm{MW}$. The peak value of $\dot{Q}$ was obtained earlier in those tests when jet fuel was present (Tests 3, 5 , and 6). The noise or range of scatter in the data was on the order of $200 \mathrm{~kW}$ for all of the tests. The relative expanded uncertainty of the heat release measurement was estimated as 15 percent (see NIST NCSTAR 1-5C).

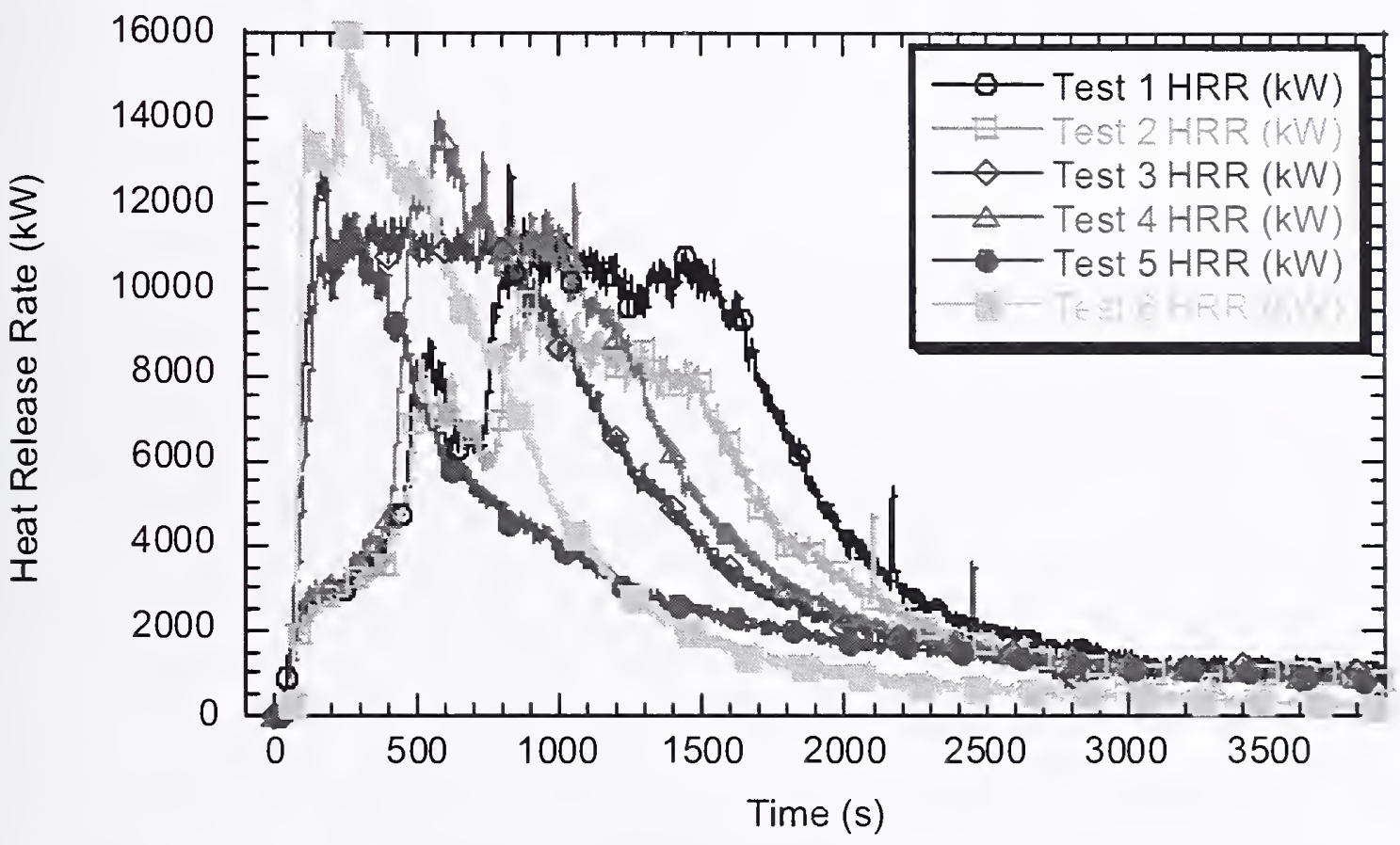

Figure 5-1. The heat release rate as a function of time for Tests 1 through 6.

The largest value of the heat release rate was almost $16 \mathrm{MW}$, which was measured in Test 6 . This test was configured with four glass window panels located to the left of the vents on the west wall of the enclosure. The lower left single-pane glass window cracked and fell out of the frame approximately $185 \mathrm{~s}$ after ignition, and the upper did the same about $212 \mathrm{~s}$ after ignition. Manzello (2005) discusses the window behavior during this test in detail. Breakage of the windows provided relatively higher amounts of ventilation than in the other tests and was probably responsible for the higher peak heat release rate observed during this test. The double-pane glass windows on the right never fell out.

The heat release rate measurements complemented the mass loss measurement results. The load cell data for all of the tests, presented in Chapter 4, show that the largest mass loss occurred simultaneously in all three workstations, during the fast burning period. The peak heat release rate also occurred during this 
period. Typical results are shown in Fig. 5-2, in which the mass loss and heat release rate $(\dot{Q})$ are plotted as a function of time during Test 1. Measurement during the single open workstation burns yielded peak values of $\dot{Q}$ equal to $8 \mathrm{MW}$ to $9 \mathrm{MW}$, depending on the test conditions (NIST

NCSTAR 1-5C), with the spray burner contributing $2 \mathrm{MW}$. The peak $\dot{Q}$ values for Tests 1 through 6 were small relative to what might be expected if each workstation simultaneously produced $8 \mathrm{MW}$ to $9 \mathrm{MW}$. Over-ventilated fires simultaneously involving all three workstations undergoing the fast burning period, should have yielded a total of $24 \mathrm{MW}$ to $27 \mathrm{MW}$. The relatively small value of the measured peak heat release rate seen in Fig. 5-1 as compared to this reference value suggests that the compartment fire was ventilation limited.

Table 5-2 lists the total heat release, which represents integration of the measured time dependent heat release rate from the time of ignition until 3,900 s in each of the six experiments. For most of the tests, the heat release rate was relatively small after 3,900 s. Table 5-2 shows that the average of the total heat release for the tests, excluding Test 5 , was $15.8 \mathrm{GJ}$ with a standard deviation of 13 percent. A portion of the total heat release was associated with items other than the workstations, including the heptane spray fire and the wall lining material. The contributions by the jet fuel and the ceiling tiles are also discussed.

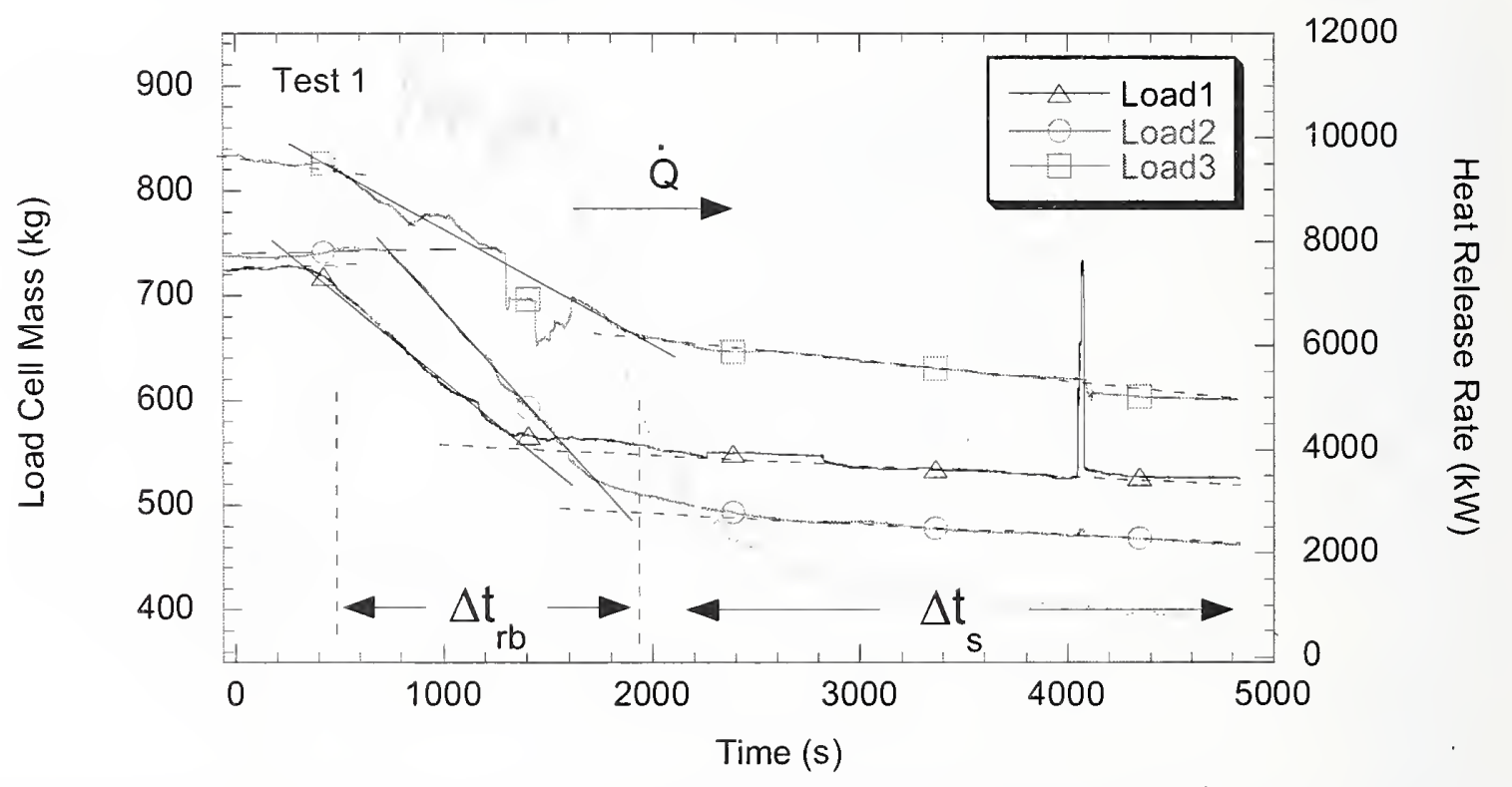

Figure 5-2. The load cell mass loss and the heat release rate $(\dot{Q})$ as a function of time during Test 1 . The rapid burning $\left(\Delta t_{r b}\right)$ and slow burning $\left(\Delta t_{s}\right)$ periods are indicated. 
Table 5-2. Total heat release.

\begin{tabular}{|c|c|c|c|}
\hline Test & $\begin{array}{c}\text { Total Heat Release } \\
\text { (G.J) }\end{array}$ & $\begin{array}{c}\text { Corrected for } \\
\text { Spray Fire (G.J) }\end{array}$ & $\begin{array}{c}\text { Corrected for Spray Fire, Jet } \\
\text { Fuel, Tiles \& Wall Lining (G.J) }\end{array}$ \\
\hline $\mathbf{1}$ & 16.5 & 15.3 & 11.7 \\
\hline $\mathbf{2}$ & 12.8 & 11.6 & 13.4 \\
\hline $\mathbf{3}$ & 14.6 & 14.3 & 12.7 \\
\hline $\mathbf{4}$ & 14.0 & 12.8 & 12.7 \\
\hline $\mathbf{5}$ & 8.8 & 8.6 & 8.2 \\
\hline $\mathbf{6}$ & 11.3 & 11.1 & 10.8 \\
\hline Average (Tests 1-4, 6) & $13.8( \pm 14 \%)$ & $13.0( \pm 14 \%)$ & $12.3( \pm 8 \%)$ \\
\hline
\end{tabular}

a. Using the definition that the total energy is released between the time of ignition and the time when the HRR falls to $2 \mathrm{MW}$.

The heptane spray burner provided $2 \mathrm{MW}$ of power for varying amounts of time, depending on the test: $120 \mathrm{~s}$ in Tests 5 and 6, $150 \mathrm{~s}$ in Test 3, and $600 \mathrm{~s}$ in Tests 1, 2, and 4, yielding 0.24 GJ, 0.30 GJ, and 1.2 GJ of energy during the tests, respectively. Table 5-2 shows the value of the total heat release measurement after correction for the energy associated with the heptane spray fire.

During Tests 1 and 3, the compartment lining material may have contributed to the measured heat release rate. In Test 1, the three layers of the wall and ceiling lining material were exposed to heat for the first time. Before Test 3, the exposed layer of lining material was replaced because it was cracked and breaking. The lining material was composed of calcium silicate sheets, which contained 4 percent to 8 percent organic fibers that release energy upon heating. Lyon (2004) used a micro-calorimeter to measure the heat content of a sample of the lining material. Their measurements showed that under aerobic conditions the total heat release for a virgin calcium silicate sample was $0.68 \mathrm{~kJ} / \mathrm{g} \pm 5$ percent. Walters and Lyons also measured a fire-exposed sample extracted from the compartment after Test 6, which was measured to have a value nearly equal to $0 \mathrm{~kJ} / \mathrm{g}$. The mass of calcium silicate for each layer in the compartment was estimated as $1,750 \mathrm{~kg}$, which had the potential to yield $1.2 \mathrm{GJ}$ of energy. The hypothesis that the lining material contributed to the heat release rate was supported by the video record made during the tests, which clearly showed that during Test 1 the walls glowed red hot. This type of visible evidence was not present in the video record for Test 2 , in which the organic fiber content of the lining materials presumably would have been reduced due to previous fire exposure. This hypothesis may explain the difference in the heat release rate (and its integrated value) between Tests 1 and 2 as noted in Fig. 5-1 and Table 5-2. If all of the calcium silicate lining material underwent pyrolysis over a $20 \mathrm{~min}$ $(1,200 \mathrm{~s})$ period (during the fast burning period, for example), then the lining material would have been responsible for $3 \mathrm{MW}$ of the measured heat release rate observed during that period and $3.6 \mathrm{GJ}$ of energy over the duration of the test.

During Tests 3 through 5, 138 ceiling tiles (per test) were distributed throughout the workstations and the carpeted hallway. In addition to the wall lining material discussed above, Lyon (2004) measured the heat content of a ceiling tile sample using the micro-calorimeter. Their measurements showed that under aerobic conditions, the total heat release for an unexposed ceiling tile sample was $1.07 \mathrm{~kJ} / \mathrm{g} \pm 5$ percent. Each tile weighed $0.51 \mathrm{~kg}$, indicating that approximately $0.13 \mathrm{GJ}$ of potential energy was associated with the tiles. 
The contribution of the jet fuel spilled before Tests 4 through 6 was a negligible contribution to the total heat release. The heat of combustion of the jet fuel was $42.6 \mathrm{~kJ} / \mathrm{g}$ (Hamins et al. 2003), so the $13 \mathrm{~L}$ ( $10 \mathrm{~kg}$ ) of jet fuel would be expected to contribute $430 \mathrm{MJ}$ to the fires. If the jet fuel burned in a steady manner for about $1 \mathrm{~min}$, then the heat release rate associated with jet fuel in all three workstations would be expected to be about $7 \mathrm{MW}$. This number is consistent with the measurements shown in Fig. 5-1, in which the initial heat release rate is on the order of $10 \mathrm{MW}$ for the tests with the dispersed jet fuel. Approximately $2 \mathrm{MW}$ of the heat release rate for early times in Tests 3, 5, and 6, as shown in Fig. 5-1, can be attributed to the spray burner.

Tests 1 and 3 had the largest total heat release values (from Fig. 5-1) as seen in Table 5-2. In Test 5, the total heat release was 11.6 GJ or approximately 73 percent of the mean of the other tests. Although the mass of combustibles in Test 5 was the same as the other tests, the configuration in Test 5 was arranged such that the combustibles were shielded from the fire to simulate "rubble." The results in Table 5-2 complement the mass loss data shown in Table 4-2. It was not surprising, therefore, that the total heat release was significantly lower in Test 5 than in the other tests.

As mentioned above, the total heat release was impacted by the heptane spray fire and to a lesser extent by the presence of the jet fuel, the wall lining material, and the ceiling tiles, depending on the test conditions. Table 5-2 lists corrected values for the total heat release, in which the energy associated with the spray burner has been subtracted. In a separate column, the total heat release has been corrected for the energy associated with the spray burner, the jet fuel, the ceiling tiles and the lining material. The correction for the lining material assumes that all previously unexposed lining material completely pyrolyzed, contributing energy to the fire. Table 5-2 shows that the average value of the total heat release for Tests 1 through 4 and 6 decreased from $15.8 \mathrm{GJ}$ to $13.8 \mathrm{GJ}$ once the corrections were applied. In principle, the corrected value represents the measured heat release from the furnishings only, for all of the tests. This notion is supported by the fact that, after the corrections were applied, the standard deviation among the tests reduced from 13 percent to 8 percent and the total heat release measured in Tests 1 and 2 were nearly equal.

The total heat release and the mass loss measured during the single open workstation burns yielded approximately $3.9 \mathrm{GJ}$ and $200 \mathrm{~kg}$ on-average, respectively, which varied somewhat depending on the test conditions (NIST NCSTAR 1-5C). For the three workstations burning in the experiments reported here, the measured total heat release and mass loss per workstation were equal to $4.6 \mathrm{GJ}$ and $227 \mathrm{~kg}$, respectively, as derived from Tables 5-2 and 4-2. These somewhat larger values are consistent with the idea that radiation from a well-developed hot upper layer and the walls of the compartment radiated onto the fuel, leading to faster burning and more complete combustion.

\subsection{REFERENCES}

Bryant, R., Ohlemiller, T., Johnsson, E., Hamins, A., Grove, B., Guthrie, W. F., Maranghides, A., and Mulholland, G. 2003. The NIST 3 Megawatt Quantitative Heat Release Rate Facility-Procedures and Guidance, NIST Special Report 1007, National Institute of Standards and Technology, Gaithersburg, MD, December.

Galbraith Labs. 2003. Report of Test Results. Knoxville, TN, March. 
Hamins, A., Maranghides, A., and Mulholland, G. .2003. The Global Combustion Behravior of $1 \mathrm{MW}$ to 3 MW Hydrocarbon Spray Fires Burning in an Open Environment, NISTIR 7013, National Institute of Standards and Technology, Gaithcrsburg, MD, June.

Huggett, C. 1980. Estimation of the Rate of Heat Release by Means of Oxygen Consumption, Journal of Fire and Materials, 12, 61-65.

Janssens, M., Parker, W. J. .1995. "Oxygen Consumption Calorimetry," in Heat Release in Fires, (Babrauskas, V., Grayson, S. J., Eds., E \& FN Spon), pp. 31-59, London, UK.

Manzello, S. L., Gann, R. G., Kukuck, S. R., Prasad, K. R., and Jones, W. W. 2005. Fire Performance of a Non-Load Bearing Glass Wall Assembly, to be submitted to Fire and Materials.

Parker, W. J. 1982. Calculations of the Heat Release Rate by Oxygen Consumption for Various Applications, NBSIR 81-2427, National Bureau of Standards.

Lyon, R. E. 2004. Report of Micro-Calorimeter Tests, Federal Aviation Administration, William J. Hughes Technical Center, NJ.

Walters, R. N., and Lyon, R. E. 1997. Proc. 42 ${ }^{\text {nd }}$ Int. SAMPE Symposium and Exhibition, 42(2), $1335-1344$. 
This page intentionally left blank. 


\section{Chapter 6 \\ GAS TEMPERATURE}

\subsection{INSTRUMENTATION}

Thermocouple trees were constructed by National Institute of Standards and Technology (NIST) personnel and located at four locations inside the compartment. Appendix A lists the coordinate locations of each of the thermocouples. Thermocouples were placed at four positions, namely, $2.5 \mathrm{~cm}, 91 \mathrm{~cm}$, $83 \mathrm{~cm}$ and $274 \mathrm{~cm}$ below the ceiling. The thermocouple beads were located on individual horizontal "branches" approximately $6 \mathrm{~cm}$ from the vertical tree support. Each tree was suspended from the ceiling and attached to the floor with a screw to provide tension for maintaining vertical alignment. During Tests 1 and 2, a number of aspirated thermocouples were positioned near Tree 4 to assess the effect of radiative exchange on the bare bead thermocouple measurements. For these tests (Tests 1 and 2), thermocouples were placed on Tree 4 near the aspirated probes, $213 \mathrm{~cm}$ and $305 \mathrm{~cm}$ below the ceiling.

The intense temperatures encountered during the test series, as well as mechanical damage during compartment preparation, occasionally caused a thermocouple to fail. After each test, the thermocouple extensions were visually inspected and were observed to be undamaged. Applying heat to the thermocouple junctions while monitoring the data acquisition system output assured proper function of the thermocouples. This insured that thermocouples were functioning, located properly, wired correctly and located on the proper channel of the data acquisition file. Thermocouples that did not function properly were replaced.

Thermocouples used in Test 1 employed high-temperature glass fiber insulation rated to $704{ }^{\circ} \mathrm{C}$. Except for the thermocouple junction and minimal thermocouple insulation, thermocouples within the compartment were wrapped with mineral wool insulation with embedded, single pass water-cooling lines. Temperatures at all four thermocouple trees during Test 1 exceeded $700{ }^{\circ} \mathrm{C}$, and the exposed portions of the thermocouples showed severe thermal damage. As a result, for Tests 2 through 6 , thermocouples insulated with ceramic insulation (Nextel) were installed along the outside of the existing thermocouple trees. In all tests, the thermocouple conductors were type K, 24 gage chromel and alumel junctions of "special limits of error" (SLE) wire. Chromel is an alloy of primarily nickel and chromium, whereas alumel is comprised primarily of nickel, aluminum, manganese and silicon.

Two aspirated thermocouples were installed adjacent to two tree thermocouples during Tests 1 and 2. The aspirated thermocouples were useful for assessment of the thermocouple measurement error due to radiative exchange. Aspirated thermocouples are constructed such that the thermocouple junction is within two concentric steel tubes. Air was drawn through the tubes to engulf the sensing junction with sample gas. Concurrently, the concentric tubes protected the thermocouple sensing junction from impinging thermal radiation providing a "true" gas temperature. Further details can be found in Blevins (1999) and Blevins and Pitts (1999). 


\subsection{UNCERTAINTY}

Several sources of error must be considered in order to understand the behavior of a thermocouple signal and to estimate the thermocouple measurement accuracy. Thermocouple measurement errors can be due to breakdown of the thermocouple insulation at high temperatures, decalibration at high temperatures, inherent measurement accuracy limited by materials effects, and error due to radiative exchange.

High temperatures decrease the resistance of insulation materials. A shunt can occur when the electrical resistance of the insulation approaches that of the thermocouple circuit. Shunt impedance can occur, especially in environments where long, small conductor thermocouples are installed within extreme temperature environments (Omega 2004). The resulting shunt completes the thermocouple circuit at a point other than the thermocouple junction, resulting in erroneous temperature measurements.

A number of reports list decalibration as a source of thermocouple measurement error due to high temperature oxidizing conditions (Burns et al. 1993; Omega 2004). At elevated temperatures, the crystal lattice of the conductors can undergo physical change. These uncertainty changes facilitate permeation of chemical species from the air into the conductors ultimately changing the chemical composition of the conductors. The end result is a deviation from the reference function used to convert the voltage to temperature. Multiple manufacturers report techniques and equipment that can be employed to eliminate, or at a minimum quantify, the decalibration. An alternative technique to address this issue is frequent replacement of the thermocouples, which was employed during this test series.

The manufacturer reported accuracy for thermocouples employing SLE wire is $1.1{ }^{\circ} \mathrm{C}$ for temperatures between $0{ }^{\circ} \mathrm{C}$ and $293{ }^{\circ} \mathrm{C}$. and 0.4 percent between $293{ }^{\circ} \mathrm{C}$ and $1,250^{\circ} \mathrm{C}$. Type $\mathrm{K}$ thermocouples are capable of measuring temperatures as high as $1,350^{\circ} \mathrm{C}$ for brief periods of time, although this may lead to changes in the thermocouple calibration (Burns et al. 1993). These uncertainty values are interpreted as the 95 percent confidence interval or an expansion factor of two for expression of the uncertainty. At temperatures greater than $870^{\circ} \mathrm{C}$, the rating of the thermocouple conductors is exceeded, but the thermocouples are still capable of measuring temperature albeit subject to more rapid deterioration. Given that the exposures to these temperatures were brief, the uncertainty specifications were multiplied by a factor of two at temperatures greater than $870{ }^{\circ} \mathrm{C}$ as a conservative estimate of accuracy degradation. In this study, data from thermocouples that experienced temperatures above $1,350{ }^{\circ} \mathrm{C}$ were considered inaccurate and are not reported. The standard uncertainty values are listed in Table $6-1$ as $\mu_{w}$.

Table 6-1. Component and expanded temperature measurement uncertainty.

\begin{tabular}{|c|c|c|c|c|c|}
\hline $\begin{array}{c}\text { Temperature } \\
\left({ }^{\circ} \mathbf{C}\right)\end{array}$ & $\begin{array}{c}\boldsymbol{\mu}_{\mathbf{w}} \\
\left({ }^{\circ} \mathbf{C}\right)\end{array}$ & $\begin{array}{c}\boldsymbol{\mu}_{\mathbf{r}} \\
\left({ }^{\circ} \mathbf{C}\right)\end{array}$ & $\begin{array}{c}\boldsymbol{\mu}_{\mathrm{a}} \\
\left({ }^{\circ} \mathbf{C}\right)\end{array}$ & $\begin{array}{c}\text { Combined } \\
\text { Uncertainty } \boldsymbol{\mu}_{\mathrm{c}} \\
\left({ }^{\circ} \mathbf{C}\right)\end{array}$ & $\begin{array}{c}\text { Expanded } \\
\text { Uncertainty }\left({ }^{\circ} \mathbf{C}\right) \\
(\mathbf{k}=\mathbf{2})\end{array}$ \\
\hline 0 & 1.1 & 5.6 & 0 & 6 & 11 \\
\hline 120 & 1.1 & 5.6 & 1 & 6 & 12 \\
\hline 150 & 1.1 & 30 & 1 & 30 & 60 \\
\hline 870 & 1.8 & 30 & 5 & 30 & 61 \\
\hline 900 & 3.6 & 61 & 5 & 61 & 122 \\
\hline 1,350 & 5.4 & 61 & 7 & 61 & 122 \\
\hline
\end{tabular}


Blevins (1999) reported on the development of a model to computc radiation effects on thcrmocouple error. Radiation exchangc between the thermocouplc and walls, flame gases, soot, and ambient environment being the predominant sources rcportcd. In the same document, report of soot accumulation on the thermocouple bcad or sensing junction and changing its thermo-physical propertics is also credited with contributing to error. Furthermore, variability in the convective heat transfer betwcen the sample gas and the thermo-junction is cited as a source of crror. To estimate the magnitude of the measurement crror due to radiative exchange, a number of thermocouple measurements were compared to measurements by nearby aspirated thermocouples. Figures 6-1 through 6-4 compare the aspirated thermocouples and adjacent bare bead type $\mathrm{K}$ thermocouples in Tests 1 and 2. Figure 6-1 shows that during Test 1 , the bare bead thermocouple $213 \mathrm{~cm}$ below the ceiling on Tree 4 recorded a sharp decrease in temperature starting $979 \mathrm{~s}$ after ignition, as comparcd to the aspirated thermocouple. The thermocouple appears to recover and match the aspirated thermocouple measurement during the period from $1,250 \mathrm{~s}$ to $1,350 \mathrm{~s}$. Other thermocouples on Tree 4 do not exhibit similar behavior to the bare bead thermocouple at 1,250 s. Figures 6-2 through 6-4 show that the other pairs of aspiratcd thermocouples and bare bead thermocouples experienced some amount of deviation from each other, but generally tracked each other to within $70^{\circ} \mathrm{C}$. This led to the conclusion that this thermocouple experienced some type of failure perhaps chromium oxidation in the positive leg of the thermocouple circuit or a failure of the insulation, at least for the $280 \mathrm{~s}$ of data following the $979 \mathrm{~s}$ mark. For this reason, that data were not used in subsequent analysis.

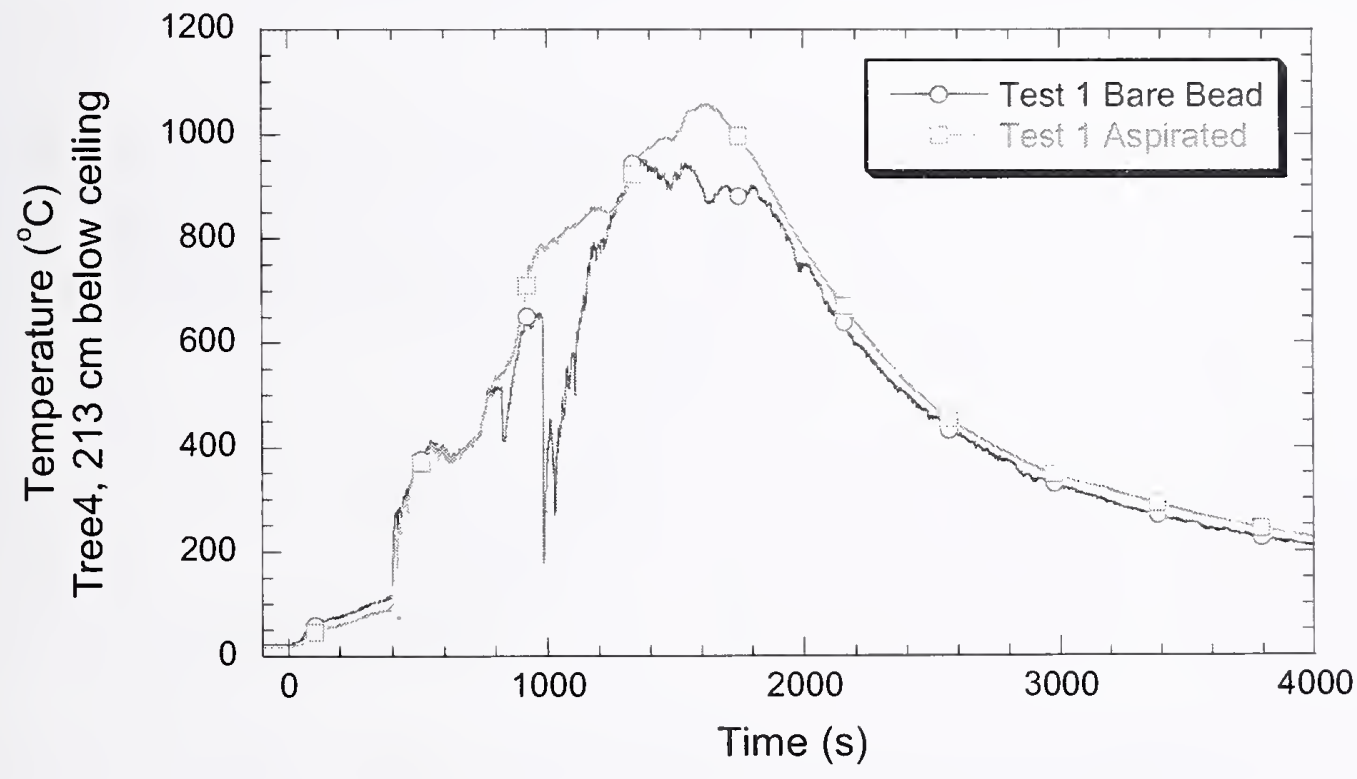

Figure 6-1. Comparison of bare bead and aspirated thermocouple measurements as a function of time at a location $213 \mathrm{~cm}$ below the ceiling on Tree 4 during Test 1. 


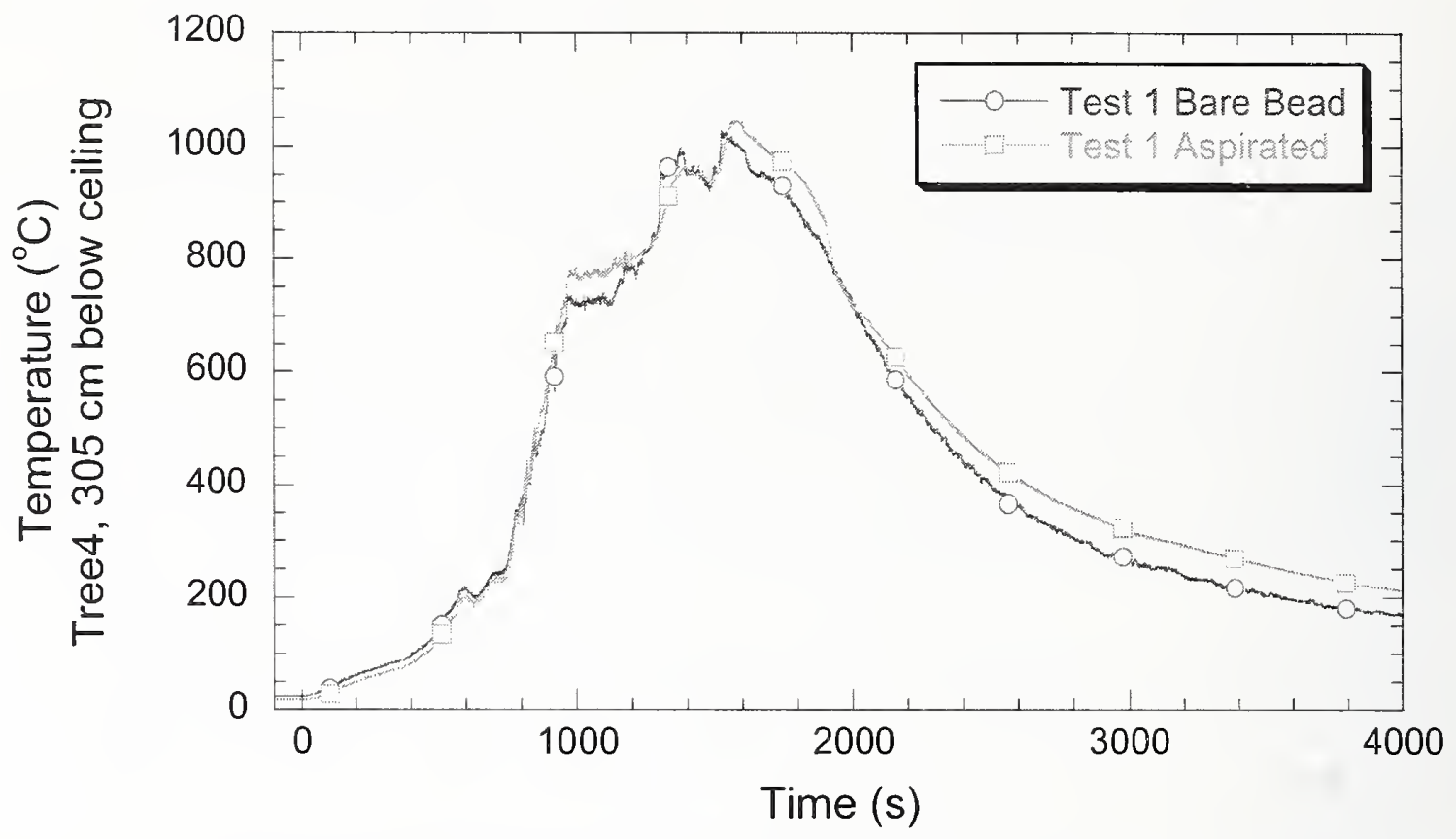

Figure 6-2. Comparison of bare bead and aspirated thermocouple measurements as a function of time at a location $305 \mathrm{~cm}$ below the ceiling on Tree 4 during Test 1.

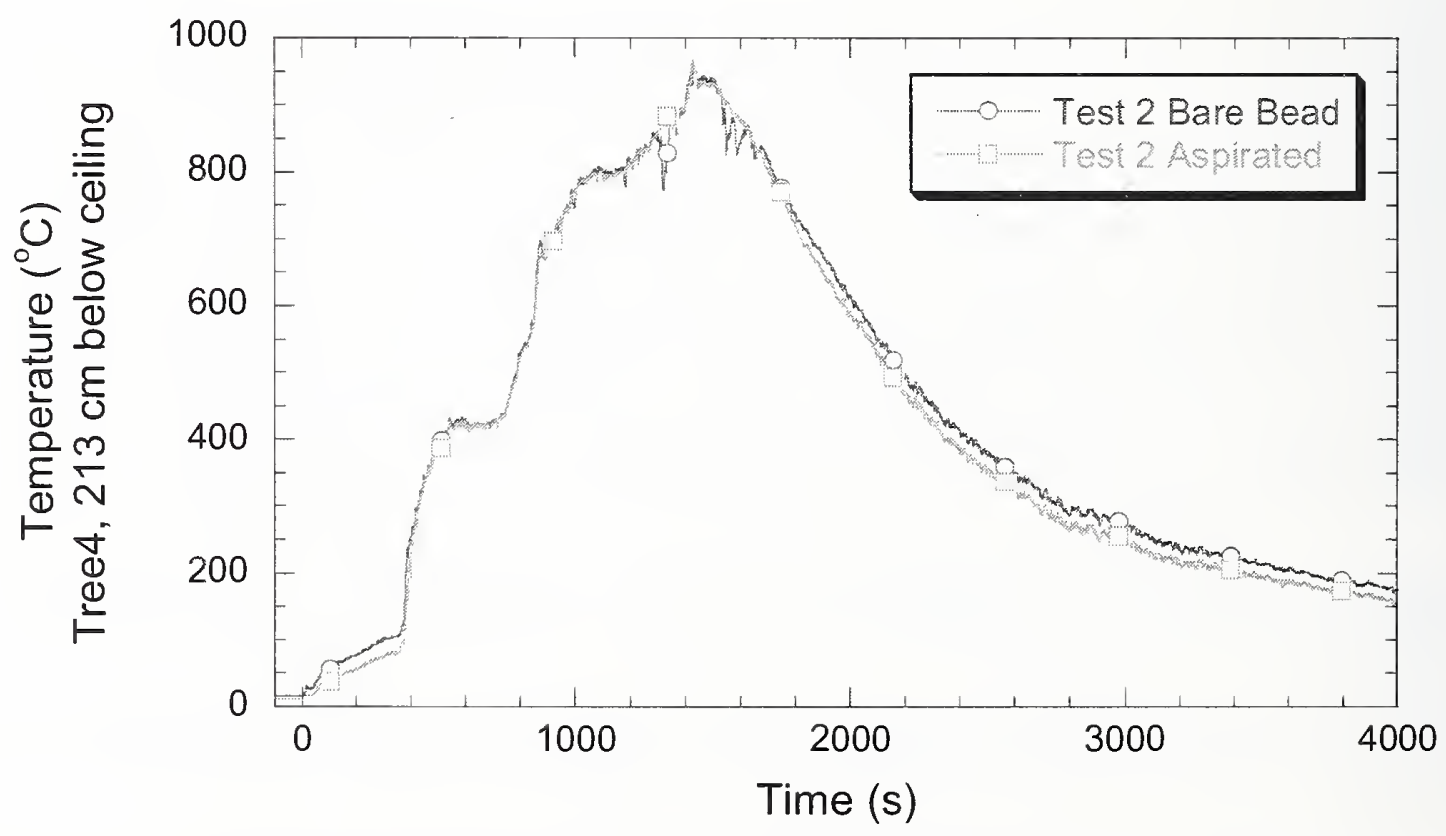

Figure 6-3. Comparison of bare bead and aspirated thermocouple measurements as a function of time at a location $213 \mathrm{~cm}$ below the ceiling on Tree 4 during Test 2. 


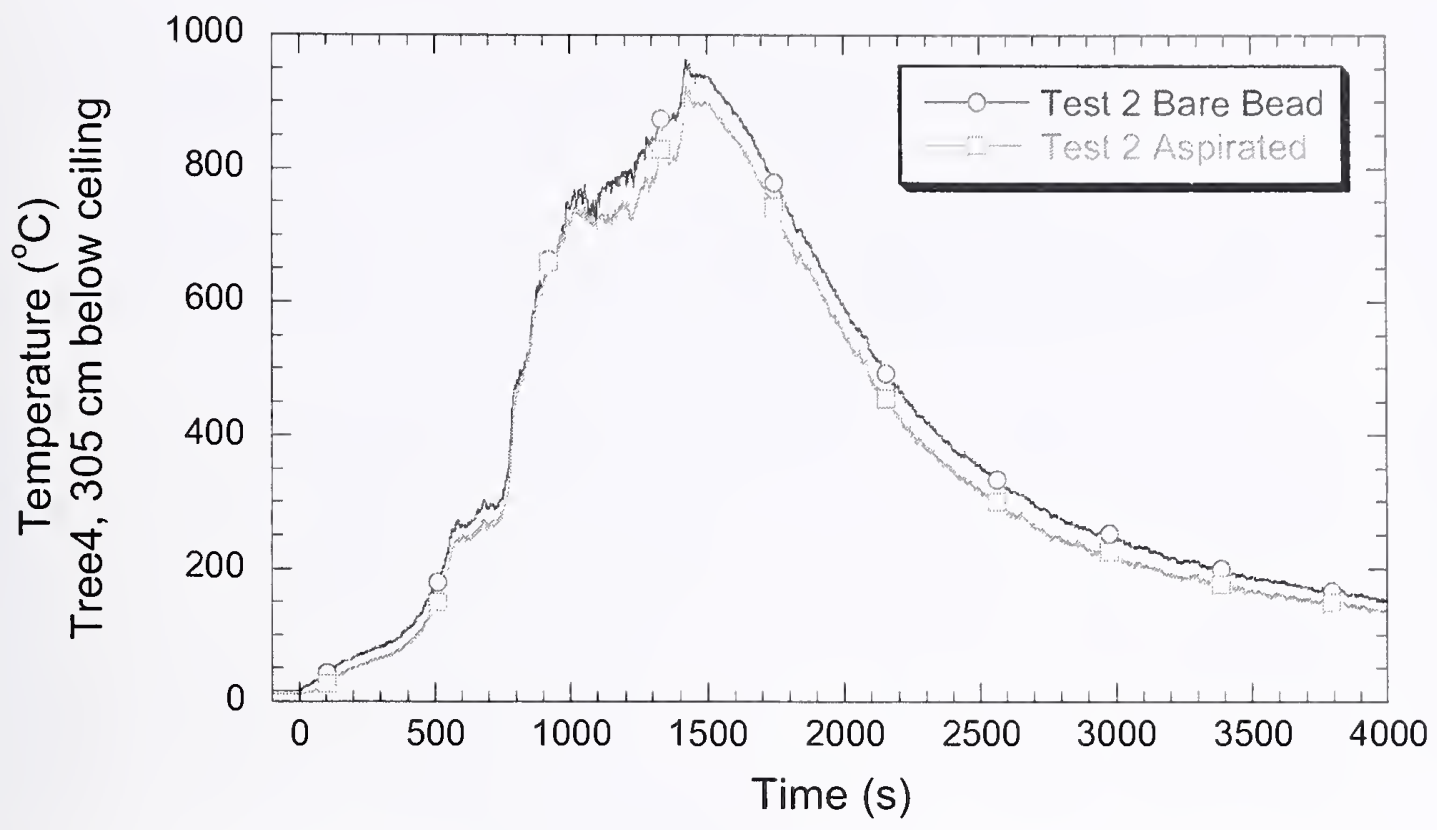

Figure 6-4. Comparison of bare bead and aspirated thermocouple measurements as a function of time at a location $305 \mathrm{~cm}$ below the ceiling on Tree 4 during Test 1.

To estimate the standard thermocouple error due to radiation, the temperatures recorded by the aspirated thermocouples were subtracted from the tcmperatures recorded by the adjacent bare bead thermocouples. The differences calculated for each of the two thermocouples for both Test 1 and Test 2 were combined and plotted as a function of the bare bead thermocouple reading and are shown in Fig. 6-5. The data spread was evaluated statistically in three distinct ranges to estimate the thermocouple radiation error. Below $130^{\circ} \mathrm{C}$, approximately 9,300 data points have an average value of $9{ }^{\circ} \mathrm{C}$ and a sample standard deviation of $6{ }^{\circ} \mathrm{C}$. Between $130^{\circ} \mathrm{C}$ and $870^{\circ} \mathrm{C}$, the ratcd maximum of the thermocouple conductors, over 15,000 data points average $-2{ }^{\circ} \mathrm{C}$ with a sample standard deviation of $30^{\circ} \mathrm{C}$. For temperatures greater than $870^{\circ} \mathrm{C}$, the computed average of roughly 1,600 data points equals $-26^{\circ} \mathrm{C}$ with a sample standard deviation of $60.6^{\circ} \mathrm{C}$. These results are used as approximations of the standard error due to radiation within the temperature ranges of interest and are reported in Table 6-1 below as $\mu_{\mathrm{r}}$. An additional uncertainty associated with the aspirated probe measurement itself is listed in the table as $\mu_{\mathrm{a}}$ with a value taken as approximately $7{ }^{\circ} \mathrm{C}$ at $1,350{ }^{\circ} \mathrm{C}$, which varied inversely with temperature (Blevins 1999).

Table 6-1 lists individual component uncertainties for the bare bead thermocouple measurement. The component uncertainties in Table 6-1 were added in quadrature to compute the combined uncertainty, $\mu_{c}$. The expanded uncertainty, equivalent to two standard deviations, is also listed in the table. The majority of the combined thermocouple measurement uncertainty is due to radiation. 


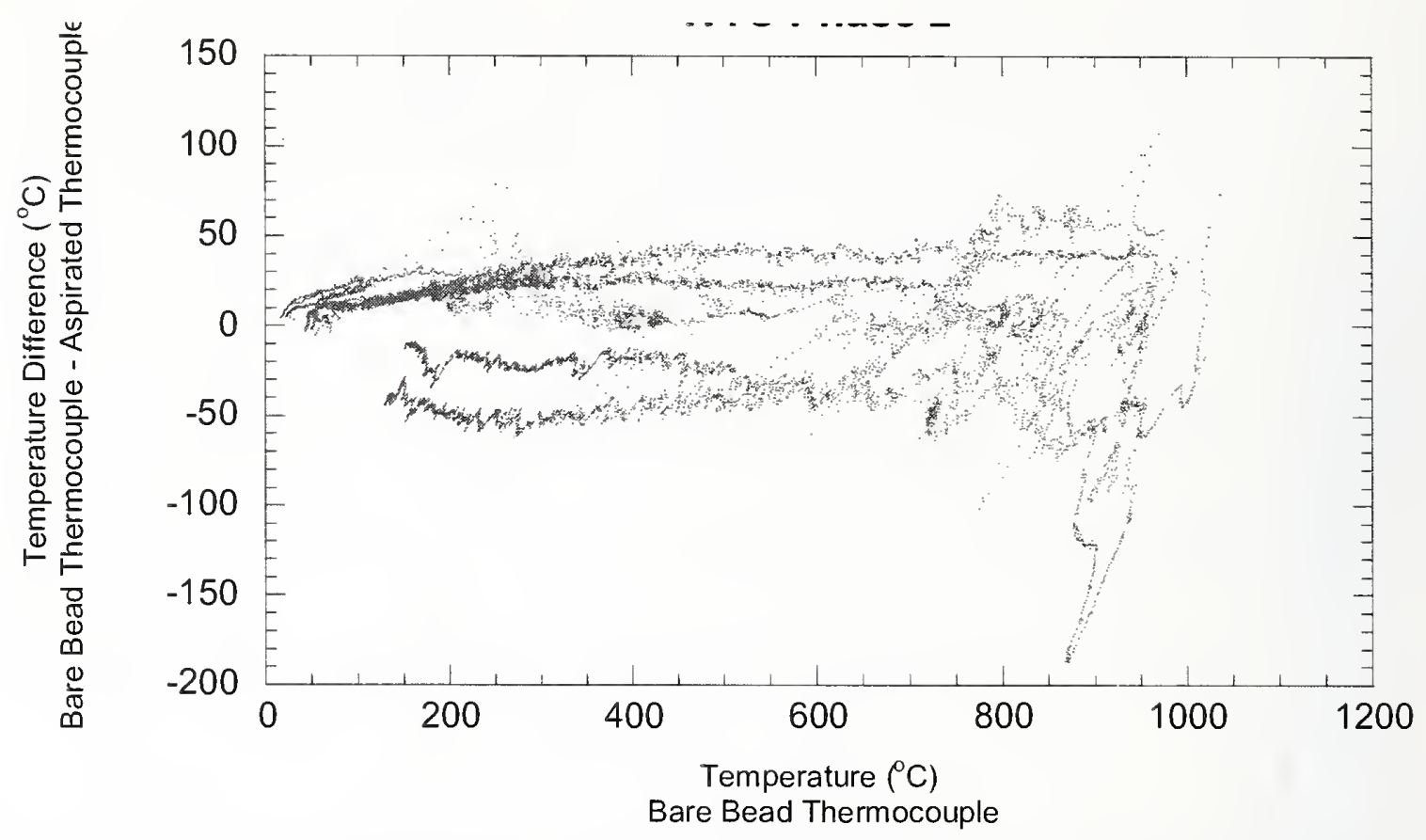

Figure 6-5. The difference between the bare bead and the aspirated thermocouple measurements as a function of the bare bead temperature for the data presented in Figs. $6-1$ through $6-4$.

\subsection{DISCUSSION AND RESULTS}

Figures 6-6 through 6-11 and Figs. 6-12 through 6-17 show the bare bead thermocouple measurements on Trees 1 and 4, respectively, during Tests 1 through 6 . Tree 1 was located in the middle of the front of the compartment at $(\mathrm{x}, \mathrm{y})=(285 \mathrm{~cm}, 351 \mathrm{~cm})$, in the passageway adjacent to Workstation 1, whereas Tree 4 was located at the rear of the compartment at $(x, y)=(969 \mathrm{~cm}, 575 \mathrm{~cm})$, almost $3 \mathrm{~m}$ from Workstation 3, which was the nearest workstation. Figure 2-2 provides a plan view of the compartment and the instrumentation, and Appendix A presents the coordinates of the thermocouple trees and other important instrumentation.

Figures 6-6 through 6-11 show that early in the tests, the highest temperatures were measured at locations closer to the ceiling. As time continued, the upper layer descended, and the readings of the lower thermocouples were not unlike the upper thermocouples. At early times in the tests, the temperatures increased at a faster rate when jet fuel was dispersed throughout the compartment (Tests 3, 5, and 6). At later times, this pattern broke down. A number of the thermocouples failed during the tests.

During Test 2 for example, the bare bead thermocouple $2.5 \mathrm{~cm}$ below the ceiling on Tree 1 recorded a sharp increase in temperature starting $1,000 \mathrm{~s}$ after ignition. The temperature reading exceeded $1,400{ }^{\circ} \mathrm{C}$, a sign of possible failure for a type $\mathrm{K}$ thermocouple. The temperatures recorded by the other thermocouples on Tree 4 during Test 1 show that the behavior was unique to the thermocouple located $2.5 \mathrm{~cm}$ from the ceiling. For this reason, the data following the 1,000 s mark are not plotted in the figure. Other failures occurred during the other tests, and the data are handled in a similar fashion. 
Test 2 was a repeat of Test 1. The peak temperatures measured in Test 1 were similar to those in Test 2. A comparison of Figs. 6-1 and 6-2 to Figs. 6-3 and 6-4 show that the peak aspirated thermoeouple temperatures at $213 \mathrm{em}$ and $303 \mathrm{em}$ from the eciling on Tree 4 were about $50{ }^{\circ} \mathrm{C}$ higher in Test 1 than Test 2. On the other hand, a eomparison of Figs. 6-6 and 6-7 show that the peak bare bead thermocouple measurements in Test 1 were $30^{\circ} \mathrm{C}$ to $100{ }^{\circ} \mathrm{C}$ lower than those in Test 2 at Tree 1 . With the measurement uncertainty of the bare bead thermocouples nearly $120^{\circ} \mathrm{C}$ (Table 6-1), these differences in the peak temperatures cannot be eonsidered significant.

Figures 6-8 through 6-11 show the bare bead thermoeouple measurements on Tree 1 during Tests 3 through 6 . The three thermocouples closest to the eeiling typically obtained peak temperatures over $1,000{ }^{\circ} \mathrm{C}$ to $1,100{ }^{\circ} \mathrm{C}$ exeept in Test 5 in which the peak temperatures were lower likely due to lower heat release rate obtained during that test. The temperature measurements in the rear of the eompartment were generally smaller as seen in Figs. 6-12 through 6-17, which represent bare bead thermocouple measurements on Tree 4 during Tests 1 through 6 . These results indicate that the compartment temperatures eloser to the windows obtained the largest peak temperatures, a result that was not unexpected. Appendix $\mathrm{C}$ contains plots of the thermocouple measurements on Trees 2 and 3 during Tests 1 through 6 .

The time dependent temperature data reported here will be useful for eomparison to that predieted by the Fire Dynamies Simulator and will be discussed in Chapter 8.

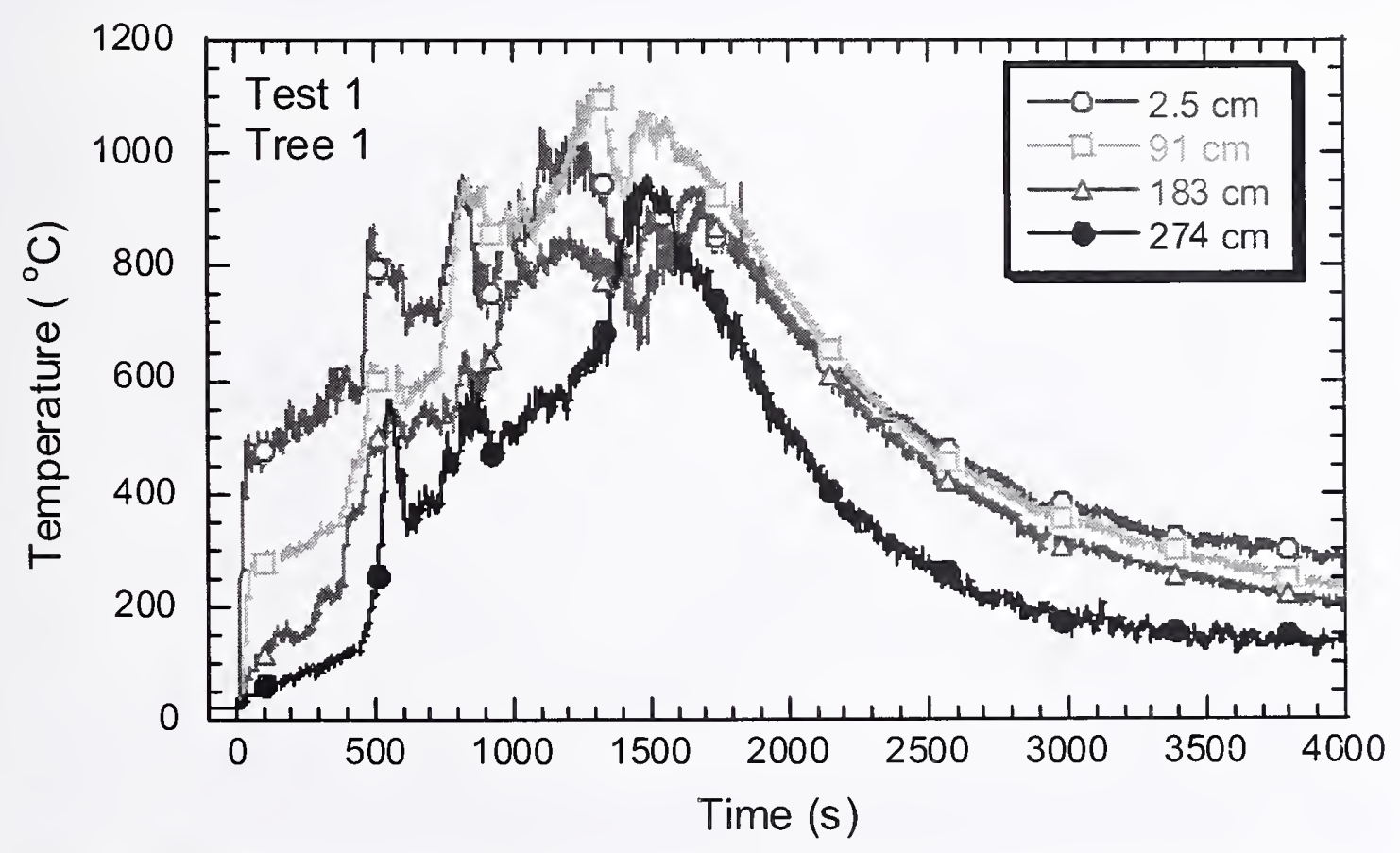

Figure 6-6. Bare bead thermocouple measurements as a function of time at four locations (below the ceiling) on Tree 1 during Test 1. 


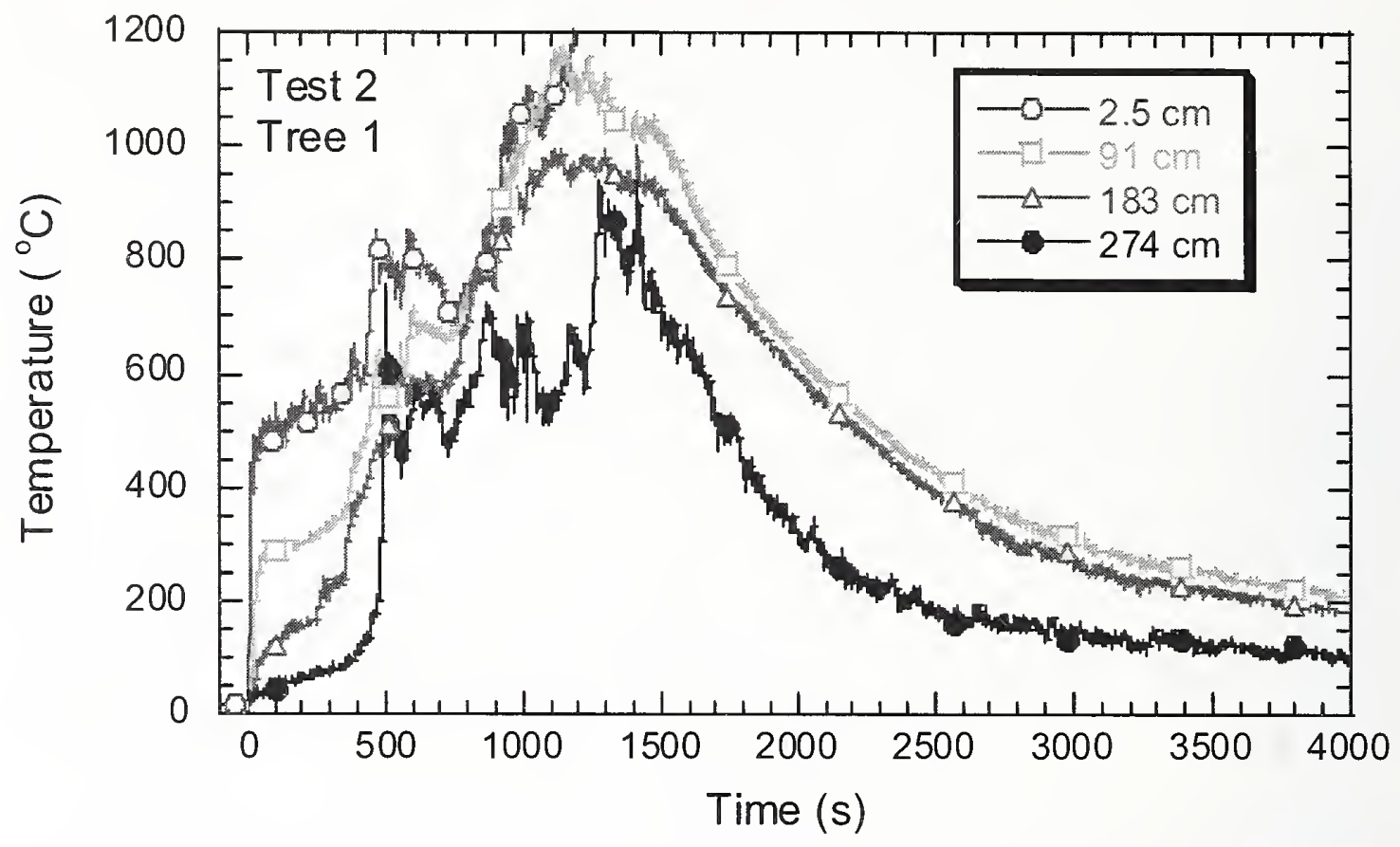

Figure 6-7. Bare bead thermocouple measurements as a function of time at four locations (below the ceiling) on Tree 1 during Test 2.

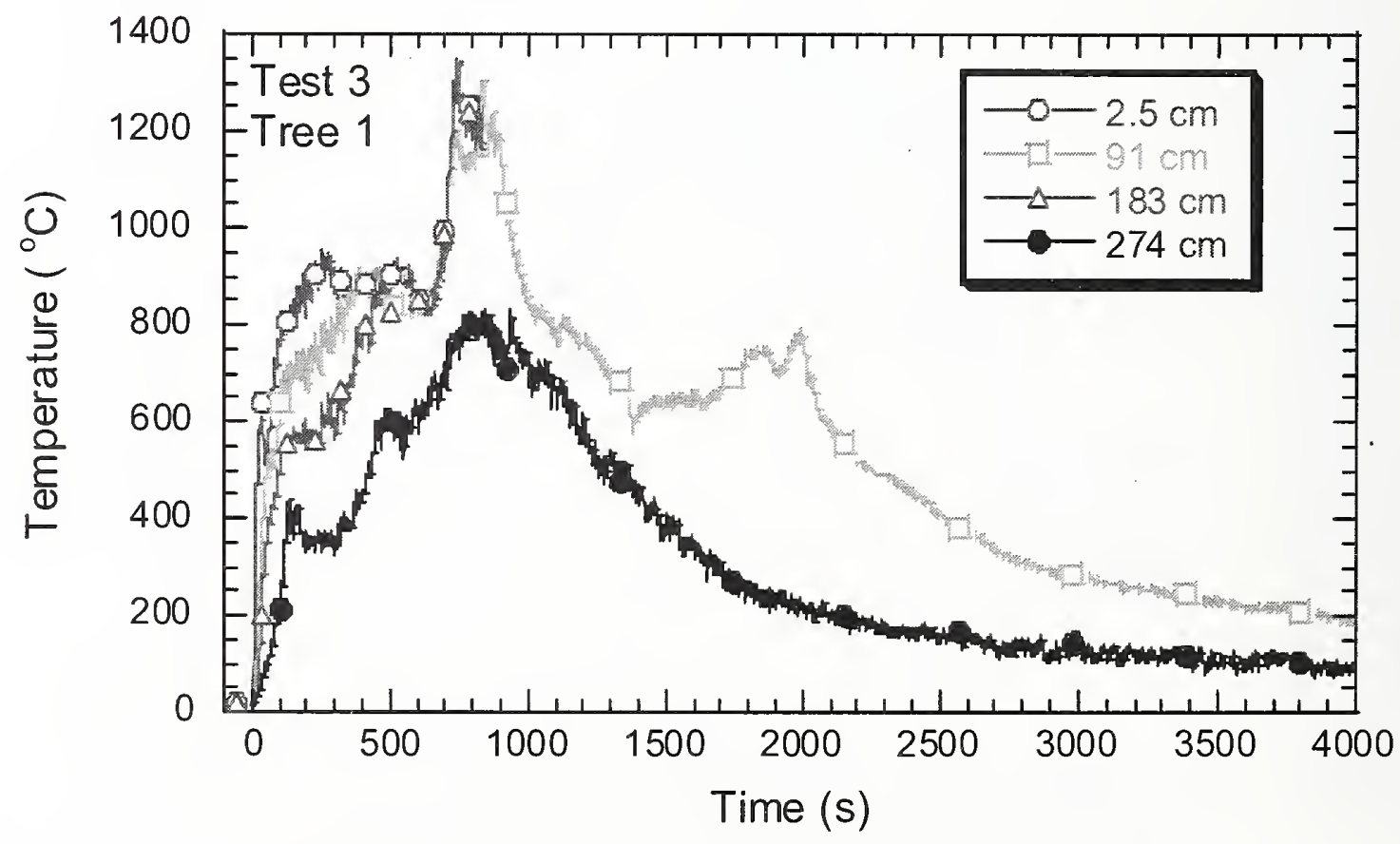

Figure 6-8. Bare bead thermocouple measurements as a function of time at four locations (below the ceiling) on Tree 1 during Test 3. 


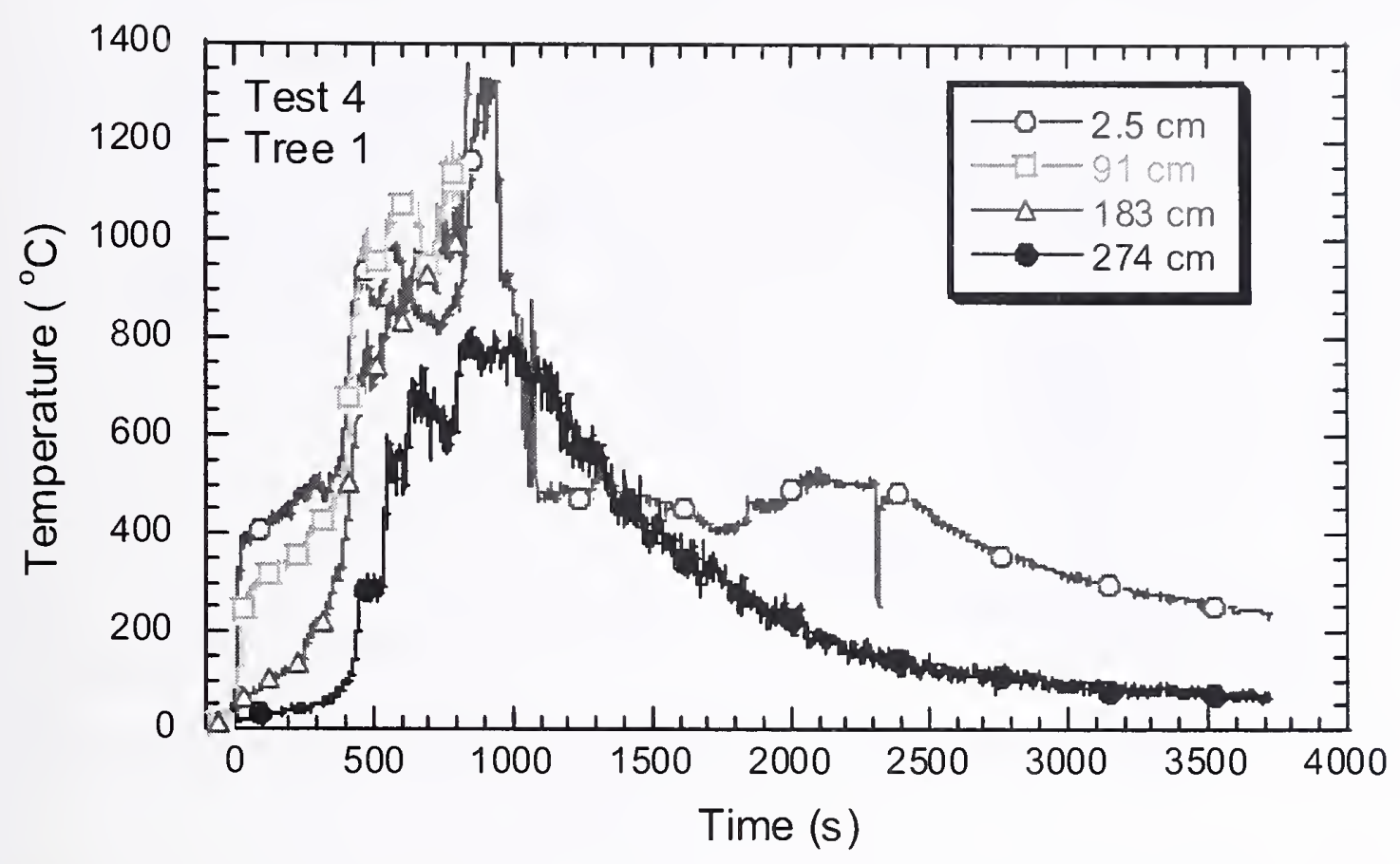

Figure 6-9. Bare bead thermocouple measurements as a function of time at four locations (below the ceiling) on Tree 1 during Test 4.

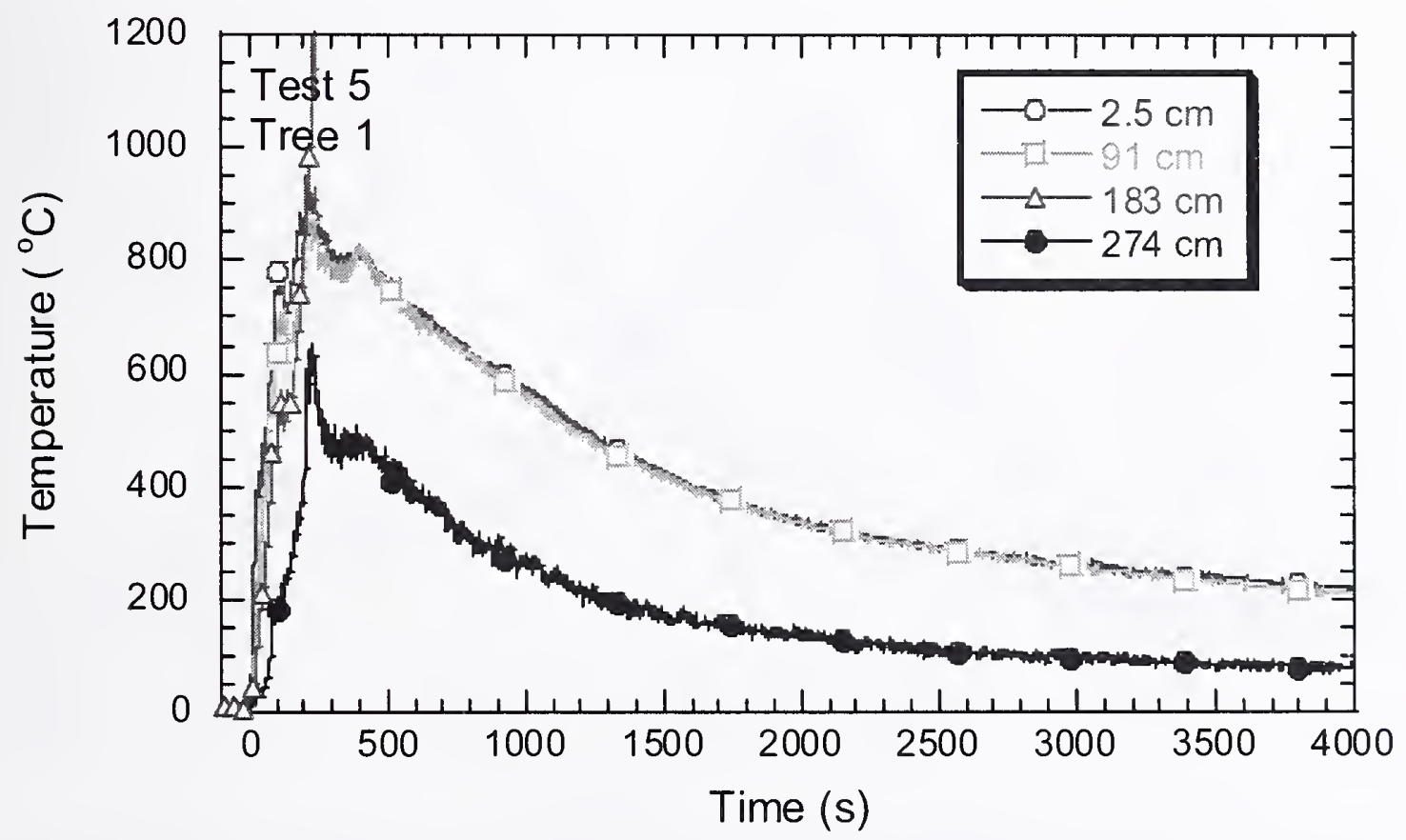

Figure 6-10. Bare bead thermocouple measurements as a function of time at four locations (below the ceiling) on Tree 1 during Test 5. 


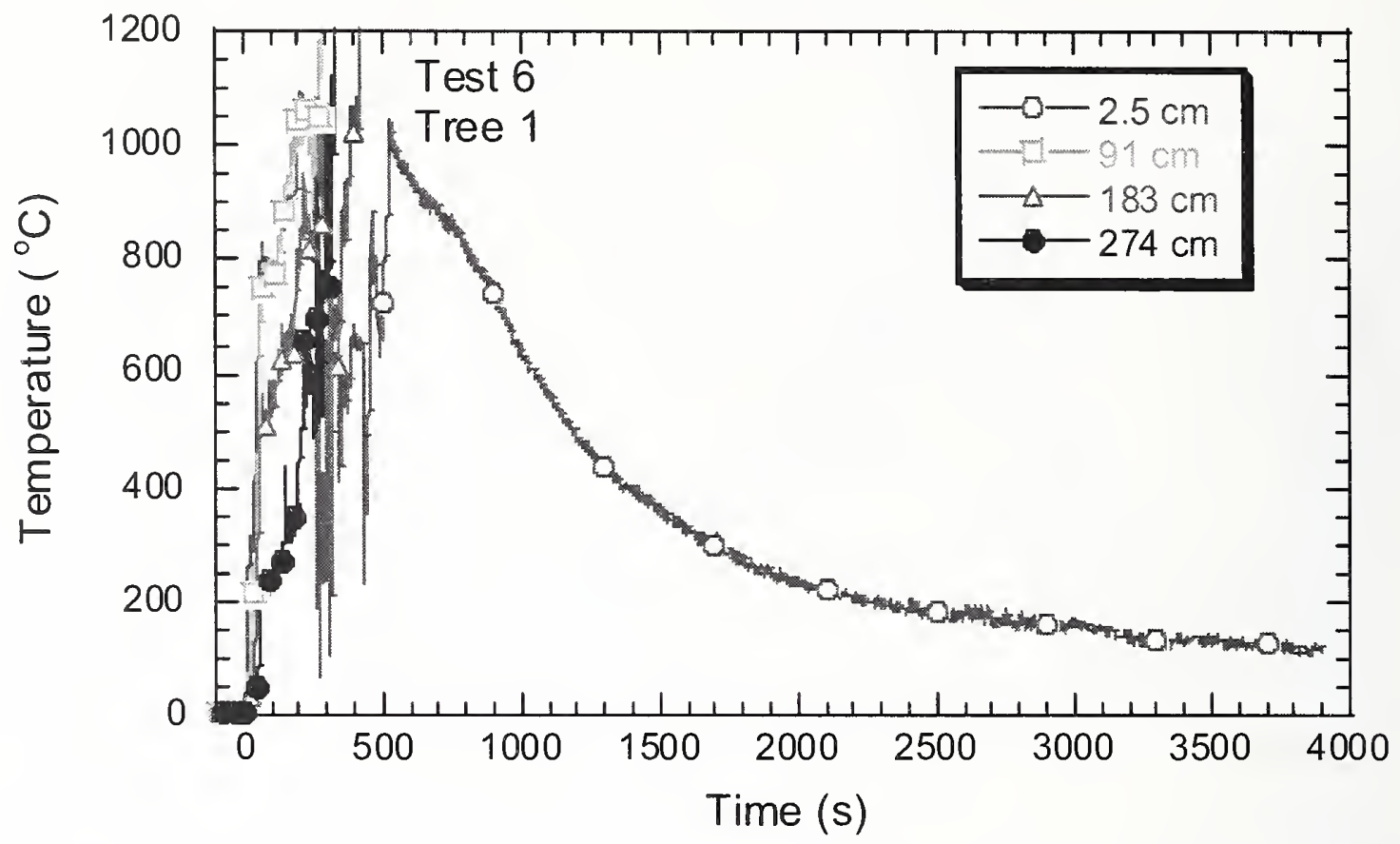

Figure 6-11. Bare bead thermocouple measurements as a function of time at four locations (below the ceiling) on Tree 1 during Test 6.

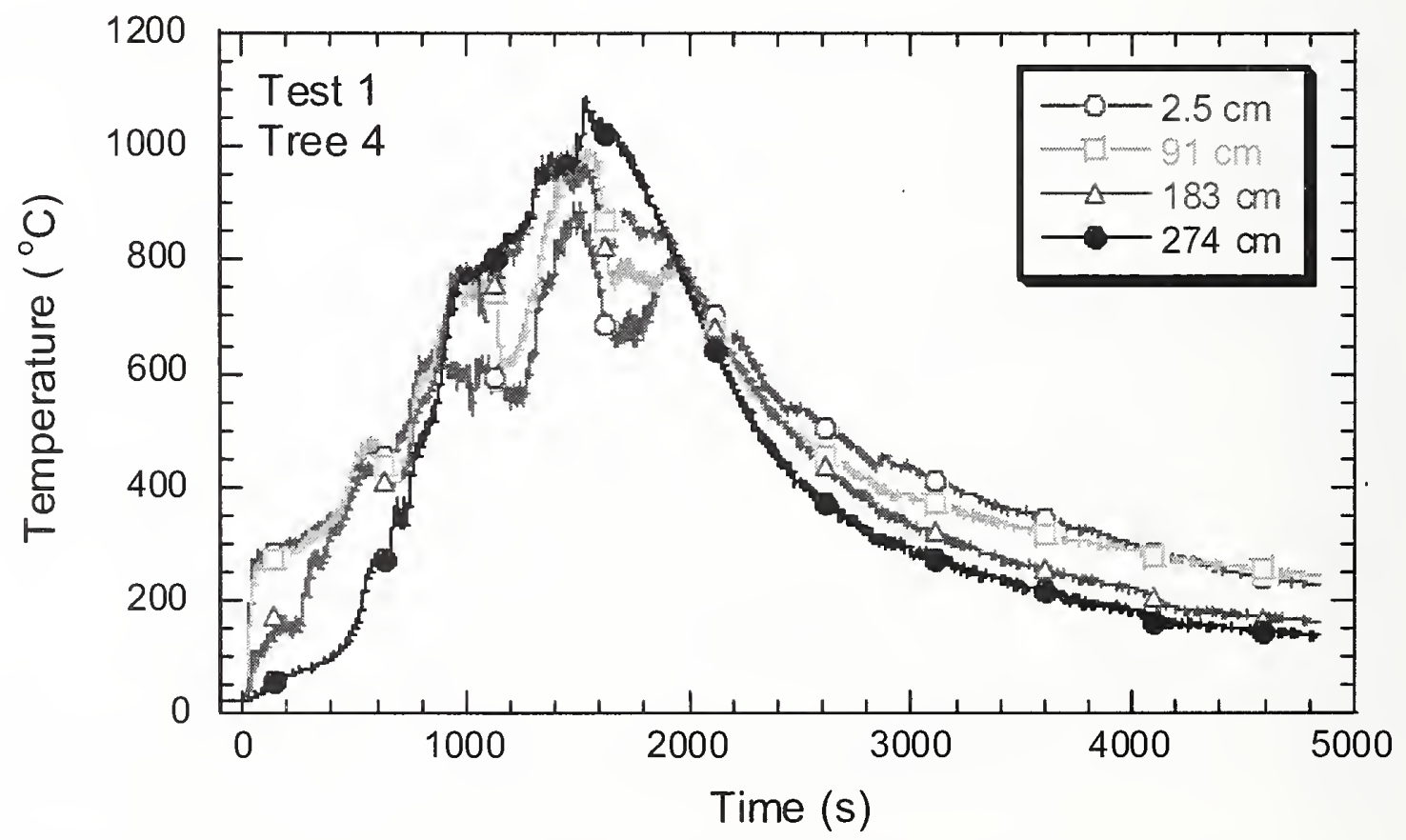

Figure 6-12. Bare bead thermocouple measurements as a function of time at four locations (below the ceiling) on Tree 4 during Test 1. 


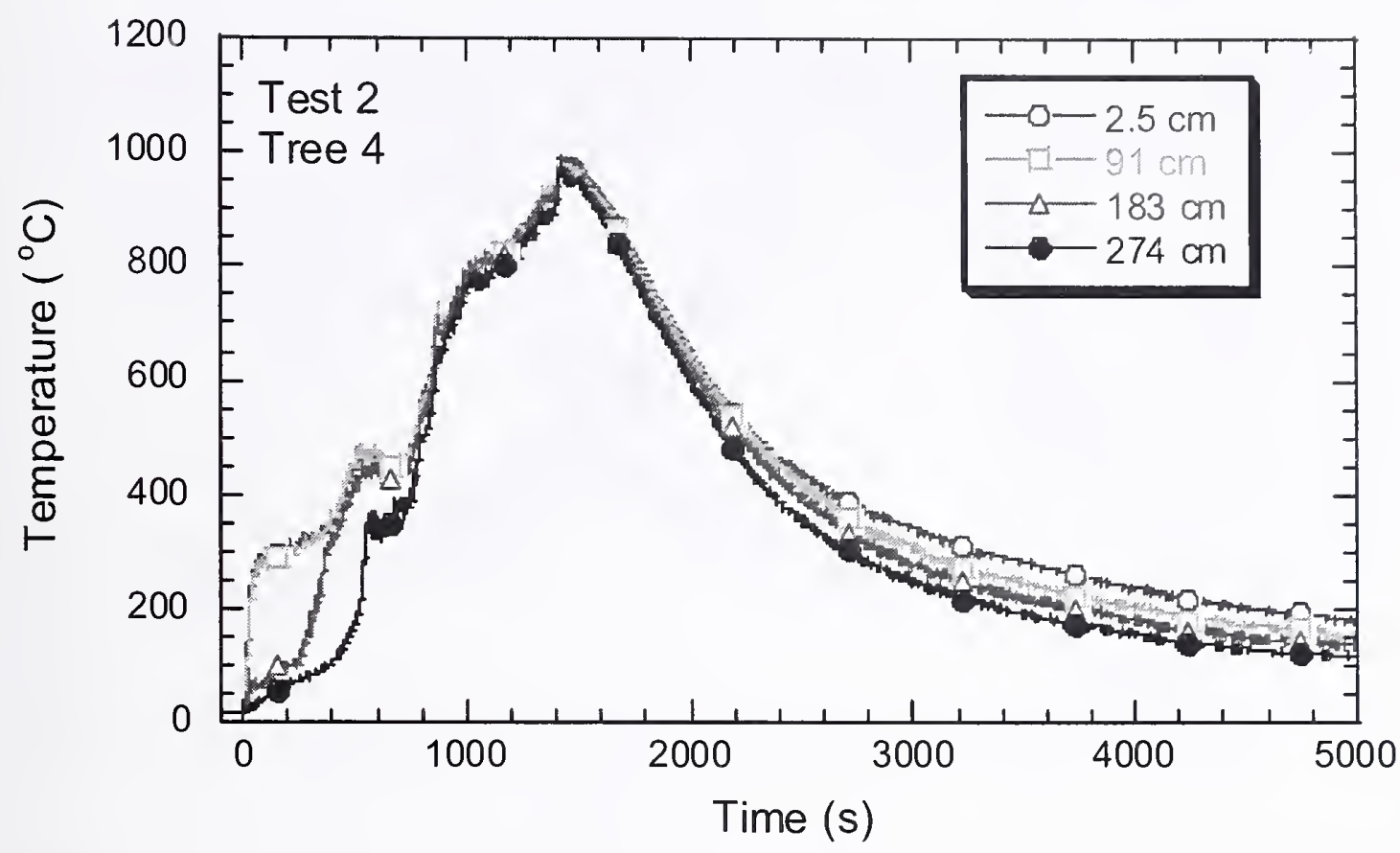

Figure 6-13. Bare bead thermocouple measurements as a function of time at four locations (below the ceiling) on Tree 4 during Test 1.

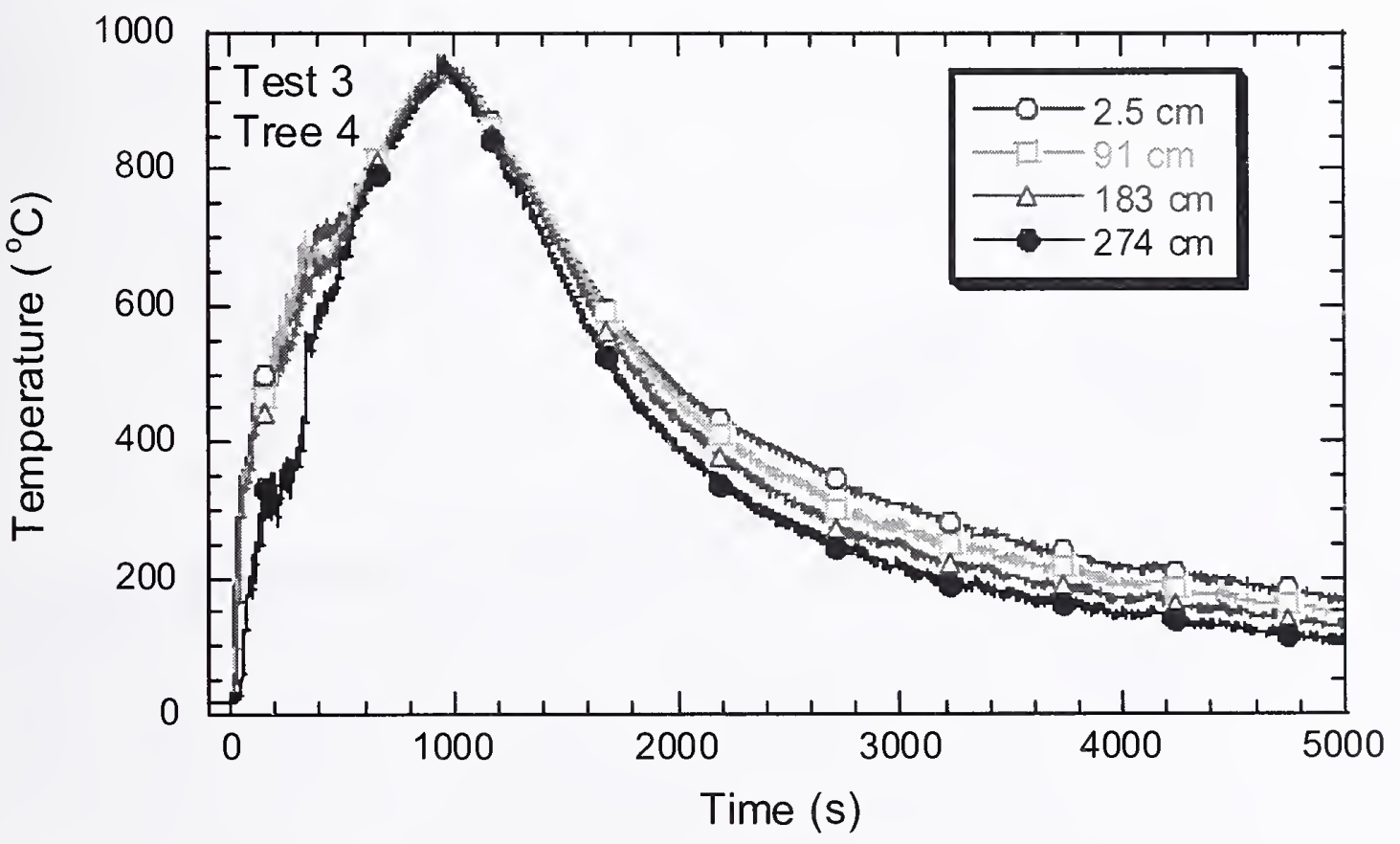

Figure 6-14. Bare bead thermocouple measurements as a function of time at four locations (below the ceiling) on Tree 4 during Test 3. 


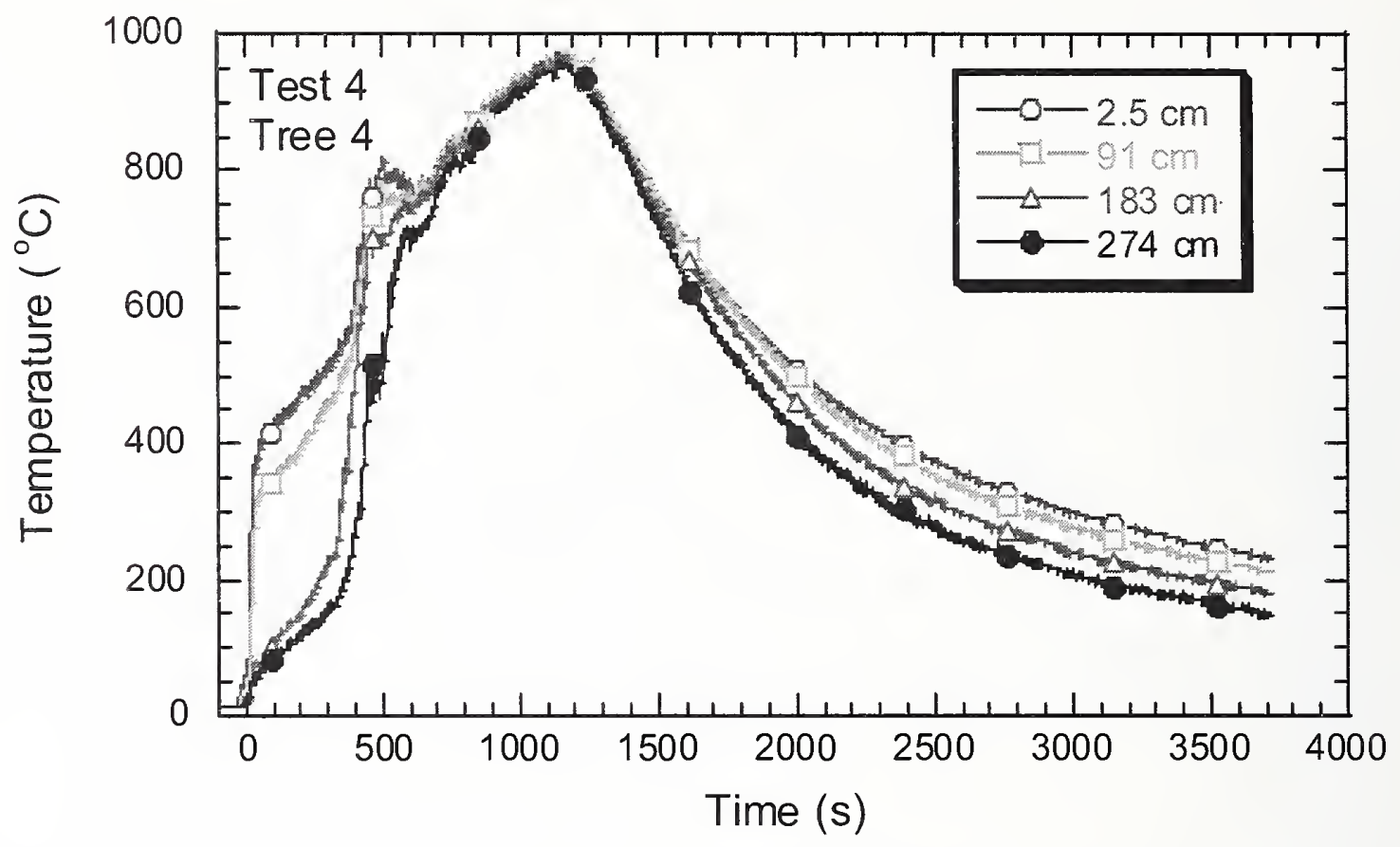

Figure 6-15. Bare bead thermocouple measurements as a function of time at four locations (below the ceiling) on Tree 4 during Test 4.

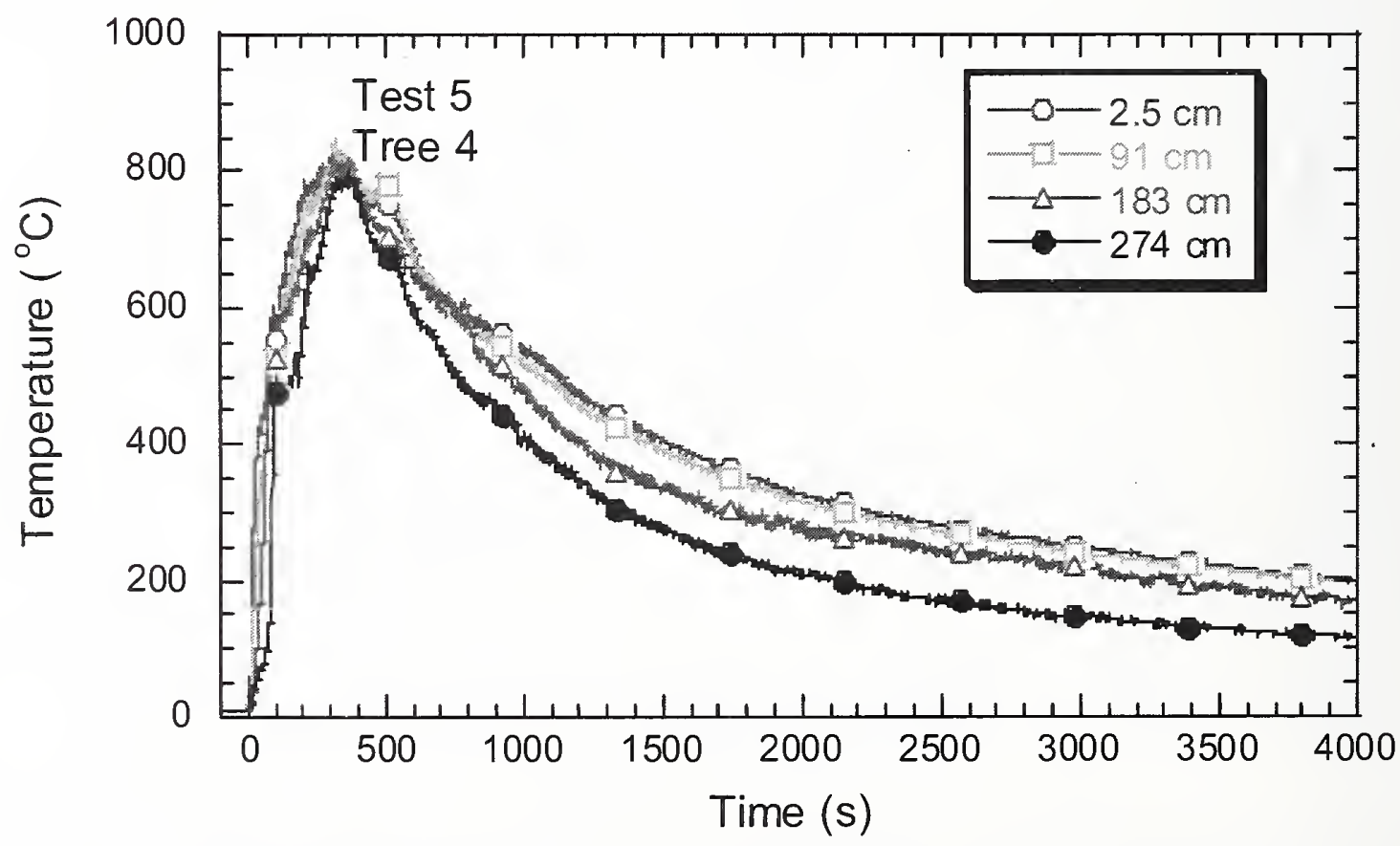

Figure 6-16. Bare bead thermocouple measurements as a function of time at four locations (below the ceiling) on Tree 4 during Test 5. 


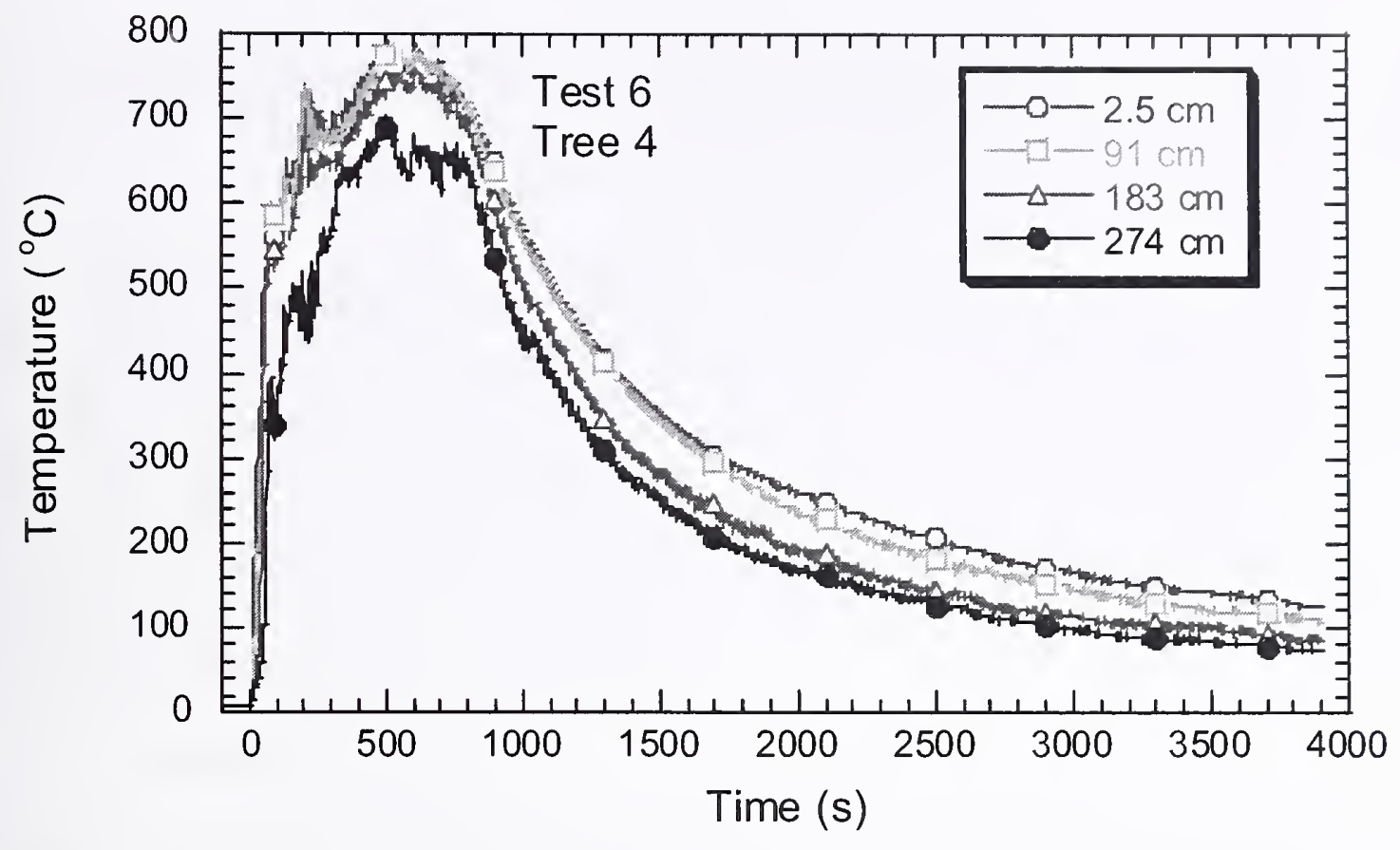

Figure 6-17. Bare bead thermocouple measurements as a function of time at four locations (below the ceiling) on Tree 4 during Test 6.

\subsection{REFERENCES}

Blevins, L. G. 1999. "Behavior of Bare and Aspirated Thermocouples in Compartment Fires,"

Proceedings of the $33^{\text {rd }}$ National Heat Transfer Conference, August 15-17, Albuquerque, NM.

Blevins, L. G., and Pitts, W. M. 1999. Fire Safety Journal, 33, 239-259; NISTIR 6310, National Institute of Standards and Technology, Gaithersburg, MD, April.

Burns, G. W., Scroger, M. G., Strouse, G. F., Croarkin, M. C., and Guthrie, W. F. 1993. TemperatureElectromotive Force Reference Functions and Tables for the Letter-Designated Thermocouple Type Based on the ITS-90, NIST Monograph 175, National Institute of Standards and Technology, Gaithersburg, MD, April.

Hamins, A., Maranghides, A., Johnsson, R., Donnelly, M., Yang, J., Mulholland, G., Anleitner, R. L. 2003. Report of Experimental Results for the International Fire Model Benclimarking and Validation Exercise \#3, NIST Special Publication 1017, National Institute of Standards and Technology, Gaithersburg, MD, November.

He, Y. P., Fernando, A., Luo, M. C. 1998. Fire Safety Journal, 31, 19-38.

McCaffrey, B. J., and Heskestad, G. 1976. Combust. Flame, 26, 125-127.

Omega Engineering, Inc. 2004. Temperature Handbook, "Using Thermocouple." (see www.omega.com/temperature/Z/pdf/z021-032.pdf). 
Pitts, W. M., Braun, E., Peacock, R. D., Mitler, H. E., Johnsson, L., Reneke, P. A., and Blevins, L. G. 2002. "Temperature Uncertainties for Bare-Bead and Aspirated thermocouple Measurements in Fire Environments," Thermal Measurements: The Foundation of Fire Standards, ASTM STP 1427, L. A. Gritzo and N. Alvares, eds., ASTM International, West Conshohocken, PA.

Pitts, W. M., Braun, E., Peacock, R. D., Mitler, H. E., Johnsson, E. L., Reneke, P. A., and Blevins, L. G. 1998. Temperature Uncertainties for Bare-Bead and Aspirated Thermoconple Measurements in Fire Emiromments; National Institute of Standards and Technology, Gaithersburg, MD, NISTIR 6242, October. 


\section{Chapter 7 \\ UPPER LAYER CONCENTRATIONS OF $\mathrm{CO}_{2}, \mathrm{CO}$, AND $\mathrm{O}_{2}$}

\subsection{GAS SAMPLING PROCEDURE}

Gas samples were pulled from the sampling location ncar the middlc of the compartment $(\mathrm{x}, \mathrm{y}, \mathrm{z}=970 \mathrm{~cm}$, $351 \mathrm{~cm}, 276 \mathrm{~cm}$ ) using a pump. The gas sample was filtered through a glass microfiber filter to rcmove particulate larger than $1.5 \mu \mathrm{m}$ diameter and routed through a glass trap immerscd in a dry ice bath to condense water vapor prior to analysis. In all cases, gas concentrations are reported on a dry basis. The gas analyzers in the calorimetcr differ only in that a sampling pump near the exhaust duct pulled the sample from the duct, through a particulate filter and pumped it to the control room. This gas was then filtered, conditioned, and pumped to the gas analyzers.

\subsection{INSTRUMENTATION}

Instrumentation was the same as that used for the calorimetry measurements described in Chapter 5. Oxygen was quantified using an analyzer that takes advantage of the paramagnetic clectron configuration of molecular oxygen in which unpaired electrons are susceptible to magnetic fields. The analyzer is sensitive and nearly free of interferences. Sample gas is passed through a cell subject to a strong magnetic field. The susceptibility of oxygen to the magnetic field causes a gas-filled dumbbell suspended in the ccll to torque from an equilibrium position. The electric current required to maintain the dumbbell's equilibrium position is proportional to the oxygen concentration.

Carbon monoxide and carbon dioxide were quantified using gas analyzers employing non-dispersive infrared technology. An infrared source was alternately directed through one ccll containing nitrogen, which does not absorb infrared radiation, and a second cell containing the flowing sample gas. Each beam of infrared light impinged on a double layer detector connectcd pneumatically and filled with the analyte of interest. Differences in absorption between the two layers results in a flow between the layers that is sensed by a microflow detector in proportion to the analyte concentration in the sample cell.

As water was removed prior to quantification, the experimental results are reported on a dry basis in terms of volume. The units employed in describing the magnitude of the species concentrations are either volume fraction or volume percent. The uncertainties in the volume fraction measurements were 5 percent, 10 percent, and 10 percent for the $\mathrm{O}_{2}, \mathrm{CO}_{2}$, and $\mathrm{CO}$ volume fractions, respectively.

\subsection{DISCUSSION}

The gas in the hot upper layer of the compartment was sampled to quantify the volume fractions of oxygen, carbon monoxide, and carbon dioxide. The sample was collected from the eastern half of the

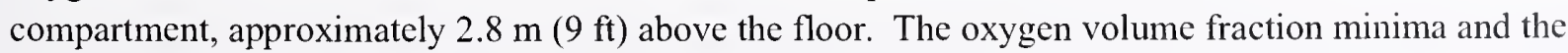
carbon monoxide and carbon dioxide volume fraction maximum are described below. Figures 7-1 through 7-6 depict the gas concentrations measured in the compartment follow the text discussion. For 
the sake of clarity, only $5 \mathrm{~min}(300 \mathrm{~s})$ of data prior to ignition and $20 \mathrm{~min}(1,200 \mathrm{~s})$ after ignition are displayed.

\subsubsection{Test Results}

Before ignition in all of the tests, the data shows that the gas species volume fractions were steady ambient values. Within $50 \mathrm{~s}$ after ignition, the oxygen volume fraction began to decline, while the carbon monoxide and carbon dioxide volume fractions began to increase. The largest rate of change of the gas species volume fraction occurred during the tests in which jet fuel was present (Tests 3, 5, and 6). In those tests, the oxygen volume fraction typically dropped from its ambient value to 0.02 within $200 \mathrm{~s}$, while the $\mathrm{CO}$ and $\mathrm{CO}_{2}$ volume fractions increased from ambient values to 0.15 and 0.03 , respectively, within the same time frame. The species volume fractions began to return to ambient values after the initial rapid change, when combustion of the jet fuel was nearly complete. Later in the tests, the data exhibit several maxima and minima, reflecting the complexity of the compartment burning process.

During the tests in which jet fuel was not present (Tests 1,2, and 4), the changes in gas species volume fraction were much more gradual. The $\mathrm{O}_{2}$ volume fraction in Tests 1,2 , and 4 , for example, decreased to values of less than 0.05 only after $500 \mathrm{~s}$ to $900 \mathrm{~s}$ of burning.

Analysis of the measurement results showed that the location of the spray burner or the presence of ceiling tiles had no discernable effects on the measured $\mathrm{O}_{2}, \mathrm{CO}$, and $\mathrm{CO}_{2}$ volume fractions. A detailed description of the measurement results for each of the tests follows.

\section{Test 1}

During Test 1, between 1,400 and 1,650 s after ignition, oxygen concentrations reached a minimum, while the carbon monoxide and carbon dioxide concentrations obtained maximum values. Oxygen decreased to below 0.1 percent, carbon dioxide exceeded 20 percent and carbon monoxide concentrations peakcd above 2 percent.

\section{Test 2}

Test 2 was a repeat of Test 1. During Test 2, maximum carbon monoxide and carbon dioxide with corresponding minimum oxygen concentration occurrcd between 800-1,000 s following ignition. Carbon monoxide and carbon dioxide peaked at approximately 1.1 percent and 16 percent, respectively. The minimum oxygen concentration was just below 2 percent. The measurable differences between Tests 1 and 2, as mentioned earlier, can in part be attributed to the organic fuel contributions from Marinite during Test 1 .

\section{Test 3}

Test 3 gas concentration extremes occurred over a prolonged period of time from $100 \mathrm{~s}$ to $1,000 \mathrm{~s}$ following ignition. Oxygen concentrations frequently decreased below 1 percent while carbon dioxide and carbon monoxide peaked above 24 percent and near 4 percent, respectively. 


\section{Test 4}

In Test 4, minimum oxygcn concentrations and maximum carbon monoxide and carbon dioxidc concentrations occurred in a relatively narrow time frame ranging from $400 \mathrm{~s}$ to $550 \mathrm{~s}$ following firc ignition. The minimum oxygen concentration during this timc was near 3 percent while carbon dioxide concentrations peaked above 13 percent and carbon monoxide peaked just below 0.5 percent.

\section{Test 5}

During Test 5, approximately 3 min after ignition, a circuit breakcr tripped causing a power failure to the compartment hot layer gas analyzers and two of the load cell networks. It took approximately $400 \mathrm{~s}$ to reset the circuit breaker and return the instruments to service. During Test 5, it is possible that the minimum oxygen concentration and maximum carbon dioxide and carbon monoxide concentration occurred while power to the gas analyzers was interruptcd. Prior to the power failure, the oxygen was as low as 4 percent by volume, while carbon monoxide and dioxide peaked at 0.6 percent and 12 percent, respectively.

\section{Test 6}

During Test 6, peak carbon monoxide and carbon dioxide, as well as minimum oxygen concentrations occurred during the first $240 \mathrm{~s}$ after ignition. Oxygen decreased to below 0.2 pcrcent while carbon monoxide and carbon dioxide peaked near 16 percent and carbon monoxide peaked near 3.6 percent.

\subsection{SUMMARY}

Gas samples were extracted and analyzed to determine the volume fractions of $\mathrm{O}_{2}, \mathrm{CO}$, and $\mathrm{CO}_{2}$. The instrumentation required removing water from the samples, and the results are reported here on a dry basis. The measurements results showed that:

- Changes in the volume fraction of gas species occurred most rapidly for the tests in which jet fuel was present.

- Analysis of the measurement results showed that there was no discernable effect of the location of the spray burner or the presence of ceiling tiles.

The species volume fractions are sensitive to a variety of fire dynamic conditions. These measurement results provide a database that represents a challenge for model validation as seen in the next Chapter. 


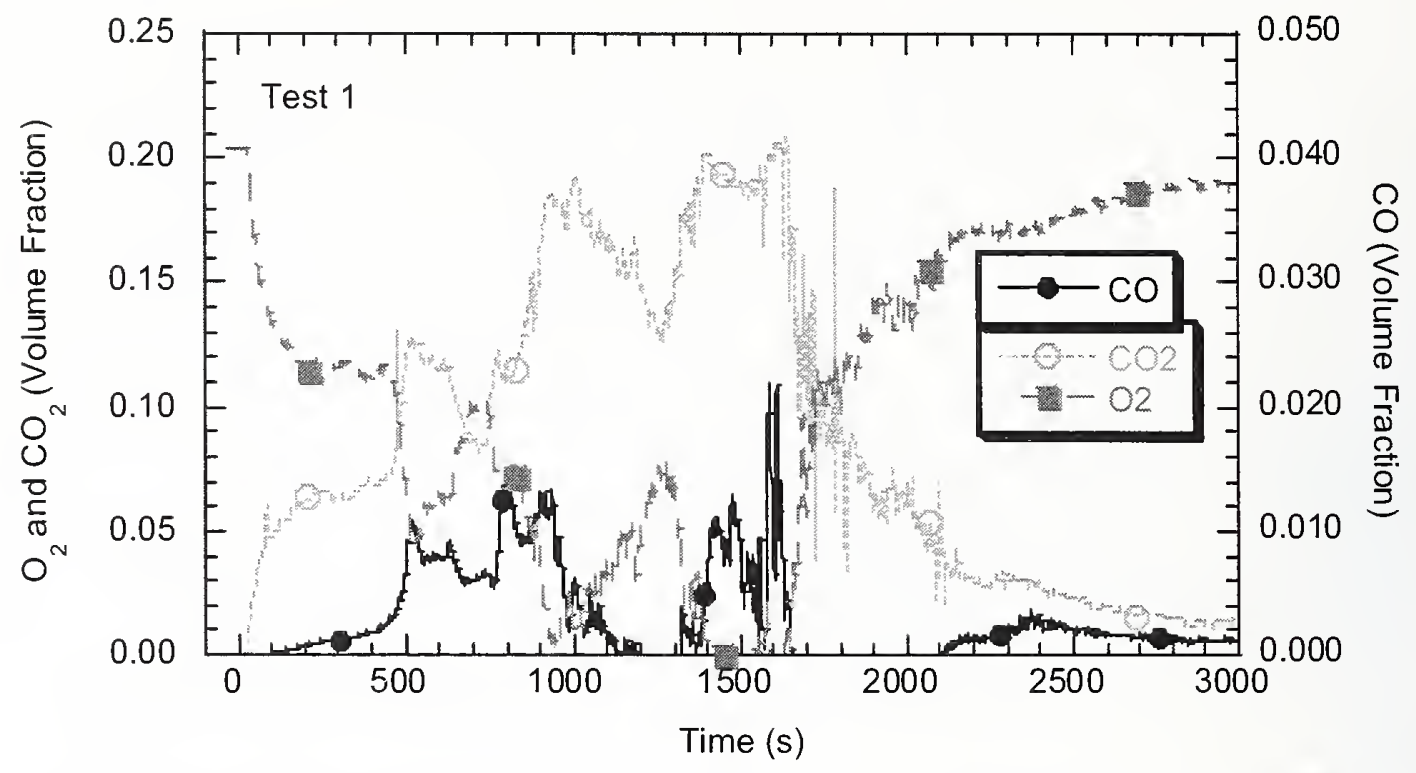

Figure 7-1. The volume fractions of $\mathrm{O}_{2}, \mathrm{CO}$, and $\mathrm{CO}_{2}$ on a dry basis as a function of time during Test 1.

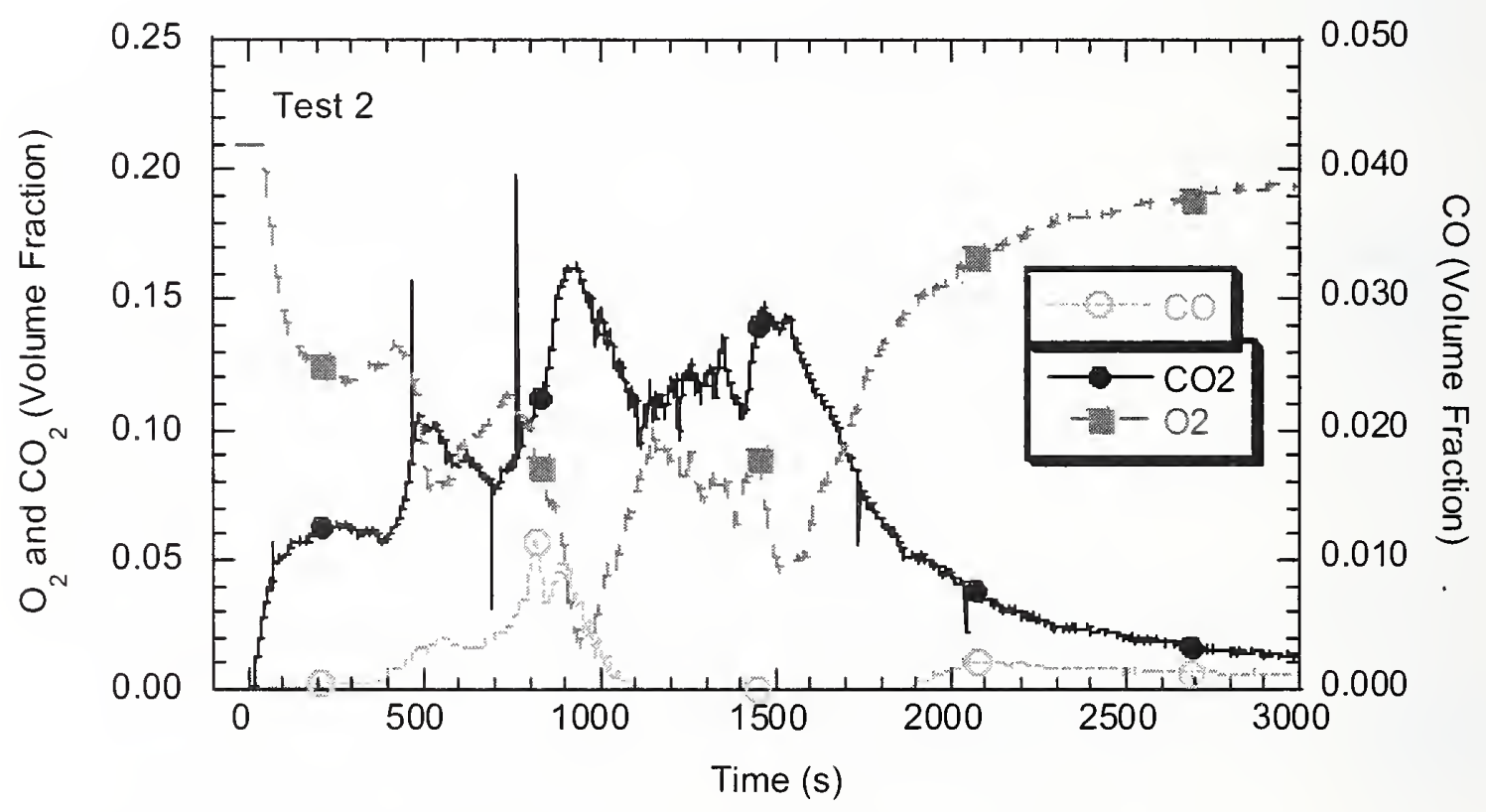

Figure 7-2. The volume fractions of $\mathrm{O}_{2}, \mathrm{CO}$, and $\mathrm{CO}_{2}$ on a dry basis as a function of time during Test 2. 


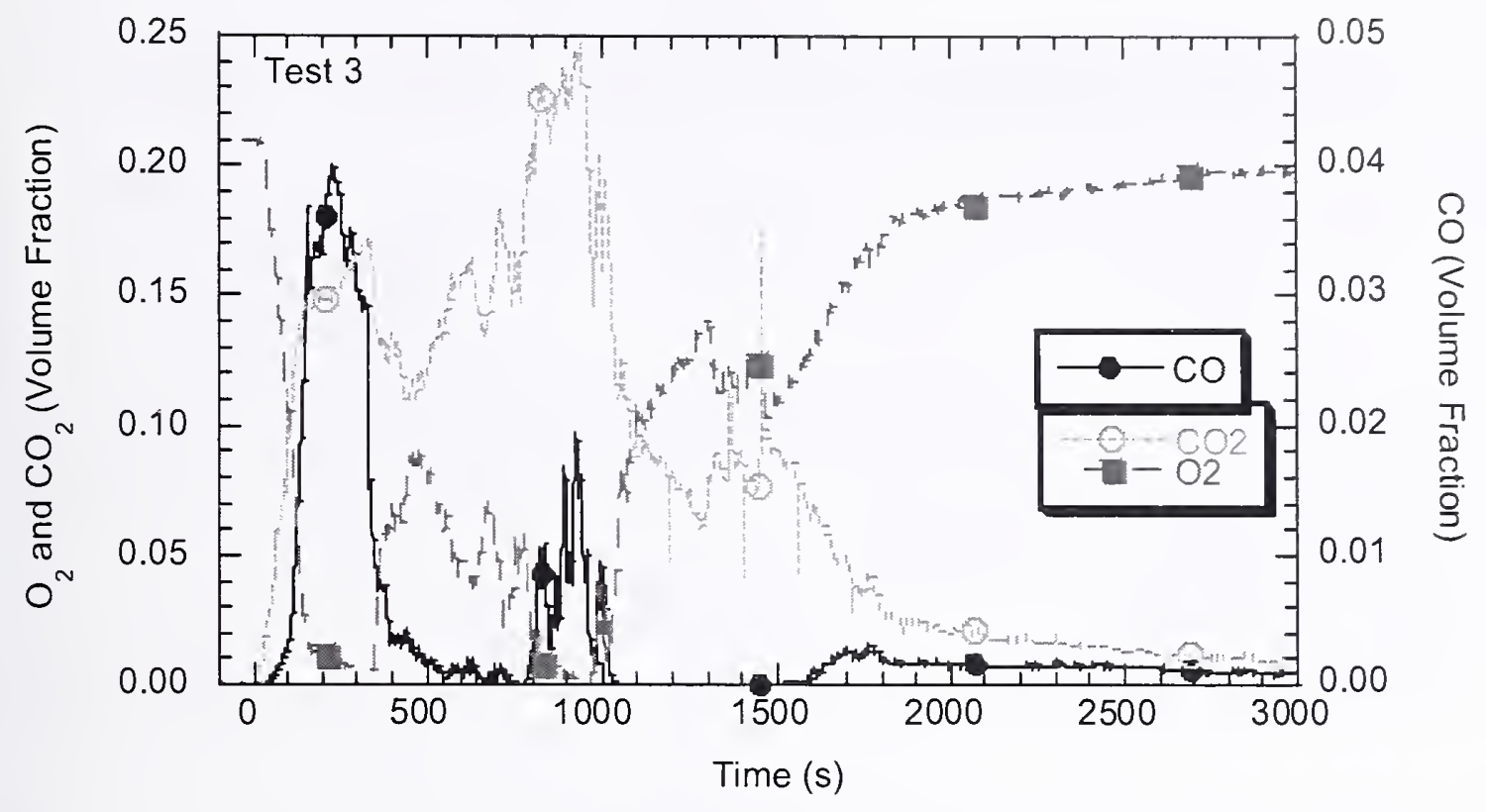

Figure 7-3. The volume fractions of $\mathrm{O}_{2}, \mathrm{CO}$, and $\mathrm{CO}_{2}$ on a dry basis as a function of time during Test 3.

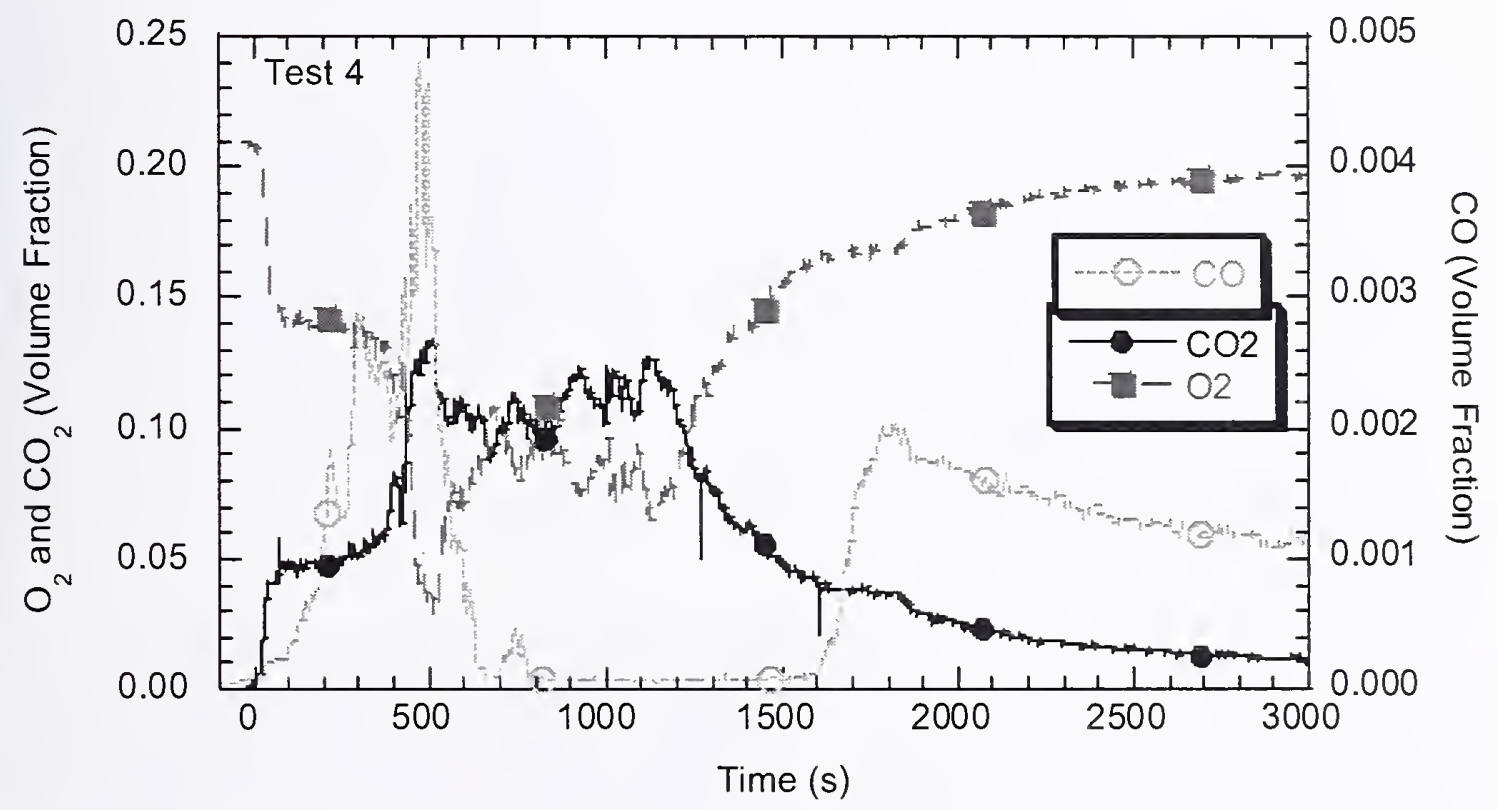

Figure 7-4. The volume fractions of $\mathrm{O}_{2}, \mathrm{CO}$, and $\mathrm{CO}_{2}$ on a dry basis as a function of time during Test 4. 


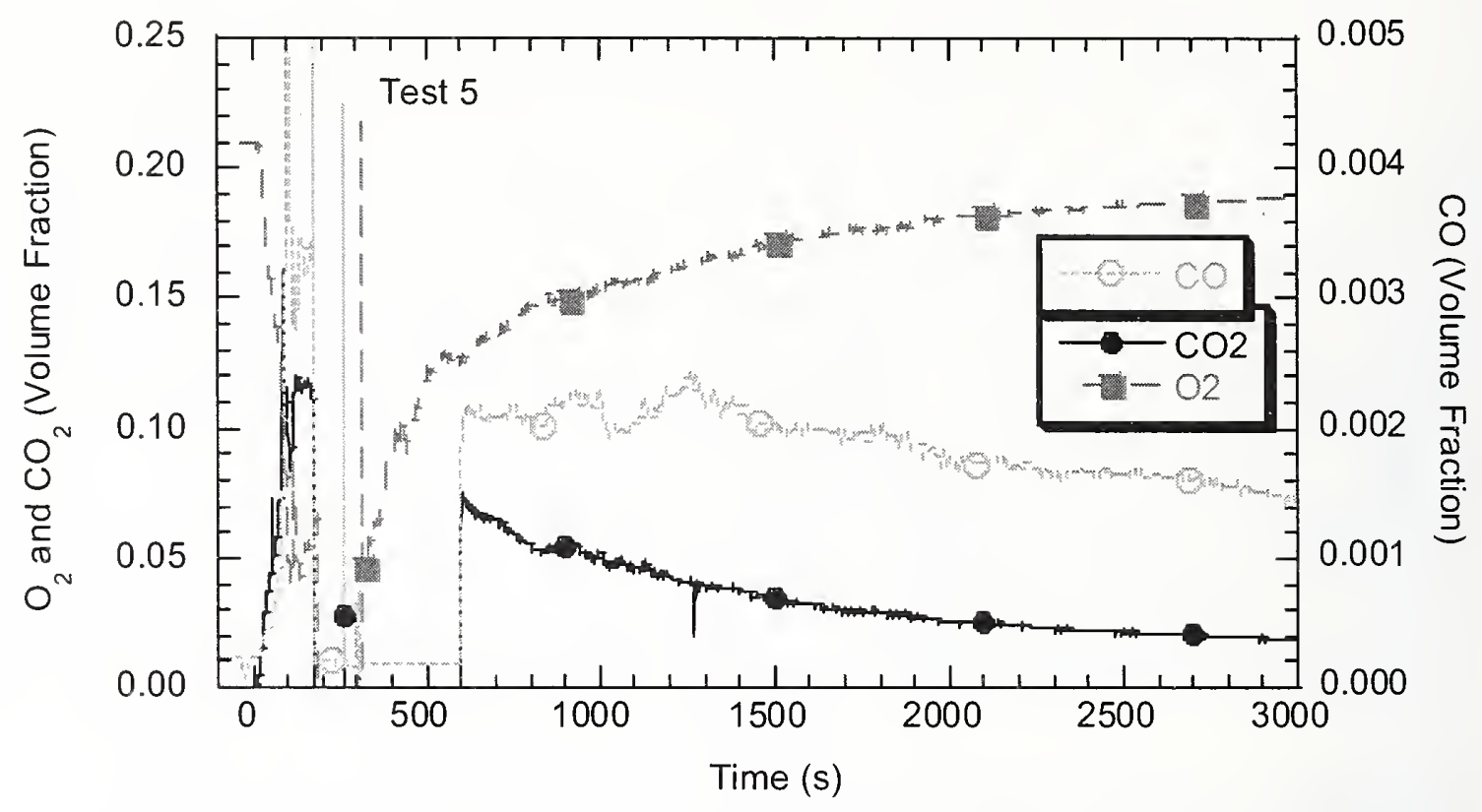

Figure 7-5. The volume fractions of $\mathrm{O}_{2}, \mathrm{CO}$, and $\mathrm{CO}_{2}$ on a dry basis as a function of time during Test 5.

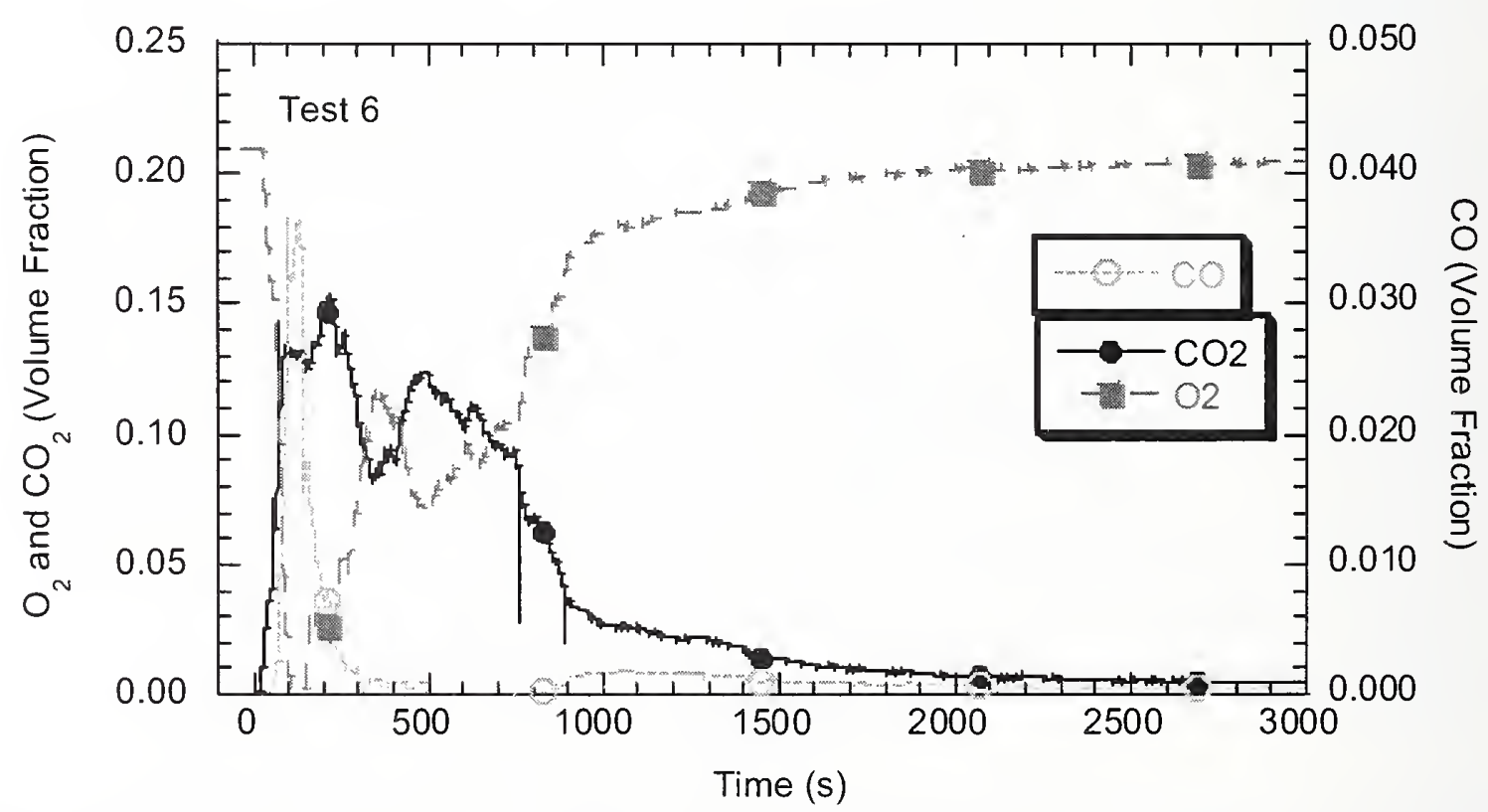

Figure 7-6. The volume fractions of $\mathrm{O}_{2}, \mathrm{CO}$, and $\mathrm{CO}_{2}$ on a dry basis as a function of time during Test 6. 


\section{Chapter 8 \\ SimULATION OF COMPARTMENT FiRE PHENOMENA}

\section{$8.1 \quad$ INTRODUCTION}

In the months following the attacks on the World Trade Center (WTC) and the Pentagon, there was an active debate in the fire protection engineering community about the fires that erupted following the impact of the aircraft on the buildings. Because fires of this magnitude in these types of buildings were rare. there was a wide spectrum of opinion about the fire temperatures and their effect on the structural steel. Much of the fire literature consists of empirical correlations derived from experiments ranging from bench scale to room scale. Extrapolating these well-known correlations to the WTC and the Pentagon requires a re-examination of the underlying physics. Many of these correlations are appropriate for a narrow range of fire sizes and building geometries and cannot be applied to the WTC.

Over the past 25 years, the National Institute of Standards and Technology (NIST) has developed several computer models, widely used by fire protection engineers to assess the impact of fire on a building. These models have become more and more detailed as computers have become faster and less expensive. The earliest models were essentially correlations of existing fire test data, followed later by simple computer programs that would solve mass and energy conservation equations for entire rooms or compartments. These models came to be known as "zone models," because they divide buildings into rooms and each room into well-mixed upper and lower zones. The concept of conserving mass and energy in "zones" has a natural extension where each room is divided into thousands or potentially millions of zones or cells. Adding conservation of momentum to mass and energy yields what is known as a computational fluid dynamics (CFD) model. Such models are used to design jet aircraft and predict the weather by solving a modeled set of partial differential equations known as the Navier-Stokes equations. The results yield a very detailed picture of the movement of fluids (either gases or liquids) as a function of time. A CFD fire model predicts the movement of hot gases from a fire as they spread throughout a building. In the case of the WTC, these calculations can provide estimates of the temperature of the smoke and hot gases surrounding the structural steel. information needed to assess the potential weakening of the steel over the course of $100 \mathrm{~min}$.

\subsection{NIST FIRE DYNAMICS SIMULATOR}

The Fire Dynamics Simulator (FDS) is a CFD model of fire-driven fluid flow. Version 1 of FDS was publicly released in February 2000. Versions 2 and 3 were publicly released in December 2001 and November 2002, respectively. To date, about half of the applications of the model have been for design of smoke handling systems and sprinkler/detector activation studies. The other half has consisted of residential and industrial fire reconstructions. FDS has been developed with the goal of solving practical fire problems in fire protection engineering, while at the same time providing a tool to study fundamental fire dynamics and combustion. Throughout its development, the model has been compared with a variety of fire experiments to ensure that its predictions are accurate. Most often, the experiments are not necessarily designed solely for the purpose of model validation, and as a result, there are often several experimental features that are difficult to model. It is then difficult to assess the overall accuracy of the 
model because the uncertainty in modeling the difficult features dominates the error. The large-scale experiments described in this report were designed specifically to extend the validation of FDS to the WTC fire scenarios.

FDS solves numerically a modeled form of the Navier-Stokes equations appropriate for low-speed, thermally-driven flow with an emphasis on smoke and heat transport from fires. The formulation of the equations and the numerical algorithm are contained in a FDS companion document, called the Fire Dynamics Simulator (Version 4) - Technical Reference Guide (McGrattan 2004). The core algorithm is an explicit predictor-corrector scheme, second order accurate in space and time. Turbulence is treated by means of the Smagorinsky form of Large Eddy Simulation (LES). For most applications, FDS uses a mixture fraction combustion model. The mixture fraction is a conserved scalar quantity that is defined as the fraction of gas at a given point in the flow field that originated as fuel. The model assumes that combustion is mixing-controlled and that the reaction of fuel and oxygen is infinitely fast. The mass fractions of all of the major reactants and products can be derived from the mixture fraction by means of "state relations," empirical expressions arrived at by a combination of simplified analysis and measurement.

Radiative heat transfer is included in the model via the solution of the radiation transport equation for a non-scattering gray gas and in some limited cases using a wide band model. The equation is solved using a technique similar to finite volume methods for convective transport, thus the name given to it is the Finite Volume Method (FVM). Using approximately 100 discrete angles, the finite volume solver requires about 15 percent of the total CPU time of a calculation, a modest cost given the complexity of radiation heat transfer.

FDS approximates the governing equations on a rectilinear grid. The user-prescribed rectangular obstructions are forced to conform with the underlying grid. All solid surfaces are assigned thermal boundary conditions and information about the burning behavior of the material. Usually, material properties are stored in a database and invoked by name by the user. Heat and mass transfer to and from solid surfaces is usually handled with empirical correlations.

\subsection{CALIBRATION AND VALIDATION EXPERIMENTS}

The experimental program concentrated on the thermal properties of the office furnishings that constituted the bulk of the combustible fuel within the WTC buildings under study. Several types of office workstations typical of those used in WTC 1 and WTC 2 were purchased. The thermal properties of the major materials making up the workstations were derived from cone calorimeter experiments (NIST NCSTAR 1-5C). These properties were input into FDS, which was used to simulate the burning behavior of a single workstation burning under a $2.5 \mathrm{~m}$ ceiling with baffles to contain a hot layer of smoke above the burning workstation. Other than the baffled ceiling, no walls surrounded the workstation other than its own privacy panels. The thermal properties of the workstation components were adjusted slightly so that the FDS prediction of the heat release rate would match the experiment. Then, the model was used to predict the heat release rate of three workstations (workstations) burning within a large enclosure. The purpose of this exercise was to determine if FDS could simulate the dynamics of a fire in a setting similar to WTC 1,2 , and 7. 
A spray flame burning a $2 \mathrm{MW}$ fire was used as a souree of ignition for the furnished compartment. The properties of the heptane fuel were obtained from measurements made on a series of unconfined burns (Hamins et al. 2003). The fuel was a blend of heptane isomers, taken to bc $\mathrm{C}_{7} \mathrm{H}_{16}$. The soot yield was set at a eonstant value equal to 1.5 pcreent. The present version of FDS does not adjust the soot yield based on compartment ventilation or eombustion efficieney. The radiative fraction for a spray fire burning the heptane blend is 0.44 . FDS eomputes the radiative loss from the fire based on the temperature and gas composition. This calculation is subject to considcrable uneertainty beeause of the fourth-power dependenee on temperature. As a eonsequence, FDS uses a user-prescribed lower bound for the radiative fraction, which in this case is 0.35 . This means that the simulated fire radiates at least 35 percent of its energy. For the simulations reported here, the radiative fraction was computed to be about 0.40 . The FDS Technical Reference Guide (MeGrattan 2004) provides a detailed discussion of how the output parameters are interpreted in the simulations.

The heat release rate of the simulated burner was set to the idealized heat rclease rate based on the fuel flow, whieh was monitored during the experiment. No attempt was made to model the spray burner. The heat release rate was assumed to be uniformly distributed over the $2 \mathrm{~m}$ by $1 \mathrm{~m}$ area in the fuel pan, consistent with observations of the hydroearbon spray fire.

\subsubsection{Description of the Workstation Components}

A detailed deseription of the various materials making up the office workstation is given in NIST NCSTAR 1-5C and in Chapter 2 of this report. Table 2-2 is a detailed list of the combustible eontents of each workstation. Cone ealorimeter experiments at three different heat fluxes were performed for the earpet, desk (wood), computer monitor, ehair, privaey panel, and staeked paper. For the simulations of the WTC fires, only the earpet, desk, and privaey panel data was used direetly. The earpet and privacy panel were modeled as thermoplastics, with the burning rate assumed to be proportional to the heat flux from the surrounding gases. The desk was modeled as a eharring solid, in whieh a pyrolysis front propagates through the material leaving a layer of ehar behind that insulates the material and reduces the burning rate. Details of the pyrolysis models ean be found in the FDS Technical Reference Guide (MeGrattan 2004). The thermal properties of the wood and its char were taken from both the ealorimeter experiments and the work of Ritehie et al. (1997). The desk was $2.8 \mathrm{~cm}$ thiek with density $450 \mathrm{~kg} / \mathrm{m}^{3}$, specifie heat $1.2 \mathrm{~kJ} / \mathrm{kg} / \mathrm{K}$ at $20{ }^{\circ} \mathrm{C}$ and $1.6 \mathrm{~kJ} / \mathrm{kg} / \mathrm{K}$ at $900{ }^{\circ} \mathrm{C}$, eonduetivity $0.13 \mathrm{~W} / \mathrm{m} / \mathrm{K}$ at $20{ }^{\circ} \mathrm{C}$ and $0.16 \mathrm{~W} / \mathrm{m} / \mathrm{K}$ at $900{ }^{\circ} \mathrm{C}$. The ignition temperature was determined to be $360{ }^{\circ} \mathrm{C}$, and the heat of eombustion was $14,000 \mathrm{~kJ} / \mathrm{kg} \pm 800 \mathrm{~kJ} / \mathrm{kg}$. Its total available energy eontent was $210 \mathrm{MJ} / \mathrm{m}^{2} \pm 50 \mathrm{MJ} / \mathrm{m}^{2}$.

The earpet was modeled as a thermoplastie, with the burning rate taken as proportional to the heat flux from the surrounding gases. Its density was $750 \mathrm{~kg} / \mathrm{m}^{3}$, speeific heat $4.5 \mathrm{~kJ} / \mathrm{kg} / \mathrm{K}$, eonduetivity $0.16 \mathrm{~W} / \mathrm{m} / \mathrm{K}$, ignition temperature $290^{\circ} \mathrm{C}$, thickness $6 \mathrm{~mm}$, heat of vaporization $2,000 \mathrm{~kJ} / \mathrm{kg}$, heat of combustion $22,300 \mathrm{~kJ} / \mathrm{kg} \pm 600 \mathrm{~kJ} / \mathrm{kg}$. Its total available energy eontent was $61 \mathrm{MJ} / \mathrm{m}^{2} \pm 2 \mathrm{MJ} / \mathrm{m}^{2}$.

The privacy panel was modeled as a thermally-thin thermoplastic. The produet of speeifie heat, thickness and density was $0.73 \mathrm{~kJ} / \mathrm{m}^{2} / \mathrm{K}$. Its surfaee density was $0.25 \mathrm{~kg} / \mathrm{m}^{2}$, ignition temperature $380{ }^{\circ} \mathrm{C}$, heat of vaporization $6,000 \mathrm{~kJ} / \mathrm{kg}$, heat of eombustion $30,000 \mathrm{~kJ} / \mathrm{kg} \pm 500 \mathrm{~kJ} / \mathrm{kg}$. Its total available energy content was $6.0 \mathrm{MJ} / \mathrm{m}^{2} \pm 1.3 \mathrm{MJ} / \mathrm{m}^{2}$. 
The compartment walls and ceiling were made of three layers of $1.27 \mathrm{~cm}(0.5 \mathrm{in})$ thick Marinite $\mathrm{I}$, a product of BNZ Materials, Inc. The manufacturer provided the thermal properties of the material used in the calculation. The density was $737 \mathrm{~kg} / \mathrm{m}^{3}$, conductivity $0.12 \mathrm{~W} / \mathrm{m} / \mathrm{K}$. The specific heat ranged from $1.2 \mathrm{~kJ} / \mathrm{kg} / \mathrm{K}$ at $93{ }^{\circ} \mathrm{C}$ to $1.4 \mathrm{~kJ} / \mathrm{kg} / \mathrm{K}$ at $425^{\circ} \mathrm{C}$. These values differed somewhat from the values measured by Taylor et al. (2003), but the calculation results were not sensitive to these differences.

In the simulations of the fires within the WTC, the chair, computer, paper, and other miscellaneous items within the workstation were modeled as a single material by lumping the mass together into large boxes and distributing them throughout the workstation. It is common practice in fire protection engineering to use surrogate materials for fire experiments, and this practice has been extended to numerical modeling. Over the years, various items have been developed that are representative of various types of commodities. For example, wood cribs are often used to represent ordinary combustibles found in residential or light industrial settings. Paper cartons with various amounts of plastic within are also used as surrogates for a wide range of retail commodities. One in particular is called the FMRC (Factory Mutual Research Corp.) Standard Plastic Commodity, or more commonly, Group A Plastic. This test fuel is often used in sprinkler approval testing at Factory Mutual and Underwriters Laboratories in the United States, and similar test fuels have been developed in Europe. In the late 1990s, FDS was used to simulate large-scale rack storage fires to determine the effectiveness of the combined use of sprinklers, roof vents, and draft curtains (curtain boards). As part of this effort, a considerable amount of work was done to characterize the thermal properties of Group A Plastic (Hamins and McGrattan, 2003). Because Group A Plastic has been shown to be fairly representative of fires fueled by a mixture of paper (cellulosic materials) and plastic, and because it has been used in numerous FDS simulations, it was decided to model the contents of the office workstations with a fuel similar to Group A Plastic. Blind predictions of the single open workstation burns were made using the material properties obtained during the sprinkler/roof vent study (McGrattan et al. 1998), and then these properties were adjusted to match the results of the experiments. Thus, the single workstation burns served to calibrate the model. They were not intended to be validation experiments.

The surrogate fuel was modeled as a homogenous solid with a density of $172 \mathrm{~kg} / \mathrm{m}^{3}$. The paper carton was treated as a thermally-thin material whose density $\times$ specific heat $\times$ thickness was equal to $1.0 \mathrm{~kJ} / \mathrm{m}^{2} / \mathrm{K}$. Its ignition temperature was $370^{\circ} \mathrm{C}$, and the heat of combustion was taken as $30 \mathrm{~kJ} / \mathrm{g}$. The heat release rate of the boxes was set to $450 \mathrm{~kW} / \mathrm{m}^{2}$. This fuel package was similar to, but not the same as, Group A Plastic. The density was increased to account for all the miscellaneous items within the workstation. Unlike the desk, partition, and carpet, the boxes were simply given a burning rate rather than a heat of vaporization, meaning that the simulated boxes burn at the given rate regardless of the heat flux upon them. The reason for this was that it is not possible to predict the burning rate using a heat feedback approach because the geometry of the scattered fuel was too complex to directly predict the response of the material to the thermal insult. By collecting all the scattered items into boxes, the geometry of the combustibles was greatly simplified, and as a result, the burning behavior required simplification as well.

Several preliminary burns of single workstations in the open were performed to test FDS for a simplified configuration. These burns served to check that the assumptions made in modeling the workstation with the simplified fuel packages would produce reasonable results. A comparison of the heat release rate $(\dot{Q})$ of a single workstation fire and that of the simulation is shown in Fig. 8-1. Note that the peak $\dot{Q}$ in the simulation occurred sooner than in the experiment. In the experiment, the time to peak $\dot{Q}$ was strongly 
influenced by the melting of the chair plastic onto the carpet. This level of detail is not capturcd in the numerical model, especially given the fact that the chair has been lumped together with various other combustible items. What is important is the fact that the model and experimental $\dot{Q}$ curves have the same basic form, peak $\dot{Q}$, and duration. When inputting the simulatcd workstations into the calculations for WTC 1, 2, and 7, the discrcpancies in $\dot{Q}$ scen in the experiments will be outwcighcd by the diffcrences in workstation content of the building tenants.

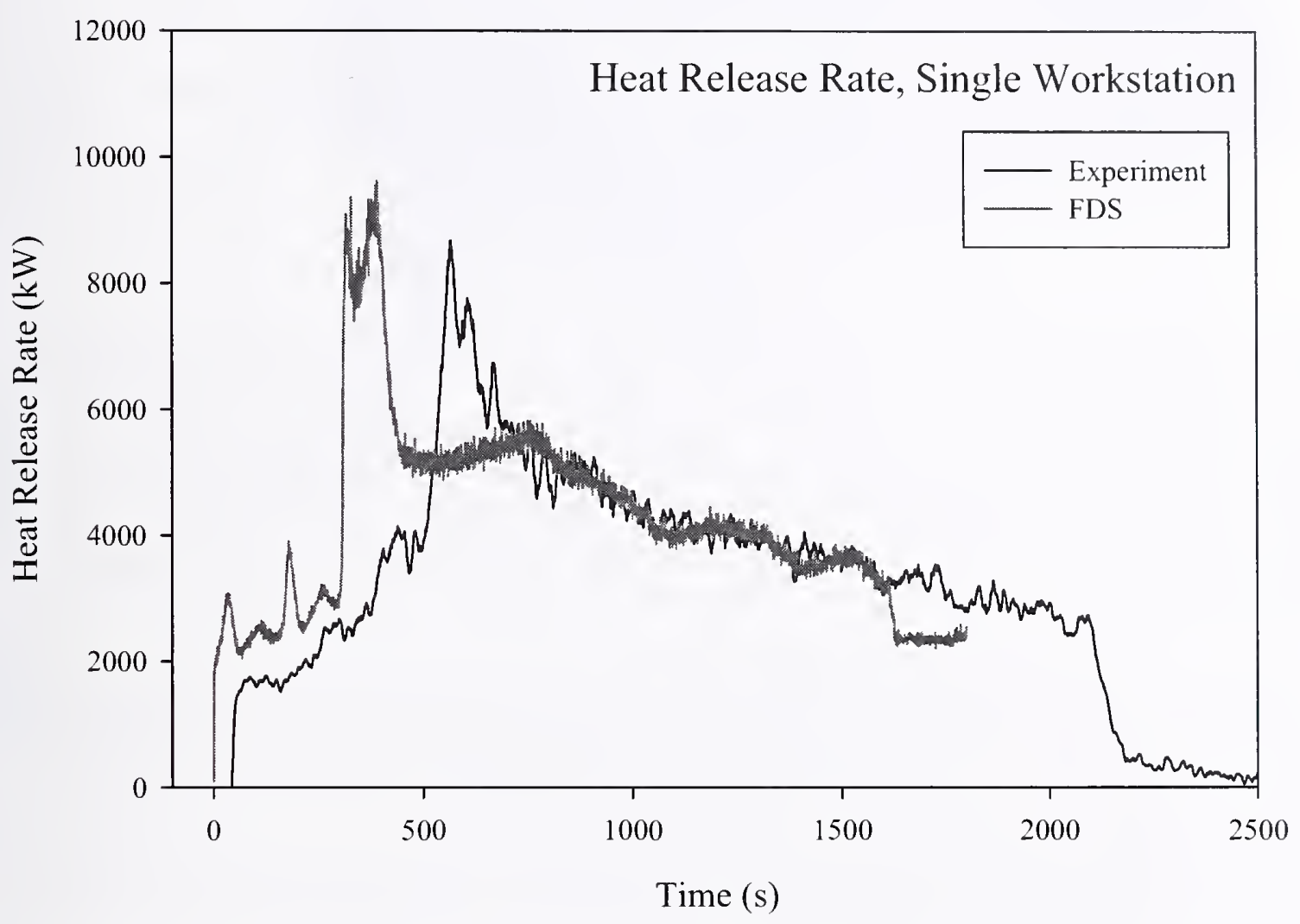

Figure 8-1. Comparison of the measured and simulated $\dot{Q}$ for a single workstation.

\subsubsection{Description of the Simulations}

Six experiments were performed within the compartment, of which five were simulated because Tests 1 and 2 were replicate tests. The geometry of the compartment used for the validation experiments was relatively simple. The overall enclosure was rectangular, as were the vents and most of the obstructions. Figure 8-2 is a snapshot of a simulation showing the fire and the major geometric features of the compartment for the simulations. Note that the surrogate fuel packages were placed roughly where the computer monitor, chair, and paper were located. In the figure, the $2 \mathrm{MW}$ heptane burner was placed near the openings of the compartment abutting workstation 1 as was the case in Tests 1, 2, and 3. For simulation of Tests 4,5 , and 6 , the burner was placed at the rear of the compartment abutting workstation 2, mimicking the experimental configuration. 


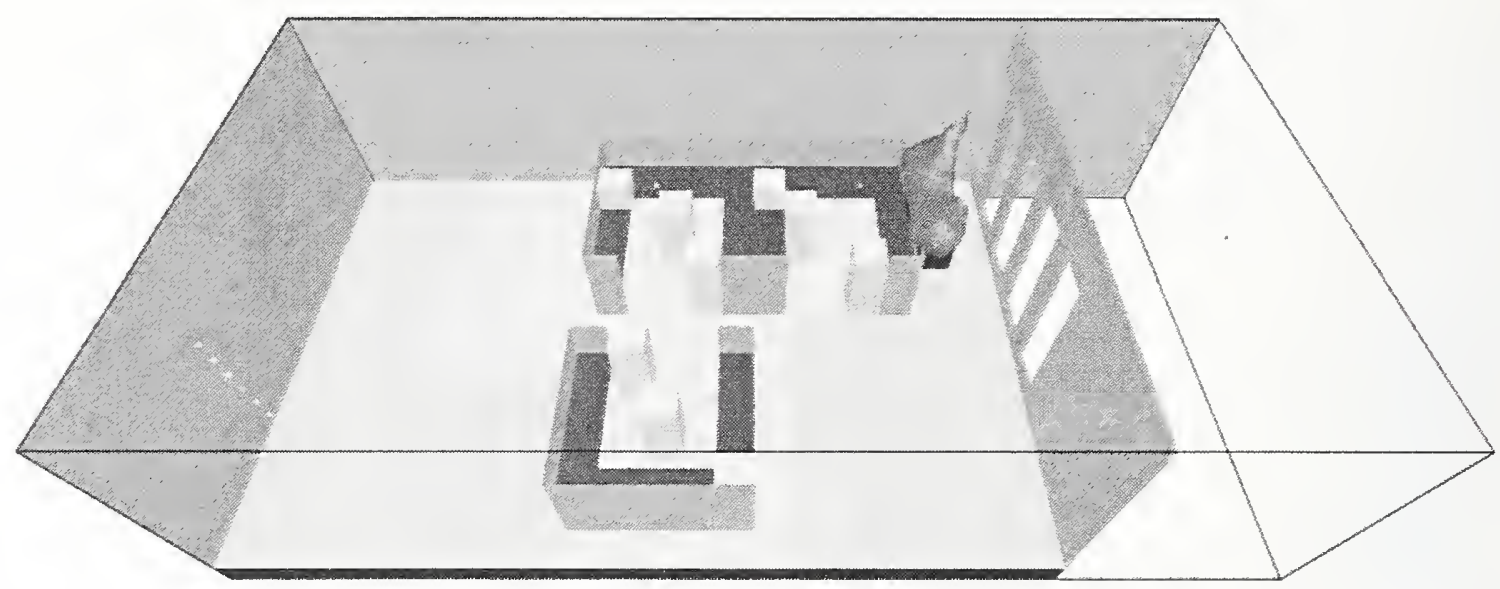

Figure 8-2. Geometry of the simulations.

In Tests 3, 5, and 6, the jet fuel was poured over the workstations and surrounding carpet. To simulate this in the model, spray nozzles were positioned over the center of each workstation, $2 \mathrm{~m}$ above the floor. These nozzles are normally used to simulate water sprinklers, but in this case, the water was replaced by a liquid having similar properties to Jet $A$. The nozzles were activated for $2 \mathrm{~s}$, in which time the equivalent amount of liquid as in the tests was ejected and spread over the furnishings. The measured and calculated heat release rate $(\dot{Q})$, the gas-phase compartment temperature, and the upper layer gas concentrations were compared.

For enclosures of the size considered in this report, it would be practical to simulate the fire using $10 \mathrm{~cm}$ grid cells. For the simulations of WTC 1,2, and 7, however, a grid $50 \mathrm{~cm}$ by $50 \mathrm{~cm}$ by $40 \mathrm{~cm}$ in height was used due to computational requirements (McGrattan et al. 2005). A grid sensitivity study was conducted to test the sensitivity of the calculation results to the grid cell size. Figure 8-3 compares the measured $\dot{Q}$ with the simulated $\dot{Q}$ (in which two grids sizes were used) for Test 1 . By simulating the experiments at $25 \mathrm{~cm}$ and $50 \mathrm{~cm}$ grid spacing, the model was tested to determine whether it produced significantly different results with grid cells of different size. Figure 8-3 shows that the two simulations differed somewhat. The calculation results using the $50 \mathrm{~cm}$ grid showed a 20 percent larger $\dot{Q}$ peak than the $25 \mathrm{~cm}$ grid results at about $600 \mathrm{~s}$, whereas the calculation results using the $25 \mathrm{~cm}$ grid showed a 20 percent larger $\dot{Q}$ peak than the $50 \mathrm{~cm}$ grid results at about $1,100 \mathrm{~s}$. Neither simulation exactly . matched the measurement results, but both calculations accurately reproduced the dominant trends of the measurements. In the WTC calculations, the workstation fires were at various stages of their combustion and the aggregate burning of a large group of workstations was expected to smear any over-predictions or under-predictions of the transient heat release rate (McGrattan et al. 2005). Furthermore, by design, the integrated heat release rate over time was equal for the two simulations. All of the simulations in this report were calculated using the same grid $(50 \mathrm{~cm})$ as used in the calculations of the WTC fires (McGrattan et al. 2005).

Figures 8-4 through 8-7 compare the measured and simulated gas-phase temperatures at thermocouples $2.5 \mathrm{~cm}$ and $270 \mathrm{~cm}$ from the ceiling on all four thermocouple trees during Test 1. Figures $8-8$ through 8-13 compare the measured and simulated $\dot{Q}$, using the same grid spacing as used in the WTC fire simulations. Figure 8-14 compares the measured and the simulated volume fraction of $\mathrm{O}_{2}$ and $\mathrm{CO}_{2}$ sampled at the rear of the compartment in Test 1. 
It should be noted that the predicted heat release rate represents the instantaneous heat release and does not account for eompartment effects, which tended to delay and time average the measured value as the products filled the upper layer of the compartment, beeame mixed, and only then flowed into the exhaust hood. During the simulation, values of the temperature, heat flux, and gas speeies volume fractions were reported as $5 \mathrm{~s}$ averages, which was more in-line with the time response of the various instruments (see Table 2-6). Linear interpolation was used to approximate values between the grid cells.

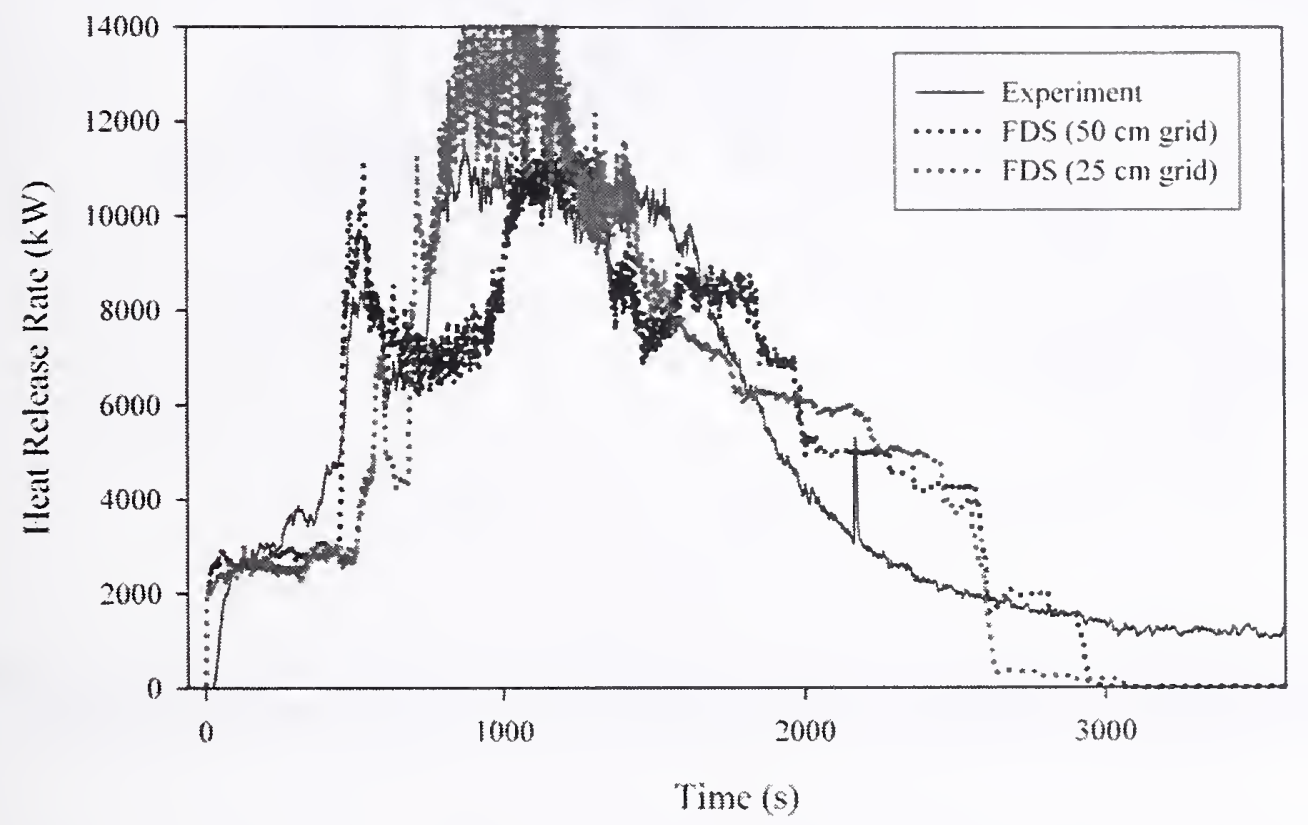

Figure 8-3. Comparison of the measured $\dot{Q}$ with the simulated $\dot{Q}$ using two grids sizes for Test 1.

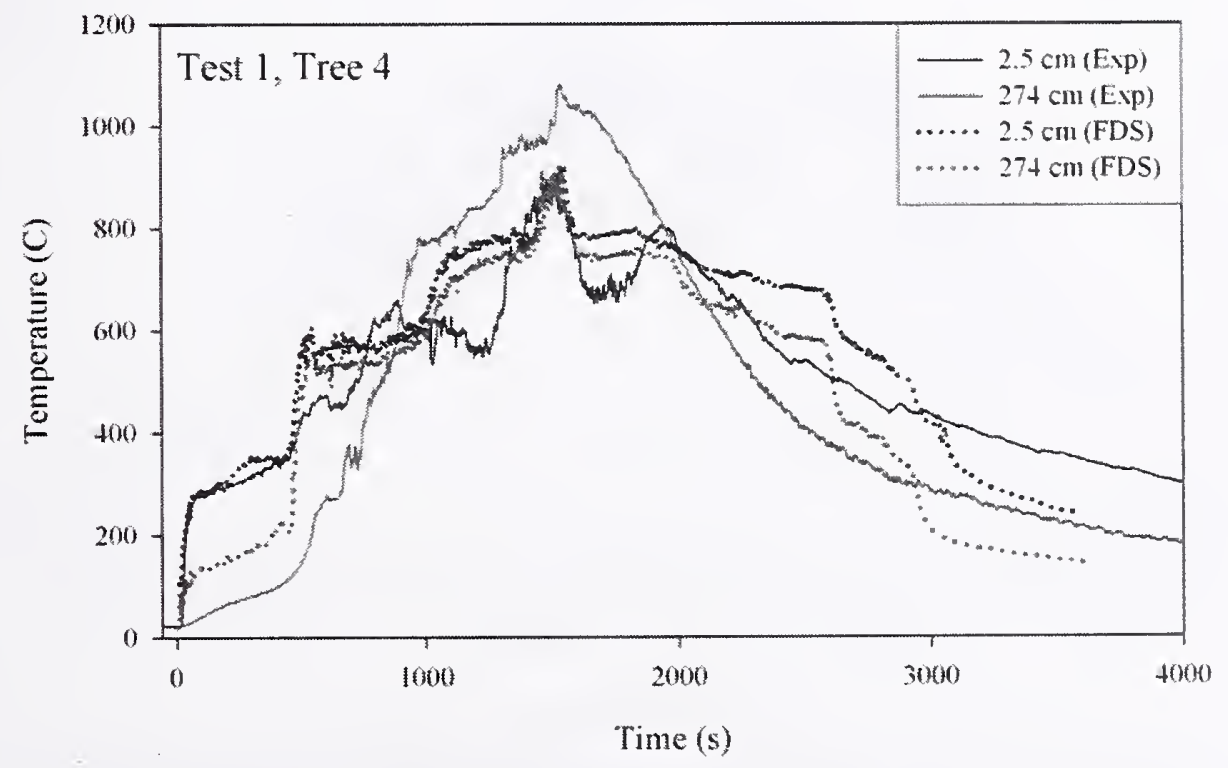

Figure 8-4. Comparison of the measured and simulated temperatures at $2.5 \mathrm{~cm}$ and $274 \mathrm{~cm}$ below the ceiling on Tree 4 (rear of the compartment) during Test 1. 


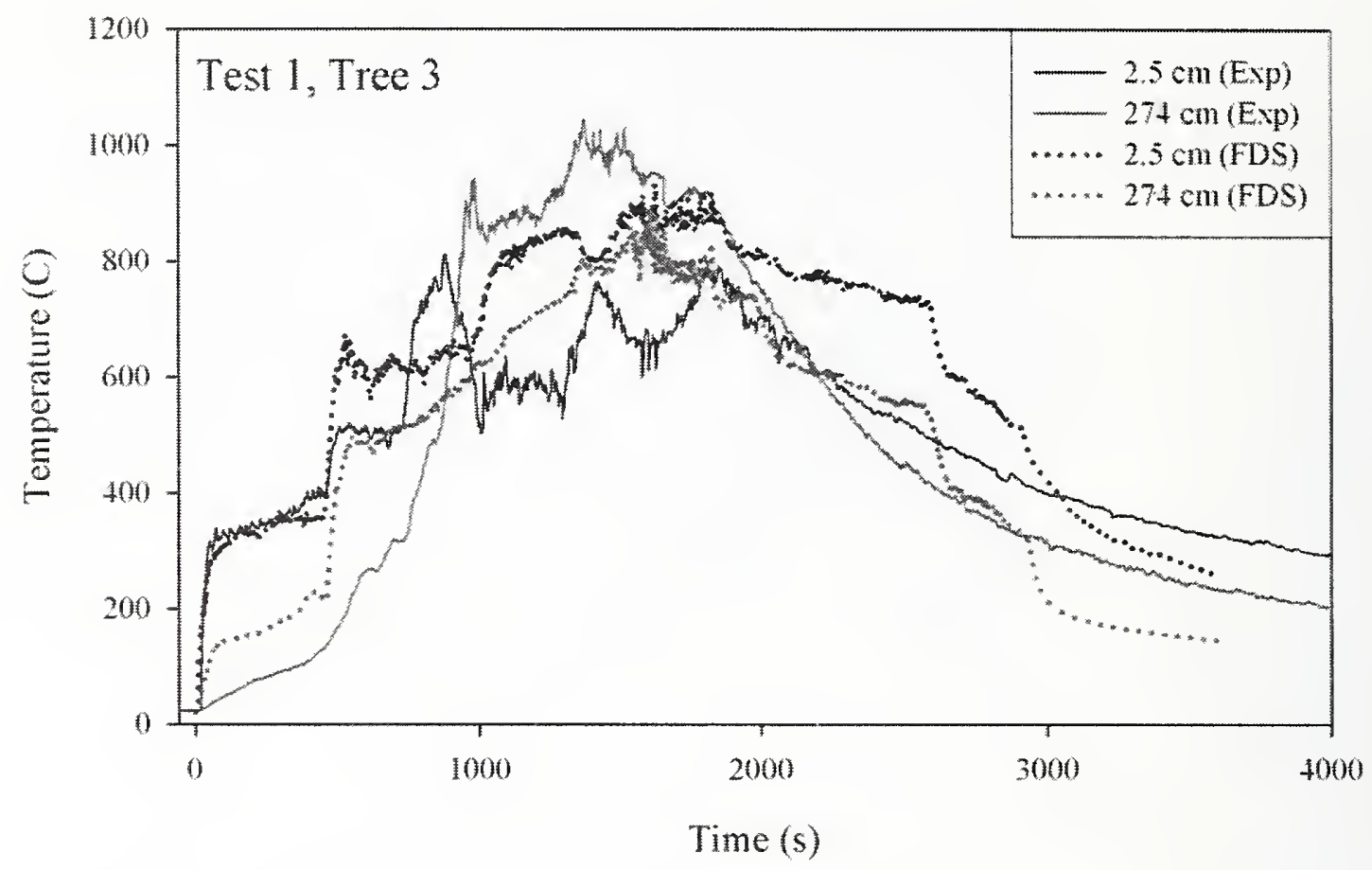

Figure 8-5. Comparison of the measured and simulated temperatures at $2.5 \mathrm{~cm}$ and $274 \mathrm{~cm}$ below the ceiling on Tree 3 (middle of the compartment) during Test 1 .

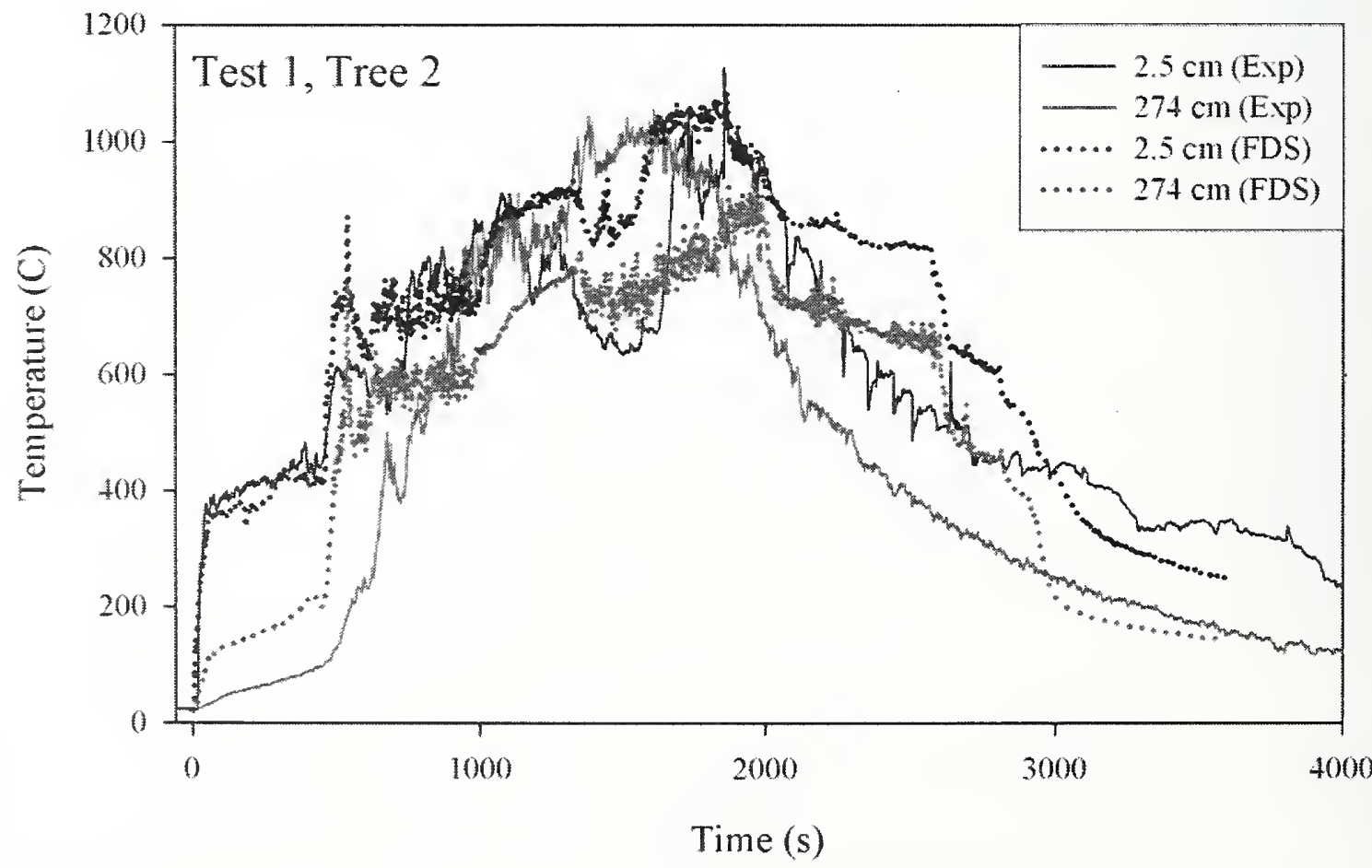

Figure 8-6. Comparison of the measured and simulated temperatures at $2.5 \mathrm{~cm}$ and $274 \mathrm{~cm}$ below the ceiling on Tree 2 (middle of the compartment) during Test 1. 


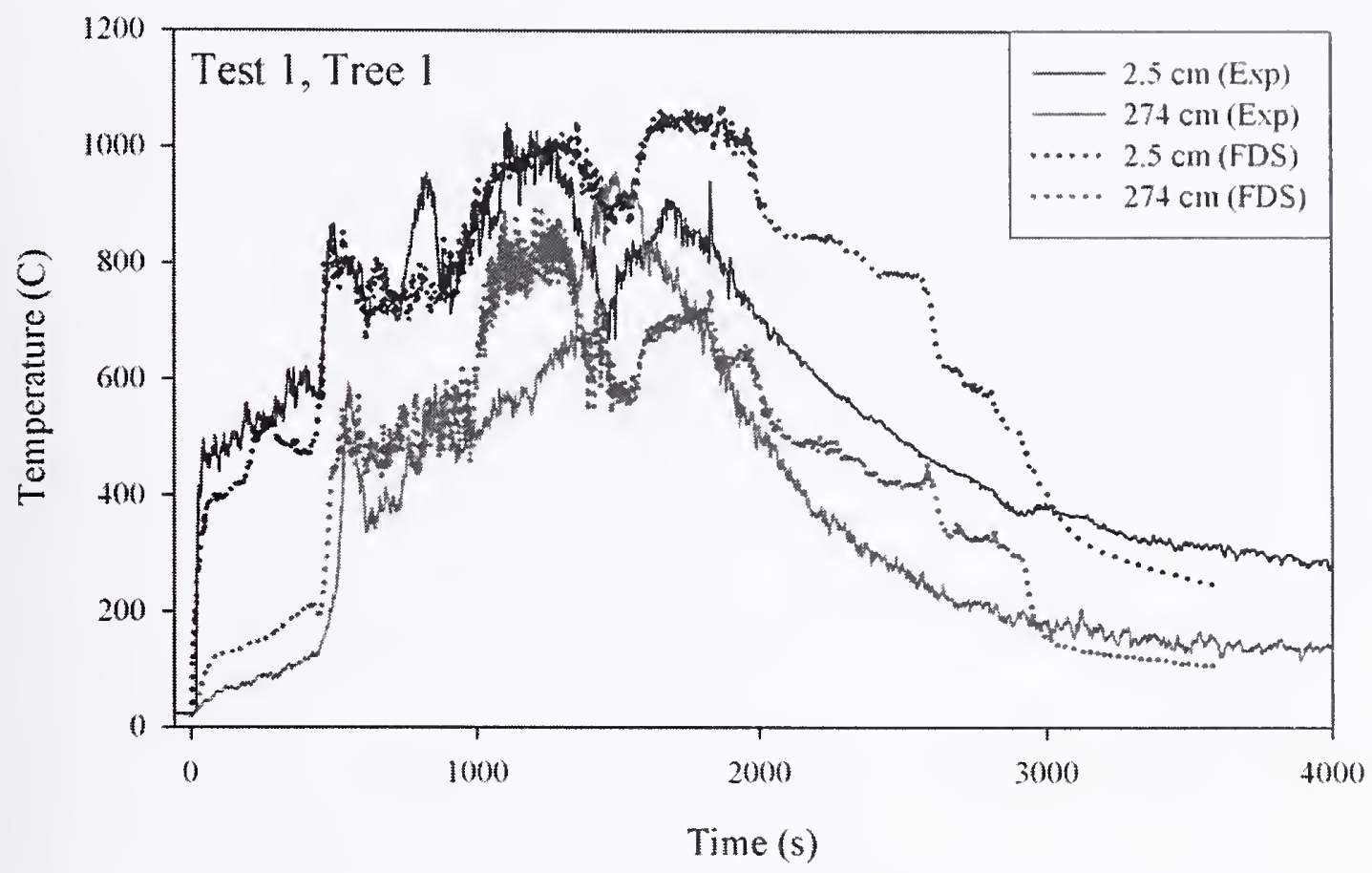

Figure 8-7. Comparison of the measured and simulated temperatures at $2.5 \mathrm{~cm}$ and $274 \mathrm{~cm}$ below the ceiling on Tree 1 (front of the compartment) during Test 1.

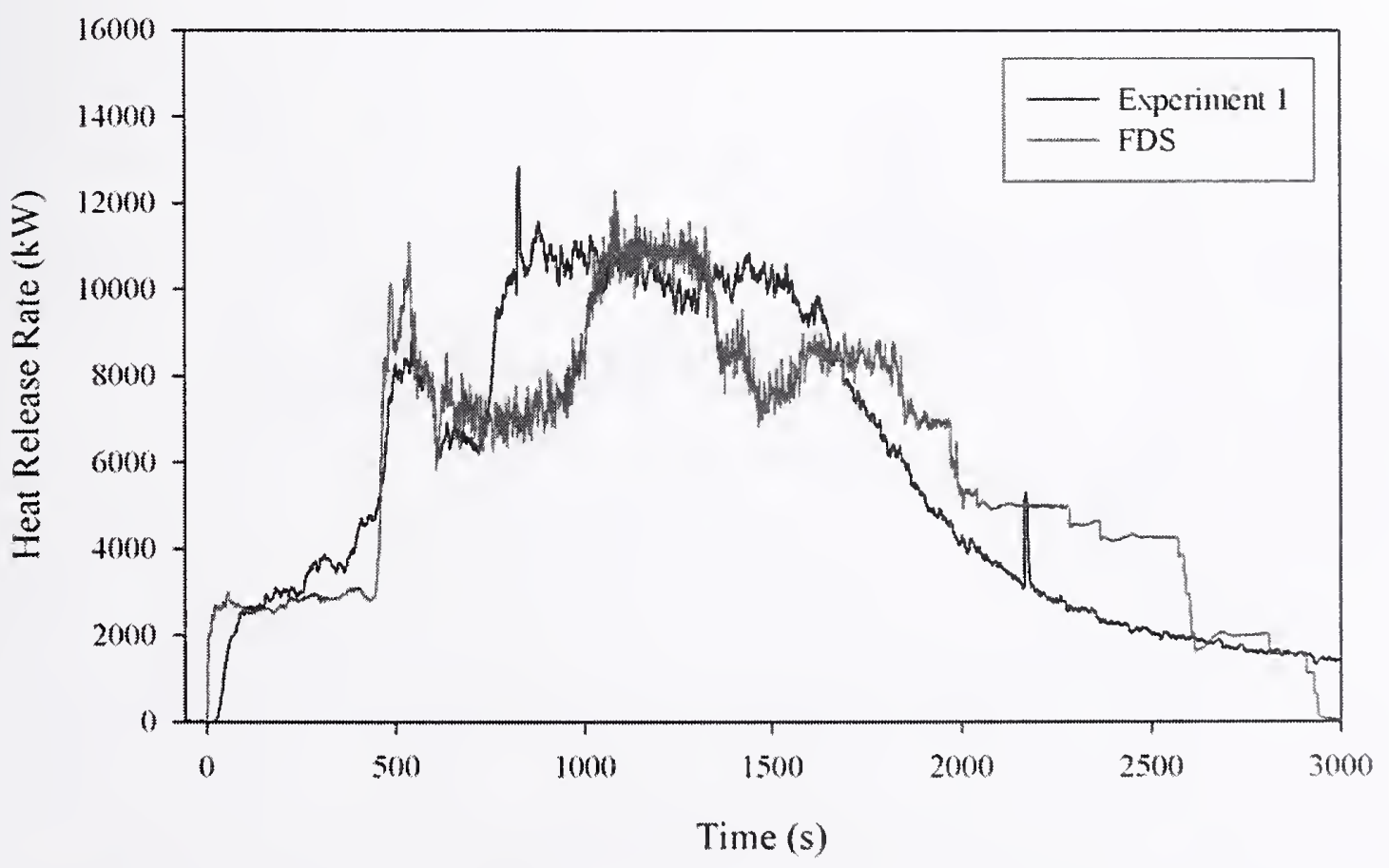

Figure 8-8. Comparison of the measured and simulated $\dot{Q}$ for Test 1. 


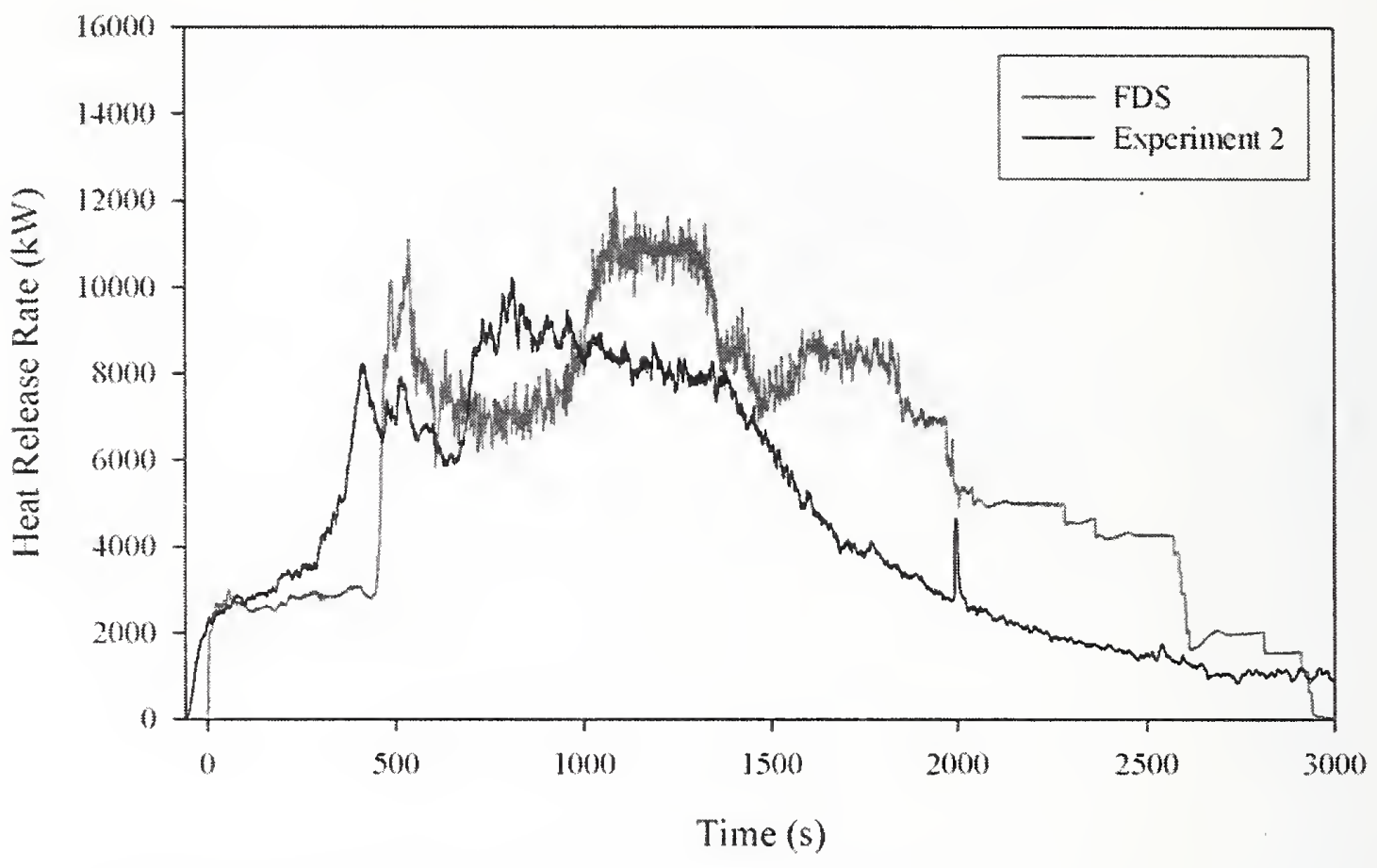

Figure 8-9. Comparison of the measured and simulated $\dot{Q}$ for Test 2.

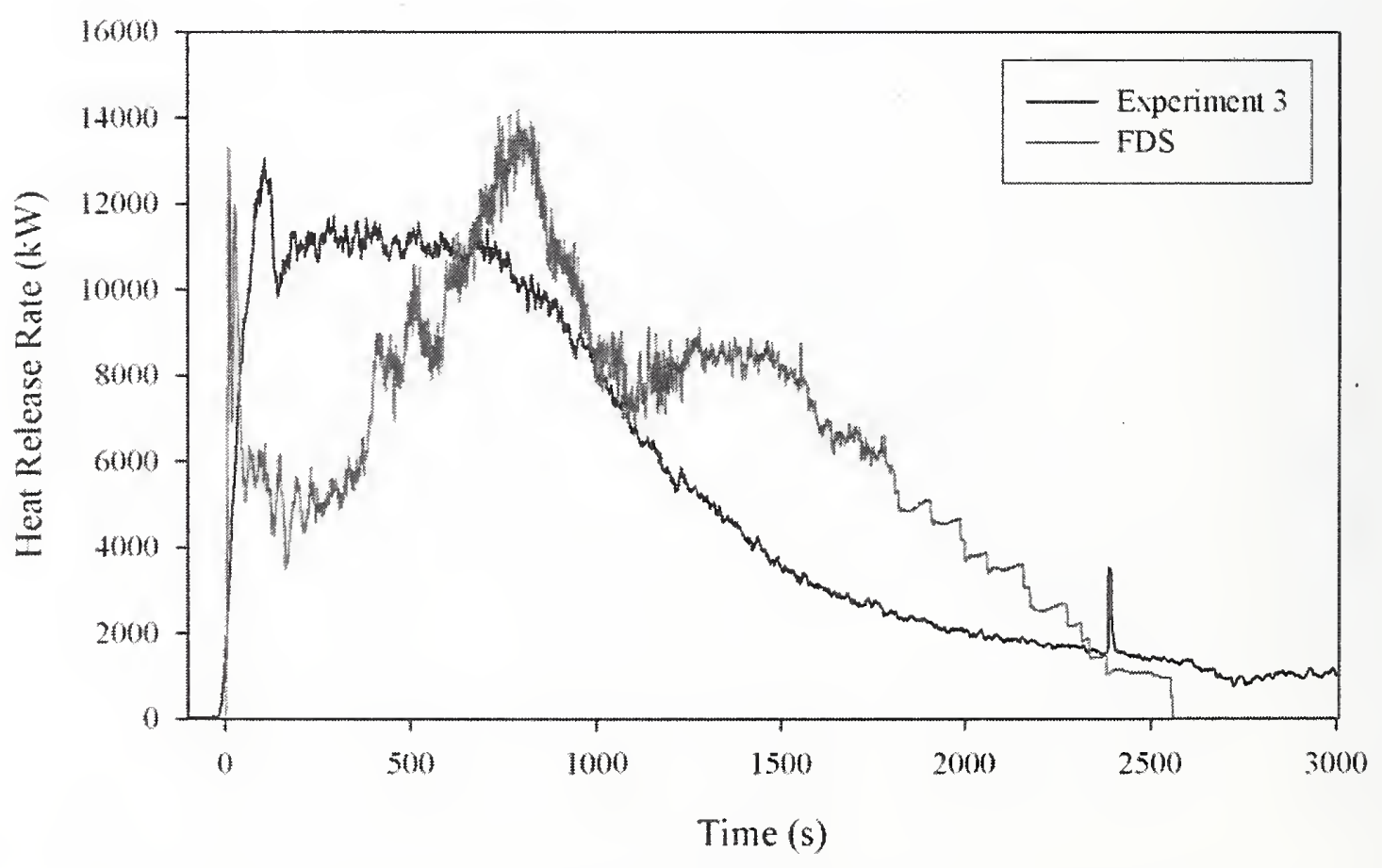

Figure 8-10. Comparison of the measured and simulated $\dot{Q}$ for Test 3. 


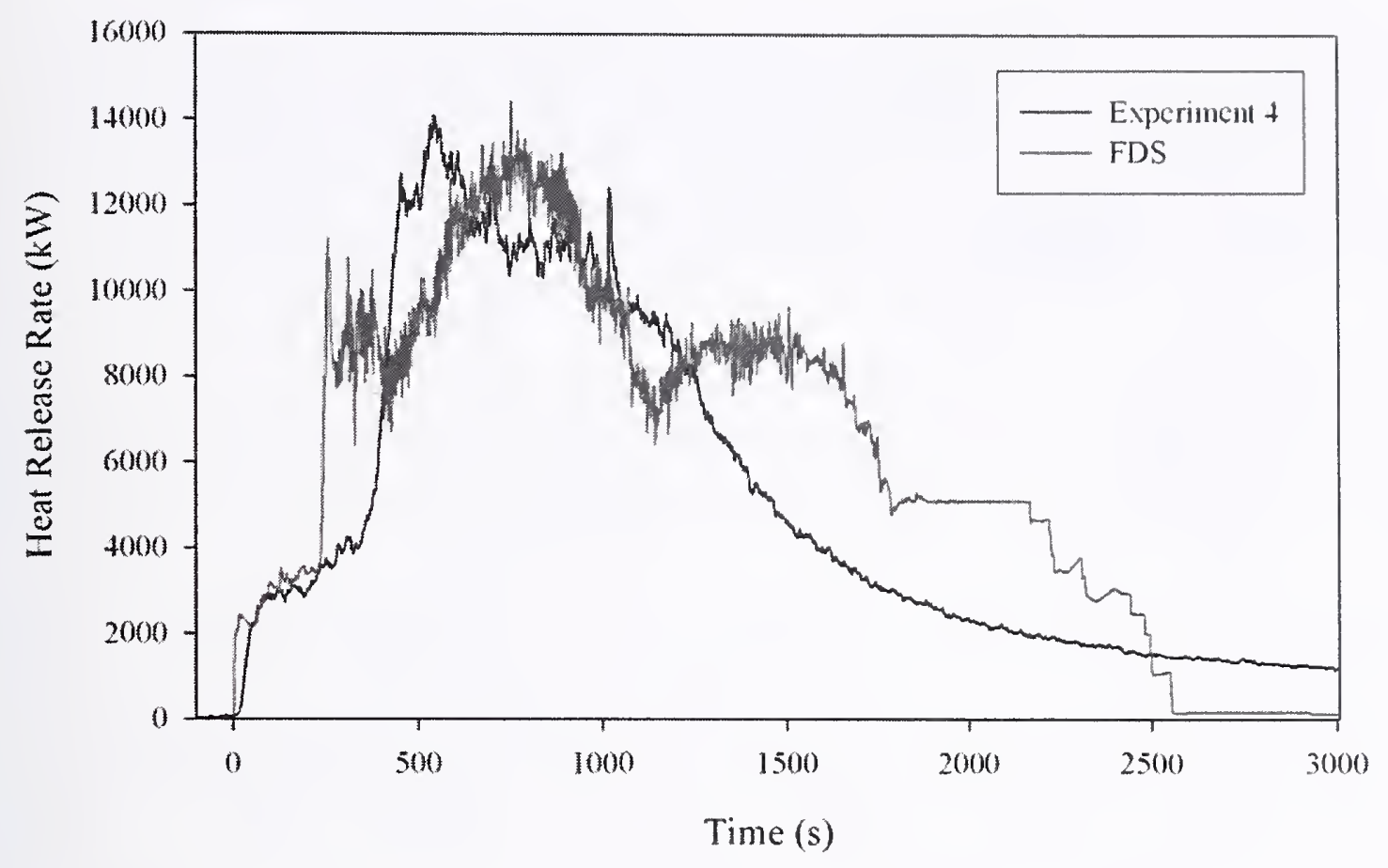

Figure 8-11. Comparison of the measured and simulated $\dot{Q}$ for Test 4 .

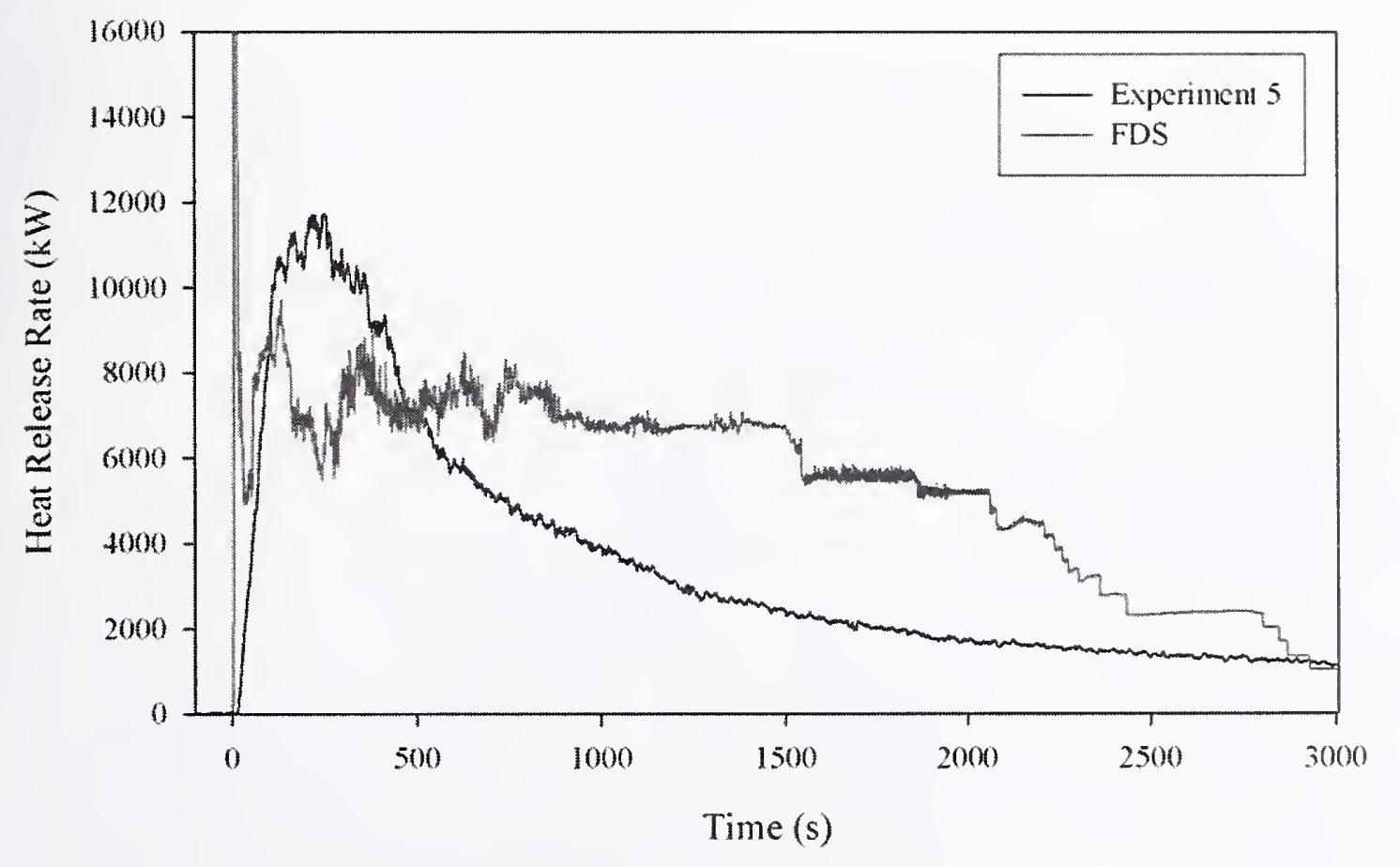

Figure 8-12. Comparison of the measured and simulated $\dot{Q}$ for Test 5. 


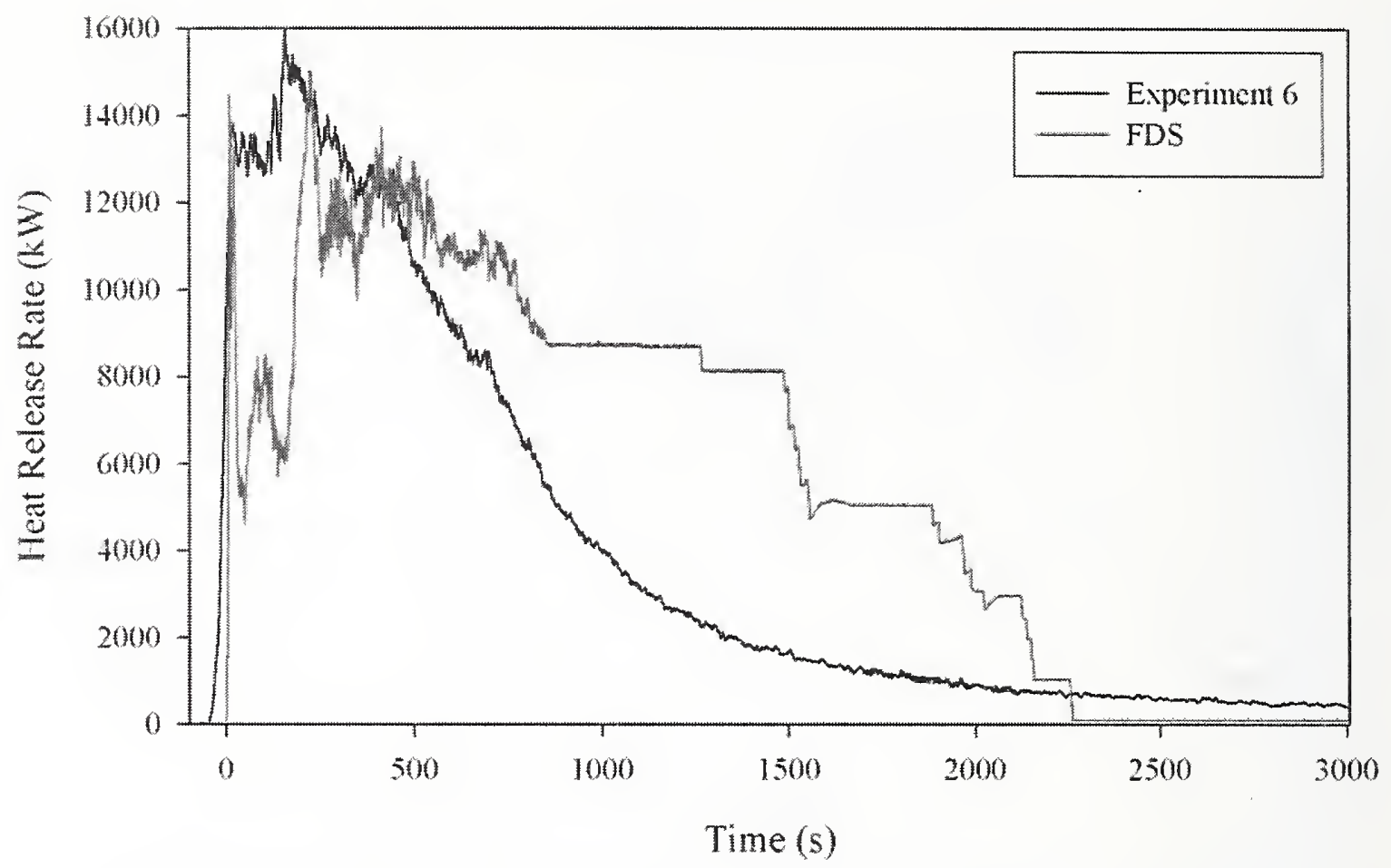

Figure 8-13. Comparison of the measured and simulated $\dot{Q}$ for Test 6 .

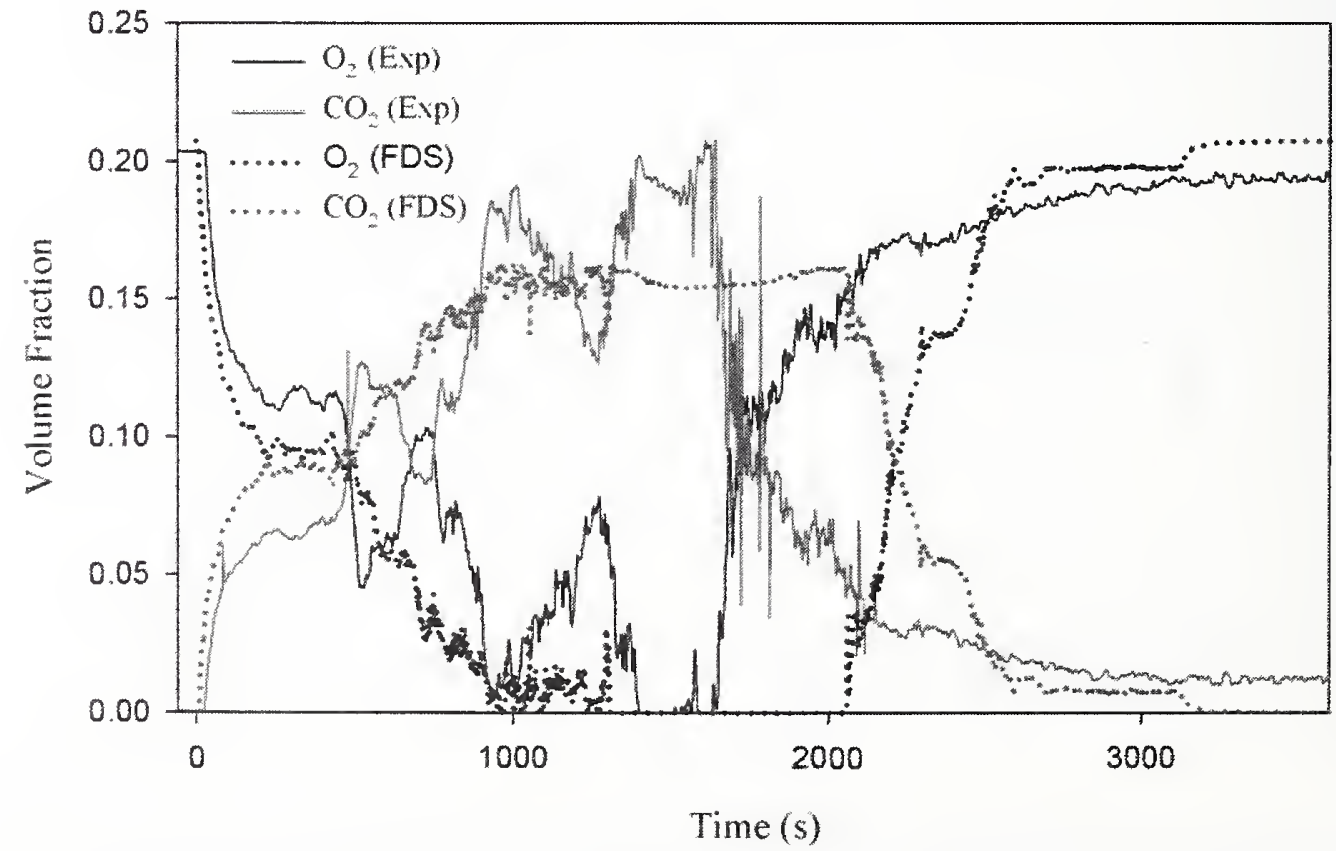

Figure 8-14. Comparison of the measured and simulated $\mathrm{O}_{2}$ and $\mathrm{CO}_{2}$ volume fractions on a dry basis for Test 1. 


\subsubsection{Discussion}

From a modeling perspcctive, the objcctive of the simulations of these expcriments was to demonstrate that a simplified model of a single office workstation can be uscd to predict the burning bchavior of a group of workstations in an enclosure with features similar to WTC 1,2, and 7. Due to the computational time required to simulate the WTC building fires, the modcl of the workstation must be fairly simple. However, because of the many uncertainties in the initial conditions of those fire simulations, the lack of detail in the model was not considercd a drawback.

The model eaptured many of the major features of the fire behavior measured during the experiments. This is seen for the measured upper layer temperatures $(2.5 \mathrm{~cm}$ from the ceiling) in Figs. $8-4$ through $8-7$ and for the heat release rates in Figs. 8-8 through 8-13. Additional data analogous to Figs. 8-4 through 8-7 for temperatures measured at thermocouple Trees 2 and 3 are presented in Appendix D.

Figures 8-8 through 8-13 compare the simulated and measured heat release rates for the six experiments. There were clearly similarities and differenees between the sets of curves. FDS was able to accurately predict the general shape and magnitude of the time dependent heat release rates. The areas under the curves were equal, guaranteed through model calibration based on the heat release rate measurements made during the single office workstation burn experiments (NIST NCSTAR 1-5C). FDS tended to under-predict the late heat release rate behavior of the slow burning pcriod of the fire when the heat release rate dropped below $1 \mathrm{MW}$ to $2 \mathrm{MW}$. When this long "tail" in the heat release rate curve was observed, FDS predicted that the fuel had already been eompletely eonsumed. Due to the relatively low heat release rate during this period, however, this behavior was considered to be of secondary significance in terms of the temperature of the upper gas layer and resulting thermal load on a structure.

The simulated $\dot{Q}$ for Tests 3,5 , and 6 showed a large spike at the start of the simulations, probably assoeiated with the Jet A fuel that had been distributed over the workstations and surrounding carpet. This was due to the fact that FDS uses a mixture fraction or a "mixed is burnt" combustion model in which vaporized fuel burns immediately upon mixing with the oxygen in the air. This spike (e.g., Figs. 8-11 and 8-12) was not observed in the experimental data since the fuel was absorbed more readily by the furnishings and thus required more time to burn. The jet fuel does significantly decrease the time to obtain the $\dot{Q}$ peak value, and this effect was captured by the model following the initial spurious spike.

In Test 5, Workstations 1 and 2 were disassembled prior to the burn and the contents placed on top of the respective load cells, and Workstation 3 was configured in a non-standard manner as described in Chapter 2 of this report. In this sense, Test 5 was a challenging experiment to model. No free burns of workstations in a similar eonfiguration had been performed, and this was the only test in which the simulated fuel packages were modified from the free-burn eonfiguration. To modcl this scenario, the burning rate of the collective fuel packages was redueed by one-half to aceount for the decreased surface area of the fuel package. The choice of one-half was somewhat ad hoc. In this regard, Test 5 can be considered a ealibration rather than a validation of the model. Reducing the burning rate of the fuel by one-half while maintaining the same fuel mass produeed reasonable results as seen in Fig. 8-12. The model adequately simulated the redueed duration of vigorous burning in the experiment subject to the general over-prediction of the slow burning period and early fuel burn-out. 
Tests 1 and 4 (Figs. 8-8 and 8-11, respectively) were similar in design except for the burner location. In Test 1, the burner was near the window openings; in Test 4 it was near the rear of the compartment. The peak heat release rate was measured to occur about $15 \mathrm{~min}$ after ignition in Test 1, whereas it occurred at about $10 \mathrm{~min}$ in Test 4 . The model showed a similar trend. The faster growth seen in Test 4 was probably due to the fact that the compartment heated up more quickly with the fire deep inside rather than near the vents, leading to more rapid spread of the fire across the pre-heated furnishings. Even though ceiling tiles were distributed over the desk and carpet in Test 4, this did not seem to have a noticeable effect on the fire growth, or at the very least the burner position seemed to have a far greater role in explaining the difference between Tests 1 and 4.

Quantitative comparison of the heat release rate curves was performed in the context of assessing the accuracy of FDS for use in simulating the fires on a full floor of workstations in the WTC. As estimated in NIST NCSTAR 1-5C, in excess of 40 workstations would have been burning concurrently in the WTC, but at various stages in their combustion "lifetimes." As the fires evolved, the key characteristics were how quickly a workstation became fully involved in the overall fire, the magnitude of the heat release rate at that time, and the time when it was no longer a significant contributor to the total heat release rate. The fire behavior was, thereby, represented by the time at which half of the total heat was released, the magnitude of the heat release rate at that time, and the time at which $\dot{Q}$ fell below $2 \mathrm{MW}$. This value was selected because below approximately $2 \mathrm{MW}$ combustion of the workstations was in its "slow" burning period (see the discussion in Chapters 4 and 5, and Figs. 4-8 and 5-2), when the mass loss rate was relatively small and the fires smoldered for long periods of time, typically for thousands of seconds. In this regard, the fire duration in this study was defined as the time of ignition to the time when $\dot{Q}$ fell below $2 \mathrm{MW}$. The value of the total heat release was determined over the same period.

Tables 8-1 through 8-3 summarize the degree of agreement between the simulated and measured $\dot{Q}$ profiles. Table 8-1 compares the simulated and measured $\dot{Q}$ when half of the total energy of the fire was released. On average, the value of $\dot{Q}$ was approximately $13 \mathrm{MW}$ for both the measurements and the simulations. The simulations over-predicted the measurements for one-half of the tests. The difference between the predictions and the measurements was 1.1 MW (or 9 percent) on average for Tests 1 through 4 and 6, which was within the 15 percent experimental uncertainty that is discussed in Chapter 5. As described above, Test 5 was a special case in which the experiments were in a non-standard configuration and those experiments should be regarded as a calibration rather than a validation. The reported $\dot{Q}$ for Tests 1 and 3 were not corrected for the contributions by the wall lining material (see Chapter 5), because the value of the period upon which the correction should be based is uncertain.

Table 8-2 compares the simulated and measured time when half of the total energy of the fire was released. The value of this time was approximately $900 \mathrm{~s}$ and $1,090 \mathrm{~s}$ for the measurements and simulations, respectively, and the difference was $190 \mathrm{~s}$ (or 22 percent) on average for Tests 1 through 4 , and 6 . The simulations were larger than the measurements for all of the tests. The largest differences were for Tests 5 and 6 . In Test 6 , additional ventilation was available to the fire several minutes into the test as the glass windows cracked and broke through. The model was somewhat low in the prediction of the early burning behavior of the fire. Table 8-3 compares the simulated and measured fire duration. The difference in the predictions and the measurements was $310 \mathrm{~s}$ (or 15 percent) on average for Tests 1 through 4 and 6 when the fire duration was on the order of 2,000 s. The simulations were larger than the measurements for all of the tests. 
Table 8-1. Heat release rate, $\dot{Q}$, when one-half of the energy was released.

\begin{tabular}{|c|c|c|c|}
\hline Test & Measured $\dot{Q}(\mathbf{M W})^{\mathbf{a}}$ & Simulated $\dot{Q}(\mathbf{M W})^{\mathbf{a}}$ & $\begin{array}{c}\text { Difference (MW) and } \\
\text { (Percentage Difference) }^{\mathbf{c}}\end{array}$ \\
\hline 1 & 12.1 & 11.4 & $-0.7(-6 \%)$ \\
\hline 2 & 9.9 & 11.4 & $1.5(14 \%)$ \\
\hline 3 & 11.5 & 13.7 & $1.8(14 \%)$ \\
\hline 4 & 13.9 & 13.2 & $-0.7(-5 \%)$ \\
\hline 5 & 11.7 & 8.3 & $-3.4(-34 \%)$ \\
\hline 6 & 15.6 & 14.7 & $0.9(6 \%)$ \\
\hline Average $^{\mathrm{d}}$ & $12.6 \pm 18 \%$ & $12.9 \pm 11 \%$ & $1.1(9 \%)$ \\
\hline
\end{tabular}

a. Using the definition that the total energy is released between the time of ignition and the time when the HRR falls to $2 \mathrm{MW}$.

b. Differenee $=($ Simulated - Measured $)$.

c. Percentage Difference $=100 \times 2 \times($ Simulated-Measured $) /($ Simulated + Measured $)$.

d. The value represents the average of the absolute value of the differences for Tests 1 through 4 and 6 .

Table 8-2. Time when one-half of the energy was released. ${ }^{a}$

\begin{tabular}{|c|c|c|c|}
\hline Test & Measured Time (s) & Simulated Time (s) & $\begin{array}{c}\text { Difference }(\mathrm{s})^{\mathrm{b}} \text { and } \\
\text { (Percentage Difference) }^{\mathrm{c}}\end{array}$ \\
\hline 1 & 1210 & 1,300 & $90(7 \%)$ \\
\hline 2 & 1120 & 1,300 & $180(14 \%)$ \\
\hline 3 & 750 & 970 & $230(26 \%)$ \\
\hline 4 & 920 & 1,040 & $120(12 \%)$ \\
\hline 5 & 540 & 1,110 & $570(78 \%)$ \\
\hline 6 & 510 & 830 & $320(49 \%)$ \\
\hline Average $^{d}$ & $900 \pm 31 \%$ & $1,090 \pm 19 \%$ & $190(22 \%)$ \\
\hline
\end{tabular}

a. Using the definition that the total energy is released between the time of ignition to the time when $\dot{Q}$ falls to $2 \mathrm{MW}$.

b. Difference $=($ Simulated - Measured $)$.

c. Percentage Difference $=100 \times 2 \times($ Simulated - Measured $) /($ Simulated + Measured $)$.

d. The value represents the average of the absolute value of the differences for Tests 1 through 4 and 6 .

Table 8-3. Fire duration. ${ }^{\mathrm{a}}$

\begin{tabular}{|c|c|c|c|}
\hline Test & Measured Duration (s) & Simulated Duration (s) & $\begin{array}{c}\text { Difference (s) }^{\mathbf{b}} \text { and (Percentage } \\
\text { Difference) }^{\mathbf{c}}\end{array}$ \\
\hline $\mathbf{1}$ & 2,540 & 2,610 & $70(3 \%)$ \\
\hline $\mathbf{2}$ & 2,340 & 2,610 & $270(11 \%)$ \\
\hline $\mathbf{3}$ & 2,110 & 2,320 & $210(9 \%)$ \\
\hline $\mathbf{4}$ & 2,190 & 2,490 & $310(13 \%)$ \\
\hline $\mathbf{5}$ & 1,720 & 2,850 & $1,120(47 \%)$ \\
\hline $\mathbf{6}$ & 1,450 & 2,150 & $700(39 \%)$ \\
\hline Average $^{\mathbf{d}}$ & $2,130 \pm 19 \%$ & $2,440 \pm 8 \%$ & $310(15 \%)$ \\
\hline
\end{tabular}

a. The duration is defined as the time from ignition to the time when $\dot{Q}$ falls to $2 \mathrm{MW}$.

b. Differenee $=($ Simulated - Measured $)$.

c. Percentage Difference $=100 \times 2 \times($ Simulated - Measured $) /($ Simulated + Measured $)$.

d. The value represents the average of the absolute value of the differences for Tests 1 through 4 and 6 . 
Figures 8-4 through 8-7 show the measured and simulated temperatures on two thermocouples for each of the four trees in Test 1. The simulations show trends similar to the measurements with the simulated and measured profiles increasing, obtaining one or more peaks, and then decreasing later in the experiments. The peak values were in general agreement although there were some differences in the time at which they occurred. The agreement between the curves is driven to a large extent by the agreement in the simulated and measured heat release rates. Accurate prediction of the upper layer of the compartment temperature depends on an accurate prescription of the fire $\dot{Q}$. According to an empirical correlation by McCaffrey, Quintiere and Harkleroad (Walton and Thomas 2003), the rise in the upper layer gas temperature $\Delta T_{g}$ in a compartment is related to the overall $\dot{Q}$ by the relation:

$$
\Delta T_{g}=6.85\left(\frac{\dot{Q}^{2}}{A_{0} \sqrt{H_{0}} h_{k} A_{T}}\right)^{1 / 3}
$$

where:

$$
\begin{aligned}
& A_{0}=\text { area of openings }\left(\mathrm{m}^{2}\right) \\
& H_{0}=\text { height of openings }(\mathrm{m}) \\
& A_{T}=\text { total area of compartment surfaces }\left(\mathrm{m}^{2}\right) \\
& h_{k}=k / \delta \\
& k=\text { thermal conductivity of walls }(\mathrm{kW} / \mathrm{m} / \mathrm{K}) \\
& \delta=\text { wall thickness }(\mathrm{m})
\end{aligned}
$$

Equation 8-1 shows that the temperature rise in a compartment is proportional to $\dot{Q}$ to the $2 / 3$ power. At the time when half of the energy was released, for example, the difference between the measured and simulated peak values of $\dot{Q}$ were about 9 percent (see Table $8-1$ ). According to Eq. 8-1, a 9 percent discrepancy in $\dot{Q}$ corresponds to a 6 percent discrepancy in the temperature rise $(=2 / 3 \times 9 \%)$. For temperatures of approximately $1,000{ }^{\circ} \mathrm{C}$, this translates to roughly a $\pm 90{ }^{\circ} \mathrm{C}$ temperature difference between measurements and simulations due solely to differences in the measured and simulated values of $\dot{Q}$. The comparison of the measured and simulated temperatures considered the values of the peak temperature, which were considered representative of the level of agreement. The average difference between the simulated and measured peak temperatures shown in Figs. 8-4 through 8-7 for Test 1 and in Figures D-1 through D-20 (in Appendix D) for Tests 2 through 6 was $90^{\circ} \mathrm{C}$, which was in accord with the sensitivity to differences in $\dot{Q}$. The thermocouple measurement uncertainty of approximately $100{ }^{\circ} \mathrm{C}$ for the peak temperatures was also considered, and the agreement between measurements and simulations, therefore, was regarded as good.

Figure 8-14 shows that the measured and the simulated $\mathrm{O}_{2}$ and $\mathrm{CO}_{2}$ volume fractions in Test 1 were in good agreement while the fire was rapidly burning. The model under-predicted the $\mathrm{O}_{2}$ volume fraction at the rear of the compartment for a few hundred seconds as the heat release rate began to rapidly decrease. This is simply a result of not accurately predicting the exact duration of the fire. Comparison of the $\mathrm{CO}$ 
concentration is not presented, as the mixturc fraction chcmistry model in FDS docs not adcquatcly predict combustion intermediates such as $\mathrm{CO}$.

\subsection{SUMMARY}

In an assessment of the model, it is important to maintain pcrspective on the accuracy required to reconstruct the actual WTC fires or fires that were sufficiently severe that they threatened the structural integrity of the building, many workstations burned concurrently. The workstations were at various stages of their combustion, and the aggregate burning of a large group of workstations is expected to average any over-predictions or under-predictions of the heat release rate, which will improve modcl accuracy. The sign of errant prediction of the WTC fires, if any occurred, would be the prediction of too short a burning time. Thus, in the simulations of the WTC fires, this output feature should be checked against observations.

In summary, the peak $\dot{Q}$ and temperature were predicted within measurement uncertainty. The duration of significant heating by the fires was also well represented by the model, although the long tail in the heat release rate curve was under-predicted. Both the peak values and the duration of the heat release rate are important for the WTC simulations because it is not only important to predict the temperatures that the structural steel was exposed to, but also the duration of the exposure. In the actual WTC fires, the degree of damage to the workstations by aircraft is unknown, which introduces an additional degree of complexity and uncertainty to the analysis results. The results of this study demonstrate that FDS provides an adequate representation of the thermal environment during the WTC fires.

\subsection{REFERENCES}

Hamins, A., Maranghides, A., and Mulholland, G. 2003. The Global Combustion Behavior of 1 MW to 3 MW Hydrocarbon Spray Fires Burning in an Open Environment, NISTIR 7013, National Institute of Standards and Technology, Gaithersburg, MD, June.

Hamins, A., and McGrattan, K. B. 2003. "Reduced-Scale Experiments on the Water Suppression of a Rack-Storage Commodity Fire for Calibration of a CFD Fire Model." Fire Safety Science: Proceedings of the Seventh International Symposium. International Association for Fire Safety Science, 457-468.

McGrattan, K. B., ed. 2004. Fire Dynamics Simulator (Version 4), Teclinical Reference Guide. NIST Special Publication 1018. National Institute of Standards and Technology, Gaithersburg, MD, July.

McGrattan, K. B., Hamins, A., and Stroup, D. W. 1998. Sprinkler, Smoke and Heat Vent, Draft Curtain Interaction: Large Scale Experiments and Model Development. NISTIR 6196-1, National Institute of Standards and Technology, Gaithersburg, MD, September.

Ritchie, S. J., Steckler, K. D., Hamins, A., Cleary, T., Yang J., and Kashiwagi, T. 1997. "The Effect of Sample Size on the Heat Release Rate of Charring Materials," Proceedings of the Fifth International Symposium on Fire Safety Science, 177-188.

Taylor, R. E., Groot, H., and Ferrier, J. 2003. Thermophysical Properties of PVC, PE, and Marinite, Report No. TPRL 2958, Thermophysical Properties Research Laboratory, Inc.. April. 
Walton, W. D., and P. H. Thomas. 2003. "Estimating Temperatures in Compartment Fires." Fire Protection Handbook, $3^{\text {rd }}$ Ed. National Fire Protection Association, Quincy MA. 


\section{Chapter 9 \\ SUMMARY OF RESULTS}

A series of large-scale compartment fires experiments was conducted in an effort to validate aspccts of model calculations conducted using the National Institutc of Standards and Technology (NIST) Fire Dynamic Simulator (FDS). This report describcs measurcments that were conducted to assess the accuracy of the FDS fire model, which was used to simulate the fires and their thermal impact on structural components in the investigation of the World Trade Center (WTC) fire and collapse. This study involved a series of wcll-controlled cxperiments that were dcsigned to recreate aspects of the WTC fire, including issues associated with limited ventilation, fire spread and growth on real furnishings, the effect of inert ceiling tiles, and the effects of debris and jet fuel on the hcat release rate of the fires. The experimental compartment was instrumented so that sevcral aspects of the model were tested. Model calculations were performed before testing began to provide a baselinc set of "blind" predictions. The objective of the study was to assess the accuracy with which the NIST FDS predicted the thermal environment in a burning compartment and to establish a data set to validate the prediction of the heat release rate associated with the burning of the furnishings. The accuracy of the model was assessed with consideration of experimental uncertainty.

Using a large compartment, office workstations were burned under conditions that recreated aspects similar to those that occurred on September 11, 2001. Three computer workstations that were composed of tables, desks, fabric-lined partitions, carpeting, a task chair, paper-filled filing cabinets and bookshelves, a personal computer, keyboard, and monitor, wcre placed within a steel-frame compartment (nominally $3 \mathrm{~m}$ by $7 \mathrm{~m}$ by $4 \mathrm{~m}$ high) lined with calcium silicate boards. The workstations were representative of typical office furnishings, not unlike those found in WTC 1,2, and 7. The same configuration of furnishings was used in all of the experiments, except one test in which the workstation components were rearranged and broken into component pieces to represent a disrupted (non-standard) configuration, which may have occurred after aircraft entered the WTC structure. In some experiments, several liters of jet fuel were distributed about the workstation components, and in some experiments, ceiling tiles were distributed about the compartment. A $2 \mathrm{MW}$ hydrocarbon fire, burning for as long as $10 \mathrm{~min}$, was used to ignite the compartment furnishings. The fire was generated by a liquid fuel spray, which was directed onto a $1 \mathrm{~m}$ by $2 \mathrm{~m}$ pan from four nozzles. The fuel used was a commercial blend of heptane isomers.

Six fire experiments were conducted, and nearly 50 instruments were used, to measure a number of important variables, including the heat release rate of the fire, and the vertical profiles of gas phase temperature. The overall fire behavior was documented using video cameras viewing the fire from different orientations. Following the establishment of baseline signals from all the measurement devices, the spray burner, and the jet fuel, when present, were ignited. The spray fire continued to burn at a steady rate for $10 \mathrm{~min}$ (or $2 \mathrm{~min}$ if jet fuel was present). The fire itself spread through the workstations and was allowed to burn until the compartment contents had become an unrecognizable charred jumble and the 
heat release rate was small, which was typically 1 hour after fire initiation. The measurements led to findings regarding the thermal behavior of the compartment and the importance of the jet fuel and the presence of the ceiling tiles:

- In the presence of jet fuel, fire spread rapidly, and the heat release rate rapidly increased, reaching a maximum within a few minutes.

- The ceiling tiles had little apparent impact on the rate of fire spread or the heat release rate.

- Upper layer temperatures obtained values as high as $800^{\circ} \mathrm{C}$ to $1,200{ }^{\circ} \mathrm{C}$ after $20 \mathrm{~min}$ to $30 \mathrm{~min}$ of exposure, depending on the test conditions and the location within the compartment.

- The measured mass loss burning rate of workstations reconfigured into "rubble" to represent what may have occurred after aircraft entered the WTC structure was about 40 percent smaller than workstations burning in a standard configuration.

- Comparison of the measured heat release rates to analogous measurements for single workstations burning in the open suggested that the burning conditions were underventilated or oxygen limited.

The FDS software was used to simulate the heat release rate and thermal environment in a complex fire environment involving limited ventilation, realistic furnishings, and a compartment configuration that mimicked many aspects of the WTC buildings. The numerical accuracy of the FDS predictions was quantitatively compared with the measurements. The findings can be summarized as follows:

- FDS was able to accurately predict the general shape and magnitude of the time dependent heat release rate.

- FDS predicted the time at which one-half of the energy was released to within approximately 3 min or 22 percent of the measurements.

- FDS predicted the value of the heat release rate when one-half of the energy was released to within 1.1 MW or 9 percent of the measurements on average, which was good agreement considering the measurement uncertainty.

- FDS predicted the duration of significant heating of the fires to within approximately 6 min or 15 percent of the measurements on average, although the long tail in the heat release rate curve was under-predicted.

- FDS predicted the peak upper layer gas temperature to within approximately 10 percent of the measurements on average, which was accurate considering model sensitivity to input parameters such as the heat release rate and uncertainties associated with the measurement.

The results of the comparison of the FDS calculations with measurements yielded confidence in the application of FDS to the analysis of the thermal environment in compartments with office workstations experiencing a fire, which is a key part of the WTC Investigation. 


\section{Appendix A \\ LOCATION OF COMPARTMENT CONTENTS AND INSTRUMENTATION}

The detailed coordinates of essential compartment contents and the instrumentation are listed in Tables A-1 and A-2, respectively. The origin $(0,0,0)$ is located in the southwest corner of the compartment, inside the external pillars, just outside the kneewall and on the floor as shown in Fig. 2-1. All measurements are relative to the origin.

Table A-1. Location of compartment contents.

\begin{tabular}{|l|c|c|c|}
\hline \multirow{2}{*}{\multicolumn{1}{|c|}{ Compartment Item }} & \multicolumn{2}{c|}{ Location (cm) } \\
\cline { 2 - 4 } & x-east & y-north & z-up \\
\hline Fire pan SW corner & 38 & 67 & 96 \\
\hline Fire pan NW corner & 119 & 64 & 95 \\
\hline Fire pan SE corner & 42 & 267 & 95 \\
\hline Fire pan NE corner & 124 & 264 & 95 \\
\hline Workstation 1 SW corner & 161 & 46 & 155 \\
\hline Workstation 1 NW corner & 164 & 103 & 121 \\
\hline Workstation 1 SE corner & 417 & 48 & 122 \\
\hline Workstation 1 NE corner & 419 & 305 & 121 \\
\hline Workstation 2 SW corner & 410 & 49 & 157 \\
\hline Workstation 2 NW corner & 420 & 306 & 121 \\
\hline Workstation 2 SE corner & 669 & 46 & 122 \\
\hline Workstation 2 NE corner & 678 & 303 & 122 \\
\hline Workstation 3 SW corner & 420 & 397 & 122 \\
\hline Workstation 3 NW corner & 420 & 655 & 157 \\
\hline Workstation 3 SE corner & 678 & 393 & 122 \\
\hline Workstation 3 NE corner & 678 & 655 & 122 \\
\hline
\end{tabular}


Table A-2. Location of instrumentation.

\begin{tabular}{|l|c|c|c|}
\hline \multirow{2}{*}{\multicolumn{1}{|c|}{ Instrument }} & \multicolumn{2}{c|}{ Location (cm) } \\
\cline { 2 - 4 } & x-east & y-north & z-up \\
\hline Thermocouple Tree 1 & 285 & 351 & $62,153,245,333^{\text {a }}$ \\
\hline Thermocouple Tree 2 & 564 & 351 & $62,153,245,333^{\text {a }}$ \\
\hline Thermocouple Tree 3 & 821 & 351 & $62,153,245,333^{\text {a }}$ \\
\hline Thermocouple Tree 4 & 969 & 575 & $32,122,62,153,245$, \\
\hline Aspirated thermocouples & 969 & 578 & $333^{\text {a.b }}$ \\
\hline Upper layer gas sampling & 970 & 351 & 272 \\
\hline Workstation 1 thermocouple, underside west & 230 & 80 & 74 \\
\hline Workstation 1 thermocouple, desktop & 313 & 80 & 77 \\
\hline Workstation 1 thermocouple, underside east & 374 & 80 & 74 \\
\hline Workstation 2, thermocouple, underside west & 479 & 87 & 74 \\
\hline Workstation 2 thermocouple 2, desktop & 567 & 87 & 76 \\
\hline Workstation 2 thermocouple, underside east & 618 & 87 & 74 \\
\hline Workstation 3 thermocouple, underside west & 461 & 610 & 74 \\
\hline Workstation 3 thermocouple, desktop & 519 & 610 & 9 \\
\hline Workstation 3 thermocouple, underside east & 611 & 610 & 76 \\
\hline Video cameras: & & & 74 \\
\hline 1. external: looking from outside through vents & 350 & $\approx-1,300$ & 700 \\
\hline 2. internal: & 125 & 160 & Exhaust hood sampling \\
\hline 3. internal: & 1,089 & & \\
\hline Calorimetry system & & & 74 \\
\hline
\end{tabular}

a. Thermocouple trees had four thermocouples, located at different heights.

b. Two additional thermocouples ( $32 \mathrm{~cm}$ and $122 \mathrm{~cm}$ above the floor) were added to Tree 4 during Tests 1 and 2 . 


\section{Appendix B \\ GAS ANALYZER DATA}

The gas analyzer data sheet shown below provides information on the gas analyzers used for calorimetry and for the determination of gas concentrations from sampling within the compartment.

\section{CONTINUOUS GAS SAMPLING DATA SHEET}

Date:

DAQ File Name:

\section{Calorimeter Analyzers}

\begin{tabular}{|c|c|}
\hline $\begin{array}{l}\text { Servomex } 540 \mathrm{~A} \mathrm{O}_{2} \text { Analyzer } \\
0-25 \%=0-1 \text { Volt } \\
\text { Zero gas: } \mathrm{N}_{2}\end{array}$ & $\begin{array}{l}\text { NIST ID: } 549709 \text { S/N: --a } 4 \text { (no units) } \\
\text { Flow: Bypass } 2.4 \text {, Sample } \\
\text { Span gas: Breathing Grade Compressed Air }\end{array}$ \\
\hline $\begin{array}{l}\text { Siemens Ultramat } 5 E \text { CO Analyzer } \\
0-20 \text { mA Output, } 249 \Omega 0.1 \% \text { resistor }\end{array}$ & $\begin{array}{l}\text { NIST ID: } 559934 \text { S/N: D8-562 } \\
\text { Flow: } 1 \text { pm }\end{array}$ \\
\hline Zero Gas: $\mathrm{N}_{2}$ & $\begin{array}{l}\text { Span Gas: Matheson } 4.004 \% \text { CO, } 9.017 \% \\
\mathrm{CO}_{2}, \mathrm{~N}_{2} \text { balance, Lot\# } 102-36-00269 \text {, Cyl. \# } \\
17453 \text {, Exp. 01/21/06, NIST Cert: } 194474-1\end{array}$ \\
\hline Ranges: $0-3 / 5 / 10 / 20 \%$ & Range Constants: $0.620 / 1.034 / 2.069 / 4.0$ \\
\hline $\begin{array}{l}\text { Siemens Ultramat } 5 \mathrm{E} \mathrm{CO}_{2} \text { Analyzer } \\
0-20 \mathrm{~mA} \text { Output, } 249 \Omega 0.1 \% \text { resistor }\end{array}$ & $\begin{array}{l}\text { NIST ID: } 561170 \text { S/N: DN-683 } \\
\text { Flow: } 1 \mathrm{pm}\end{array}$ \\
\hline Zero Gas: $\mathrm{N}_{2}$ & $\begin{array}{l}\text { Span Gas: Matheson } 4.004 \% \text { CO, } 9.017 \% \\
\mathrm{CO}_{2}, \mathrm{~N}_{2} \text { balance, Lot\# 102-36-00269, Cyl. \# } \\
17453 \mathrm{P} \text {, Exp. 01/21/06, NIST Cert: 194474-1 }\end{array}$ \\
\hline Ranges: $0-5 / 10 / 30 / 50 \%$ & Range Constants: $1.033 / 2.026 / 6.203 / 4.0$ \\
\hline
\end{tabular}

\section{Ceiling Sample - Rack \#2}

\begin{tabular}{|c|c|c|}
\hline 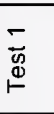 & $\begin{array}{l}\text { Columbus Instruments Paramax } 101 \\
0-25 \%=4-20 \mathrm{~mA}, 249 \Omega 0.1 \% \text { resistor } \\
\text { Zero gas: } \mathrm{N}_{2}\end{array}$ & $\begin{array}{l}\text { NIST ID: } 605206 \text { S/N: 02470-1-w/Display } \\
\text { Flow: } 2 \text { SCFH (0.94 LPM) } \\
\text { Span gas: Breathing Grade Compressed Air }\end{array}$ \\
\hline \multirow{3}{*}{ o } & Servomex 4100 Gas Purity 02 analyzer & NIST ID: 609438 \\
\hline & $0-25 \%=0-20 \mathrm{~mA}, 249 \Omega 0.1 \%$ resistor & Flow: $200 \mathrm{~mL}$ per minute \\
\hline & Zero gas: $\mathrm{N}_{2}$ & Span gas: Breathing Grade Compressed Air \\
\hline \multirow{2}{*}{\multicolumn{2}{|c|}{$\begin{array}{l}\text { Siemens Ultramat } 5 E \text { CO Analyzer } \\
0-20 \text { mA Output, } 249 \Omega 0.1 \% \text { resistor } \\
\text { Zero Gas: } N_{2}\end{array}$}} & $\begin{array}{l}\text { NIST ID: } 566024 \text { S/N: E9-955 } \\
\text { Flow: } 1 / p m\end{array}$ \\
\hline & & $\begin{array}{l}\text { Span Gas: Matheson } 7.0018 \% \mathrm{CO} \text {, } \\
18.0012 \% \mathrm{CO}_{2}, \mathrm{~N}_{2} \text { balance, Lot\# 102-26- } \\
\text { 2403, Cyl. \# AH019996, Exp06/19/05, NIST } \\
\text { Cert: } 107-304\end{array}$ \\
\hline \multicolumn{2}{|c|}{ Ranges: $0-3 / 5 / 10 / 20 \%$} & Range Constants: $0.623 / 1.033 / 2.066 / 4.0$ \\
\hline \multirow{2}{*}{\multicolumn{2}{|c|}{$\begin{array}{l}\text { Siemens Ultramat } 5 \mathrm{E} \mathrm{CO}_{2} \text { Analyzer } \\
0-20 \mathrm{~mA} \text { Output, } 249 \Omega 0.1 \% \text { resistor } \\
\text { Zero Gas: } \mathrm{N}_{2}\end{array}$}} & $\begin{array}{l}\text { NIST ID: } 566026 \text { S/N: E9-959 } \\
\text { Flow: } 1 \mathrm{lpm}\end{array}$ \\
\hline & & $\begin{array}{l}\text { Span Gas: Matheson } 7.0018 \% \mathrm{CO} \text {, } \\
18.0012 \% \mathrm{CO}_{2}, \mathrm{~N}_{2} \text { balance, Lot\# 102-26- } \\
2403 \text {, Cyl. \# AHO19996, Exp06/19/05, NIST } \\
\text { Cert: } 107-304\end{array}$ \\
\hline \multicolumn{2}{|c|}{ Ranges: $0-5 / 10 / 30 / 50 \%$} & Range Constants: $1.036 / 2.069 / 6.217 / 4.0$ \\
\hline
\end{tabular}


This page intentionally left blank. 


\section{Appendix C \\ Gas Phase Temperatures}

Chapter 6 presents representative measurements of the gas phase temperature. This appendix presents the measured time-temperature histories (Figs. $\mathrm{C}-1$ through $\mathrm{C}-12$ ) recorded by the bare bead thermocouples located on Thermocouple Trees 2 and 3 during Tests 1 through 6.

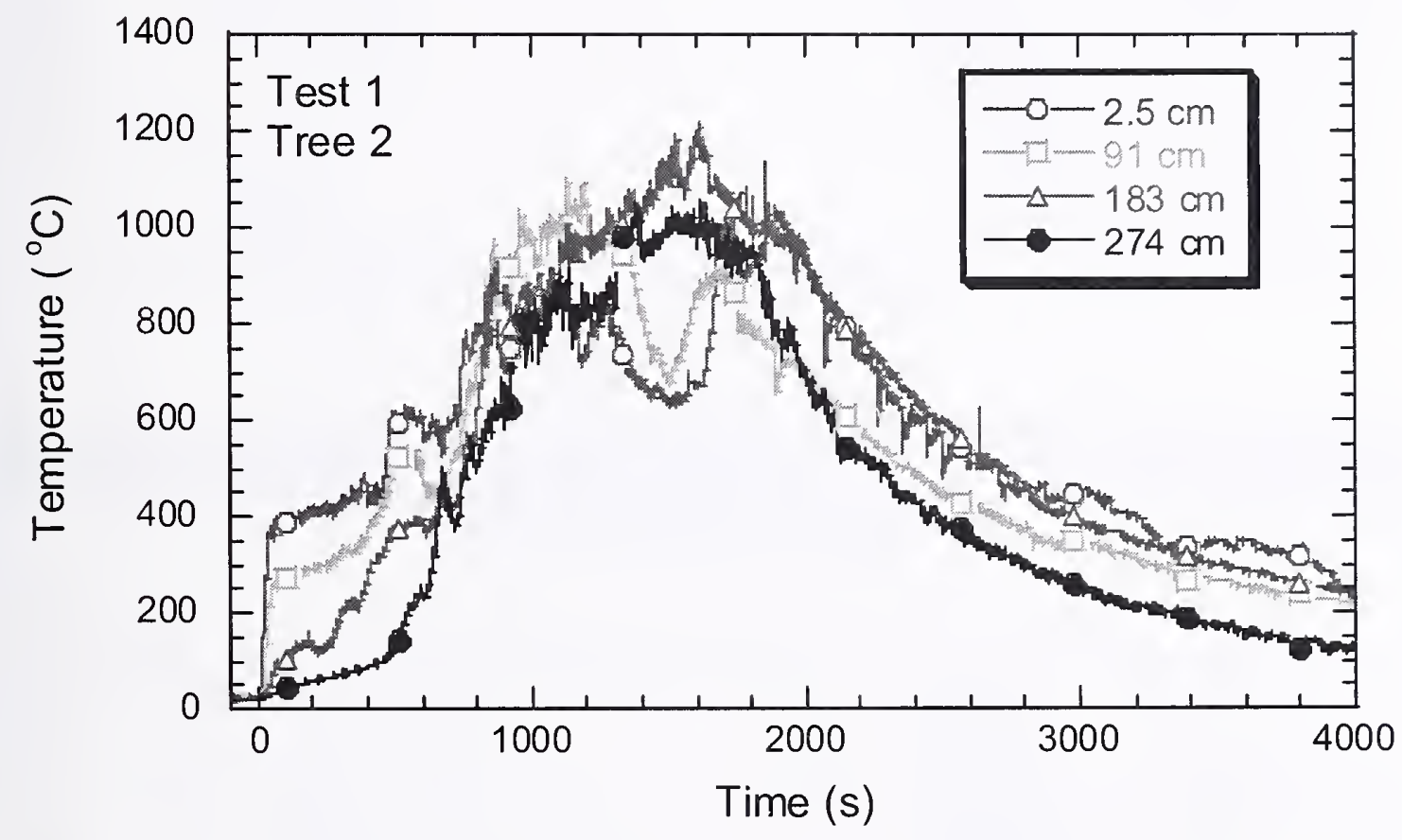

Figure C-1. Bare bead thermocouple measurements as a function of time at four locations (below the ceiling) on Tree 2 during Test 1. 


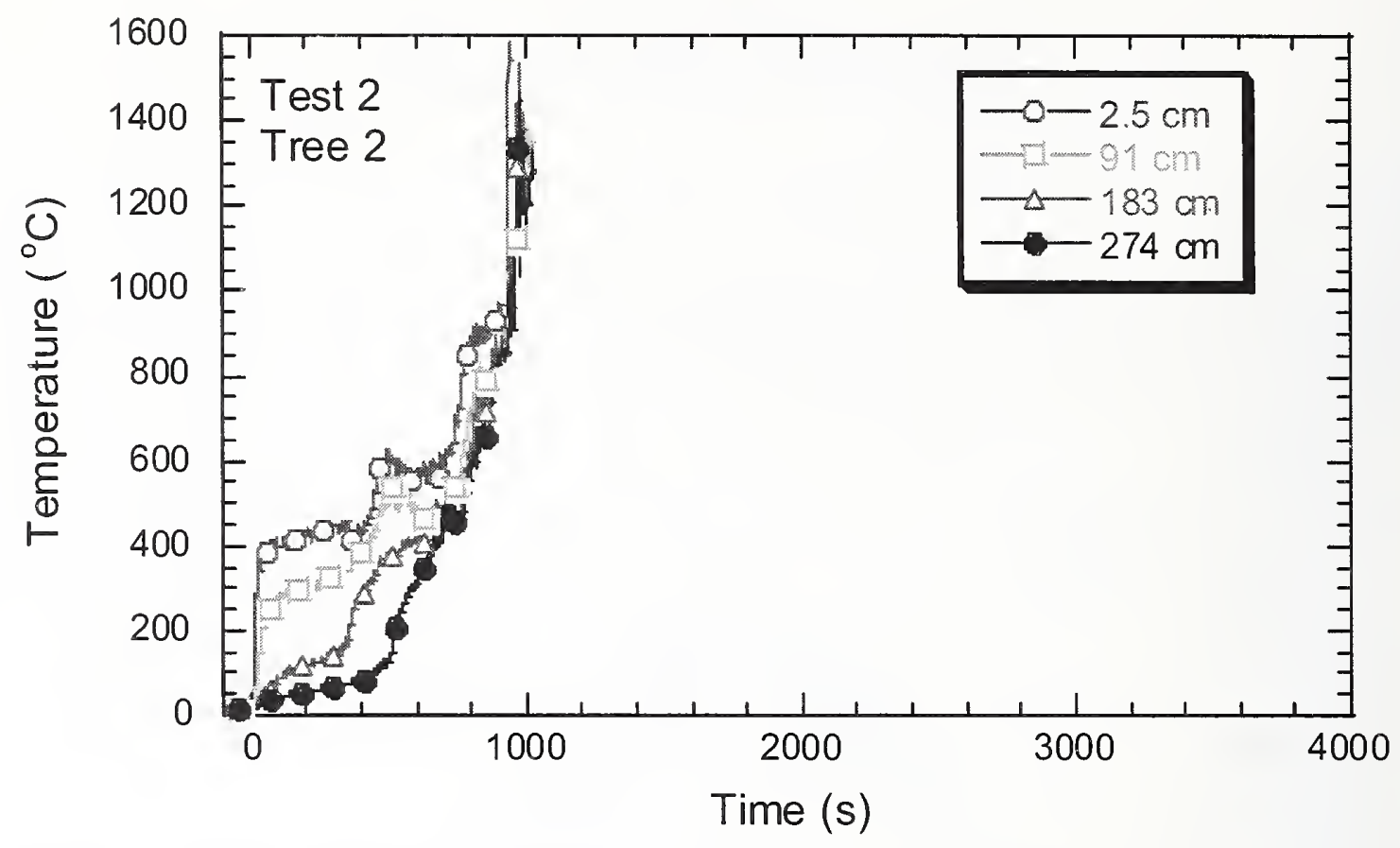

Figure $\mathrm{C}-2$. Bare bead thermocouple measurements as a function of time at four locations (below the ceiling) on Tree 2 during Test 2 . After approximately $1,000 \mathrm{~s}$, the thermocouples failed in this test.

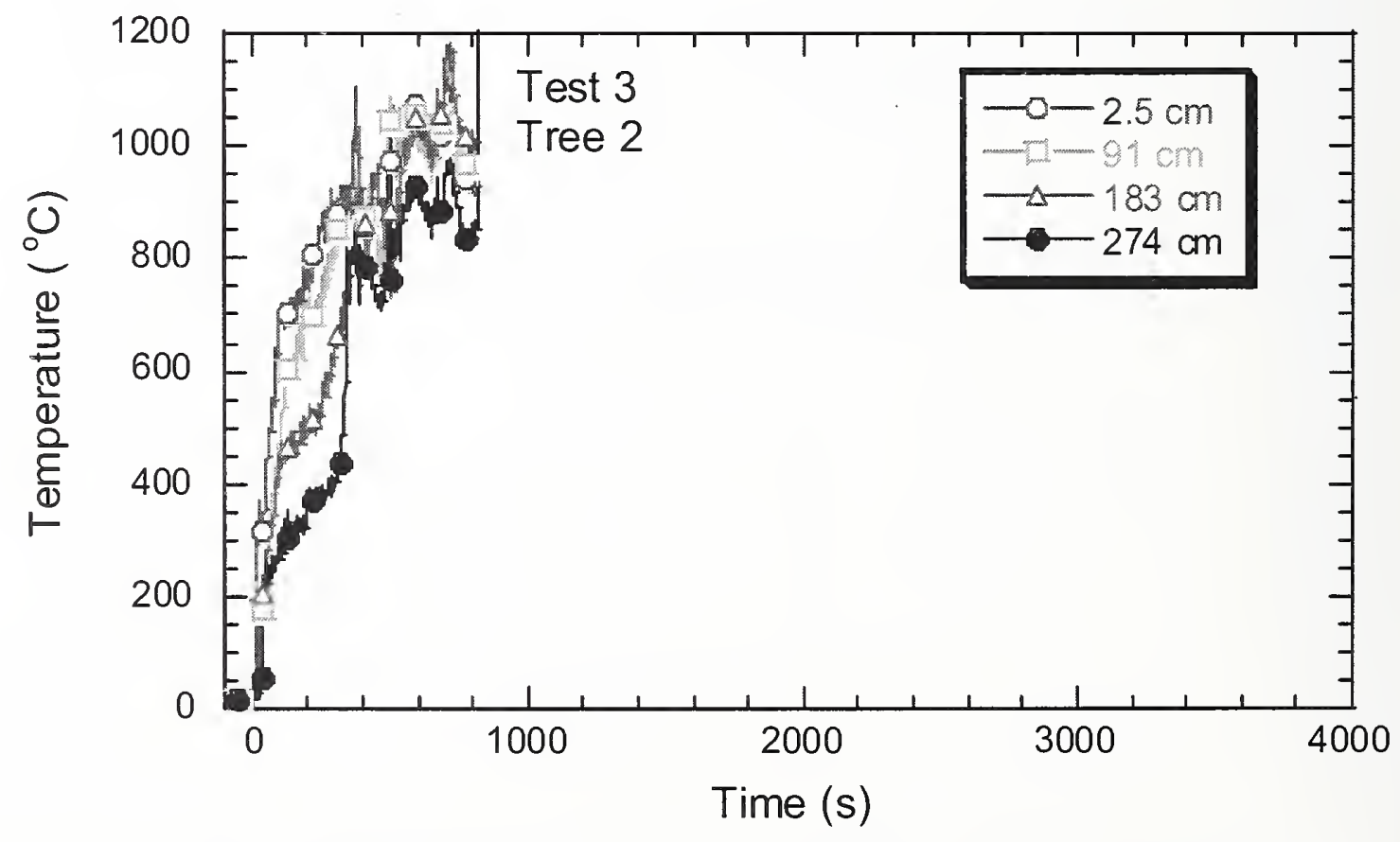

Figure C-3. Bare bead thermocouple measurements as a function of time at four locations (below the ceiling) on Tree 2 during Test 3 . After approximately $800 \mathrm{~s}$, the thermocouples failed in this test. 


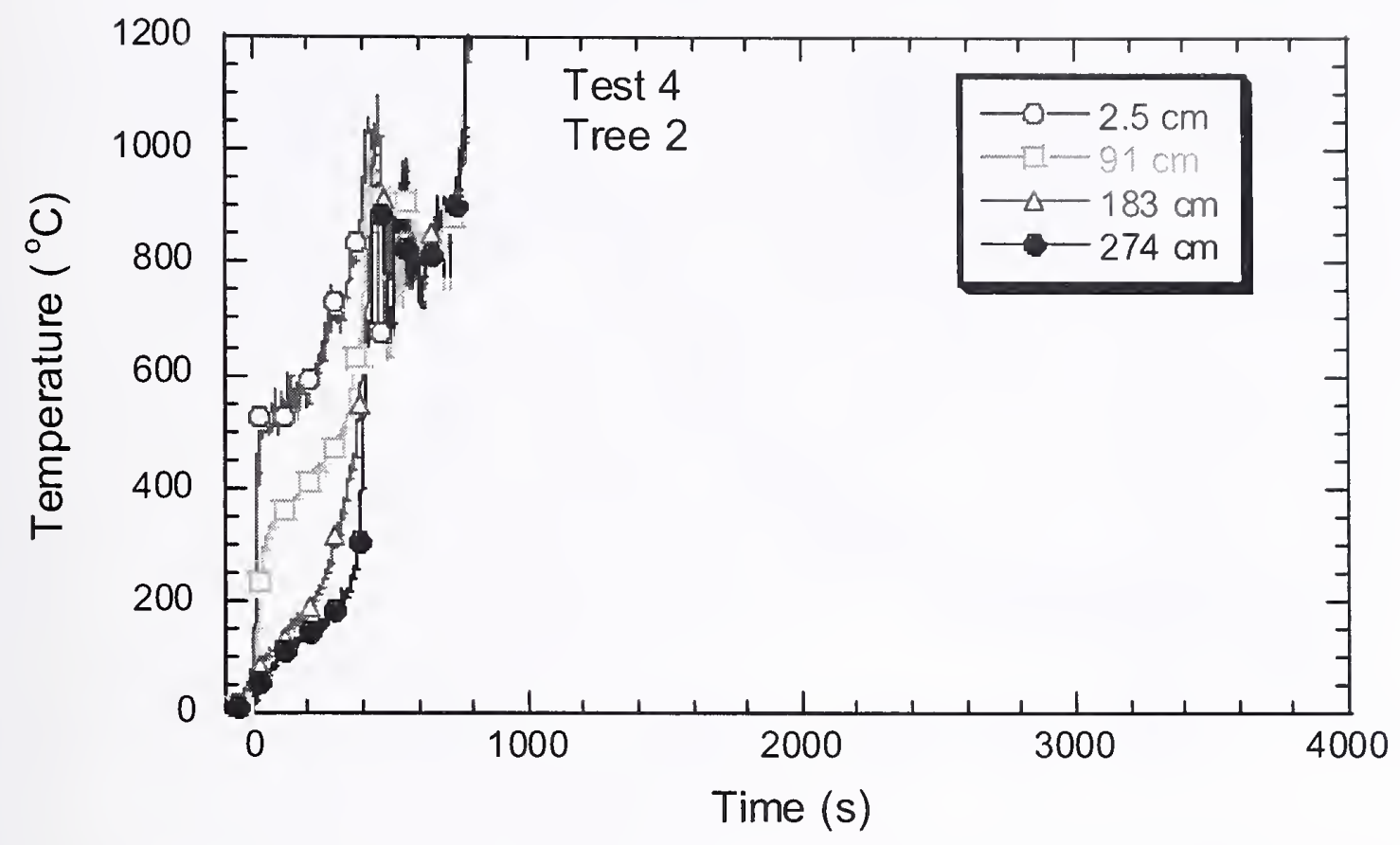

Figure C-4. Bare bead thermocouple measurements as a function of time at four locations (below the ceiling) on Tree 2 during Test 4 . After approximately $750 \mathrm{~s}$, the thermocouples failed in this test.

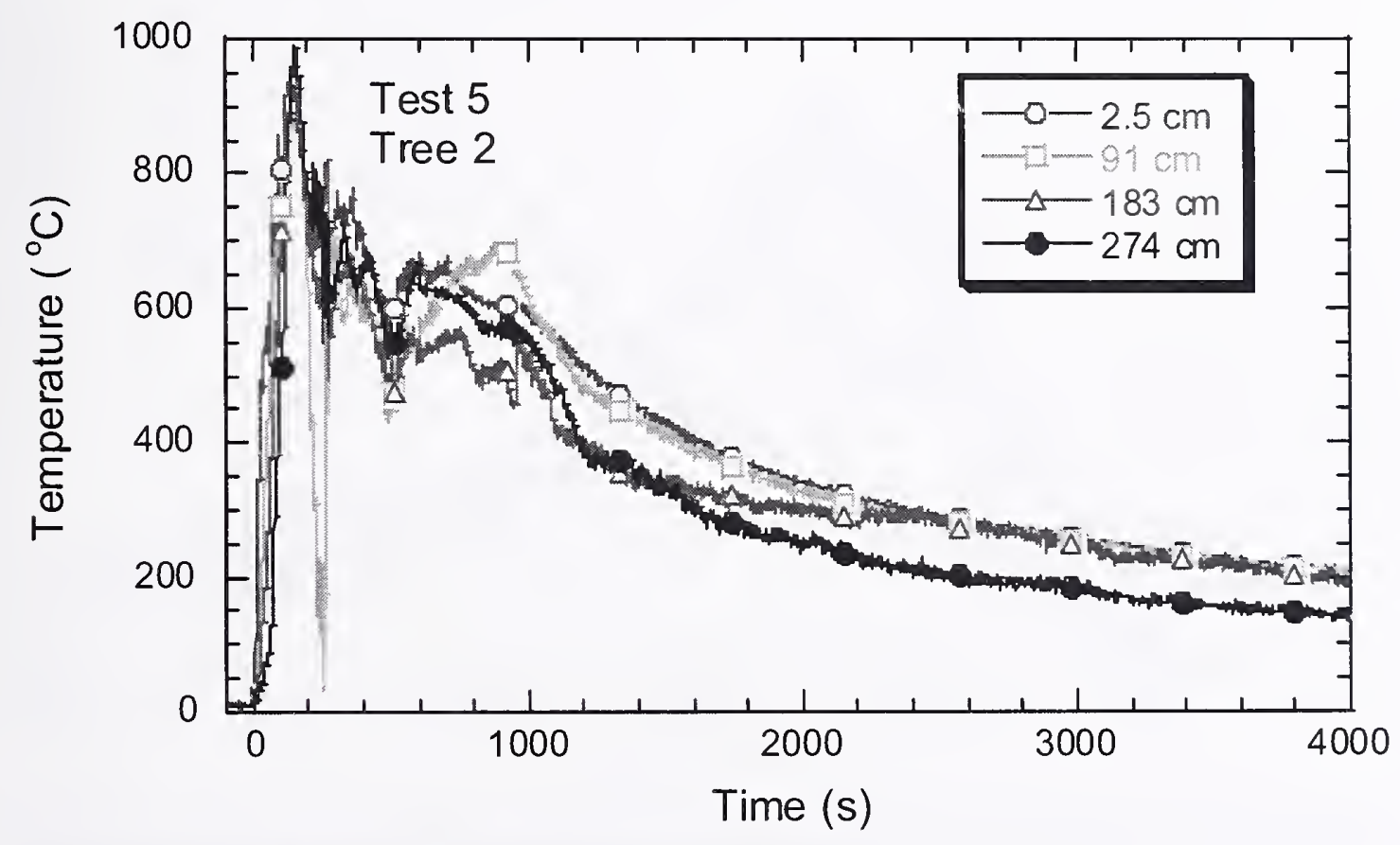

Figure $\mathrm{C}-5$. Bare bead thermocouple measurements as a function of time at four locations (below the ceiling) on Tree 2 during Test 5. 


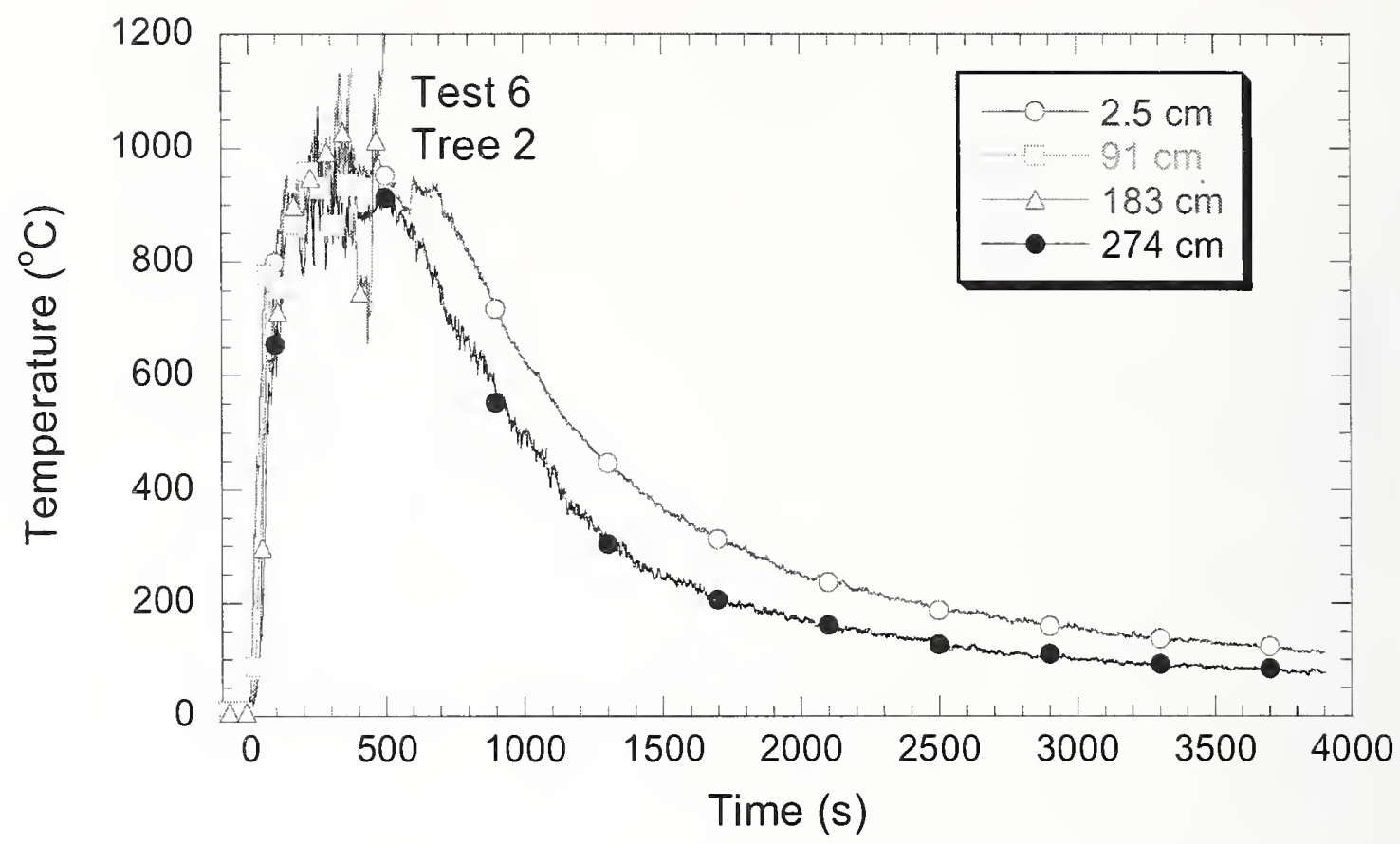

Figure $\mathrm{C}-6$. Bare bead thermocouple measurements as a function of time at four locations (below the ceiling) on Tree 2 during Test 6.

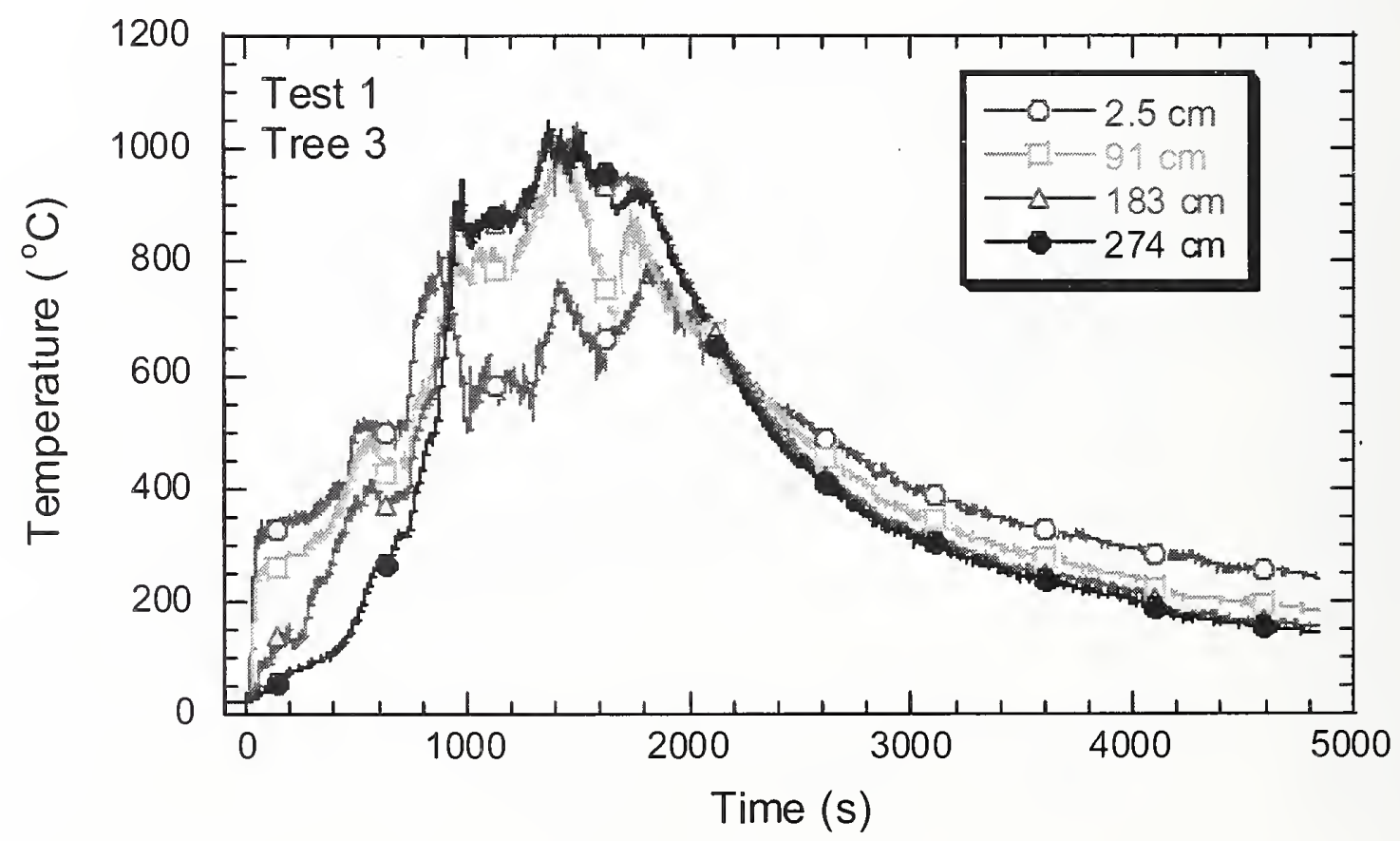

Figure $\mathrm{C}-7$. Bare bead thermocouple measurements as a function of time at four locations (below the ceiling) on Tree 3 during Test 1. 


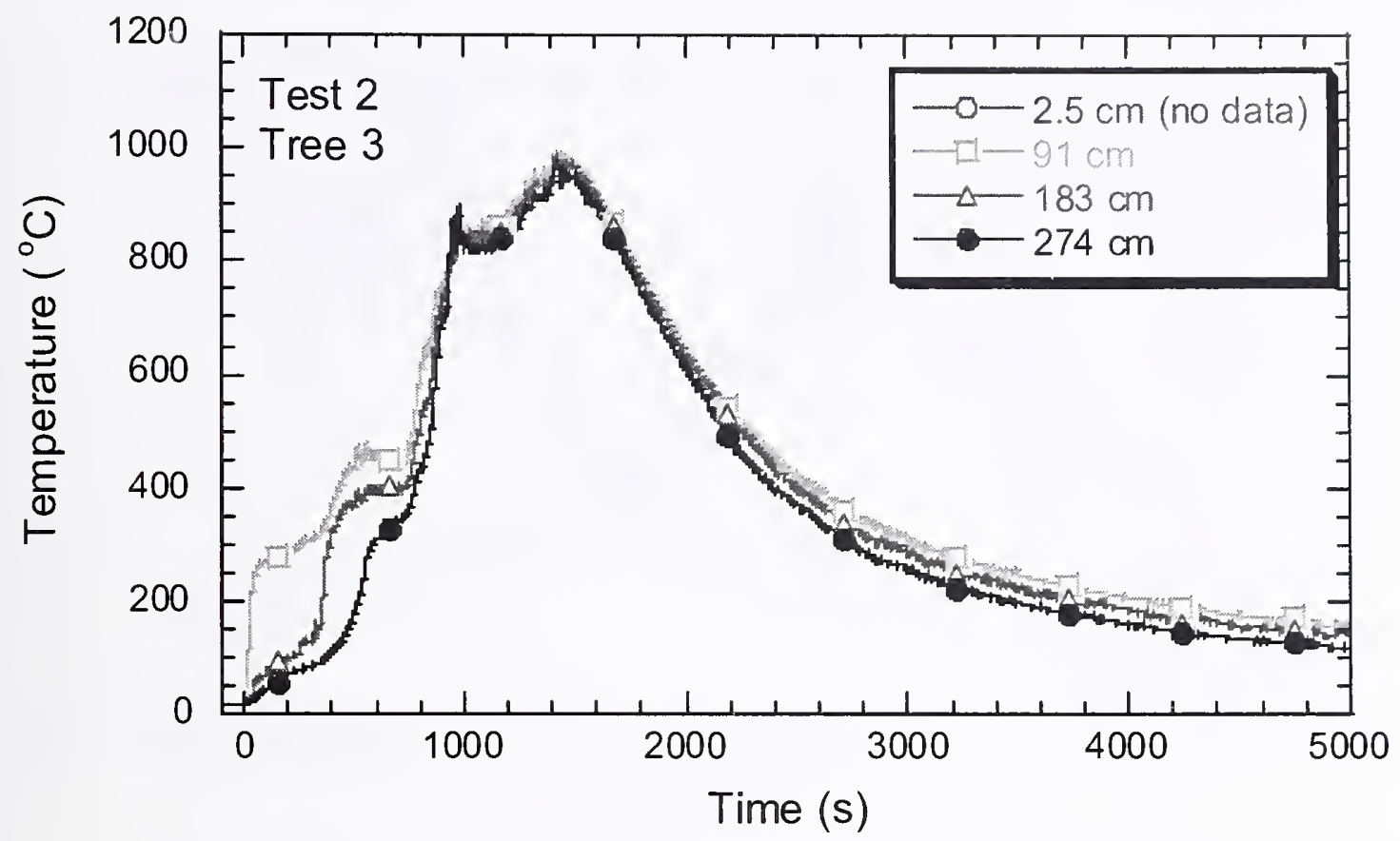

Figure C-8. Bare bead thermocouple measurements as a function of time at three locations (below the ceiling) on Tree 3 during Test 2.

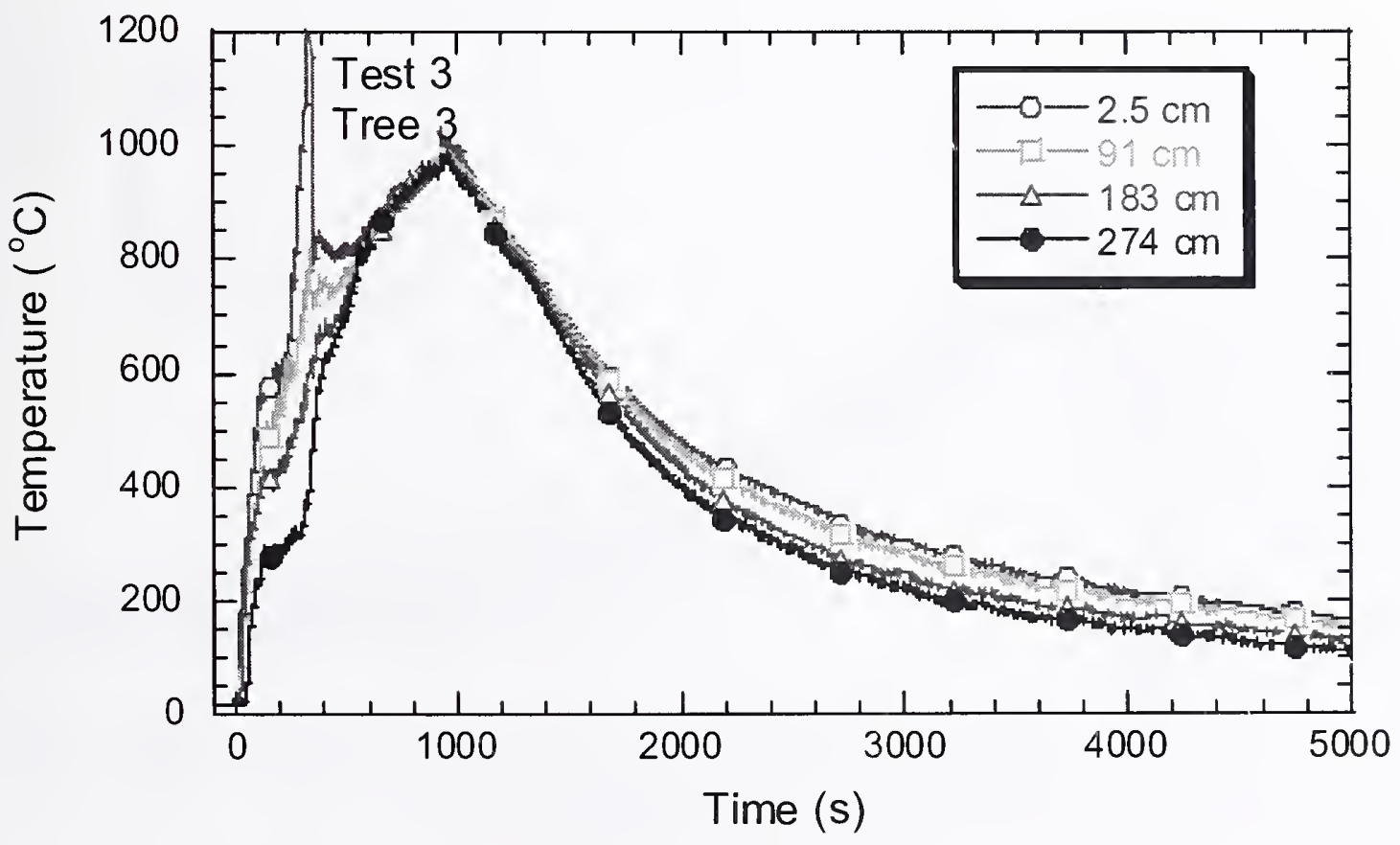

Figure C-9. Bare bead thermocouple measurements as a function of time at four locations (below the ceiling) on Tree 3 during Test 3. 


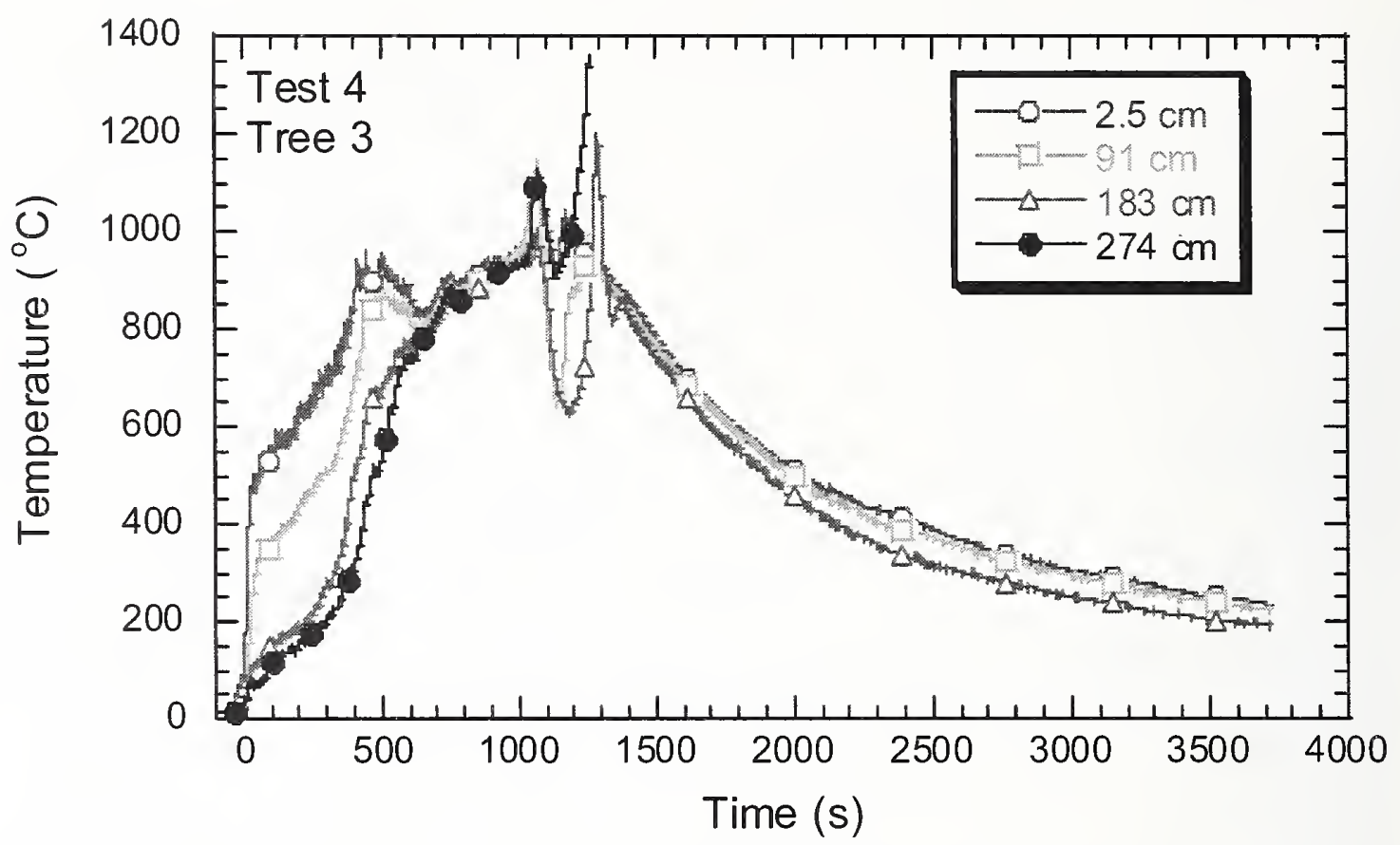

Figure C-10. Bare bead thermocouple measurements as a function of time at four locations (below the ceiling) on Tree 3 during Test 4 .

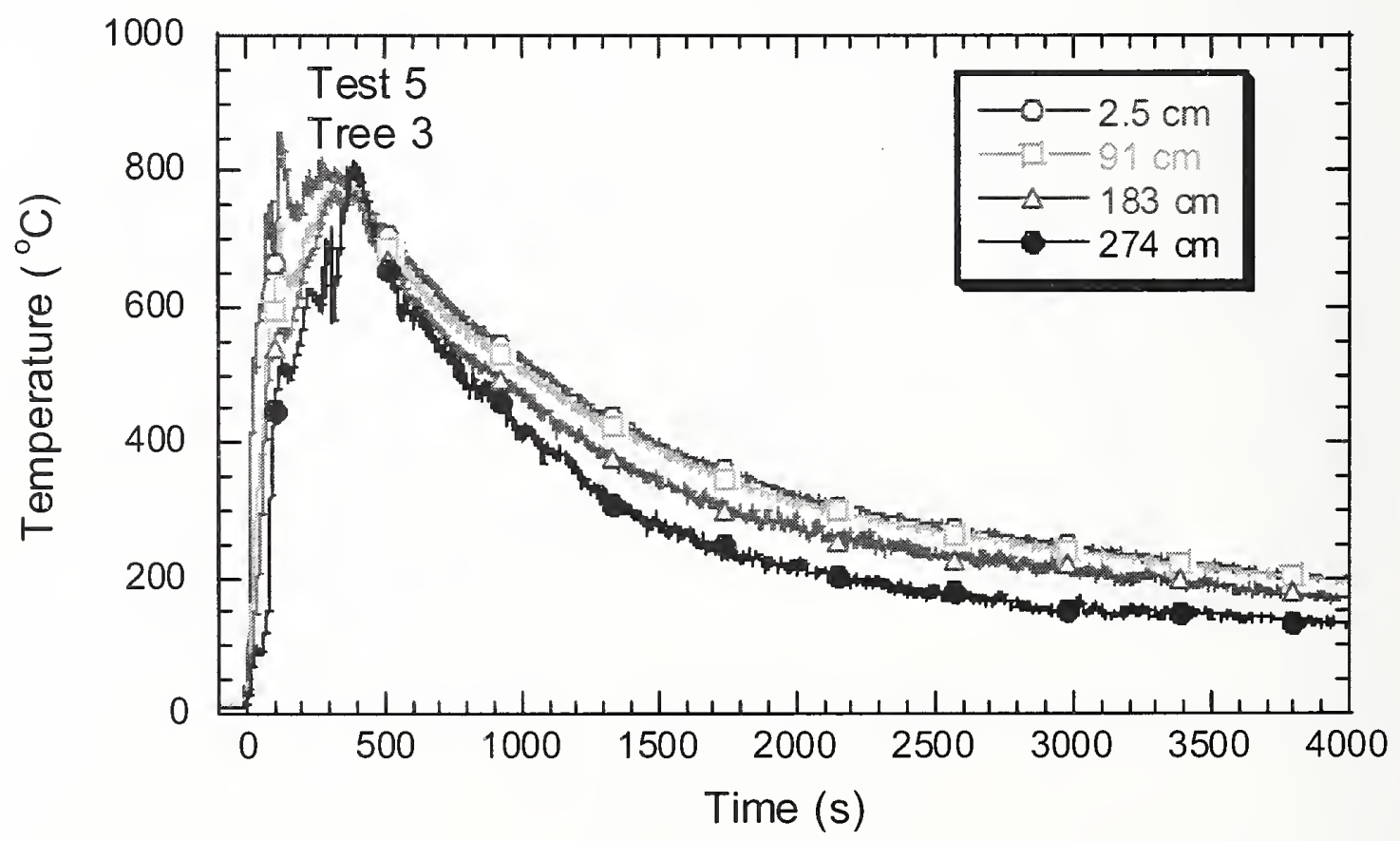

Figure C-11. Bare bead thermocouple measurements as a function of time at four locations (below the ceiling) on Tree 3 during Test 5. 


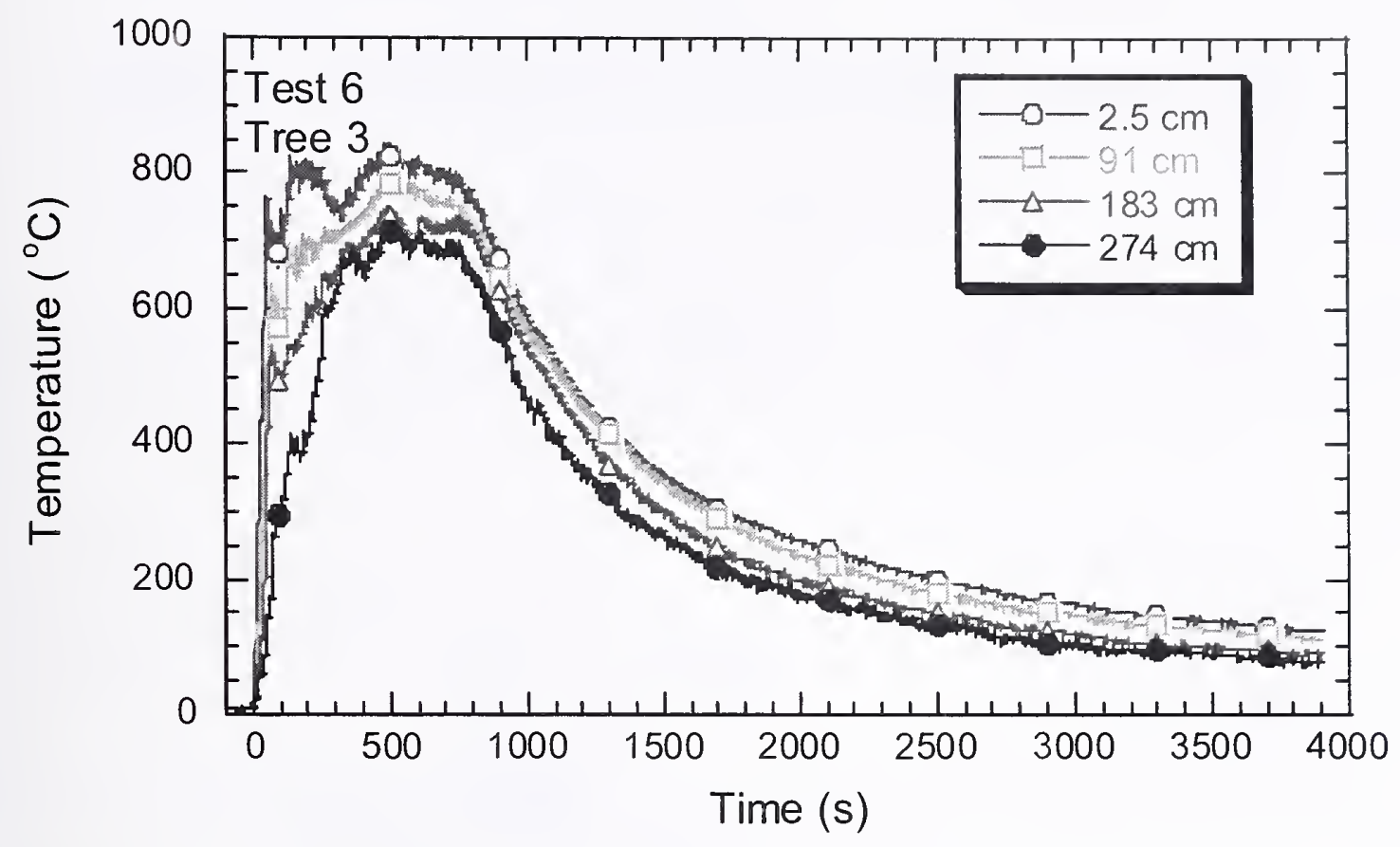

Figure C-12. Bare bead thermocouple measurements as a function of time at four locations (below the ceiling) on Tree 3 during Test 6. 
This page intentionally left blank. 


\section{Appendix D \\ COMPARISON OF SIMULATIONS AND MEASUREMENTS}

Chapter 8 presents representative comparisons of the fire simulations and the measurements of the gas phase temperatures and the volume fraction of the gas phase species. This appendix presents data plots (Figs. D-1 through D-20) not shown in Chapter 8 that are analogous to Figs. 8-3 through 8-6 for temperature.

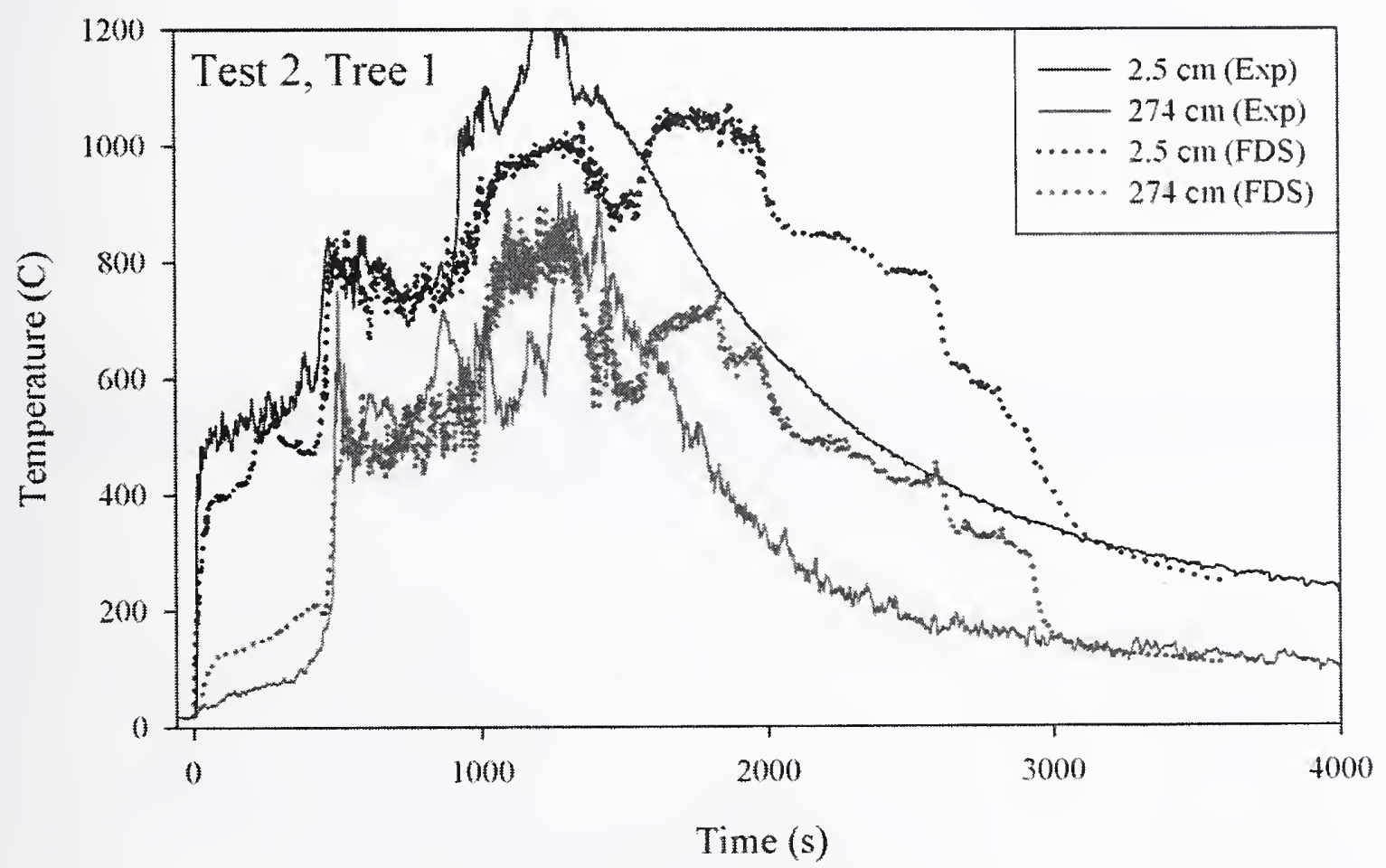

Figure D-1. Comparison of the measured and simulated temperatures at $2.5 \mathrm{~cm}$ and $274 \mathrm{~cm}$ below the ceiling on Tree 1 (rear of the compartment) during Test 2. 


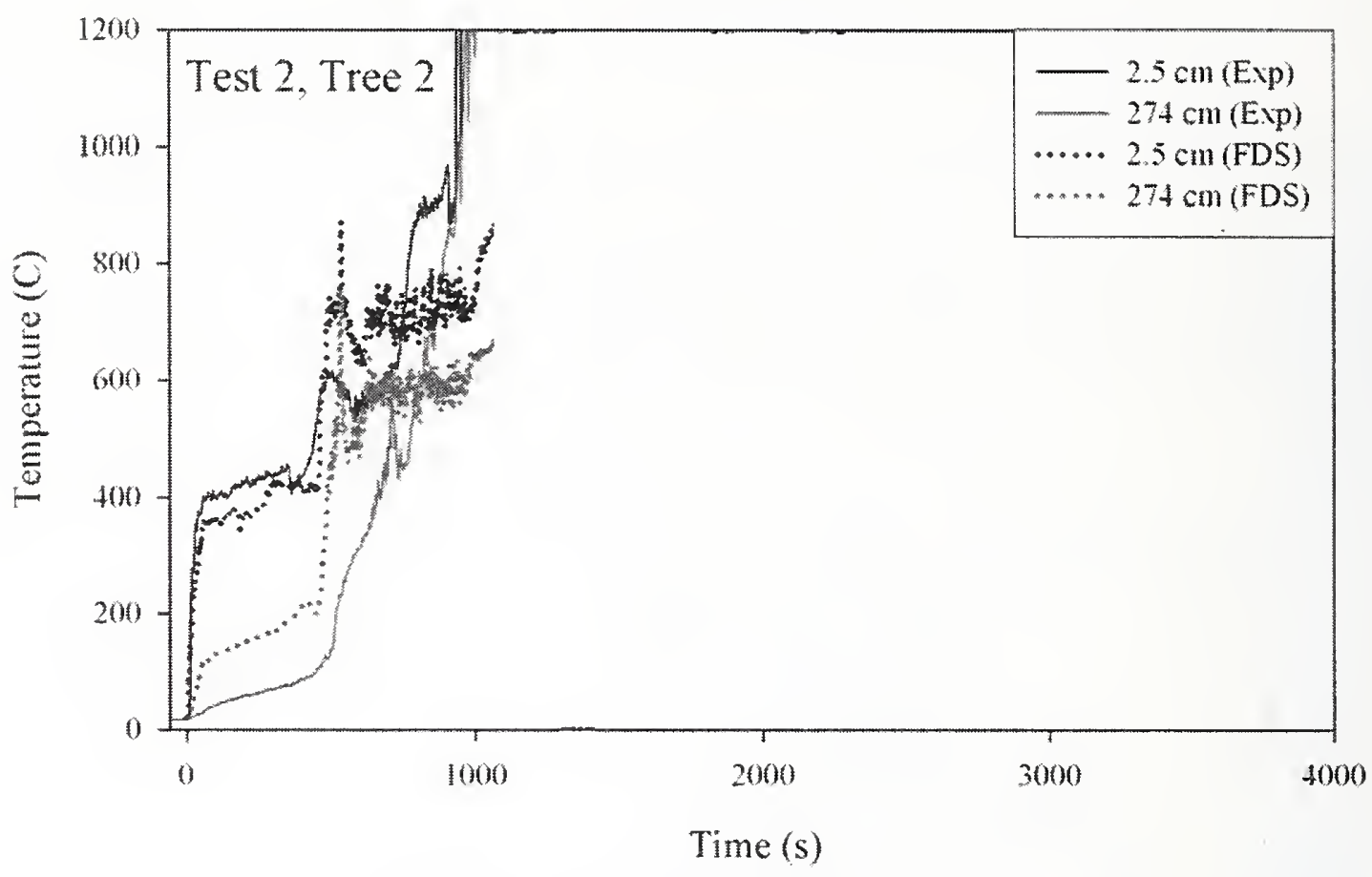

Figure D-2. Comparison of the measured and simulated temperatures at $2.5 \mathrm{~cm}$ and $274 \mathrm{~cm}$ below the ceiling on Tree 2 (middle of the compartment) during Test 2 . After approximately $1,000 \mathrm{~s}$, the thermocouples failed.

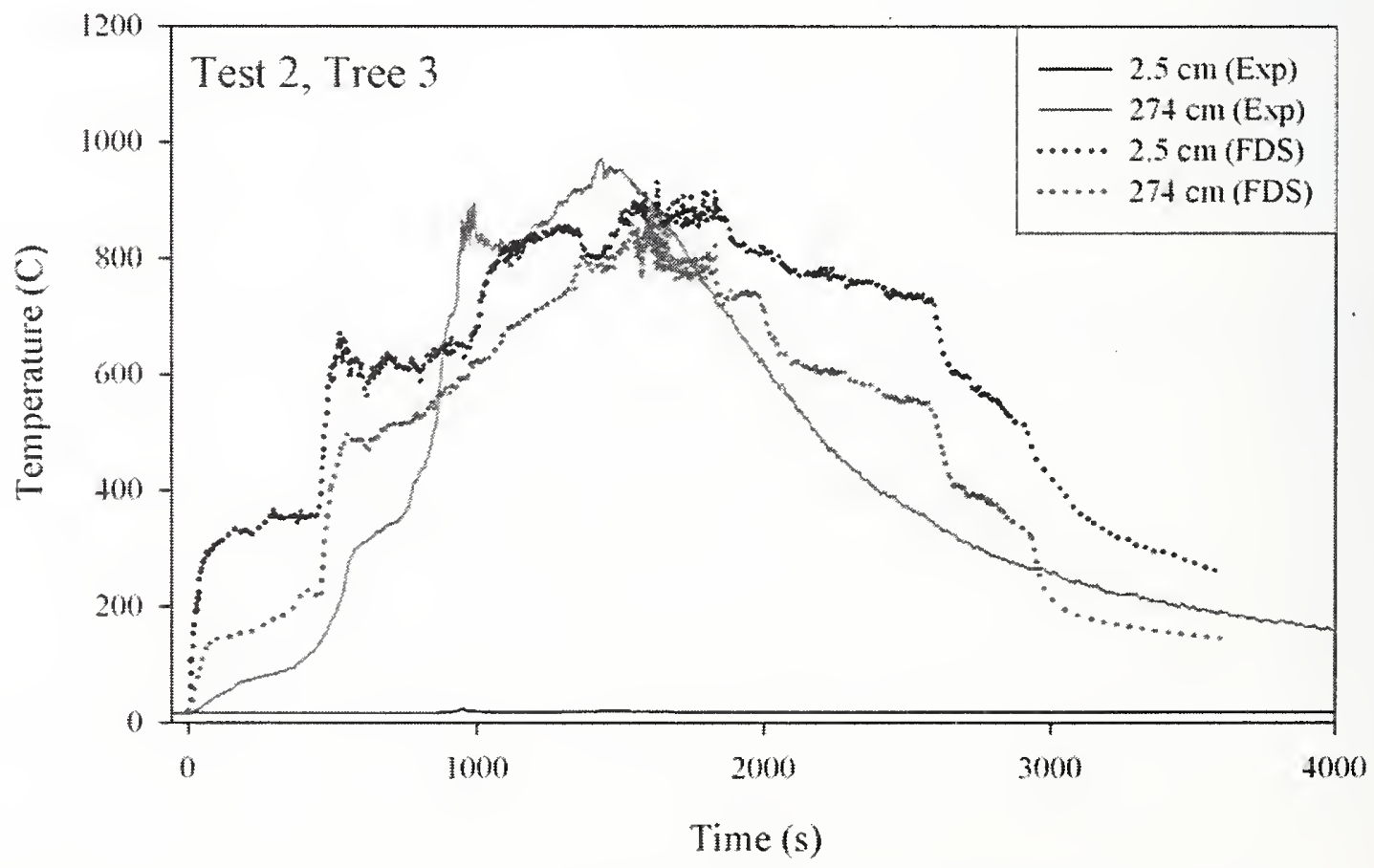

Figure D-3. Comparison of the measured and simulated temperatures at $2.5 \mathrm{~cm}$ and $274 \mathrm{~cm}$ below the ceiling on Tree 3 (middle of the compartment) during Test 2. 


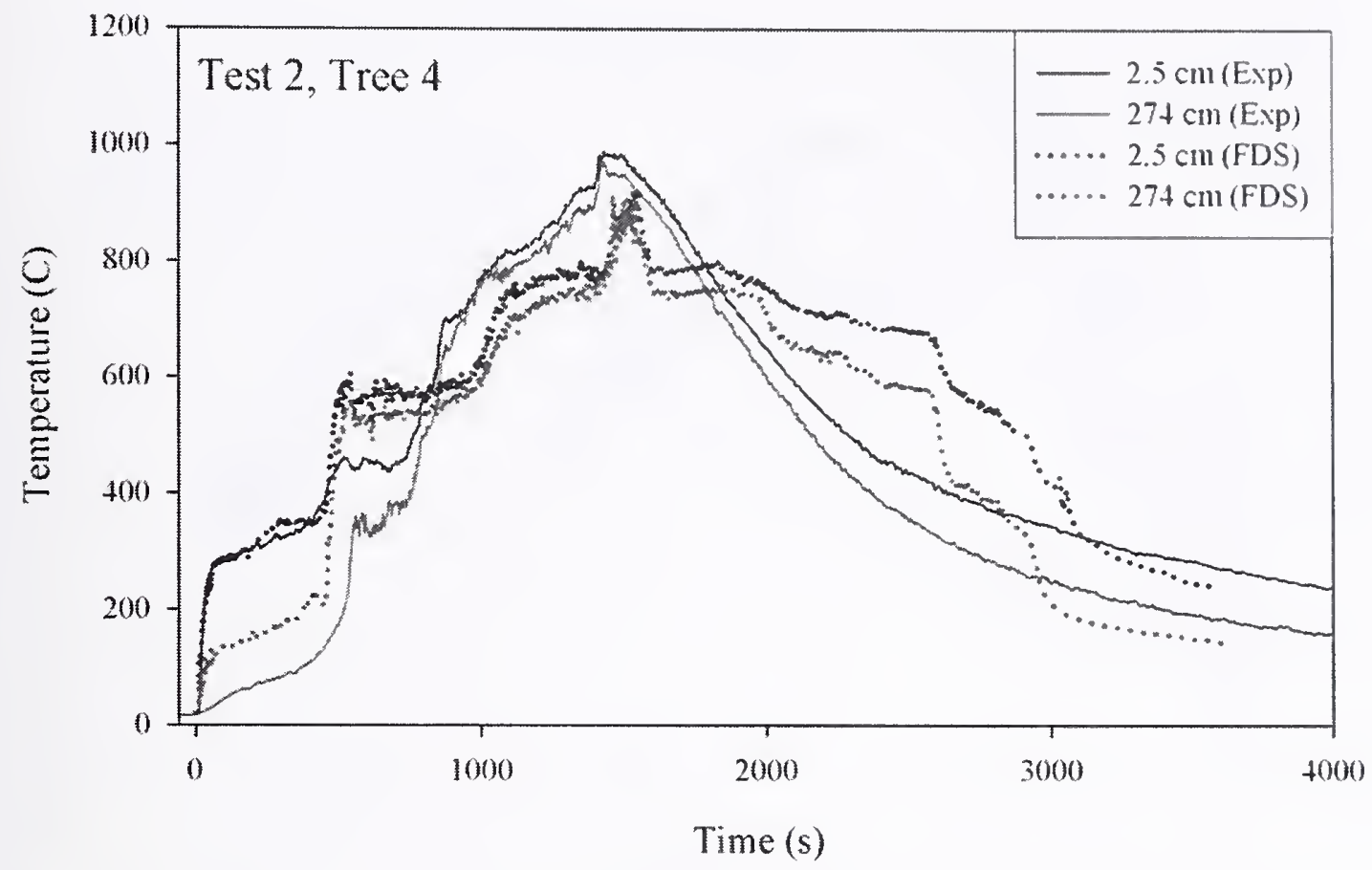

Figure D-4. Comparison of the measured and simulated temperatures at $2.5 \mathrm{~cm}$ and $274 \mathrm{~cm}$ below the ceiling on Tree 4 (rear of the compartment) during Test 2 .

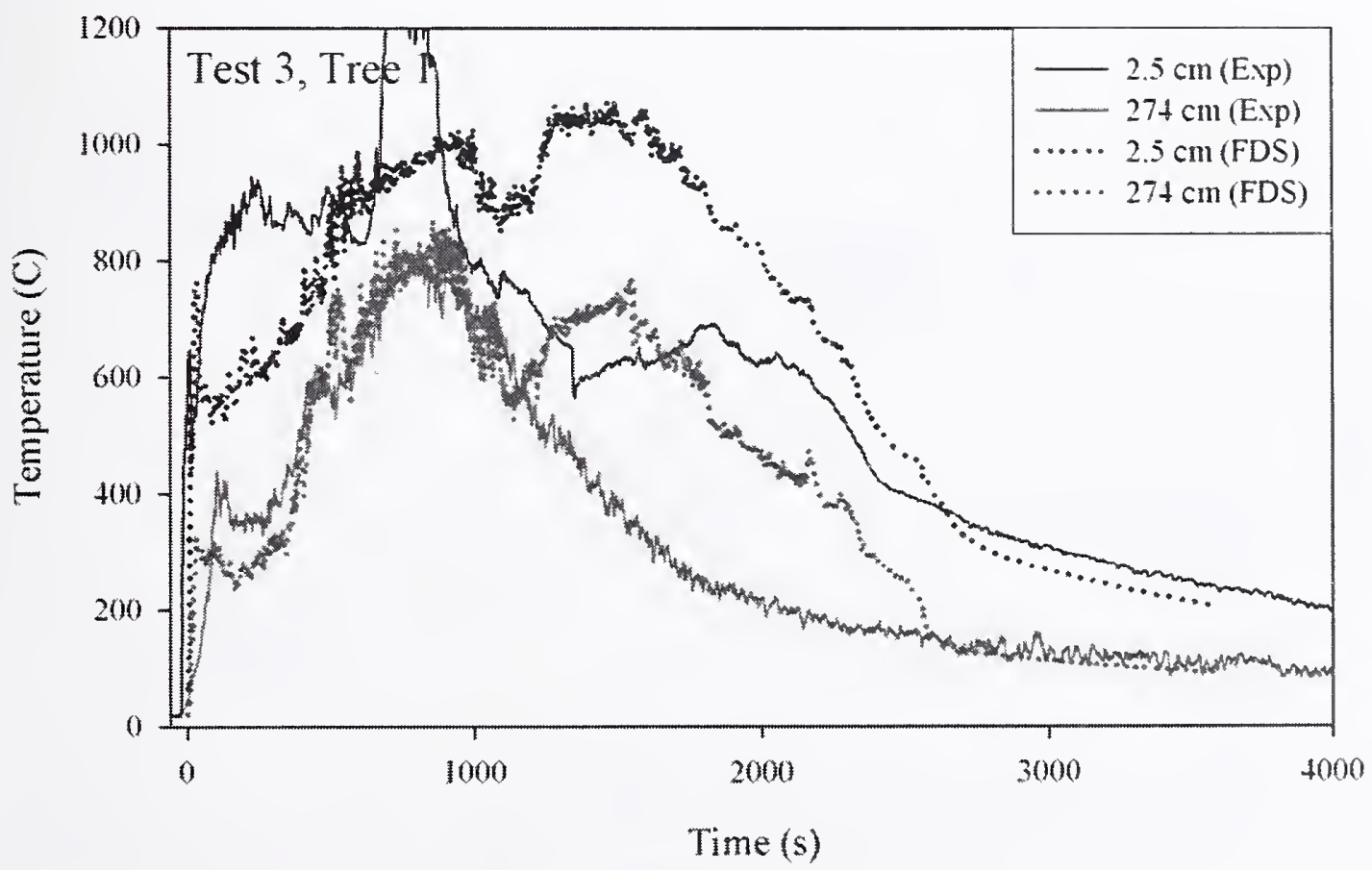

Figure D-5. Comparison of the measured and simulated temperatures at $2.5 \mathrm{~cm}$ and $274 \mathrm{~cm}$ below the ceiling on Tree 1 (front of the compartment) during Test 3 . 


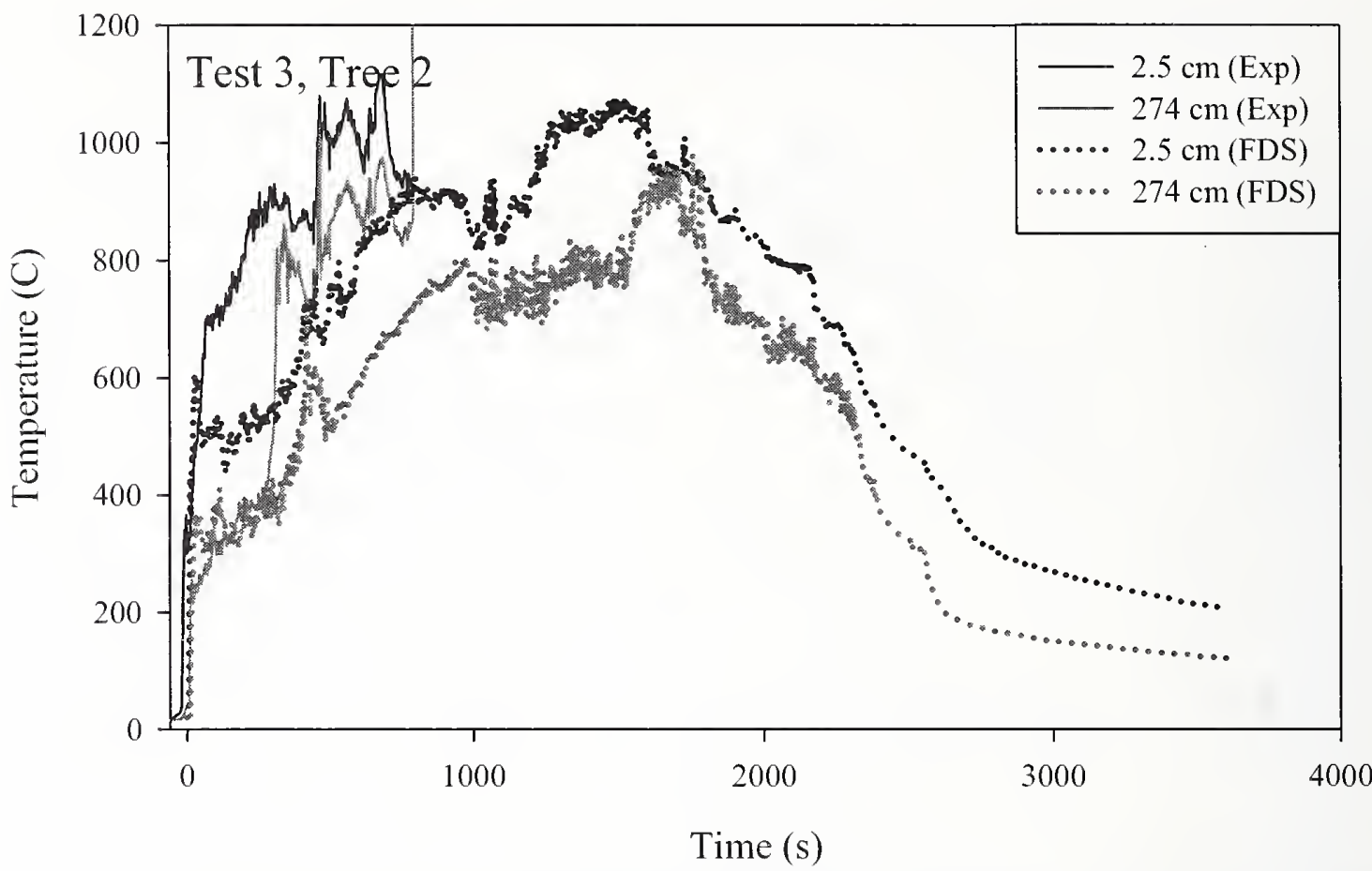

Figure D-6. Comparison of the measured and simulated temperatures at $2.5 \mathrm{~cm}$ and $274 \mathrm{~cm}$ below the ceiling on Tree 2 (middle of the compartment) during Test 3 . After approximately $800 \mathrm{~s}$, the thermocouples failed in this test.

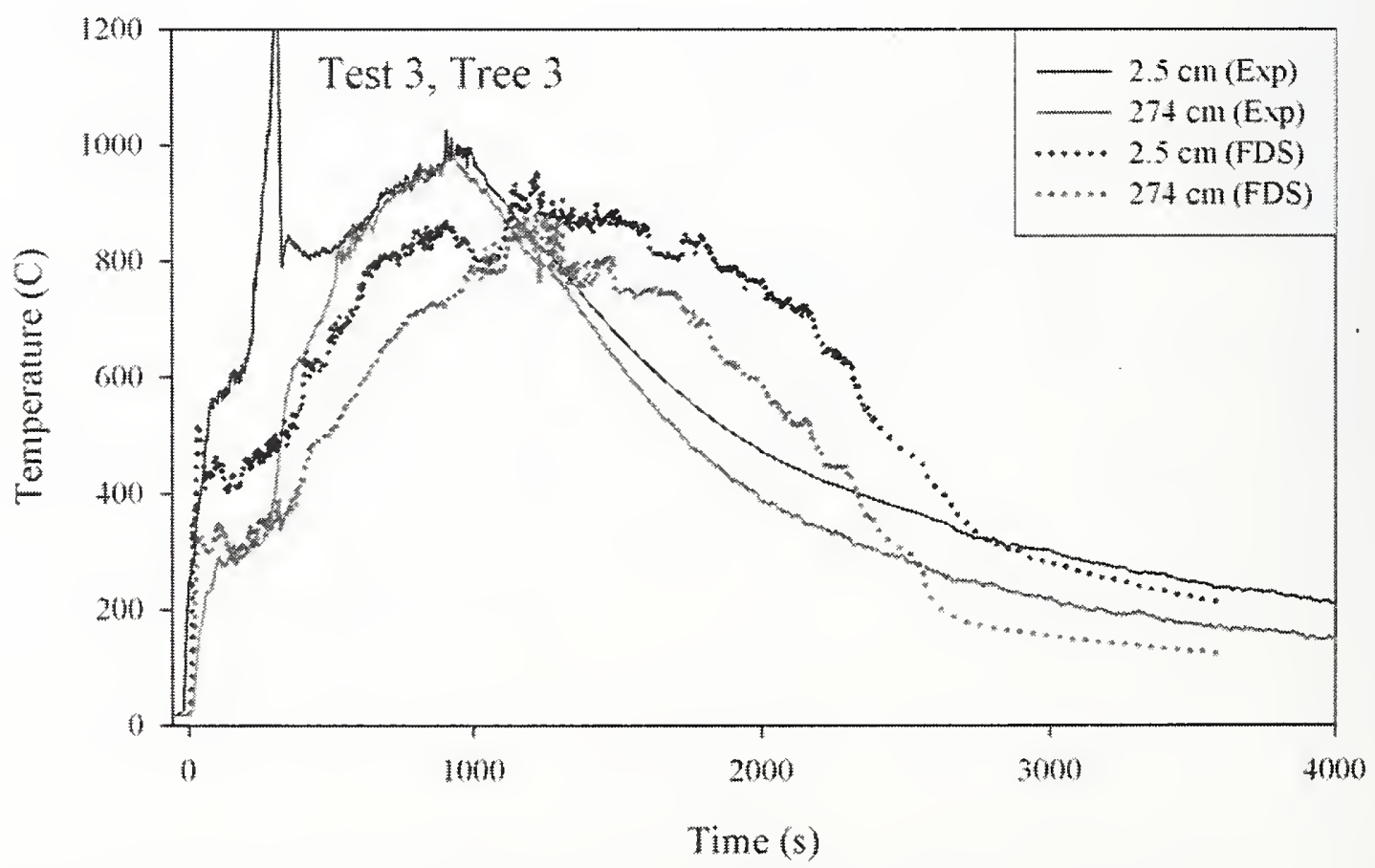

Figure D-7. Comparison of the measured and simulated temperatures at $2.5 \mathrm{~cm}$ and $274 \mathrm{~cm}$ below the ceiling on Tree 3 (middle of the compartment) during Test 3 . 


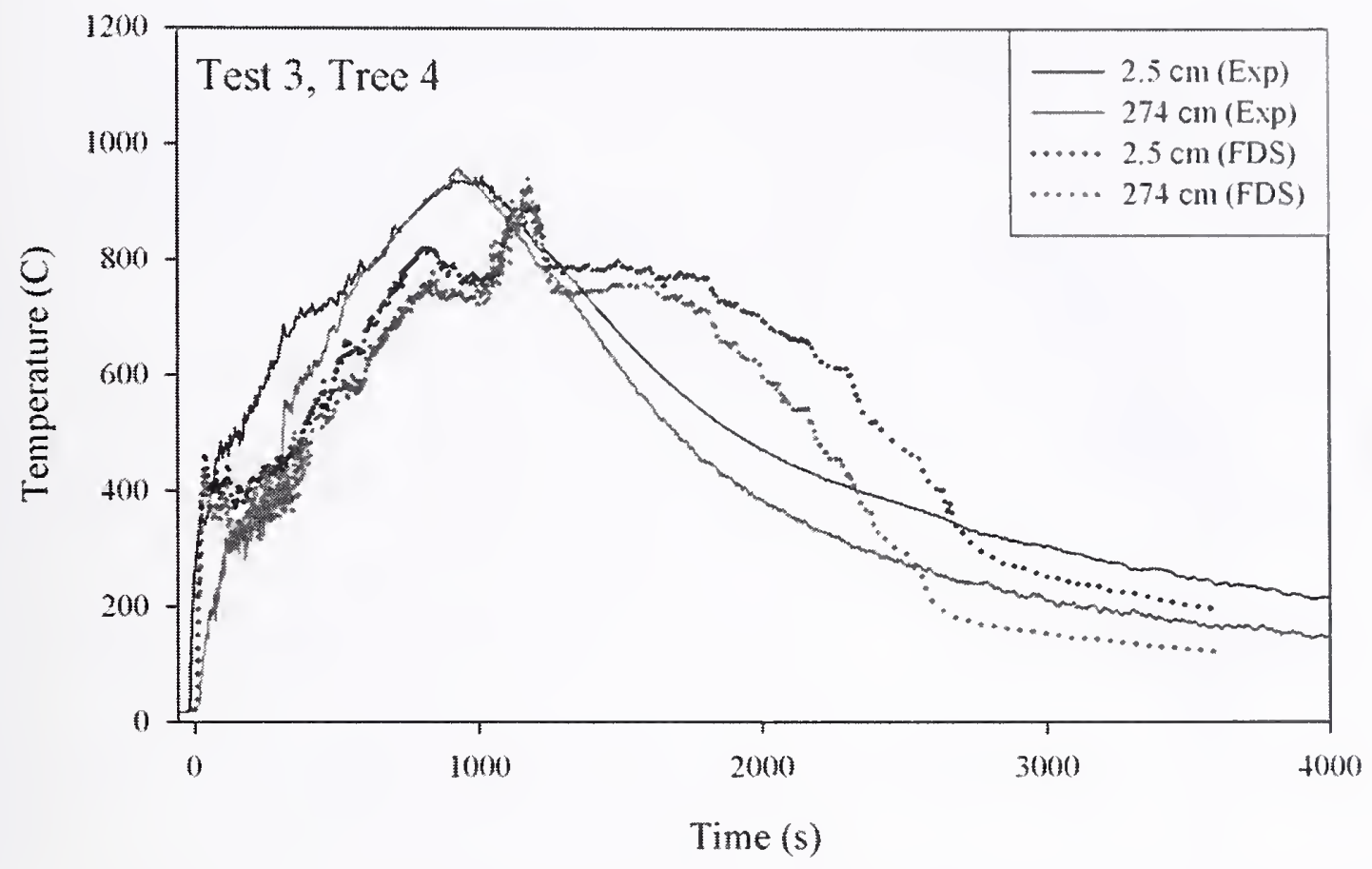

Figure D-8. Comparison of the measured and simulated temperatures at $2.5 \mathrm{~cm}$ and $274 \mathrm{~cm}$ below the ceiling on Tree 4 (rear of the compartment) during Test 3.

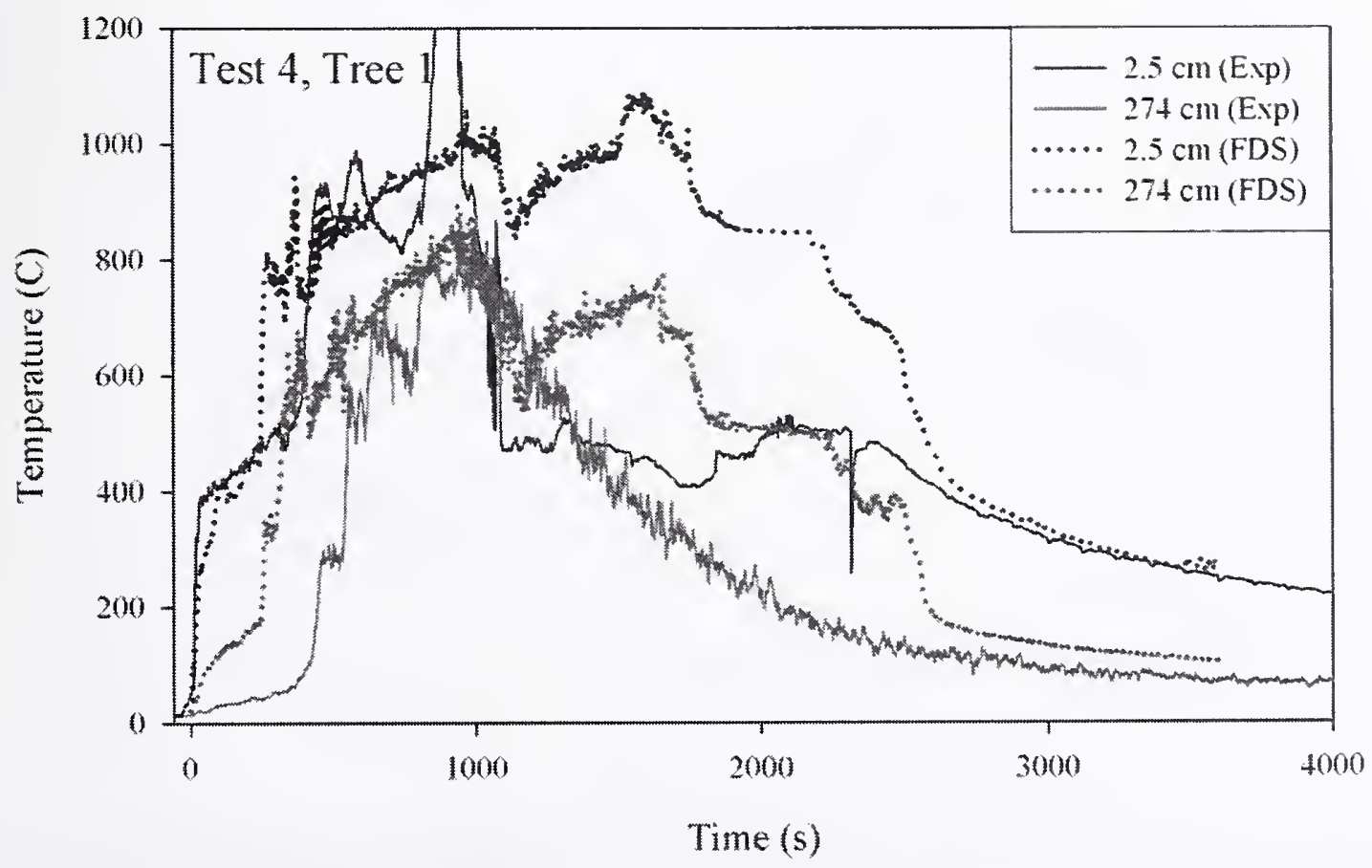

Figure D-9. Comparison of the measured and simulated temperatures at $2.5 \mathrm{~cm}$ and $274 \mathrm{~cm}$ below the ceiling on Tree 1 (front of the compartment) during Test 4. 


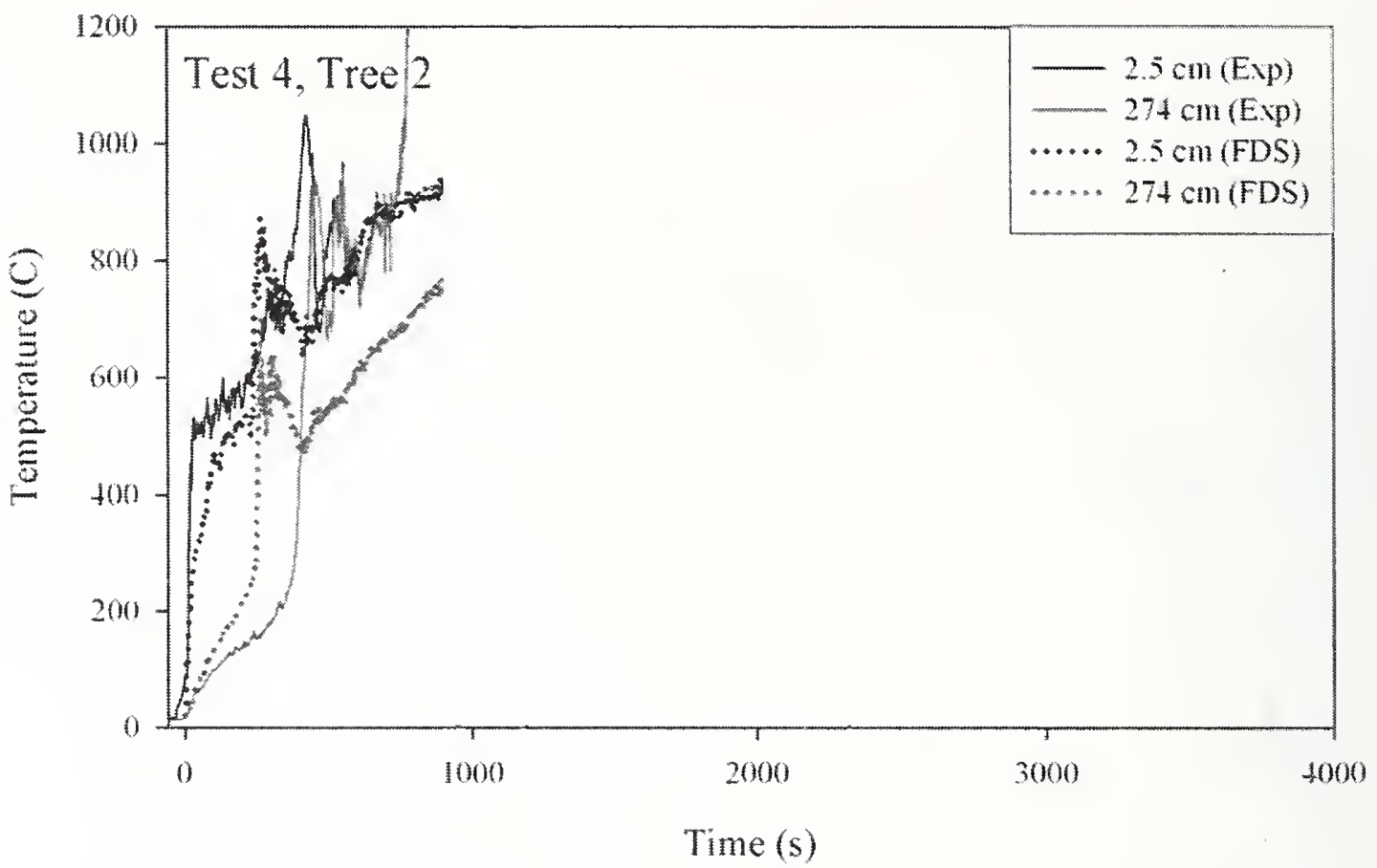

Figure D-10. Comparison of the measured and simulated temperatures at $2.5 \mathrm{~cm}$ and $274 \mathrm{~cm}$ below the ceiling on Tree 2 (middle of the compartment) during Test 4 . After approximately $750 \mathrm{~s}$, the thermocouples failed.

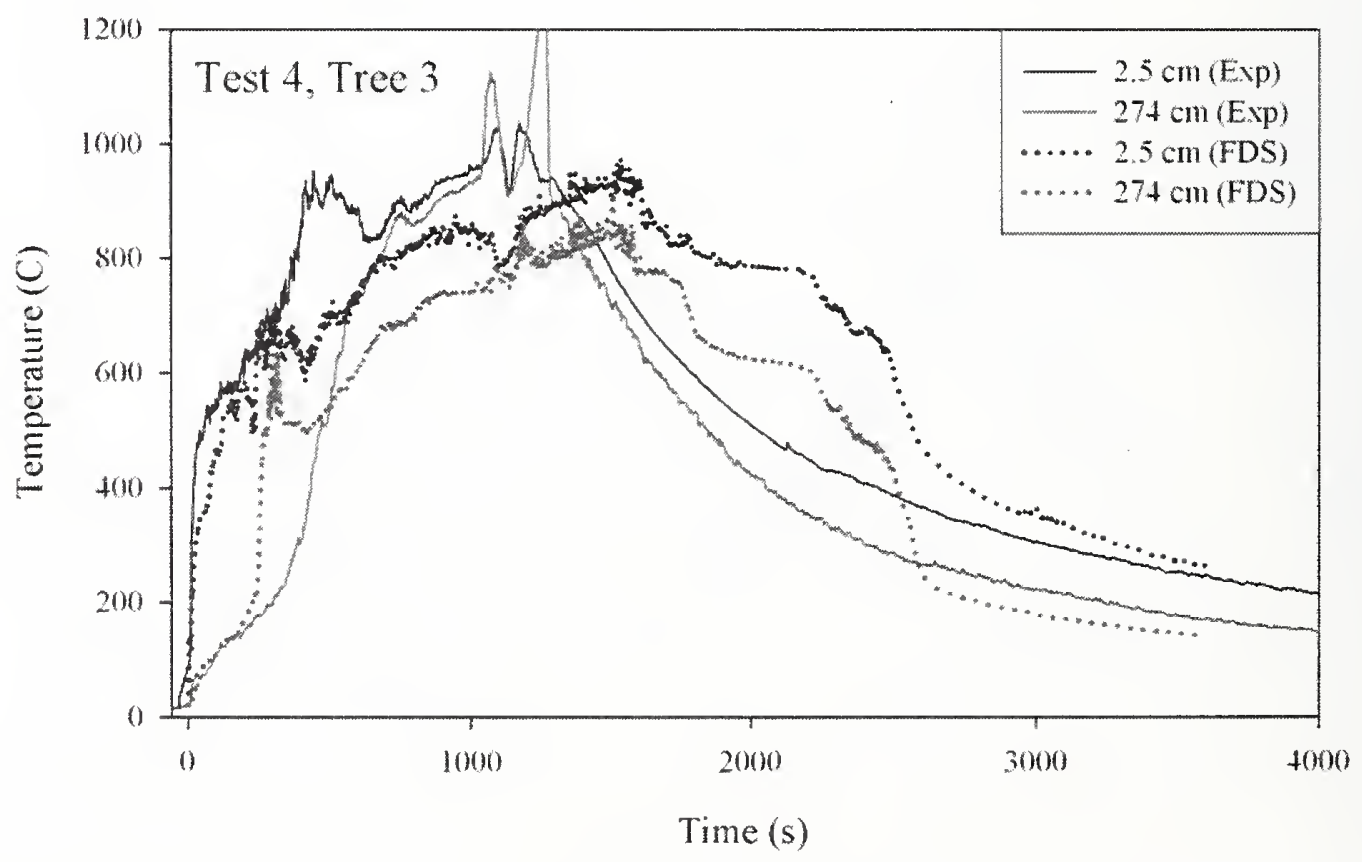

Figure D-11. Comparison of the measured and simulated temperatures at $2.5 \mathrm{~cm}$ and $274 \mathrm{~cm}$ below the ceiling on Tree 3 (middle of the compartment) during Test 4 . 


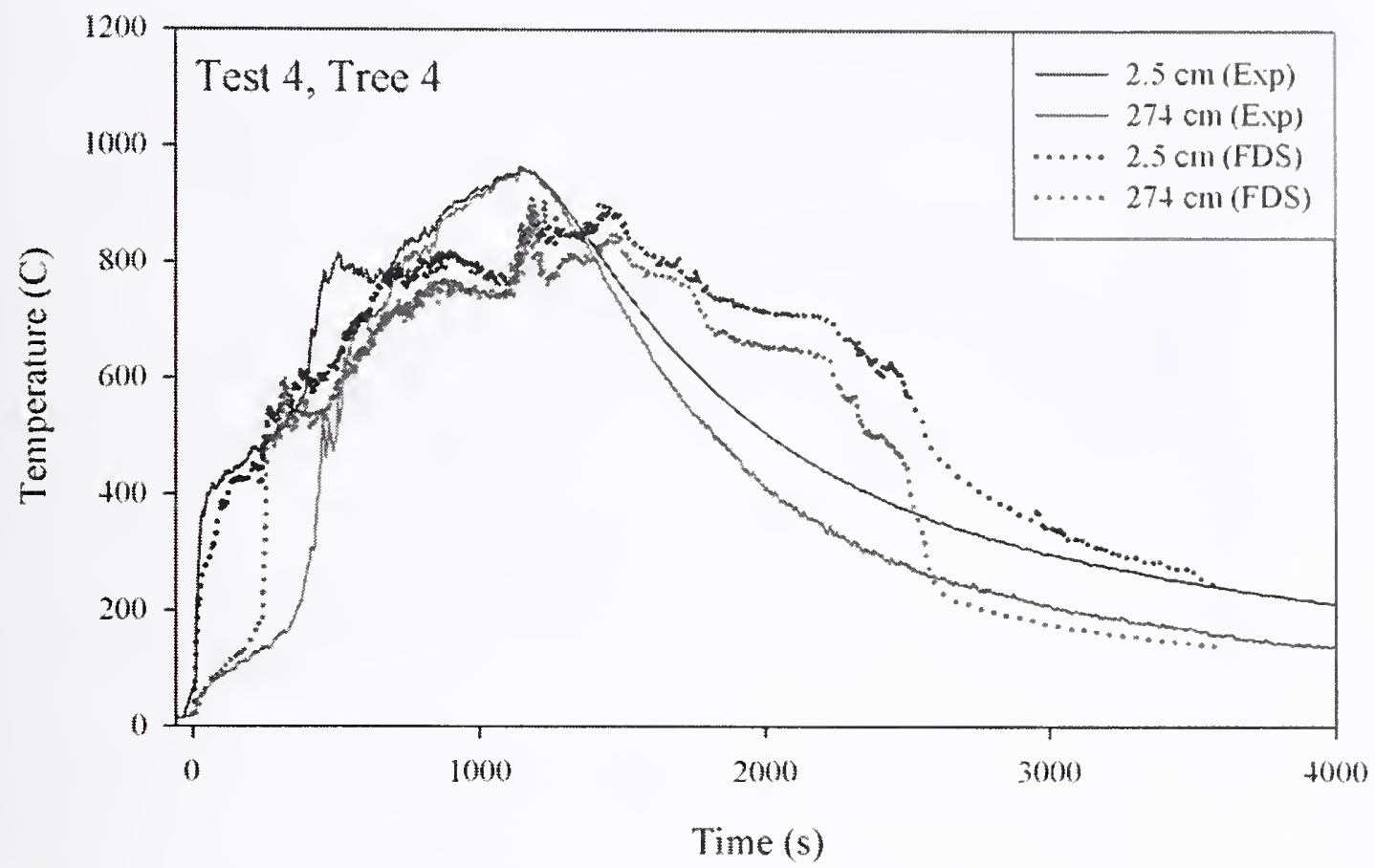

Figure D-12. Comparison of the measured and simulated temperatures at $2.5 \mathrm{~cm}$ and $274 \mathrm{~cm}$ below the ceiling on Tree 4 (rear of the compartment) during Test 4.

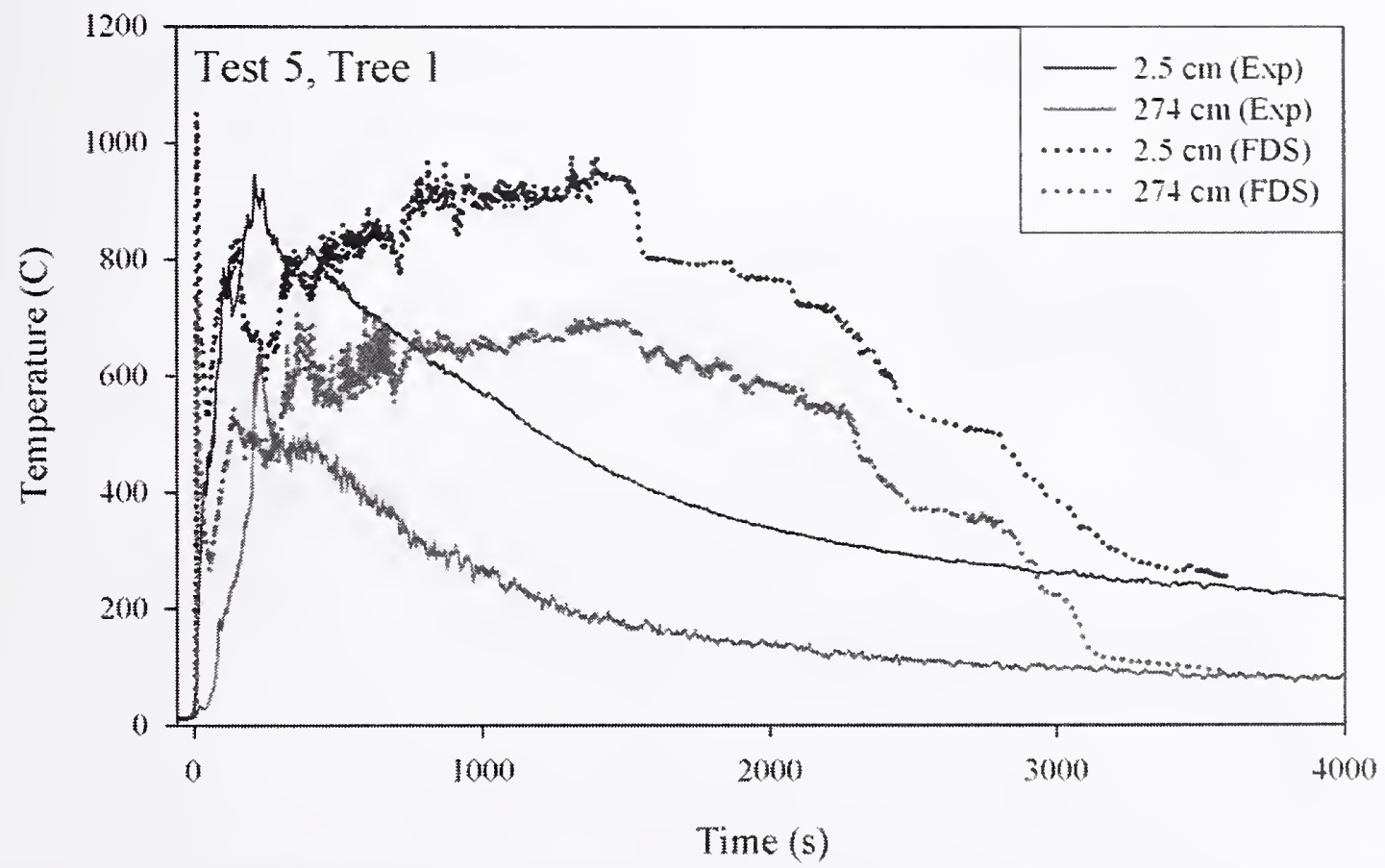

Figure D-13. Comparison of the measured and simulated temperatures at $2.5 \mathrm{~cm}$ and $274 \mathrm{~cm}$ below the ceiling on Tree 1 (front of the compartment) during Test 5. 


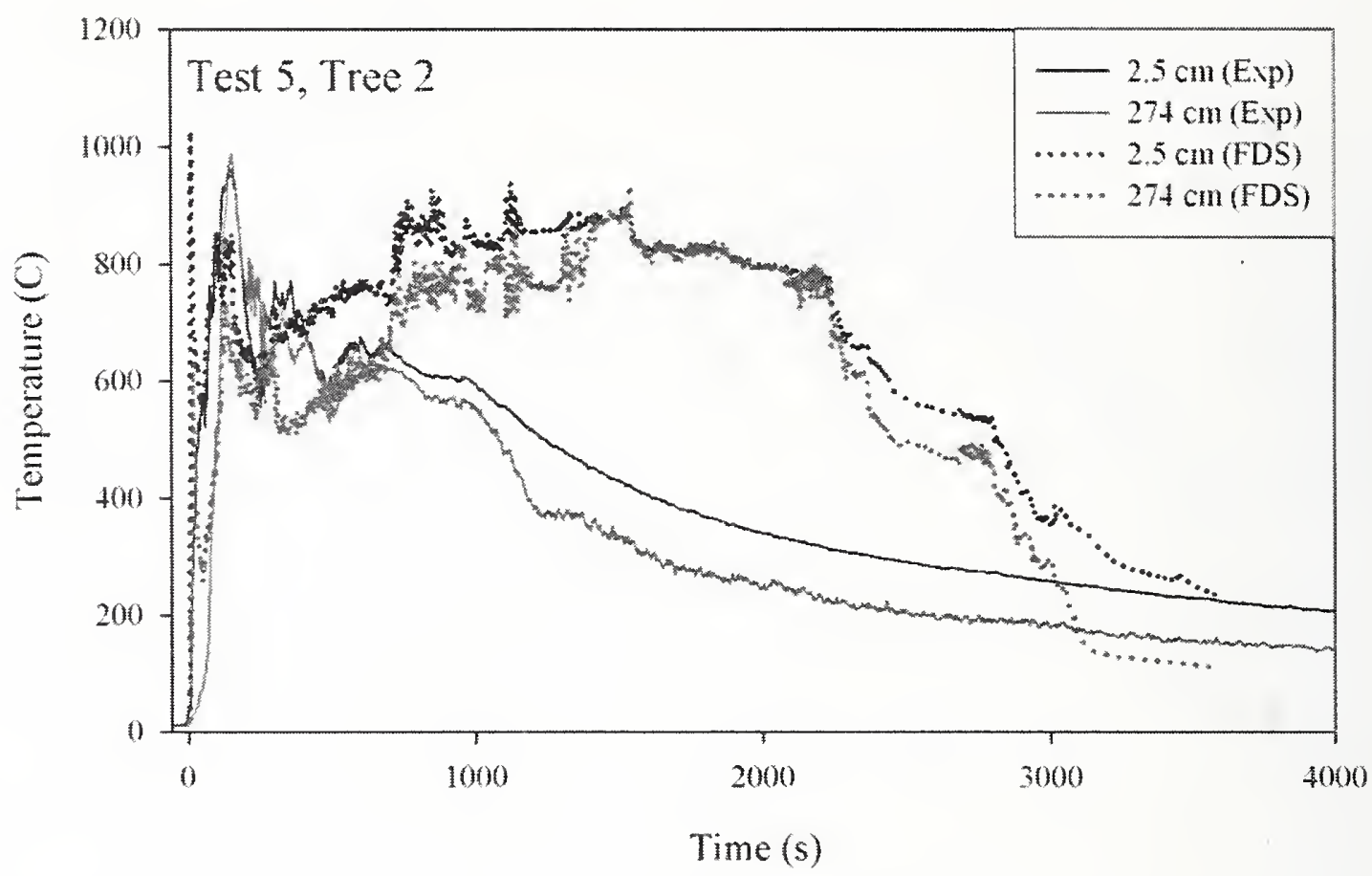

Figure D-14. Comparison of the measured and simulated temperatures at $2.5 \mathrm{~cm}$ and $274 \mathrm{~cm}$ below the ceiling on Tree 2 (middle of the compartment) during Test 5 .

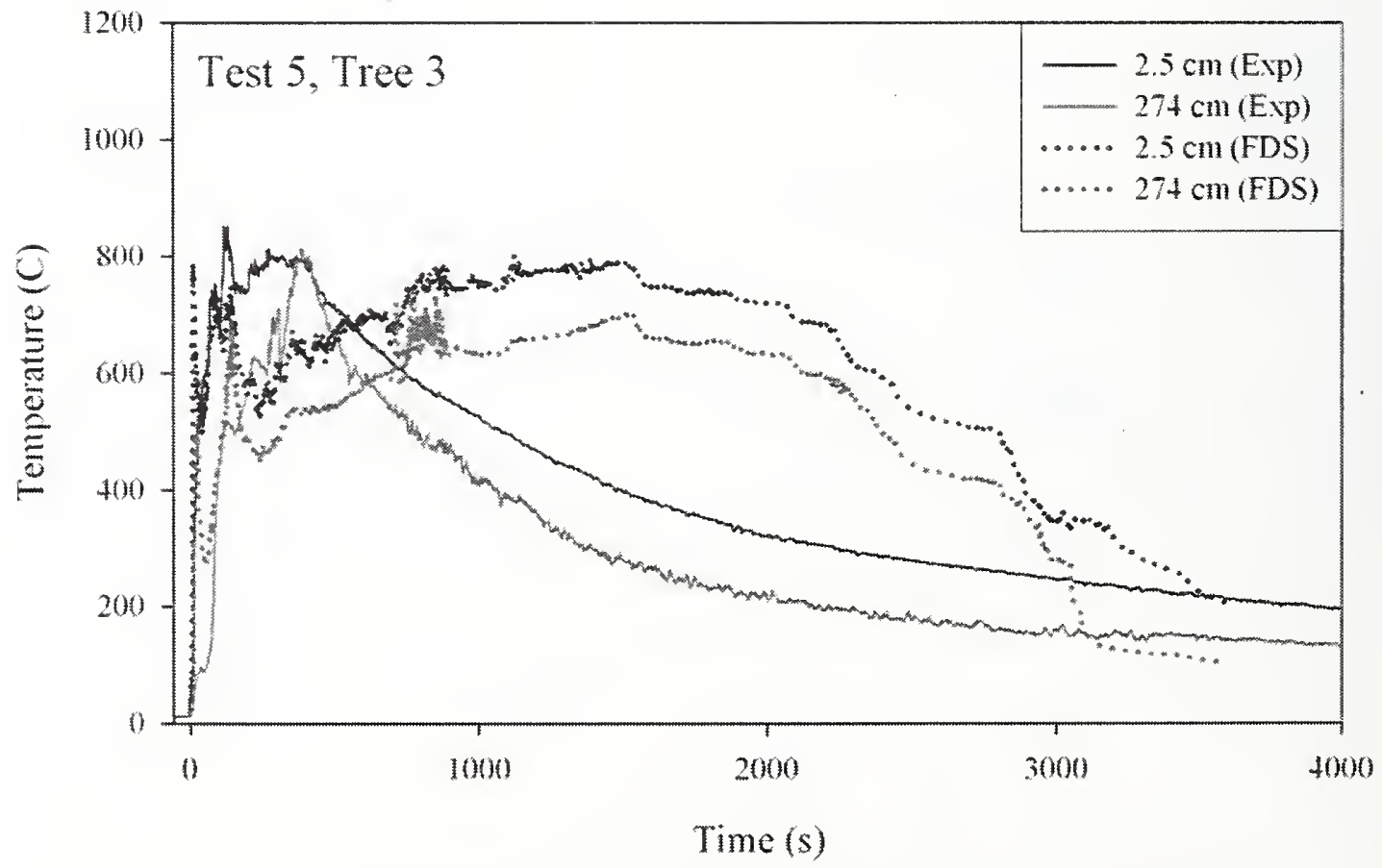

Figure D-15. Comparison of the measured and simulated temperatures at $2.5 \mathrm{~cm}$ and $274 \mathrm{~cm}$ below the ceiling on Tree 3 (middle of the compartment) during Test 5 . 


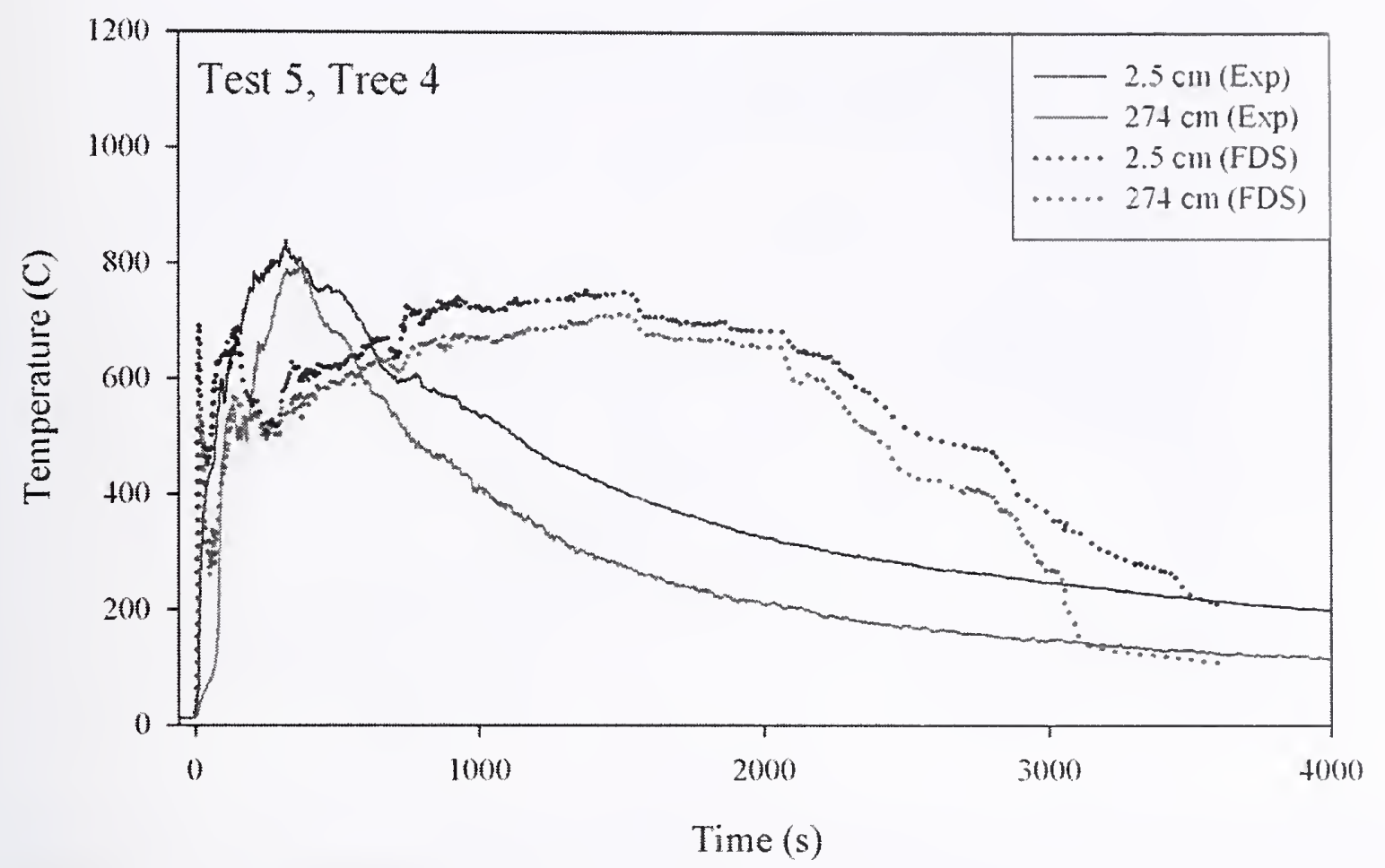

Figure D-16. Comparison of the measured and simulated temperatures at $2.5 \mathrm{~cm}$ and $274 \mathrm{~cm}$ below the ceiling on Tree 4 (rear of the compartment) during Test 5 .

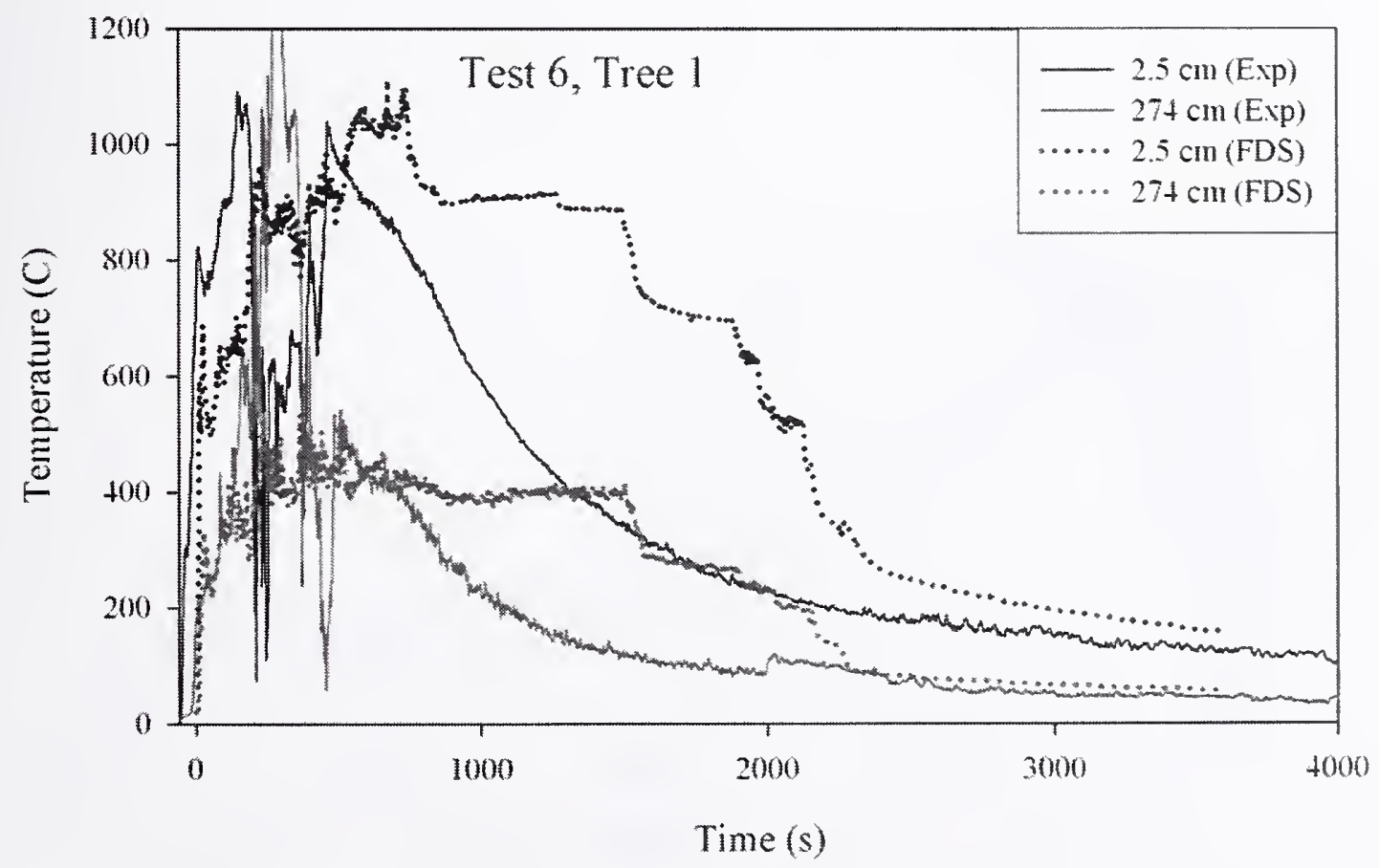

Figure D-17. Comparison of the measured and simulated temperatures at $2.5 \mathrm{~cm}$ and $274 \mathrm{~cm}$ below the ceiling on Tree 1 (front of the compartment) during Test 6 . 


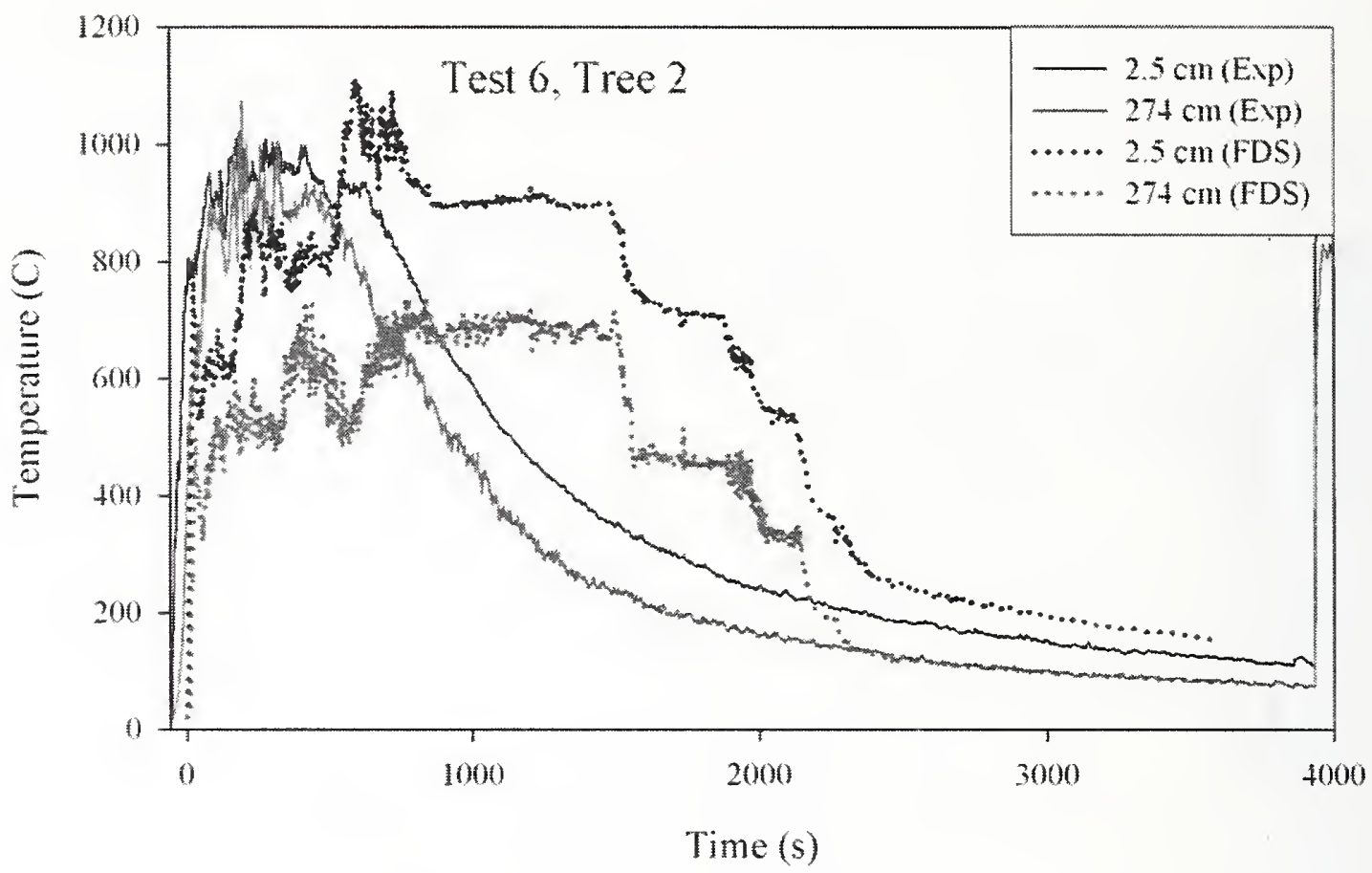

Figure D-18. Comparison of the measured and simulated temperatures at $2.5 \mathrm{~cm}$ and $274 \mathrm{~cm}$ below the ceiling on Tree 2 (middle of the compartment) during Test 6 .

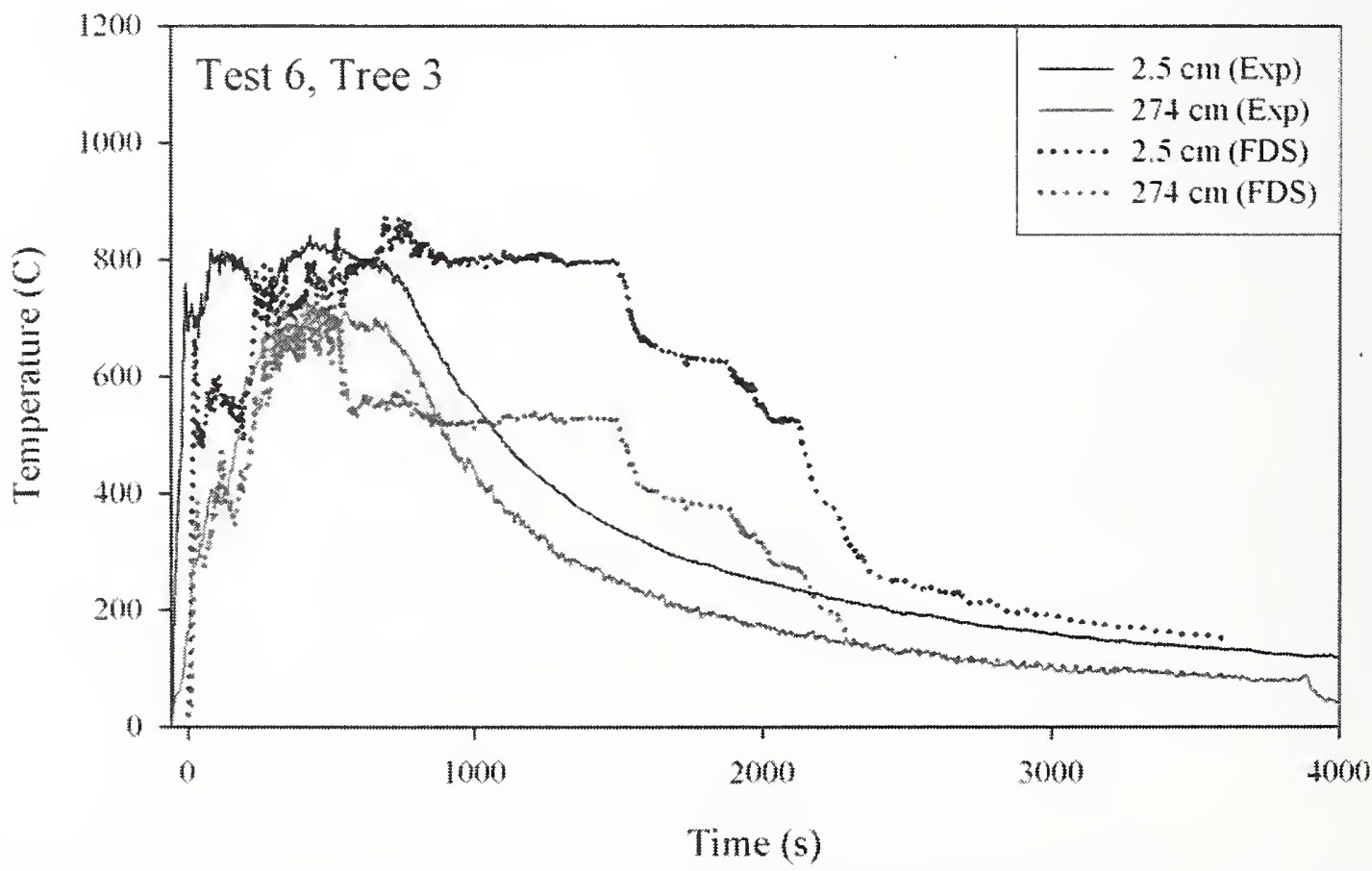

Figure D-19. Comparison of the measured and simulated temperatures at $2.5 \mathrm{~cm}$ and $274 \mathrm{~cm}$ below the ceiling on Tree 3 (middle of the compartment) during Test 6 . 


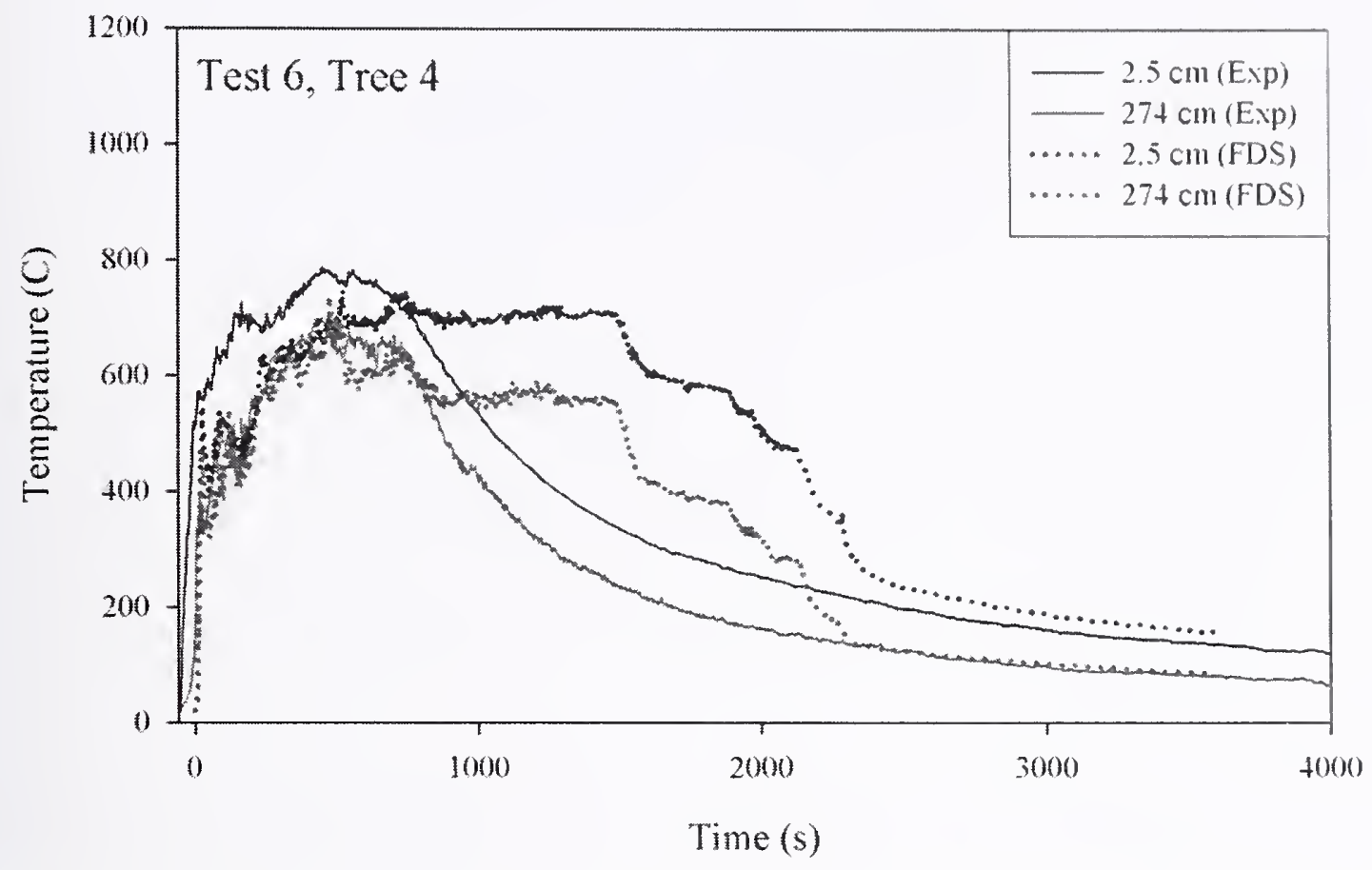

Figure D-20. Comparison of the measured and simulated temperatures at $2.5 \mathrm{~cm}$ and $274 \mathrm{~cm}$ below the ceiling on Tree 4 (rear of the compartment) during Test 6. 
This page intentionally left blank. 

